\title{
COMPORTAMENTO FÍSICO E QUÍMICO DE UM LATOSSOLO ROXO EM FUNÇÃO DO SEU PREPARO NA CULTURA DO MILHO (Zea maYS L.)
}

\author{
ORLANDO MELO DE CASTRO \\ Engenheiro Agrônomo
}

Orientador: Dr. SIDNEY ROSA VIEIRA

\begin{abstract}
Tese apresentada à Escola Superior de Agricultura "Luiz de Queiroz", da Universidade de são Paulo, para obtenção do titulo de Doutor em Agronomia, Área de Concentração: Solos e Nutrição de Plantas.
\end{abstract}

\author{
Piracicaba \\ Estado de São Paulo - Brasil \\ Maio - 1995
}


CATALOGAC̣ÃO NA PUBLICAÇÃO

DIVISÃo DE BIBLIOTECA E DOCUMENTAC̣̃̃O - CAMPUS "LUIZ DE QUEIROZ"/USP

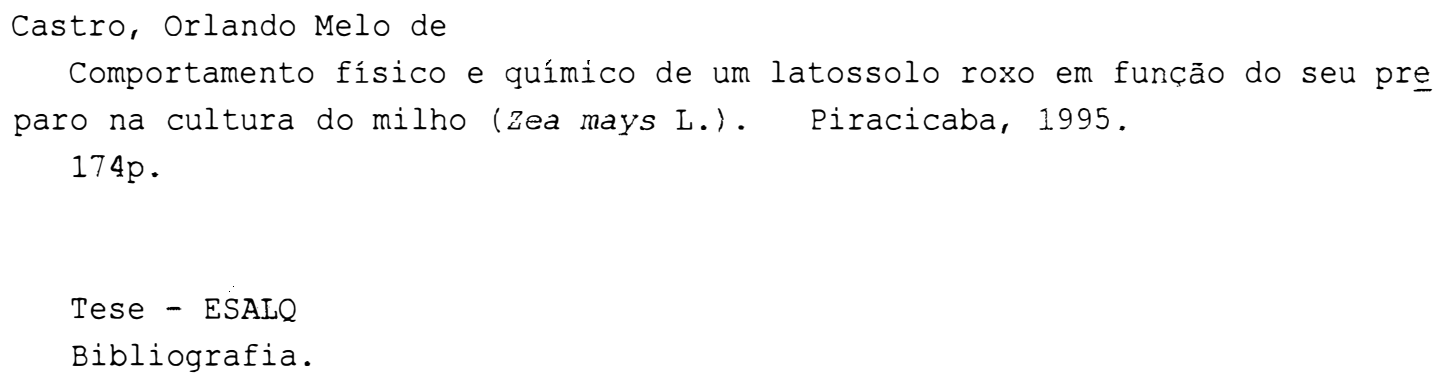

1. Latossolo roxo 2. Milho - Produção 3. Solo - Manejo 4. Solo - Preparo Efeito 5. Solo - Propriedade físico-químico I. Escola Superior de Agricultura Luiz de Queiroz, Piracicaba

CDD 631.4

631.51 
COMPORTAMENTO FÍSICO E QUÍMICO DE UM LATOSSOLO ROXO EM FUNÇÃO DO SEU PREPARO NA CULTURA DO MILHO (Zea mays I.)

ORLANDO MELO DE CASTRO

Aprovada em: 18/8/1995

Comissão julgadora:

Prof. Dr. Carlos Roberto Espindola EEAGRI/UNICAMP

Prof. Dr. Gerd Sparovek ESALQ/USP

Prof. "Dr. "Marlene Cristina Alves UNESP/ILHA SOLTEIRA Dr. Silvio Crestana CNPDIA/EMBRAPA

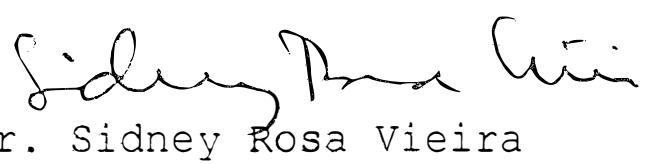

- Orientador - 


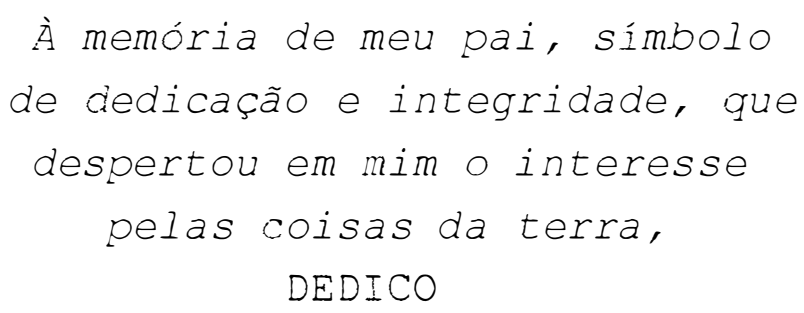

À minha mãe e minhas irmãs, que não mediram sacrificios para minha formação, OEEREÇO 


\section{Agradecimentos}

Ao Dr. Sidney Rosa Vieira, pela orientação, confiança, dedicação e auxílio para realização deste trabalho.

Aos Pesquisadores da Seção de Conservação do Solo pelo apoio e sugestões, mas principalmente pela manifestação de carinho e amizade.

À Técnica de Apoio Luzia Aparecida Eelisbino da Silva, da Seção de Conservação do Solo, pelo auxilio nos trabalhos de laboratório.

Às Técnicas de Processamento de Dados, Silvana Cristina Teixeira e Margarete Aparecida das Chagas pelos trabalhos de digitação e editoração.

Aos Euncionários de campo da Seção de Conservação do solo e do Centro Experimental de Campinas pelo auxilio na condução dos experimentos de campo.

Ao Engenheiro Agrônomo Paulo Cesar Nascimento pelo auxílio nas avaliações de cobertura do solo.

Ao Instituto Agronômico pela oportunidade de realizar este treinamento.

À Escola Superior de Agricultura "Luiz de Queiroz"-USP e ao seu corpo docente pelos ensinamentos.

Ao Conselho Nacional de Desenvolvimento Científico e Tecnológico - CNPq, pelo apoio financeiro.

A Deus, por tudo. 
SUMÁRIO

Página

LISTA DE FIGURAS . . . . . . . . . . . . . . . . . . v

LISTA DE TABELAS . . . . . . . . . . . . . . . . . . $x i$

RESUMO . . . . . . . . . . . . . . . . . . . $x i v$

SUMMARY . . . . . . . . . . . . . . . . . . . xvi

1. INTRODUÇÃO . . . . . . . . . . . . . . . . . . . . 1

2. REVISÃO DE LITERATURA . . . . . . . . . . . . . . 4

2.1. Sistemas de preparo e a compactação do solo. 6

2.2. Capacidade de infiltração . . . . . . . . . . 10

2.3. Disponibilidade hídrica . . . . . . . . . . . 15

2.4. Fertilidade do solo... . . . . . . . . . 18

2.5. Produção das culturas . . . . . . . . . . . . 21

3. MAterial e métodos . . . . . . . . . . . . . . . . 24

3.1. Área Experimental . . . . . . . . . . . . . . 24

3.1.1. Localização da área . . . . . . . . . 24

3.1.2. Clima regional. . . . . . . . . . . 24

3.1.3. Solo............... . 25

3.2. Descrição do experimento de campo . . . . . . 26

3.3. Determinações . . . . . . . . . . . . . 28

3.3.1. Potencial matricial do solo durante $\circ$ ciclo do milho. . . . . . . . . . . . 28

3.3.2. Avaliação de estrutura, resistência à penetração, curva de retenção de água, capacidade de água disponível e de aeração do solo. . . . . . . . . . . 
3.3.3. Infiltração e condutividade hidráulica do solo saturado no campo, com permeâmetro. . . . . . . . . . . . .

3.3.4. Determinação da condutividade hidráulica

e da capacidade de campo . . . . . . .

3.4. Análise granulométrica e da fertilidade do solo

3.5. Avaliações fenológicas . . . . . . . . . . 37

3.6. Análise dos dados . . . . . . . . . . . . . . 39

4. RESULTADOS E DISCUSSÃO . . . . . . . . . . . . . . . 40

4.1. Análise granulométrica do solo. . . . . . . . 40

4.2. Análise quimica do solo. . . . . . . . . . 40

4.3. Densidade do solo, resistência à penetração e a distribuição de raizes. . . . . . . . . . 47

4.4. Infiltração e condutividade hidráulica do solo saturado - permeâmetro de Guelph . . . . . . 52

4.5. Potencial matricial da água no solo . . . . . 56

4.6. Retenção de água do solo . . . . . . . . . . 68

4.7. Capacidade de aeração (Car) e de água disponivel (Cad) . . . . . . . . . . . . . . . . 82

4.8. Condutividade hidráulica da água do solo . . 90

4.9. Produção das culturas . . . . . . . . . . . 110

5. CONCLUSÕes . . . . . . . . . . . . . . . . . . . . . . 112

6. CONSIDERAÇÕES FINAIS . . . . . . . . . . . . . . . 114

REFERÊNCIAS BIBLIOGRÁFICAS . . • . . . . . . . . . . . 117

APÊNDICES . . . . . . . . . . . . . . . . . . . . . . . . . . . 129 
Figura 1. Balanço hídrico da região de Campinas, de 1956 a 1987, pelo método de THORNTHWAITE \& MATHER (1955). . . . . . . . . . .

Figura 2. Densidade do solo, em diferentes profundidades, nos três sistemas de preparo do solo. . . . . . . . . . . . . . . . .

Figura 3. Valores de resistência à penetração, com penetrômetro de bolso, em diferentes profundidades, nos três sistemas de preparo de solo. . . . . . . . . . . . . . . . .

Figura 4. Densidade de raiz de milho, em diferentes profundidades, nos três sistemas de preparo do solo. . . . . . . . . . . . . . .

Figura 5. Potencial matricial, na profundidade de $10 \mathrm{~cm}$, nos três sistemas de preparo de solo, durante o ciclo do milho. . . . .

Figura 6. Potencial matricial, na profundidade de $20 \mathrm{~cm}$, nos três sistemas de preparo de solo, durante o ciclo do milho. . . . .

Figura 7. Potencial matricial, na profundidade de $30 \mathrm{~cm}$, nos três sistemas de preparo de solo, durante o ciclo do milho. . . . . .

Figura 8. Potencial matricial, na profundidade de $60 \mathrm{~cm}$, nos três sistemas de preparo de solo, durante o ciclo do milho. . . . . 


\section{Página}

Figura 9. Potencial matricial, na profundidade de $90 \mathrm{~cm}$, nos três sistemas de preparo de solo, durante o ciclo do milho. . . . .

Figura 10. Potencial matricial, na profundidade de $120 \mathrm{~cm}$, nos três sistemas de preparo de solo, durante o ciclo do milho. . . . .

Figura 11. Precipitação diária, durante o ciclo do milho, no local do experimento . . . .

Figura 12. Cobertura morta do solo (A) e cobertura pelo milho ao longo do ciclo (B), nos três sistemas de preparo do solo. . . . . .

Figura 13. Retenção de água nos três sistemas de preparo do solo, na profundidade de $5 \mathrm{~cm}$.

Figura 14. Retenção de água nos três sistemas de preparo do solo, na profundidade de $10 \mathrm{~cm}$.

Figura 15. Retenção de água nos três sistemas de preparo do solo, na profundidade de $15 \mathrm{~cm}$. . . . . . . . . . . . .

Figura 16. Retenção de água nos três sistemas de preparo do solo, na profundidade de $20 \mathrm{~cm}$.

Figura 17. Retenção de água nos três sistemas de preparo do solo, na profundidade de $25 \mathrm{~cm}$. . . . . . . . . . . . . 
vii.

Página

Figura 18. Retenção de água nos três sistemas de preparo do solo, na profundidade de $30 \mathrm{~cm}$.

Figura 19. Retenção de água nos três sistemas de preparo do solo, na profundidade de $45 \mathrm{~cm}$.

Figura 20. Retenção de água nos três sistemas de preparo do solo, na profundidade de $60 \mathrm{~cm}$

Figura 21. Retenção de água nos três sistemas de preparo do solo, na profundidade de $75 \mathrm{~cm}$.

Figura 22. Retenção de água nos três sistemas de preparo do solo, na profundidade de $90 \mathrm{~cm}$

Figura 23. Retenção de água nos três sistemas de preparo do solo, na profundidade de $120 \mathrm{~cm}$. . . . . . . . . . . . .

Figura 24. Capacidade de aeração média, determinada para as profundidades até $30 \mathrm{~cm}$, nos três sistemas de preparo de solo. . . . . .

Figura 25. Capacidade de água disponível média, determinada para as profundidades até $30 \mathrm{~cm}$, nos três sistemas de preparo do solo. . . . . . . . . . . . . 
Figura 26. Classificação da condição estrutural do solo, em termos de capacidade de aeração (Car) e de água disponível (Cad), para o plantio direto. . . . . . . . . . . .

Figura 27. Classificação da condição estrutural do solo, em termos de capacidade de aeração (Car) e de água disponivel (Cad), para o preparo com escarificador. . . . . . .

Figura 28. Classificação da condição estrutural do solo, em termos de capacidade de aeração (Car) e de água disponível (Cad), para o preparo convencional. . . . . . . . .

Figura 29. Umidade volumétrica $(\boldsymbol{\theta})$, em função do tempo de drenagem, para os três sistemas de preparo do solo, na profundidade de $10 \mathrm{~cm}$.

Figura 30. Umidade volumétrica $(\boldsymbol{\theta})$, em função do tempo de drenagem, para os três sistemas de preparo do solo, na profundidade de $20 \mathrm{~cm}$.

Figura 31. Umidade volumétrica $(\boldsymbol{\theta})$, em função do tempo de drenagem, para os três sistemas de preparo do solo, na profundidade de $30 \mathrm{~cm}$.

Figura 32. Umidade volumétrica $(\boldsymbol{\theta})$, em função do tempo de drenagem, para os três sistemas de preparo do solo, na profundidade de $60 \mathrm{~cm}$.

Figura 33. Umidade volumétrica $(\boldsymbol{\theta})$, em função do tempo de drenagem, para os três sistemas de preparo do solo, na profundidade de $90 \mathrm{~cm}$. 


\section{Página}

Figura 34. Umidade volumétrica $(\theta)$, em função do tempo de drenagem, para os três sistemas de preparo do solo, na profundidade de $120 \mathrm{~cm} \mathrm{.} \mathrm{.} \mathrm{.} \mathrm{.} \mathrm{.} \mathrm{.} \mathrm{.} \mathrm{.} \mathrm{.} \mathrm{.} \mathrm{.} \mathrm{.} \mathrm{.} \mathrm{.}$

Figura 35. Perfil de umidade do solo no sistema de plantio direto, em vários tempos e após inundação. . . . . . . . . . . . . . . .

Figura 36. Perfil de umidade do solo no sistema de preparo com escarificador, em vários tempos

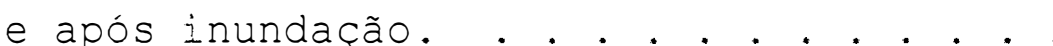

Figura 37. Perfil de umidade do solo no sistema de preparo convencional, em vários tempos e após inundação. . . . . . . . . . . . .

Figura 38. Condutividade hidráulica $(K)$, em função da umidade do solo $(\boldsymbol{\theta})$, para os três sistemas de preparo do solo, na profundidade de $10 \mathrm{~cm}$. . . . . . . . . . . . .

Figura 39. Condutividade hidráulica $(K)$, em função da umidade do solo $(\boldsymbol{\theta})$, para os três sistemas de preparo do solo, na profundidade de $20 \mathrm{~cm}$. . . . . . . . . . . .

Figura 40. Condutividade hidráulica $(K)$, em função da umidade do solo $(\boldsymbol{\theta})$, para os três sistemas de preparo do solo, na profundidade de $30 \mathrm{~cm}$. . . . . . . . . . . . .

Figura 41. Condutividade hidráulica (K), em função da umidade do solo $(\boldsymbol{\theta})$, para os três sistemas de preparo do solo, na profundidade de $60 \mathrm{~cm}$. . . . . . . . . . . . . 
$\mathrm{x}$.

Página

Figura 42. Condutividade hidráulica $(K)$, em função da umidade do solo $(\boldsymbol{\theta})$, para os três sistemas de preparo do solo, na profundidade de

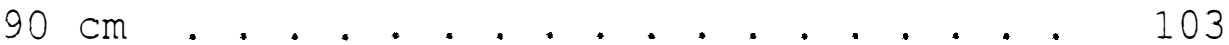

Figura 43. Condutividade hidráulica (K), em função da umidade do solo $(\boldsymbol{\theta})$, para os três sistemas de preparo do solo, na profundidade de $120 \mathrm{~cm} \mathrm{................} \mathrm{.} 104$ 
xi.

\section{IISTA DE TABELAS}

Página

Tabela 1. Análise granulométrica do solo sob três sistemas de preparo, em diferentes profundidades (média de três repetições).

Tabela 2. Valores médios de matéria orgânica, em diferentes profundidades, nos três sistemas de preparo do solo. . . . . . . . . . .

Tabela 3. Valores médios de fósforo (resina), em diferentes profundidades, nos três sistemas

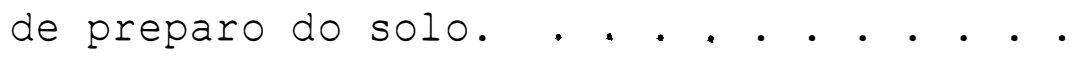

Tabela 4. Valores médios de potássio, em diferentes profundidades, nos três sistemas de preparo do solo. . . . . . . . . . . . . . . .

Tabela 5. Valores médios de cálcio, em diferentes profundidades, nos três sistemas de preparo do solo. . . . . . . . . . . . . . . . .

Tabela 6. Valores médios de magnésio, em diferentes profundidades, nos três sistemas de preparo

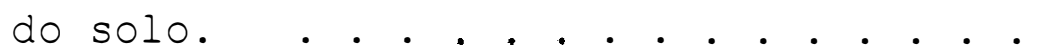

Tabela 7. Valores médios de pH, em diferentes profundidades, nos três sistemas de preparo do solo. . . . . . . . . . . . . .

Tabela 8. Valores médios de saturação por bases $(V \%)$, em diferentes profundidades, nos três sistemas de preparo do solo. . . . . . 
xii.

Página

Tabela 9. Comparação estatística dos dados de densidade do solo. . . . . . . . . . 48

Tabela 10. Análise estatística dos valores de resistência à penetração, com penetrômetro de bolso, em diferentes profundidades, nos três sistemas de preparo do solo e umidade volumétrica no momento da avaliação, a 10, 30 e $60 \mathrm{~cm}$. . . . . . . . . . .

Tabela 11. Análise estatística dos dados de densidade de raiz de milho, em diferentes profundidades, nos três sistemas de preparo do solo. . . . . . . . . . . .

Tabela 12. Valores de infiltração e condutividade hidráulica do solo saturado (Kfs), determinadas com permeâmetro de Ghelph, na superficie, a $20 \mathrm{~cm}$ e a $40 \mathrm{~cm}$ de profundidade, nos três sistemas de preparo do solo. . . . . . . . . . . . . . .

Tabela 13. Parâmetros da equação de GENUCHTEN \& NIELSEN (1985), para cada profundidade, nos três sistemas de preparo do solo . . .

Tabela 14. Parâmetros da equação $K(\boldsymbol{\theta})$ e $r^{2}$, para cada profundidade, nos três sistemas de preparo do solo................

Tabela 15. Valores de condutividade hidráulica na capacidade de campo (KCC), em cm. $\mathrm{h}^{-1}$ para os três sistemas de preparodo solo, em cada profundidade . . . . . . . . . . . 
xiii.

Página

Tabela 16. Valores de umidade volumétrica $(\boldsymbol{\theta})$ em amostras de solo ( $\theta$ medido) retiradas nas parcelas de drenagem após estabilização das leituras dos tensiômetros, valores calculados ( $\boldsymbol{\theta}$ calculado) pela equação de GENUCHTEN \& NIELSEN (1985) e tensão correspondente, para os três sistemas de preparo do solo. ............. 109

Tabela 17. Valores de produção de palha de aveia preta, estande, palha e grãos de milho nos três sistemas de preparo do solo e produção média de milho de 1983/84 a 1989/90. . . 110 
xiv.

\section{COMPORTAMENTO FÍSICO E QUÍMICO DE UM LATOSSOLO ROXO EM FUNÇÃO DO SEU PREPARO NA CULTURA DO MILHO (Zea mays L.)}

Autor: ORLANDO MELO DE CASTRO

Orientador: DR. SIDNEY ROSA VIEIRA

\section{RESUMO}

Com a finalidade de buscar a forma mais adequada de manejo do solo em condições edafoclimáticas específicas, fez-se 0 estudo de diferentes sistemas de preparo avaliando-se seus efeitos sobre as caracteristicas físicas e quimicas que atuam no processo de armazenamento de água e na produção de grãos da cultura de milho. O trabalho foi realizado aproveitando-se um experimento de manejo do solo iniciado em $1983 / 84$ em um latossolo roxo distrófico muito argiloso (Typic Haplorthox), no Centro Experimental de Campinas, do Instituto Agronômico. Os tratamentos utilizados foram os de milho rotacionado com soja, após aveia preta cultivada no outono-inverno, sob preparo com escarificador, arado de discos (convencional) e plantio direto, com três repetições. As avaliações deste estudo ocorreram em 1990/91, quando se determinou: potencial matricial no ciclo do milho, densidade do solo, resistência à penetração, com penetrômetro de bolso, densidade de raízes, fertilidade do solo, cobertura 
morta e pela cultura, retenção de água até $1.500 \mathrm{kPa}$, capacidade de aeração e de água disponível, infiltração e condutividade hidráulica com permeâmetro e pelo método de saturação do perfil, e produção de grãos da cultura de milho.

Os resultados obtidos revelaram que o plantio direto apresentou mais beneficios ao desenvolvimento das plantas e ao solo que o sistema convencional, entre os quais pode-se destacar: acúmulo de matéria orgânica e fósforo próximo à superfície, maior homogeneidade ao longo do perfil quanto a estrutura, com melhor desenvolvimento radicular do milho, maior infiltração e condutividade hidráulica, maior umidade no solo na fase inicial da cultura, maior reserva de água no solo abaixo de $60 \mathrm{~cm}$ de profundidade e maior retenção de água nas camadas mais superficiais. o preparo com escarificador apresentou muitos resultados semelhantes ao plantio direto, como teor de matéria orgânica, densidade de raiz, infiltração, condutividade hidráulica, umidade do solo e outros até melhores que o plantio direto, como maior teor de potássio, cálcio e magnésio e menor resistência à penetração. Quanto ao preparo convencional destaca-se a formação de uma camada compactada em torno de $20 \mathrm{~cm}$ de profundidade, que refletiu no menor crescimento de raízes abaixo desta camada. Em que pese a maior acidificação no plantio direto e os baixos teores de cálcio e magnésio, o sistema possibilitou a maior produção de grãos de milho em relação aos demais. 
$x \vee i$

\section{PHYSICAL AND CHEMICAL BEHAVIOUR OF A DUSKY RED LATOSOL AS FUNCTION OF TILLAGE SYSTEMS IN CORN (Zea maYS L.)}

Author: ORLANDO MELO DE CASTRO Adviser: DR. SIDNEY ROSA VIEIRA

\section{SUMMARY}

Different corn crop management systems were evaluated, considering their effects on soil physical and chemical characteristics, aiming to find the most feasible soil management for different edaphoclimatic conditions. The experiment was carried out using a crop management plot iniciated in $1983 / 84$ on a Dusky Red Latosol (Typic Haplorthox), at the "Centro Experimental de Campinas", of the Instituto Agronômico, São Paulo State, Brazil. The experiments considering the rotation of corn and soybean after oats cultivated during the autumm - winter consisted of soils prepared with: chisel plow, disc plow and no tillage, with three replications. Evaluations were done during 1990/91 and consisted of: matric potential during the corn crop cycle; soil density; penetrometer resistence; root density; soil fertility; mulch; water retention up to $1.500 \mathrm{KPa}$; air and water capacities; infiltration and hydraulic conductivity measured with the Guelph permeameter and by the profile saturation method, and corn yield. 
xvii.

The results showed that the treatment no tillage cropping system was better than conventional tillage for crop development and soil conditions as far as: enhancement of organic matter and phosphorus near the soil surface; higher structural homogenity through soil profile with better corn root development; higher water infiltration and hydraulic conductivity; higher soil water content at the begining of the crop; higher water soil content below $60 \mathrm{~cm}$ depth and higher soil holding capacity at soil surface layers. The chisel plow cropping system showed similar results to the no-tillage, such as organic matter content, root density, infiltration rate, hydraulic conductivity, and soil moisture. Some attributes were better than for the no tillage, such as potassium, calcium and magnesium contents, and lower penetration resistance. The conventional tillage system showed a clear compacted layer at $20 \mathrm{~cm}$ deph which refleted on smalier root growth in this layer. In spite of the high values of soil acidity, the lower levels of calcium and magnesium, the no tillage cropping system showed higher values of corn yield as compared to the other treatments. 


\section{INTRODUÇÃO}

O preparo do solo usado na agricultura tem variado amplamente em termos de implementos utilizados, profundidade de trabalho e a intensidade de movimentação. Entretanto, muitas áreas agrícolas recebem o mesmo tipo de preparo na mesma profundidade por vários anos seguidos, propiciando a formação de duas camadas distintas: uma camada superficial desagregada, sujeita à formação de crosta, e outra camada subsuperficial, compactada, resultante da pressão dos implementos agrícolas, quando trabalham na mesma profundidade e agravadas em condições inadequadas de umidade.

Estas camadas compactadas, além de dificultarem a infiltração de água no solo e a penetração das raízes, reduzem a quantidade de água armazenada, expondo as plantas a periodos de déficits hídricos que podem afetar a produção.

Nos últimos anos se passou a questionar a utilização de sistemas de preparo que mobilizam excessivamente a camada arável do solo, favorecendo a erosão, - predominio de determinadas espécies de ervas invasoras, 0 agravamento de certas pragas e doenças de solos e, principalmente, aumentando a relação custo/benefício. 
o preparo excessivo do solo, o monocultivo e a eliminação dos residuos culturais são as principais causas do processo acelerado de degradação física dos solos, pois tais práticas levam à oxidação da matéria orgânica, desagregação do solo por ação das gotas de chuva e erosão acelerada.

O estado em que se encontra a superfície do solo determinará a velocidade de infiltração da água da chuva, bem como a presença da camada superficial desagregada sobre uma camada compactada. As operações de preparo do solo podem alterar a velocidade de infiltração e a capacidade de armazenamento de água, não só pelo efeito na estrutura do solo, mas também pela manutenção de resíduos na superfície que podem minimizar as perdas de água por evaporação.

Sistemas conservacionistas de preparo do solo constituem um meio com potencial para reduzir as perdas de água por evaporação e erosão, aumentando o armazenamento de água no solo (SIDIRAS et al., 1982). Destes sistemas, os de maior uso são o plantio direto e o preparo com arado escarificador. Estes sistemas mantêm o solo com maior umidade, em relação aos sistemas convencionais, por aumentar a infiltração e por reduzir a evaporação, devido à cobertura morta que fica na superficie. Isto é mais evidente no plantio direto, pois os restos culturais ficam totalmente na superficie, reduzindo as possibilidades de evaporação de água do solo. 
O aumento de umidade do solo necessariamente não implica em mais água disponível às plantas, pois se a estrutura do solo resultante do manejo adotado aumentar a microporosidade, a água pode ficar mais fortemente retida, aumentando a força necessária para sua extração (LETEY, 1991). Esta é uma situação que ocorre no plantio direto. A não-movimentação periódica do solo torna-o mais compactado que o convencional na camada arável, aumentando a retenção de água. Por outro lado a cobertura morta no plantio direto reduz a evaporação, prolongando o período úmido do solo, fase em que a água é mais fracamente retida.

A menor mobilização do solo também afeta a disponibilidade de nutrientes às plantas, pois concentra os nutrientes nas camadas superficiais, formando camadas estratificadas de concentração (MUZILLI, 1983). Por outro lado, a absorção de nutrientes está relacionada com o desenvolvimento do sistema radicular que será determinado pela presença ou não de camadas compactadas.

llos últimos anos, com a introdução de novos implementos agrícolas na busca de mudar os sistemas de preparo do solo, vem se desenvolvendo sistemas de preparo que visam diminuir o tráfego de máquinas e implementos agrícolas sobre o solo. Com a finalidade de contribuir para definir de forma mais adequada o manejo do solo, sob dadas condições de solo e clima, foi conduzido o presente trabalho. o objetivo foi o estudo do efeito de diferentes sistemas de preparo do solo sobre as características físicas e químicas que atuam no processo de armazenamento de água no solo e na produção de grãos da cultura de milho. 


\section{REVISÃO DE IITERATURA}

As primeiras ferramentas de preparo do solo foram feitas de pedras, madeira e, possivelmente, de ossos e conchas. Foram utilizadas para eliminar ervas invasoras e fazer um sulco superficial que permitisse a colocação das sementes no solo. Mais tarde, animais foram usados para puxar hastes de madeira em formas apropriadas que, com o tempo, foram munidas com pontas ou partes de metal. Posteriormente, o ferro foi utilizado na confecção de implementos, até chegar ao arado de aiveca de tração animal e, com isto, possibilitar o aumento das áreas trabalhadas. A sua invenção revolucionou a agricultura mundial (CASTRO, 1989).

Desde então, o preparo do solo vem evoluindo, com implementos cada vez maiores, tracionados por tratores cada vez mais pesados e potentes. Mas, muitos efeitos negativos acompanham os benefícios obtidos com essa evolução, como a compactação do solo abaixo da camada preparada, comumente chamadas de "pé-de-grade" ou "pé-de-arado". 
Estas camadas compactadas, além de dificultarem a infiltração de água no solo, reduzem a quantidade de água armazenada e o desenvolvimento do sistema radicular é prejudicado, seja por falta ou por excesso de água (CASTRO et al., 1987a). A redução na infiltração implica no aumento do escoamento superficial, com maior transporte de terra e conseqüente empobrecimento do solo agrícola.

Nas duas últimas décadas, muito se tem questionado sobre a utilização de sistemas de preparo que mobilizam excessivamente o solo, favorecendo a erosão. Neste sentido, muitos trabalhos vêm sendo desenvolvidos procurando alternativas de sistemas de preparo do solo, visando sua conservação, mas sem prejuízo à produção das culturas. Estes sistemas, denominados preparos conservacionistas do solo, segundo sammer et al. (1986) citados por DERPSCH et al. (1991), garantem uma camada de cobertura morta próxima a superficie, através da mistura, com o solo, dos restos vegetais existentes após a colheita da planta comercial e/ou da planta de adubo verde, ou onde estes restos vegetais permanecem sobre 0 solo como cobertura, sem serem incorporados. As sementes são depositadas no solo através desta camada de restos vegetais. Para ALLMARAS \& DOWDY (1985) são conservacionistas os métodos de preparo do solo e plantio, nos quais mais de $30 \%$ do solo permanecem cobertos por restos vegetais após a semeadura. 


\title{
2.1. Sistemas de preparo e a compactação do solo
}

\author{
É comum encontrar, em áreas sob preparo
} convencional, com aração e gradagens, camadas compactadas próximas à superficie. As operações de preparo do solo sempre na mesma profundidade formam, gradativamente, esta camada. Ao passar pelo solo, qualquer implemento de preparo provoca a compactação de uma camada cuja espessura pode ser aumentada pelo excesso de umidade no momento da operação. Se - implemento for passado sempre na mesma profundidade, esta camada, aos poucos, vai ficando tão densa que dificulta a infiltração de água e a penetração das raizes no solo.

Contrapondo-se aos sistemas de preparo com mobilização total do solo superficial, foi desenvolvido um sistema com mobilização apenas na linha de semeadura, com o restante da superficie do solo ficando coberta pelos restos da cultura anterior. Este sistema tem recebido denominações várias como plantio sem preparo, semeadura na palha e plantio direto.

Mas o não-revolvimento do solo no plantio direto provoca adensamento da camada superficial que se traduz por aumento da densidade do solo e redução da porosidade, devido à diminuição do volume de macroporos (SIDIRAS et al., 1982). 
Em trabalhos onde se comparam sistemas de preparo, via de regra a densidade do solo e a resistência à penetração são maiores no plantio direto na camada superficial, enquanto que abaixo desta a tendência é de ser igual ou maior no sistema convencional. Isto pode ser observado nos trabalhos de SIDIRAS et al., 1982; BIEVINS et al., 1983; VIEIRA \& MUZILLI, 1984; CENTURION \& DEMATTÊ, 1985 e CASTRO et al., $1987 \mathrm{~b}$.

Por outro lado, trabalhos de MACHADO \& BRUM (1978) e LEITE \& MEDINA (1984) mostraram valores de densidade do solo menores em plantio direto em comparação ao sistema convencional.

Estas contradições observadas na literatura se devem principalmente à falta de informação dos trabalhos quanto ao tipo de equipamento utilizado no plantio e época de amostragem. No caso da máquina de semeadura para plantio direto ser provida de sulcador na adubadeira, isto reduz a compactação superficial do plantio direto (DERPSCH et al., 1991). Com relação à época de amostragem, DERPSCH et al. (1991), trabalhando com sistemas convencional, escarificador e plantio direto na cultura de trigo, em latossolo roxo, mostram que as densidades do solo superficiais são iguais antes do preparo e ao final do ciclo do trigo mas significativamente maiores no plantio direto da semeadura até - espigamento. 
Uma regra geral que se encontra nestes trabalhos já citados é a compactação subsuperficial no sistema de preparo convencional, logo abaixo da camada mobilizada. De acordo com CAMARGO (1983), esta compactação é formada pelas rodas do trator, que exercem pressão para baizo sobre a camada não cortada pelos discos do arado. Além disso, o elemento cortante do arado ou grade exerce também uma pressão sobre o solo na área de contato, acentuando a compactação. Esta operação realizada com o mesmo equipamento e sempre na mesma profundidade leva à formação de uma capa compactada, chamada "pé-de-grade" ou "pé-de-arado".

Tal fato não se observa quando se utilizam equipamentos de preparo providos de hastes, como os arados escarificadores. Assim é, que solos preparados com este tipo de equipamento tendem a apresentar valores de densidade do solo elou resistência menores que o sistema convencional e com menor diferenciação entre camadas, conforme relatado por DERPSCH et al., 1986; OLIVEIRA et al., 1990; DE MARIA et al., 1993.

Quando se fala em compactação do solo, uma das preocupações é o crescimento radicular. Não se dispõe de muitos trabalhos sobre avaliação de sistema radicular em diferentes situações de preparo do solo para nossas condições. VIEIRA (1981), numa comparação entre o sistema convencional e plantio direto com a cultura de soja, mostrou que neste último o sistema radicular apresentou uma distribuição melhor em profundidade, superando o sistema convencional em 50\% do volume de raiz abaixo dos $20 \mathrm{~cm}$. 
DE MARIA et al., (1993) mostraram que, no sistema de plantio direto em latossolo roxo, a soja apresentou, em relação ao preparo convencional, densidade radicular duas vezes maior na camada abaixo dos $20 \mathrm{~cm}$, onde o solo arado apresentava 0 "pé-de-arado", apesar dos valores de resistência à penetração e densidade do solo serem semelhantes, sendo maior apenas na camada superficial do plantio direto.

CANNEL (1981) sugeriu que $\bigcirc$ melhor desenvolvimento radicular em solos não-mobilizados é devido à continuidade dos poros, mantidos pelos canais de raízes que apodrecem e pelas minhocas, sendo que a atividade destas depende da cobertura morta. LAL (1978), trabalhando na Nigéria em solos não-mobilizados, com e sem cobertura morta, verificou menor crescimento radicular de milho e menor atividade de minhocas no solo descoberto. A descontinuidade dos poros explica o menor crescimento radicular no sistema convencional pois, ao atingir a camada compactada, as raízes não têm por onde penetrar e, se a resistência for maior que a força que ela pode exercer, a tendência é o crescimento lateral (CAMARGO, 1983). A umidade do solo pode minimizar o problema, visto que a presença da água reduz a resistência à penetração.

Com relação ao crescimento radicular no plantio direto, DREW \& SAKER (1978), observaram que o aumento de nutrientes na camada superficial, especialmente fósforo, pode levar a um desenvolvimento excessivo de radicelas nesta camada, que num período de seca prolongada, pode prejudicar a planta se não houver um crescimento em profundidade. 


\subsection{Capacidade de infiltração}

O aumento da infiltração de água nos solos, por meios mecânicos ou biológicos, é uma das mais importantes medidas no controle da erosão hídrica. A vegetação, a umidade antecedente e a estrutura podem afetar a infiltração de água no solo (LAL, 1979).

Valores de densidade do solo maior e macroporosidade menor em solos sob plantio direto levam a pensar que a infiltração neste sistema de plantio deva ser menor que no preparo convencional, onde a superficie normalmente é mais porosa. Mas isto contraria os inúmeros trabalhos sobre perdas de solo e água por erosão, onde o plantio direto reduz as perdas em até $80 \%$ em relação aos sistemas convencionais de preparo do solo (MANNERING \& BURWELL, 1968; HARROLD, 1972; BENATTI et al., 1977; VIEIRA et al., 1978; MONDARDO et al., 1979; CASTRO et al., 1986).

Esta aparente contradição pode ser explicada pela ação física da chuva sobre o terreno descoberto. As gotas de chuva ao atingirem o solo já desestruturado pelo preparo, desagregram ainda mais as particulas de solo, provocando sua penetração nos poros, levando ao que se denomina de encrostamento. Conseqüentemente, apesar da maior porosidade do solo no preparo convencional, a água tem dificuldade em penetrar e grande parte perde-se pelo escoamento superficial. Os resíduos que cobrem o terreno no plantio direto amortecem o impacto da chuva, eliminando este encrostamento e mantendo a capilaridade do solo. 
A cobertura funciona também como obstáculo ao escoamento da água, retendo-a mais tempo na superfície e favorecendo sua infiltração (EHLERS, 1975; SIDIRAS et al., 1984).

A influência da cobertura morta na intensidade de infiltração da água relaciona-se com a qualidade e quantidade dos residuos vegetais que a constituem. Em princípio, culturas com alta produção de palha e sendo esta formada por material mais fino, dão origem a coberturas mortas densas e espessas, que protegem bem 0 solo e favorecem a infiltração. SIDIRAS \& ROTH (1987), estudando estes efeitos, concluíram que a resteva da aveia preta era a que proporcionava maiores taxas de infiltração de água, em relação às outras espécies de gramíneas e leguminosas.

O sistema de plantio direto sem cobertura morta, ou com pouca cobertura, pode ser tão danoso como o sistema convencional. ROTH \& MEYER (1983) obtiveram uma infiltração básica determinada com chuva simulada de $59 \mathrm{~mm} / \mathrm{h}$ num latossolo roxo com plantio direto; retirando-se porém a cobertura morta, a infiltração caiu para $17 \mathrm{~mm} / \mathrm{h}$. Isto representou uma queda de $71 \%$ só devido à remoção da cobertura, sendo menor que a infiltração obtida no preparo convencional, de $28 \mathrm{~mm} / \mathrm{h}$.

Quanto à quantidade ideal de cobertura no solo para garantir uma alta infiltração, e conseqüente controle da erosão, diversos autores, como MANNERING \& MEYER (1963), HUDSON (1971) e LAL (1982), afirmam que de 4 a 6 t/ha de cobertura morta por ano são suficientes para se obter $100 \%$ de solo coberto, o que permitiria infiltração total da água de chuva. 
LOMBARDI NETO et al., (1988), trabalhando em Campinas-SP, num latossolo roxo com 13\% de declive, obtiveram com 4 a 6 t/ha de restos de milho cerca de $70 \%$ de cobertura e $75 \%$ de controle das perdas de solo e água em relação ao solo descoberto. Estes níveis de cobertura na região sudeste do Brasil só podem ser conseguidos com dois cultivos ao ano e com rotação de culturas que tenham gramíneas, pois estas garantem coberturas mais duráveis, por terem relação $\mathrm{C} / \mathrm{N}$ alta.

Além da cobertura do solo, outro fator que atua no processo de infiltração é a continuidade dos poros e a presença de camadas compactadas. No sistema convencional, tem-se uma camada de solo preparado com predominância de macroporos que permite uma velocidade de infiltração sempre maior que na camada abaixo, quando esta está compactada pelo uso contínuo de um mesmo sistema de preparo. Assim é que DALIA ROSA (1981), trabalhando em latossolo roxo, determinou uma infiltração básica de $8 \mathrm{~mm} / \mathrm{h}$, medida com infiltrômetro na camada compactada, situada a $25-30 \mathrm{~cm}$, enquanto que na superficie obteve valores 6 vezes maiores e abaixo dela 24 vezes maiores, onde o solo praticamente não sofreu efeitos do manejo.

DERPSCH et al., (1991), trabalhando com vários dados de infiltração obtidos com simulador de chuvas com diferentes tipos de cobertura e estádio de desenvolvimento de plantas, calcularam um indice para melhor definir o encrostamento. 
Este índice é composto pela soma da erosividade existente um mês antes das medições de infiltração, corrigido pelo grau de cobertura do solo durante o mesmo mês. Foram encontradas correlações altamente significativas entre este indice e a infiltração total. As diferenças de densidade do solo e proporção de macroporos praticamente não influiram na infiltração. Evidentemente, portanto, a infiltração e, com esta, a suscetibilidade a erosão, são primeiramente definidas pelas condições na superfície do solo, ou seja, pela formação de um encrostamento superficial mais ou menos pronunciado como conseqüência da erosividade das chuvas e da cobertura do solo.

Em vista do exposto acima, é de se concluir que avaliações de infiltração em trabalhos sobre preparo do solo devem apresentar resultados mais próximos das condições naturais quando realizados com simuladores de chuva. De fato, resultados obtidos por DERPSCH et al., (1986), ROTH et al., (1988) e ARZENO (1990) com simulador de chuva mostraram que a infiltração no plantio direto pode ser 2 vezes maior que no sistema convencional, ficando o preparo com escarificador numa posição intermediária.

Por outro lado, determinações realizadas com infiltrômetros têm apresentado resultados diametralmente opostos. Estudo comparativo realizado por SIDIRAS \& ROTH (1987) indicou valores de infiltração maiores no preparo convencional que no plantio direto quando determinada com infiltrômetros e com valores até 6 vezes maiores que os obtidos no sistema com chuva simulada. Diferenças deste tipo foram também apresentadas por VIEIRA \& MUZILLI (1984) e CASTRO et al., (1987a). 
"Evidentemente, o processo de selamento superficial, decisivo para a formação de erosão não ocorre nos anéis do infiltrômetro. contudo, as determinações obtidas com infiltrômetros reproduzem bem a proporção de poros existentes no solo, encontrando-se correlações significativas entre proporção de macroporos e infiltração" (SIDIRAS \& VIEIRA, 1984).

A condutividade hidráulica pode fornecer dados que ajudam a caracterizar o movimento da água no solo. Sendo dependente do número, continuidade e tamanho dos poros, é um parâmetro que pode ser útil na diferenciação dos efeitos de sistemas de preparo na movimentação de água no perfil. A compactação do solo e a descontinuidade dos poros reduz significativamente a condutividade hidráulica do solo saturado. Durante uma chuva pesada, a continuidade dos poros, principalmente poros grandes deixados por minhocas e insetos, pode permitir uma drenagem mais rápida da água para camadas mais profundas abaixo até da zona radicular. Em principio, o plantio direto, por apresentar um sistema permanente de bioporos e canais deixados por raizes que apodrecem, tem esta situação de drenagem (BOONE, 1988). De fato ARZENO (1990) obteve valores de condutividade hidráulica do solo saturado nos sistemas de plantio direto e escarificador cerca de duas vezes maior que no sistema convencional em um latossolo roxo.

Quando o solo se encontra insaturado, a condutividade hidráulica, dita não saturada, é reduzida. Nesta situação, ROTH et al., (1988) não encontraram diferenças entre sistemas de preparo do solo em diferentes profundidades, observando redução da condutividade nas camadas mobilizadas em relação à camada mais profunda que não foi afetada pelos preparos. 


\subsection{Disponibilidade hidrica}

O sistema do preparo do solo é uma das formas pela qual pode-se aumentar ou diminuir, tanto a erosão como - armazenamento de água na zona radicular. Para as condições climáticas do Estado de São Paulo, onde é freqüente a ocorrência de veranicos, a adoção de sistemas capazes de manter mais água disponível para as plantas é importante para se evitar quebras na produção.

A drenagem interna, condicionada pela estrutura do solo, e a evaporação, condicionada pela cobertura e encrostamento superficial, são fatores preponderantes no armazenamento de água no solo.

A evaporação de água do solo, sob condições de campo, ocorre por meio de uma série de ciclos de secagem interrompidas por precipitações ocasionais. Após umedecimento do solo, a evaporação pode ser caracterizada por três estádios. O primeiro estádio, ou de taxa constante, ocorre quando a superfície está úmida e envolve rápida perda de água controlada basicamente pelas condições externas. Quando se estabelece uma resistência ao fluxo de perda de água há um decréscimo exponencial na taxa de evaporação, caracterizando - segundo estádio, que é regido mais pelas condições intrínsecas do solo. O terceiro estádio é caracterizado por uma evaporação muito baixa, mas constante, onde o movimento de água através da superfície do solo seco é principalmente por difusão de vapor. 
Tentar limitar a evaporação de água utilizando-se cobertura morta, como no plantio direto, pode ter pequenos benefícios a longo prazo, a menos que a redução na taxa de evaporação inicial permita que se tenha acréscimo na percolação, aumentando a água disponível no solo. Independentemente da cobertura do solo, a evaporação cumulativa de um solo nu ou coberto pode ser muito semelhante após um período prolongado de secamento. Porém, quando se tem chuvas sucessivas, em que o solo não chega a secar, a evaporação cumulativa é menor no solo coberto com restos culturais, podendo resultar em aumento na água armazenada (BOND \& WILIIS, 1969). Assim, a cobertura morta atenua os efeitos de veranicos, pois prolongando o período de umidade reduz a possibilidade de ocorrer déficits hidricos para a cultura instalada.

$$
\text { BOND \& WILIIS (1970), trabalhando com }
$$
diferentes quantidades de palha para cobertura do solo, verificaram que no solo descoberto, com taxa de evaporação em torno de $8 \mathrm{~mm} /$ dia, o primeiro estádio do processo é de cinco dias. Com a cobertura morta há redução na taxa de evaporação, sendo que, com 4,5 t/ha é de $2,5 \mathrm{~mm} / \mathrm{dia}$, o que permite que o primeiro estádio se prolongue por vinte dias. Como não sefez reumedecimento do solo, por volta de trinta dias todos os tratamentos estavam na mesma taxa de evaporação, correspondente ao terceiro estádio. 
Portanto, a grande influência da cobertura do solo está na primeira fase do processo, reduzindo a taxa de evaporação e prolongando este período. Essa redução da evaporação se deve não só à ação da cobertura em si, que dificulta a saída do vapor d'água, mas também ao menor aquecimento do solo e redução da secagem superficial por ação do vento.

Este efeito da cobertura morta sobre a evaporação explica as vantagens que o plantio direto apresenta em relação ao preparo convencional na disponibilidade hídrica em diversos trabalhos. Determinações realizadas por VIEIRA (1981) em cultura de soja, mostraram que o solo sob plantio direto pode conter até 15\% a mais de água que o convencional na profundidade de $0-5 \mathrm{~cm}$, em períodos de estiagem. SIDIRAS et al. (1983) determinaram, no plantio convencional, um déficit hidrico de 23\% durante veranico na cultura de soja, enquanto o plantio direto apresentou $20 \%$ de água disponível para as plantas e o preparo com escarificador 5\% de água disponível, na camada de $0-10 \mathrm{~cm}$ de profundidade. DERPSCH et al. (1986), trabalhando com trigo no Paraná, verificaram que, apesar das baixas precipitações, o plantio direto teve água disponível para a cultura cerca de 30 dias a mais que o sistema convencional, na camada de 0-20 cm de profundidade. Essa é uma das razões porque o plantio direto apresenta menor variação de produção ao longo dos anos. As vantagens do plantio direto são citadas por BLEVINS et al. (1971), LAL (1975), PHILLIPS (1984) e ARZENO (1990). 


\subsection{Fertilidade do solo}

Os sistemas de preparo provocam modificações na fertilidade do solo, uma vez que a quantidade, a distribuição e a disponibilidade dos nutrientes podem ser alteradas em função das diferentes operações realizadas. As principais alterações na fertilidade do solo sob sistemas de preparo reduzido e plantio direto em relação aos sistemas convencionais são função da não-movimentação do solo, que determina uma tendência para o acúmulo na superficie de material orgânico e de nutrientes. Outro fator é a erosão do solo, muito mais acentuada nos sistemas convencionais, determinando perdas significativas de nutrientes, e conseqüentemente maior empobrecimento do solo (CASTRO et al., 1986).

O teor de matéria orgânica nos solos com menor mobilização mecânica tende a ser mais alto nas camadas superficiais (MUZILII, 1983; EITZ et al., 1989). Mas, este acúmulo de matéria orgânica é dependente do tipo de solo, clima e quantidade de resteva produzida pelas culturas. Assim é que CASTRO et al. (1987b) não encontraram diferenças significativas no teor de matéria orgânica entre plantio direto e preparo convencional em Latossolo de textura média na região de Casa Branca-SP, mas em Latossolo argiloso na região de Itatiba-SP $\circ$ plantio direto apresentou acréscimos significativos no teor de matéria orgânica. 
A introdução de graminea no sistema de produção parece ser fundamental para manter os niveis de matéria orgânica elevados no solo. DE MARIA \& CASTRO (1993) mostraram que a aveia preta leva a maiores teores de matéria orgânica na camada arável do solo que a crotalária. Por outro lado, ALVES (1992), trabalhando com diferentes coberturas vegetais de inverno no plantio direto, não observou diferenças no teor de matéria orgânica.

Alguns autores (SHEAR \& MOSCHLER, 1969; TRIPLETT Jr. \& DOREN Jr., 1969; BLEVINS et al., 1978) afirmaram que, em áreas sob plantio direto, o aumento de cálcio e magnésio nas camadas mais superficiais só apareceu após um período prolongado de uso desse sistema, pela reciclagem que as culturas promovem. Nos trópicos, via de regra, isto não tem sido observado (MUZILLI, 1983; CENTURION et al., 1985; CASTRO et al., 1987b; OLIVEIRA et al., 1990); talvez em função da predominância da baixa CTC e da boa drenagem desses solos não ocorre este acúmulo de bases trocáveis nas camadas superficiais. Isto pode colaborar para a maior acidificação observada por alguns autores no sistema de plantio direto (SHEAR \& MOSCHLER, 1969; JUO \& LAL, 1979; CASTRO et al., 1987b; OLIVEIRA et al., 1990). Contribuiram para isto o acúmulo de matéria orgânica e de residuos da adubação química, sobretudo de fertilizantes nitrogenados, nas camadas superficiais. Quando o nitrogênio é lixiviado na forma de nitrato há sempre uma quantidade equivalente de cátions sendo removidos (SHEAR \& MOSCHLER, 1969). 
Teores de fósforo mais elevados nas camadas superficiais em sistemas de preparo reduzido têm sido determinados por diversos autores (SHEAR \& MOSCHLER, 1969; MUZILLI, 1983; CENTURION et al., 1985; ELTZ et al., 1989) e têm sido explicados como conseqüência da pequena mobilização do solo, que mantém o adubo residual na profundidade de aplicação e os restos culturais na superficie. Nos sistemas convencionais de preparo, o adubo residual e os restos vegetais são misturados a profundidades de até $20 \mathrm{~cm}$, o que facilita a adsorção específica do fósforo, pelo maior contato com sesquióxidos de Ee e Al do solo (DE MARIA \& CASTRO, 1993). Com relação ao potássio, alguns autores verificaram acúmulo de potássio na superfície em função de preparo reduzido (DREW \& SAKER, 1980; CENTURION et al., 1985; ROBBINS \& VOSS, 1991), outros não (SHEAR \& MOSCHLER, 1969; MUZILLI, 1983; ELTZ et al., 1989). Esse acúmulo provavelmente depende do tipo de solo (textura, mineral de argila), do regime de drenagem e da quantidade adicionada na adubação. CASTRO et al. (1987b), trabalhando em dois latossolos, um argiloso e outro de textura média, ambos com adubação acima do recomendável pela análise, verificaram acúmulos de potássio apenas no plantio direto do solo de textura argilosa. DE MARIA \& CASTRO (1993), trabalhando com amostras periódicas ao longo de sete anos em três sistemas de preparo, observaram acúmulos de potássio no solo sob plantio direto e preparo com arado escarificador, acúmulo este que foi eliminado num ano excessivamente chuvoso para as condições locais. 


\subsection{Produção das culturas}

O rendimento da cultura é função da combinação dos diferentes fatores abordados anteriormente, não se esquecendo dos fatores quimicos. Um solo bem estruturado, sem impedimento físico para o crescimento das raízes, com boa disponibilidade de nutrientes essenciais e água e sem competição de ervas invasoras pode garantir produções satisfatórias.

Além do preparo do solo, o sistema de rotação de culturas utilizado pode ter grande influência na produtividade. Os sistemas de rotação de culturas que incluem leguminosas, aumentam o teor de nitrogênio total do solo e, conseqüentemente, aumentam a produtividade das culturas subseqüentes, desde que sejam exigentes quanto a este elemento. Este fato foi constatado por MEDEIROS et al. (1987), trabalhando em solo podzólico vermelho-escuro, onde - feijão guandu, em três anos, aumentou o nitrogênio total em aproximadamente $900 \mathrm{~kg}$, em relação ao pousio/milho. Sistemas com outras leguminosas (trevo, lablabe, etc.) aumentaram em torno de $700 \mathrm{~kg} / \mathrm{ha}$. Conseqüentemente, o rendimento de milho no sistema aveia + trevo/milho foi $3300 \mathrm{~kg} / \mathrm{ha}$ a mais do que o sistema pousio/milho.

DERPSCH (1984), trabalhando com os sistemas de plantio direto, escarificador e convencional na cultura de milho, com e sem adubação nitrogenada, não observou grandes diferenças entre sistemas de preparo, mas sim para o efeito do tremoço branco no inverno em relação ao pousio, embora nos dois casos houvesse resposta ao nitrogênio aplicado. 
Nesta mesma linha, CASTRO (1989), num experimento conduzido em Campinas-SP, verificou que o milho cultivado após duas leguminosas, soja e crotalária, nos tratamentos com preparo do solo, dispensou a adubação nitrogenada em cobertura, enquanto que no plantio direto houve resposta para adubação com nitrogênio, sendo mais acentuada quando havia aveia preta no inverno. Isto ocorre porque, no plantio direto a decomposição dos restos vegetais é mais lenta que nos solos preparados, onde a liberação dos nutrientes dos restos vegetais é acelerada.

As gramíneas como milho e trigo têm sido mais responsivas à rotação de culturas que a soja, pois esta não é dependente do nitrogênio deixado por cultivos anteriores. A resposta das culturas à ação do sistema de preparo utilizado é muito em função dos fatores hídricos e de controle de ervas invasoras. Quando se tem o sistema de plantio direto com boa cobertura do solo, consegue-se bom controle na emergência de ervas invasoras e melhor controle da umidade do solo (ALMEIDA \& RODRIGUES, 1985).

DOREN Jr. (1965) verificou que as produções de milho foram diretamente proporcionais à fração da superficie do solo com cobertura morta, o que está associado à maior quantidade de água armazenada. DOREN Jr. et al. (1976) obtiveram maiores produções de milho em plantio direto quando a cobertura morta atingiu 70 a $80 \%$ do solo após o plantio. A cobertura, além de permitir maior infiltração de água, reduziu a quantidade perdida por evaporação. 
SHANHOLTZ \& LILLARD (1969) verificaram, em testes controlados, que a cultura de milho plantada em plantio direto utilizou cerca de $81 \%$ da água total disponível no perfil do solo e da chuva durante a fase de crescimento. No sistema convencional utilizou $57 \%$ da água disponível. Isto mostra que, quando ocorrem secas de curta duração, o sistema de plantio direto pode minimizar os efeitos da estiagem. Exemplo disto é o trabaiho de SIDIRAS et al. (1983), já citado, onde o déficit hídrico que ocorreu no sistema convencional, durante um veranico na fase de enchimento de grão da cultura de soja, significou 33\% a menos na produção em relação ao sistema de plantio direto.

Em função do exposto pode-se dizer que, em condições de boa distribuição de chuva no ciclo das culturas, é de se esperar produções semelhantes entre sistemas de preparo, mas ocorrendo períodos de seca ou de excesso de chuvas, os sistemas conservacionistas, especialmente o plantio direto, tendem a levar a maiores produções, desde que outros fatores de produção, como adubação e controle de ervas invasoras sejam satisfatórios. 


\section{MATERIAL E MÉtOdOS}

\section{1. Área Experimental}

\subsubsection{Localização da área}

- experimento localiza-se no Centro

Experimental de Campinas, do Instituto Agronômico, na latitude $22^{\circ} 53^{\prime}$ sul, longitude $47^{\circ} 04^{\prime}$ oeste, e altitude média de $660 \mathrm{~m}$.

\subsubsection{Clima regional}

A região de Campinas, de acordo com a classificação climática de Koeppen, tem o clima definido como uma transição entre os tipos Cwa e Cfa, significando clima tropical de altitude com inverno seco e verão úmido. A temperatura do mês mais quente (fevereiro) é superior a $22^{\circ} \mathrm{C}$ e a do mês mais frio (junho) menor que $18^{\circ} \mathrm{C}$. O total médio de chuva anual é $1382 \mathrm{~mm}$, sendo que o periodo mais chuvoso é de outubro a março, com um total de $1048 \mathrm{~mm}$, representando 75\% do total anual. O periodo mais seco é de junho a setembro, quando se tem uma deficiência hídrica no solo, da ordem de $7 \mathrm{~mm}$, conforme pode ser observado na Eigura 1, que apresenta o balanço hídrico na região de Campinas. 


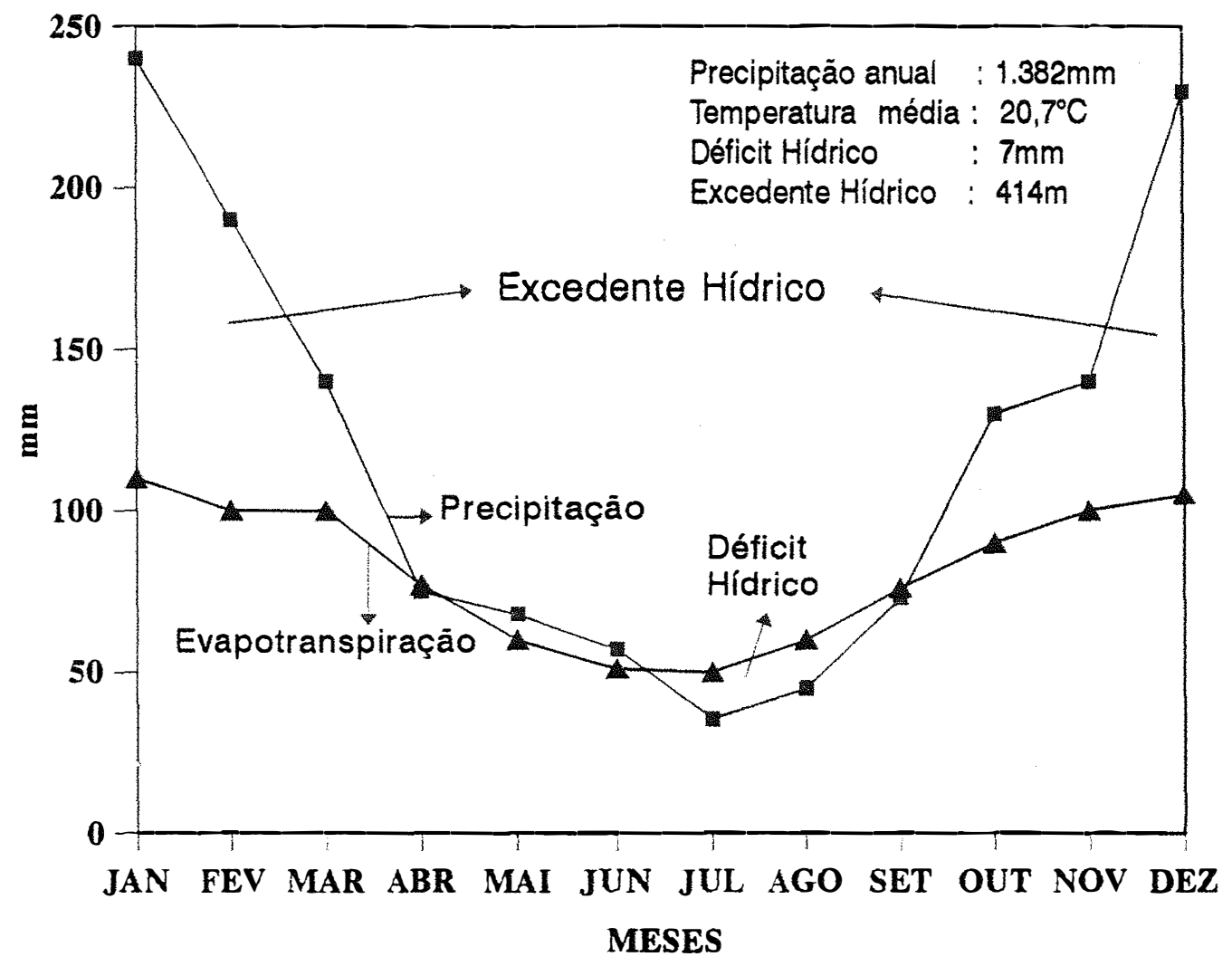

Figura 1. Balanço hídrico da região de Campinas, de 1956 a 1987, pelo método de THORNTHWAITE \& MATHER (1955).

\subsubsection{Solo}

$$
\text { O solo foi identificado no levantamento }
$$

pedológico detalhado do Centro Experimental de Campinasi, como latossolo roxo distrófico, com horizonte A moderado, textura muito argilosa, unidade Barão Geraldo. Na classificação americana corresponde ao Typic Haplorthox. A declividade da área experimental é de 6\% no sentido sul-norte.

1 OLIVEIRA, J.B. de - Seção de Pedologia, Instituto Agronômico, 1990. Comunicado pessoal. 


\subsection{Descrição do experimento de campo}

o experimento utilizado foi iniciado no ano agrícola de 1983/84, sendo que as determinações relativas a este estudo foram realizadas em 1990/91, portanto no 8." ano agrícola.

Nesta área experimental são utilizados três sistemas diferentes de preparo primário do solo: arado de discos, arado escarificador e plantio direto, em parcelas de $15 \mathrm{~m} \times 15 \mathrm{~m}$.

As culturas de verão utilizadas são milho e soja, em sistema contínuo e em rotação, resultando em três sistemas de manejo de culturas: milho contínuo, soja contínua e rotação milho-soja. No outono-inverno as parcelas são divididas ao meio sendo uma metade semeada com aveia preta (Avena strigosa) e a outra metade com Crotalaria juncea. Desse modo tem-se as culturas de primavera-verão sempre semeadas após aveia preta e crotalária, o que faz seis diferentes tratamentos de culturas, em três sistemas de preparo do solo, com três repetições.

Neste trabalho utilizou-se apenas o tratamento milho em rotação após aveia preta nos três sistemas de preparo do solo, por ser o tratamento que tem apresentado, ao longo dos anos, as maiores diferenças na produção do milho, tanto para efeito de rotação como para preparo do solo. 
Desse modo, tem-se milho após aveia preta com plantio direto, arado de discos e escarificador, com três repetições, em parcelas de $7,5 \mathrm{~m} \times 15 \mathrm{~m}$.

O preparo primário com arado de discos, aqui considerado como preparo convencional (PC), foi realizado com arado reversível de três discos de 28" a uma profundidade de $20 \mathrm{~cm}$, seguido de duas passadas de grade niveladora.

O preparo com escarificador (PE) consistiu de preparo primário com arado escarificador de sete hastes tipo oblíqua, com espaçamento entre o sulcos de $33 \mathrm{~cm}$ e profundidade de trabalho de $30 \mathrm{~cm}$. Após a escarificação fezse a gradeação por duas vezes.

O sistema de plantio direto (PD), consistiu da semeadura do milho sem preparo prévio do solo, com semeadeira adequada para o sistema, com disco ondulado para corte da palha, disco duplo na linha de semente e facão sulcador de $12 \mathrm{~cm}$ para colocar o fertilizante a $10 \mathrm{~cm}$ de profundidade. 0 controle de ervas invasoras emergidas no plantio direto foi realizado com $1,51 /$ ha de glifosate + 0,5 $1 /$ ha de $2,4 \mathrm{D}$, duas semanas antes da semeadura do milho. Nos tratamentos PC e PE fez-se a aplicação de 5 l/ha de atrazina + metolachlor após a semeadura em pré-emergência das ervas invasoras e do milho. - milho utilizado foi o cultivar C-606 da Cargill, semeado a 1,0 m entrelinhas e 7-8 sementes por metro, deixando após desbaste 6 plantas por metro. 
A adubação de plantio, realizada em 5/12/90, consistiu de $10 \mathrm{~kg} / \mathrm{ha}$ de $\mathrm{N}, 50 \mathrm{~kg} / \mathrm{ha}$ de $\mathrm{P}_{2} \mathrm{O}_{5}$ e $50 \mathrm{~kg} / \mathrm{ha}$ de $\mathrm{K}_{2} \mathrm{O} ;$ aos 50 dias após a emergência fez-se uma adubação de cobertura com $90 \mathrm{~kg} / \mathrm{ha}$ de $\mathrm{N}$, com sulfato de amônio. Em abril de 1985, cinco anos antes deste estudo, foi realizada uma calagem com 2,4 t/ha de calcário dolomítico, sendo incorporado de acordo com o preparo de cada tratamento, ou seja, no plantio direto - calcário foi deixado na superfície.

\subsection{Determinações}

\subsubsection{Potencial matricial do solo durante o ciclo do milho}

Após a emergência do milho, em 12/12/90, foram instalados, em cada parcela, uma bateria de tensiômetros de mercúrio nas profundidades de 10, 20, 30, 60, 90 e $120 \mathrm{~cm}$. As leituras dos tensiômetros foram diárias a partir de $15 / 12 / 90$.

As leituras da coluna de mercúrio foram transformadas em tensão de água pela fórmula:

$$
\Psi_{h_{2}}=-12,6 H+h_{1}+h_{2}
$$

onde:

$$
\begin{aligned}
& \psi_{\mathrm{h} 2}=\text { tensão da água no solo na profundidade } \\
& \mathrm{h}_{2} \text {, em cm de coluna d'água; } \\
& \mathrm{H}=\text { leitura da coluna de mercúrio em } \mathrm{cm} \text {; } \\
& h_{1}=\text { altura do reservatório de mercúrio ao } \\
& \text { solo, em cm; } \\
& h_{2}=\text { profundidade do tensiômetro no solo, em }
\end{aligned}
$$




\subsubsection{Avaliação de estrutura, resistência à penetração, curva de retenção de água, capacidade de água disponível e de aeração do solo.}

Após a colheita do milho foram abertas trincheiras de $1,50 \mathrm{~m}$ de profundidade e $1,0 \mathrm{~m}$ de largura em cada parcela, para leitura de resistência à penetração com penetrômetro de bolso, e coleta de amostras indeformadas com anéis volumétricos de $100 \mathrm{~cm}^{3}$, nas profundidades de 5, 10, 15, $20,25,30,45,60,75,90$ e $120 \mathrm{~cm}$.

Para a determinação de resistência à penetração fez-se um alisamento de superficie da trincheira onde se colocou um quadro de $60 \mathrm{~cm}$ x $60 \mathrm{~cm}$, quadriculado de $5 \mathrm{~cm} \times 5 \mathrm{~cm}$, considerando a superficie como profundidade zero. No centro de cada quadrado se fez uma leitura com penetrômetro de bolso modelo EIE, fazendo-se a média dos 12 pontos de cada profundidade, ficando assim com um valor médio para cada profundidade de cada trincheira.

Os anéis volumétricos foram coletados na mesma parede em que se fez a medição com penetrômetro, tomando-se o cuidado de cravá-los com o macaco hidráulico entre os pontos deixados pelo aparelho. Após a retirada dos anéis, eles foram limpos por fora, tampados e vedados com fita crepe para não perder água. Logo após a coleta foram levados ao laboratório, destampados, pesados e na base cortante do anel fixou-se uma gaze com elástico para em seguida serem colocados em bandeja plástica para saturação. 
Inicialmente se colocou uma lâmina d'água de $1 \mathrm{~cm}$ e 24 horas depois se completou de água até a borda superior dos anéis, mas sem cobri-los de água. Após 24 horas, as amostras foram retiradas da bandeja, deixando-se escoar o excesso de água para posterior pesagem.

Em seguida as amostras foram colocadas na mesa de tensão circular de $0,60 \mathrm{~m}$ de diâmetro e $15 \mathrm{~cm}$ de altura, fechada com tampa e cujo meio de tensão é constituído de esferas de vidro com diâmetro médio de $35 \mu \mathrm{m}$, utilizada para tensões até $8 \mathrm{kPa}$. Os pontos da curva caracteristica determinados pesando as amostras após ter atingido o equilíbrio a não mais perder água foram: 0,$5 ; 2,0 ; 5,0$ e $6,0 \mathrm{kPa}$. Posteriormente, as mesmas amostras foram levadas às câmaras de Richards com placa porosa para determinação de retenção de água nas tensões de 10, 30, 50, 100 e $200 \mathrm{kPa}$, pesando-se as amostras após equilíbrio em cada tensão, estabelecido por pesagens de algumas amostras até massa constante.

Após pesagem na última tensão, retirou-se a gaze e o elástico para pesagem que, somado ao peso do anel, entra na tara total para os cálculos da umidade. As amostras de solo foram secas em estufa a $105^{\circ} \mathrm{C}$ até atingir peso seco constante, o qual foi utilizado nos cálculos de densidade do solo e da umidade nos diferentes pontos da curva característica. 
o solo retirado dos anéis foi esboroado e peneirado em malha de $2 \mathrm{~mm}$ para se fazer a determinação dos pontos a 500,800 e $1.500 \mathrm{KPa}$ em câmaras de Richards (RICHARDS, 1965). A partir das umidades e suas respectivas tensões se fez o ajuste proposto por GENUCHTEN \& NIELSEN (1985), com a equação:

$$
\theta=\theta_{R}+\left(\theta_{S}-\theta_{R}\right) /\left[1+(\alpha h)^{n}\right]^{m}
$$

onde: $\boldsymbol{\theta}$ é a umidade do solo na tensão $\mathbf{h} ; \boldsymbol{\theta}_{\mathbf{R}}$ é a umidade residual; $\boldsymbol{\theta}_{\boldsymbol{s}}$ é a umidade de saturação; $\boldsymbol{\alpha}$ é o valor de entrada de ar; $\mathbf{h}$ é a tensão da água no solo; m e n são parâmetros empíricos.

Para a avaliação da capacidade de aeração (Car) e de água disponível (Cad), foram efetuados cálculos seguindo parâmetros estabelecidos por THOMASSON (1978). O autor define a capacidade de aeração (Car) como sendo a diferença do volume de ar presente em uma amostra de solo equilibrada na saturação até $5 \mathrm{KPa}$ de sucção. Por outro lado, a capacidade de água disponível (Cad) é determinada pelo volume de água retido entre $5 \mathrm{KPa}$ e $1.500 \mathrm{KPa}$ de sucção, em condições de equilíbrio. Ambos os parâmetros são expressos em porcentagem 0 volume de solo amostrado. Posteriormente, os dados obtidos são marcados em gráfico onde recebem uma classificação para a condição estrutural do solo. 
Em sintese, tem-se:

$$
\operatorname{car}=\theta_{S}-\theta_{5 K P a}
$$

$$
\mathrm{Cad}=\theta_{5 \mathrm{KPa}}-\theta_{1.500 \mathrm{KPa}}
$$

onde: $\theta_{S}$ é a umidade de saturação; $\theta_{5 \mathrm{KPa}}$ é - volume de água retido a $5 \mathrm{KPa}$ de sucção e $\theta_{1.500 \mathrm{KPa}}$ é - volume de água retido a $1.500 \mathrm{KPa}$ de sucção.

\subsubsection{Infiltração e condutividade hidráulica do solo saturado no campo, com permeâmetro.}

Utilizando permeâmetro de Guelph, cujo funcionamento é baseado no princípio de Mariotte, mediu-se a taxa constante de infiltração e calculou-se a condutividade hidráuiica do solo saturado no campo (Kfs), (REYNOLDS \& ELRICK, 1985).

Eoram feitas medições na superfície, a $20 \mathrm{~cm}$ e a $40 \mathrm{~cm}$ de profundidade, em dois pontos por parcela, dos quais se fez a média para ter um valor por parcela.

A medição na superfície foi feita utilizando um anel de folha galvanizada com $16 \mathrm{~cm}$ de diâmetro e $30 \mathrm{~cm}$ de altura, sendo que $15 \mathrm{~cm}$ foram cravados no solo. O permeâmetro foi colocado de modo que a ponta por onde sai a água ficasse em contato com a superficie. 
Para as medições a $20 \mathrm{~cm}$ e a $40 \mathrm{~cm}$ fez-se um orifício de $5 \mathrm{~cm}$ de diâmetro com trado. Depois foi passada uma escova circular de mesmo diâmetro para eliminar o espelhamento nas paredes e colocado pedrisco no fundo do orifício para evitar - entupimento na saída de água do permeâmetro. Nos três casos a operação se iniciou com uma carga hidráulica de $3 \mathrm{~cm}$ de altura, fazendo-se leituras a cada minuto. Após infiltração constante, determinada por quatro diferenças iguais entre leituras, elevou-se a carga para $6 \mathrm{~cm} e$ repetiu-se a operação.

Feitas as medições, os dados foram analisados segundo proposto por VIEIRA et al. (1988), com cálculos através de programa em FORTRAN que resolveu as equações:

$$
\begin{aligned}
& Q_{1}=\left(\frac{2 \cdot \pi \cdot H_{1}^{2}}{C_{1}}+\pi \cdot a^{2}\right) \cdot K f S+\left(\frac{2 \cdot \pi \cdot H_{1}}{C_{1}}\right) \cdot \oslash_{m} \\
& Q_{2}=\left(\frac{2 \cdot \pi \cdot H_{2}^{2}}{C_{2}}+\pi \cdot a^{2}\right) \cdot K f S+\left(\frac{2 \cdot \pi \cdot H_{2}}{C_{2}}\right) \cdot \oslash_{m}
\end{aligned}
$$

onde: Kfs é a condutividade hidráulica do solo saturado no campo, $\boldsymbol{\Phi}_{\mathrm{m}}$ é o potencial matricial de fluxo, $\boldsymbol{Q}$ é

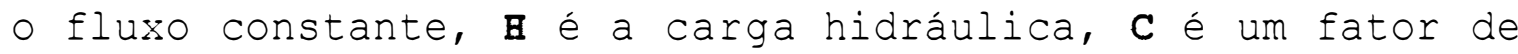
geometria, e a é o raio do orificio onde as medições foram feitas. A solução das equações (5) e (6) gera valores de kfs em $\mathrm{cm} \cdot \mathrm{h}^{-1}$. A infiltração é calculada a partir do volume de água que penetra no solo, em litros, dividido pela área de molhamento do orifício, em $\mathrm{m}^{2}$, na carga hidráulica maior. 


\subsubsection{Determinação da condutividade hidráulica e da capacidade de campo.}

Em uma parcela de cada tratamento retiraram-se os restos da cultura de milho onde foi cravado um quadro de folha galvanizada de $3 \mathrm{~m}$ x $3 \mathrm{~m}$ com $0,30 \mathrm{~m}$ de altura. Dentro desta parcela de $9 \mathrm{~m}^{2}$ foram instaladas três baterias de tensiômetros nas profundidades $10,20,30,60,90$ e $120 \mathrm{~cm}$. A parcela foi inundada até que o tensiômetro a $120 \mathrm{~cm}$ de profundidade acusasse que o solo nesta camada estava saturado. A seguir cortou-se o fornecimento de água, esperou-se acabar a água que ainda estava na superfície para em seguida se cobrir toda a parcela com plástico e palha para evitar a evaporação. Eeito isto, deu-se início às leituras dos tensiômetros com intervalo de 1 hora até completar? leituras, passando depois para intervalos de 12 horas e 24 horas até completar 17 dias, quando as leituras se estabilizaram. Estes dados permitiram determinar a condutividade hidráulica de acordo com metodologia descrita por HILLEL et al. (1972).

o método de HILLEL et al. (1972) obedece às seguintes considerações teóricas: a densidade do fluxo de água está relacionada com o gradiente de potencial total através da equação de Darcy: 


$$
q=-K(\theta) \partial \psi / \partial z
$$

que, substituída na equação da continuidade, fornece a equação diferencial geral que descreve o movimento da água no solo:

$$
\partial \psi / \partial t=\partial \psi / \partial z[K(\theta) \cdot \partial \psi / \partial z]
$$

onde: $\mathbb{R}$ é a condutividade hidráulica do solo $\left(\mathrm{cm} \cdot \mathrm{dia}^{-}\right)$, a qual é função da sua umidade $\theta\left(\mathrm{cm}^{3} \cdot \mathrm{cm}^{-3}\right) ; \psi$ é o potencial total da água no solo (cm); z é a coordenada vertical de posição $(\mathrm{cm})$ e $t$ é $\circ$ tempo $(\mathrm{seg})$. Integrando a equação (7) em relação a $z$, a partir da superficie do solo até uma profundidade $L$, genérica, obtem-se:

$$
\int_{0}^{L}(\partial \theta / \partial t) d z=[K(\theta) . \partial \psi / \partial z]_{z=L}-[K(\theta) \partial \psi / \partial z]_{z=0}
$$

Como o solo se encontra coberto com plástico em $z=0$, O fluxo nesta profundidade é nulo e a equação se reduz a:

$$
\int_{0}^{L}(\partial \theta / \partial t) d z=[K(\theta) \cdot \partial \psi / \partial z]_{z=L}
$$

de onde se pode explicitar $K(\boldsymbol{\theta})$ :

$$
K(\theta)=\frac{\int_{0}^{L}(\partial \theta / \partial t) d z}{\partial \psi / \partial z}
$$


Assim, a condutividade hidráulica é obtida a partir da densidade de fluxo q, calculada pela integral da equação (11) e do gradiente de potencial $\partial \psi / \partial z$.

Para o cálculo da condutividade hidráulica as leituras do tensiômetro foram transformadas em potencial matricial $\left(\psi_{m}\right)$ pela equação 1 . com os dados de retenção de água se estabeleceu a equação de ajuste pelo modelo de GENUCHTEN \& MIELSEN (1985) para cada profundidade e, por intermédio desta equação, se determinou o valor de umidade volumétrica $(\boldsymbol{\theta})$ para cada valor de potencial matricial $\left(\boldsymbol{\psi}_{\mathrm{m}}\right)$ gerado pelas leituras dos tensiômetros, ao longo do tempo $(t)$.

A partir dos valores de $\theta$ e $\psi_{m}$ para as diferentes profundidades $\mathbf{z}(10,20,30,60,90$ e $120 \mathrm{~cm})$, nos diferentes tempos de drenagem (t), chegou-se à determinação da condurividade hidráulica $\boldsymbol{K}$ para cada profundidade e para diferentes valores de $\theta$ por meio da equação (11) e estabeleceu-se a relação de $\operatorname{lnk}$ versus $\theta$ por regressão linear, com a equação representativa da função $K(\boldsymbol{\theta})$ para cada profundidade na forma:

$$
K=K_{0} \cdot e^{\gamma^{\left(\theta-\theta_{0}\right\rangle}}
$$

onde $\boldsymbol{\gamma}$ é o coeficiente angular da reta de LnK versus $\theta, K_{0}$ a condutividade hidráulica do solo saturado e $\theta_{0}$ a umidade volumétrica de saturação. 


\subsection{Avaliação granulométrica e da fertilidade do solo}

$\mathrm{Na}$ mesma ocasião em que se coletaram as amostras de anéis volumétricos, fez-se a coleta de amostras deformadas com trado tipo holandês para análise granulométrica e de fertilidade do solo. Coletaram-se 15 pontos por parcela nas profundidades de $0-10 \mathrm{~cm}, 10-20 \mathrm{~cm}$, 20-30 cm, 30-40 cm, 40-50 cm e 50-60 cm, fazendo-se uma amostra composta para cada profundidade. A partir desta amostra fez-se a análise granulométrica pelo método do densímetro, conforme metodologia descrita em CAMARGO et al. (1986), e análises químicas caracterizando os teores de fósforo, potássio, cálcio e magnésio pelo método de extração com resina trocadora de íons. Determinou-se também o teor de matéria orgânica através do método colorimétrico e o pH em cloreto de cálcio. As análises foram realizadas de acordo com metodologia descrita em RAIJ \& QUAGGIO (1983).

\subsection{Avaliações fenológicas}

Em cada parcela de preparo de solo, fez-se o corte rente ao solo da aveia preta, em 11/10/1990, numa área útil de 5 m $(2,0 \times 2,5 \mathrm{~m})$, para a determinação da massa seca e de grãos. Depois fez-se a colheita do restante das áreas com colheitadeira automotriz provida de picador de palha, para garantir uma cobertura mais uniforme do solo pelos restos culturais da aveia. 
Após a colheita fez-se uma avaliação da porcentagem de cobertura morta do solo utilizando o método da corda com marcas a cada $5 \mathrm{~cm}$. Num quadrado de $1 \mathrm{~m}$ de lado, fez-se uma leitura em cada diagonal, contando as marcas que coincidem com solo coberto. Esta operação foi repetida imediatamente após a semeadura do milho.

Após a emergência do milho a avaliação de cobertura foi realizada a cada 15 dias, com um aparelho proposto por ELWELL \& NENDELAAR (1977). Este aparelho consiste de uma barra de alumínio de $1,0 \mathrm{~m}$ com 10 tubos cilindricos de $1 \mathrm{~cm}$ de diâmetro e $10 \mathrm{~cm}$ de comprimento. Com um suporte de alumínio ela é mantida a $1,0 \mathrm{~m}$ de altura e posicionada num quadro de $1,0 \mathrm{~m} \times 1,0 \mathrm{~m}$. Eizeram-se as leituras de cobertura do solo através dos tubos, posicionando a barra com os tubos em diferentes posições no quadro. Desse modo pôde-se medir a avaliação da cobertura do solo com cobertura morta mais a folhagem do milho. Para separar a cobertura de uma e de outra, no mesmo local se fez a medição de cobertura morta usando o método da corda. Quando as plantas atingiram uma altura que dificultava a leitura pelos tubos de alumínio, utilizou-se uma adaptação sugerida por ELWELL \& WENDELAAR (1977), que consistia em colocar um espelho abaixo dos tubos de modo que a folhagem refletida no espelho pudesse ser vista através dos tubos, agora posicionados a $0,50 \mathrm{~cm}$ do solo para facilitar as visadas. 
Após o florescimento do milho, na fase de enchimento de grãos, foi feita a avaliação do sistema radicular em três plantas por parcela, das quais se obteve um valor médio. Utilizou-se o método de tradagem de solo ao lado de cada planta, coletando-se amostras de $10 \mathrm{~cm}$ de altura com diâmetro de $7 \mathrm{~cm}$ (volume $=384,85 \mathrm{~cm}^{3}$ ) até $60 \mathrm{~cm}$ de profundidade. Cada amostra foi colocada em saco plástico, etiquetada e levada ao laboratório onde foi lavada várias vezes até que as raízes estivessem em condições de serem peneiradas. Em seguida foram levadas à estufa a $65^{\circ} \mathrm{C}$ por 48 horas para secagem. Depois de seca fez-se uma limpeza do material, eliminando restos de plantas e outros materiais que não fossem raízes, para pesagem, expressando os resultados em massa de raiz seca/ $\mathrm{dm}^{3}$ de solo.

A colheita do milho foi feita em 12/4/1991, em parcelas de $2,0 \mathrm{~m} \times 2,5 \mathrm{~m}$, onde se determinou 0 número de plantas, peso da parte aérea e peso de grãos. Em cada parcela foi coletado uma amostra de palha e de grãos para secar em estufa, para corrigir para zero a umidade da palha e para 13\% a umidade dos grãos.

\subsection{Análise dos dados}

A comparação dos dados obtidos foi realizada aplicando-se o teste de Duncan, usando o programa estatístico SANEST, comparando-se os três sistemas de preparo do solo: plantio direto, escarificação e preparo convencional. 
40.

\title{
4. RESULTADOS E DISCUSSÃO
}

\subsection{Análise granulométrica do solo.}

\begin{abstract}
A análise granulométrica foi realizada com a finalidade muito mais de caracterizar o solo local, do que verificar a existência de um possivel efeito dos sistemas de preparo na distribuição de partículas primárias do solo. De fato, pelos dados da Tabela 1 , não se verificam diferenças que mereçam referência entre os tratamentos de preparo nas diferentes profundidades amostradas. Pode-se dizer que quanto à textura não há diferenças entre tratamentos após oito anos de execução do experimento. Esta caracterização é importante para se comparar resultados com solos semelhantes.
\end{abstract}

\subsection{Análise química do solo}

Nas Tabelas 2, 3, 4, 5, 6, 7 e 8 são apresentados os dados de análise química e a comparação estatistica entre sistemas de preparo, dentro de cada profundidade estudada, para matéria orgânica, fósforo, potássio, cálcio, magnésio, pH e saturação por bases. 
Tabela 1. Análise granulométrica do solo sob três sistemas de preparo, em diferentes profundidades (média de três repetições).

\begin{tabular}{|c|c|c|c|c|c|}
\hline $\begin{array}{c}\text { Sistemas } \\
\text { de }\end{array}$ & Profundidade & Areia grossa & Areia fina & Silte & Argila \\
\hline \multirow[t]{5}{*}{ Preparo } & $\mathrm{cm}$ & $2,00-0,25 \mathrm{~mm}$ & $0,25-0,05 \mathrm{~mm}$ & $0,05-0,002 \mathrm{~mm}$ & $<0,002 \mathrm{~mm}$ \\
\hline & & & $\%$ & 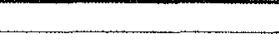 & 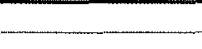 \\
\hline & $0-10$ & 10 & 9 & 8 & 73 \\
\hline & $10-20$ & 10 & 9 & 8 & 73 \\
\hline & $20-30$ & 9 & 7 & 8 & 76 \\
\hline \multirow[t]{6}{*}{ PD } & $30-40$ & 8 & 8 & 7 & 77 \\
\hline & $40-50$ & 6 & 8 & 6 & 80 \\
\hline & $50-60$ & 8 & 8 & 8 & 76 \\
\hline & $0-10$ & 9 & 10 & 7 & 74 \\
\hline & $10-20$ & 9 & 9 & 7 & 75 \\
\hline & $20-30$ & 11 & 9 & 7 & 73 \\
\hline \multirow[t]{6}{*}{$P E$} & $30-40$ & 9 & 8 & 6 & 77 \\
\hline & $40-50$ & 9 & 8 & 7 & 76 \\
\hline & $50-60$ & 7 & 8 & 8 & 77 \\
\hline & $0-10$ & 8 & 8 & 9 & 75 \\
\hline & $10-20$ & 8 & 8 & 9 & 75 \\
\hline & $20-30$ & 8 & 7 & 7 & 78 \\
\hline \multirow[t]{3}{*}{ PC } & $30-40$ & 7 & 7 & 7 & 79 \\
\hline & $40-50$ & 6 & 6 & 8 & 80 \\
\hline & $50-60$ & 7 & 7 & 8 & 78 \\
\hline
\end{tabular}


Tabela 2. Valores médios de matéria orgânica, em diferentes profundidades, nos três sistemas de preparo do solo.

\begin{tabular}{|c|c|c|c|c|c|c|}
\hline \multirow{3}{*}{$\begin{array}{l}\text { Sistemas } \\
\text { de } \\
\text { Preparo }\end{array}$} & \multicolumn{6}{|c|}{ Matéria Orgânica } \\
\hline & \multicolumn{6}{|c|}{ Profundidade, $\mathrm{cm}$} \\
\hline & $0-10$ & $10-20$ & $20-30$ & $30-40$ & $40-50$ & $50-60$ \\
\hline PD & $31 a$ & $25 a$ & $20 a$ & $22 a$ & $18 a$ & $17 a$ \\
\hline PE & $29 a b$ & $24 a$ & $20 a$ & $18 a$ & $18 a$ & $17 a$ \\
\hline$P C$ & $25 \mathrm{~b}$ & $21 a$ & $18 a$ & $18 a$ & $18 a$ & $17 a$ \\
\hline CV\% & 6,7 & 10,2 & 17,4 & 17,5 & 7,4 & 7,0 \\
\hline : & & & & & & \\
\hline
\end{tabular}

Números seguidos pela mesma letra não diferem entre si, na mesma profundidade, ao nível de 5\% de probabilidade (Duncan).

Tabela 3. Valores médios de fósforo (resina), em diferentes profundidades, nos três sistemas de preparo do solo.

\begin{tabular}{|c|c|c|c|c|c|c|}
\hline \multirow{3}{*}{$\begin{array}{c}\text { Sistemas } \\
\text { de } \\
\text { Preparo }\end{array}$} & \multicolumn{6}{|c|}{$P($ resina $)$} \\
\hline & \multicolumn{6}{|c|}{ Profundidade, $\mathrm{cm}$} \\
\hline & $0-10$ & $10-20$ & $20-30$ & $30-40$ & $40-50$ & $50-60$ \\
\hline & - & - - & $-\mathrm{mg}$ & & - & 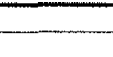 \\
\hline PD & $40 a$ & $24 a$ & $4,7 a$ & $3,0 \mathrm{a}$ & $2,3 a$ & $2,3 a$ \\
\hline$P E$ & $28 \mathrm{~b}$ & $26 a$ & $6,0 \mathrm{a}$ & $2,3 \mathrm{a}$ & 2,7 a & $2,7 \mathrm{a}$ \\
\hline PC & $23 \mathrm{~b}$ & $22 a$ & $4,3 a$ & $3,0 \mathrm{a}$ & $2,3 a$ & $2,7 \mathrm{a}$ \\
\hline $\mathrm{CV} \%$ & 10,5 & 26,5 & 30,5 & 37,9 & 27,3 & 38,0 \\
\hline
\end{tabular}

Números seguidos pela mesma letra não diferem entre si, na mesma profundidade, ao nível de 5\% de probabilidade (Duncan). 
Tabela 4. Valores médios de potássio, em diferentes profundidades, nos três sistemas de preparo do Solo.

\begin{tabular}{ccccccc}
\hline $\begin{array}{c}\text { Sistemas } \\
\text { de } \\
\text { Preparo }\end{array}$ & $0-10$ & $10-20$ & $20-30$ & $30-40$ & $40-50$ & $50-60$ \\
\hline & $2,5 a$ & $1,0 a$ & 0,6 ab & $0,6 a$ & $0,6 a$ & $0,6 a$ \\
PD & $3,3 a$ & $2,2 b$ & $0,8 a$ & $0,7 a$ & $0,6 a$ & $0,6 a$ \\
PE & $2,3 a$ & $1,4 a$ & $0,4 \quad b$ & $0,7 a$ & $0,2 a$ & $0,2 b$ \\
PC & 23,2 & 20,9 & 21,4 & 18,2 & 36,5 & 30,6 \\
\hline CV\% & & & & & & \\
\hline
\end{tabular}

Números seguidos pela mesma letra não diferem entre si, na mesma profundidade, ao nível de 5\% de probabilidade (Duncan).

Tabela 5. Valores médios de cálcio, em diferentes profundidades, nos três sistemas de preparo do solo.

\begin{tabular}{|c|c|c|c|c|c|c|}
\hline \multirow{2}{*}{$\begin{array}{l}\text { Sistemas } \\
\text { de } \\
\text { Preparo }\end{array}$} & \multicolumn{6}{|c|}{ Profundidade, $\mathrm{cm}$} \\
\hline & $0-10$ & $10-20$ & $20-30$ & $30-40$ & $40-50$ & $50-60$ \\
\hline & \multicolumn{6}{|c|}{$\mathrm{Ca}, \mathrm{cmol} / \mathrm{kg}$} \\
\hline$P D$ & $26 a$ & $14 a$ & $7,0 \mathrm{a}$ & $6,0 \mathrm{a}$ & $7,0 \mathrm{a}$ & $8,0 \mathrm{a}$ \\
\hline$P E$ & $23 a$ & $23 a b$ & $13 \mathrm{~b}$ & $7,0 \mathrm{a}$ & $7,0 \mathrm{a}$ & $10 a$ \\
\hline PC & $23 a$ & $26 b$ & 21 & c $12 \quad b$ & $9,0 \mathrm{a}$ & 9,0 a \\
\hline CV\% & 17,6 & 20,3 & 19,2 & 26,6 & 21,7 & 24,8 \\
\hline
\end{tabular}

Números seguidos pela mesma letra não diferem entre si, na mesma profundidade, ao nível de 5\% de probabilidade (Duncan). 
Tabela 6. Valores médios de magnésio, em diferentes profundidades, nos três sistemas de preparo do solo.

\begin{tabular}{|c|c|c|c|c|c|c|}
\hline \multirow{2}{*}{$\begin{array}{c}\text { Sistemas } \\
\text { de } \\
\text { Preparo }\end{array}$} & \multicolumn{6}{|c|}{ Profundidade, $\mathrm{cm}$} \\
\hline & $0-10$ & $10-20$ & $20-30$ & $30-40$ & $40-50$ & $50-60$ \\
\hline & \multicolumn{6}{|c|}{$\mathrm{Mg}, \mathrm{cmol} / \mathrm{kg}$} \\
\hline PD & $8,0 \mathrm{a}$ & $4,0 \mathrm{a}$ & $2,0 a$ & $3,0 \mathrm{a}$ & $3,0 \mathrm{a}$ & $4,0 \mathrm{a}$ \\
\hline PE & $8,0 a$ & $6,0 a$ & $5,0 a b$ & $3,0 \mathrm{a}$ & $3,0 \mathrm{a}$ & $5,0 \mathrm{a}$ \\
\hline PC & 9,0 a & $10 \mathrm{~b}$ & $7,0 \quad b$ & $6,0 a$ & $6,0 \mathrm{~b}$ & $5,0 \mathrm{a}$ \\
\hline $\mathrm{CV} \%$ & 12,9 & 23,7 & 29,3 & 32,2 & 12,8 & 27,9 \\
\hline
\end{tabular}

Números seguidos pela mesma letra não diferem entre si, na mesma profundidade, ao nível de 5\% de probabilidade (Duncan).

Tabela 7. Valores médios de pH, em diferentes profundidades, nos três sistemas de preparo do solo.

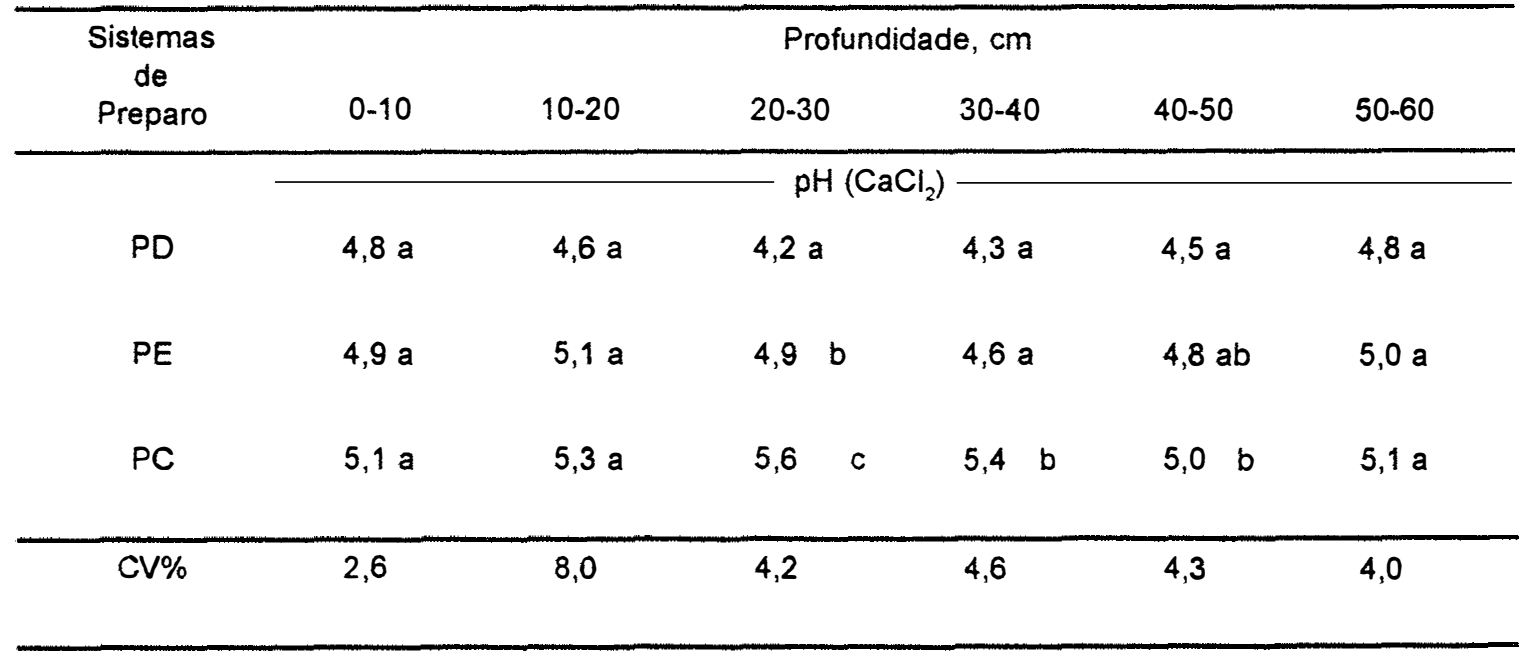

Números seguidos pela mesma letra não diferem entre si, na mesma profundidade, ao nivel de 5\% de probabilidade (Duncan). 
Tabela 8. Valores médios de saturação por bases (Vo), em diferentes profundidades, nos três sistemas de preparo do solo.

\begin{tabular}{|c|c|c|c|c|c|c|}
\hline \multirow{3}{*}{$\begin{array}{c}\text { Sistemas } \\
\text { de } \\
\text { Preparo }\end{array}$} & \multicolumn{6}{|c|}{ Saturação por bases } \\
\hline & \multicolumn{6}{|c|}{ Profundidade, $\mathrm{cm}$} \\
\hline & $0-10$ & $10-20$ & $20-30$ & $30-40$ & $40-50$ & $50-60$ \\
\hline & & & -0 & & 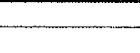 & \\
\hline$P D$ & $51 \mathrm{a}$ & $30 \mathrm{a}$ & $17 a$ & $18 \mathrm{a}$ & $24 a$ & $28 a$ \\
\hline$P E$ & $51 \mathrm{a}$ & $53 a b$ & $39 \mathrm{~b}$ & $25 \mathrm{a}$ & $27 a$ & 37 a \\
\hline PC & $55 a$ & $58 b$ & 57 & $44 \mathrm{~b}$ & $36 \mathrm{~b}$ & $36 a$ \\
\hline $\mathrm{CV} \%$ & $\overline{14,1}$ & 23,4 & 14,1 & 23,0 & 11,6 & 20,6 \\
\hline
\end{tabular}

Números seguidos pela mesma letra não diferem entre si, na mesma profundidade, ao nível de $5 \%$ de probabilidade (Duncan).

No apêndice 1 são apresentados os dados individuais por parcela, de cada tratamento, utilizados na análise estatística.

Na Tabela 2 a análise estatistica mostra uma diferença significativa entre o teor de matéria orgânica do plantio direto e do convencional apenas na camada mais superficial do solo. O maior teor de matéria orgânica nesta camada do solo sob plantio direto está de acordo com o observado por MUZILII (1983), ELTZ et al. (1989) e DE MARIA \& CASTRO (1993), todos em solos argilosos. Estes resultados se devem à preservação dos restos vegetais na superfície do plantio direto, o que garante uma decomposição mais lenta deste material, protegido da ação de altas temperaturas e da erosão. 
o acúmulo de fósforo foi significativamente maior na camada superficial no plantio direto (Tabela 3), confirmando resultados obtidos por outros autores (SHEAR a MOSCHLER, 1969; MUZILLI, 1983; DE MARIA \& CASTRO, 1993). A não-movimentação do solo sob plantio direto diminui as chances de adsorção do fósforo residual, especialmente pelos sesquióxidos de $\mathrm{Fe}$ e Al, aumentando a disponibilidade deste elemento. A imobilidade do fósforo no solo acarreta este acúmulo nas proximidades das camadas onde é colocado pela adubadeira.

Com relação ao potássio (Tabela 4 ) observou-se um acúmulo significativo no solo preparado com arado escarificador nas camadas $10-20 \mathrm{~cm}$ e $20-30 \mathrm{~cm}$. Não existe uma razão clara para este acúmulo neste sistema, superior até ao plantio direto na camada $10-20 \mathrm{~cm}$, embora DE MARIA $\hat{a}$ CASTRO (1993) tenham observado resultados semelhantes, mas com menores diferenças. Mas, como destacaram nesse mesmo trabalho, o acúmulo de potássio em solos de baixa CTC, como é o caso presente, é muito dependente do regime de chuvas e drenagem do solo, podendo ser facilmente levado pela água de drenagem se as condições forem favoráveis para isto. De fato, os níveis de potássio nos três sistemas de preparo do solo, excetuando a camada superficial, estão na faixa de baixo a muito baixo, apesar do longo período de uso do solo com adubação dentro do recomendado (RAIJ et al., 1985). 
- cálcio e o magnésio, apresentados respectivamente nas Tabelas 5 e 6, apresentaram valores significativamente maiores nos solos preparados com escarificador (PE) e convencional (PC). Uma calagem com 2,4 t/ha de calcário dolomítico, realizada em toda a área experimental 5 anos antes da presente amostragem, pode explicar estes resultados, considerando que o corretivo foi incorporado de acordo com os preparos de cada tratamento, ou seja, no plantio direto não houve incorporação. Isto não impediu que estes cátions fossem levados de algum modo da superficie, a ponto do plantio direto apresentar em todas as profundidades valores mais baixos que os demais para estes dois elementos. Isto levou à acidificação nas diferentes camadas do solo sob plantio direto, expressa no pH (Tabela 7) e na saturação por bases (Tabela 8). Possivelmente, estas bases tenham servido de ion acompanhante para o nitrato presente na superficie, fruto dos restos de adubos nitrogenados e da decomposição do material orgânico, conforme destacado por SHEAR \& MOSCHLER (1969).

\subsection{Densidade do solo, resistência à penetração e a distribuição de raízes.}

A determinação de densidade do solo, realizada ao final do experimento, revelou poucas diferenças entre tratamentos conforme pode ser verificado na Eigura 2. Na Tabela 9, onde se apresenta a análise estatistica entre tratamentos, a partir dos dados do Apêndice 2, verifica-se uma diferença significativa apenas na profundidade de $20 \mathrm{~cm}$, onde $O$ PC apresentou um valor maior, e na profundidade de $60 \mathrm{~cm}$, quando O PD apresentou maior valor de densidade do solo. 


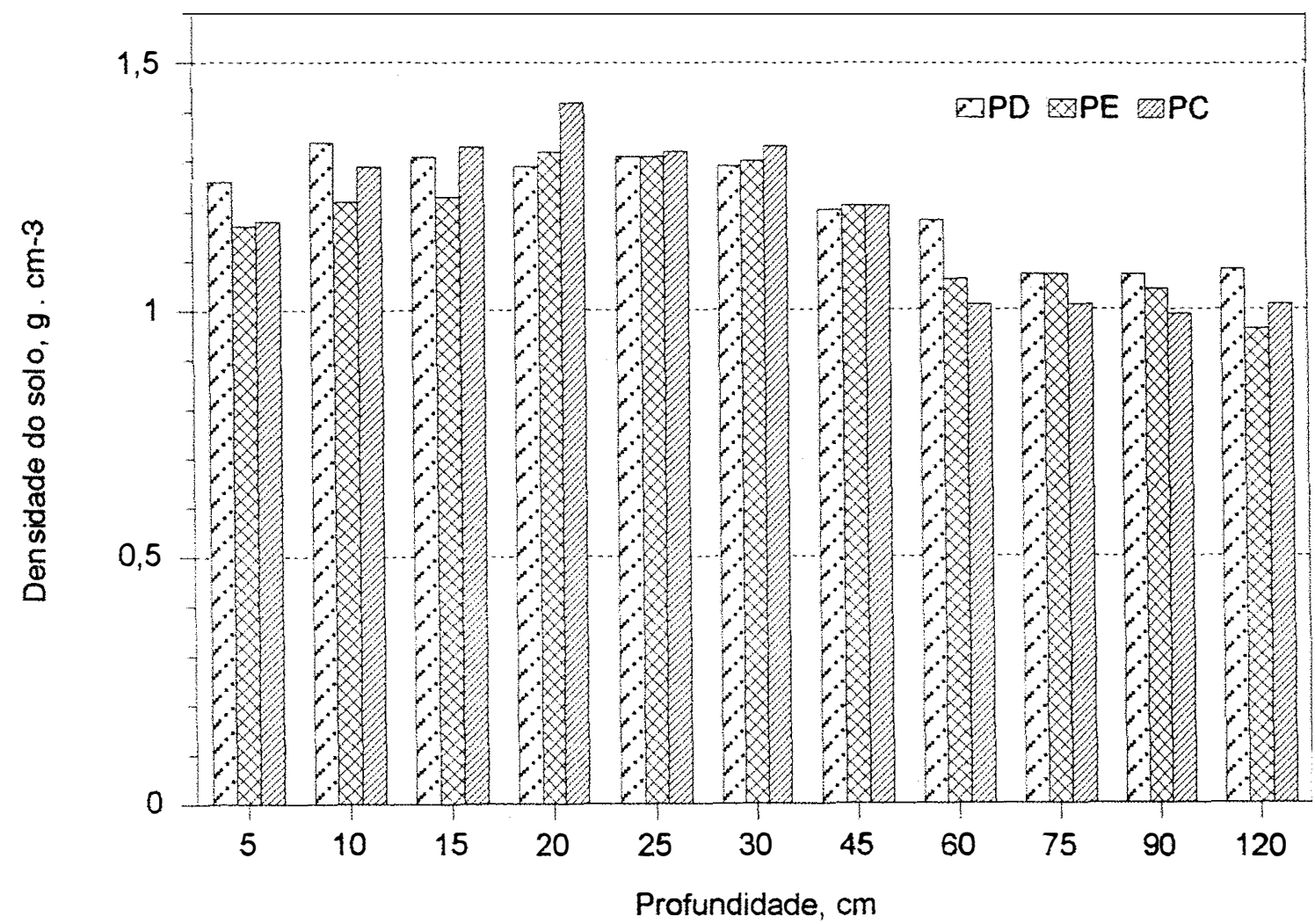

Figura 2. Densidade do solo, em diferentes profundidades, nos três sistemas de preparo do solo.

Tabela 9. Comparação estatística dos dados de densidade do solo.

\begin{tabular}{|c|c|c|c|c|c|c|c|c|c|c|c|}
\hline \multirow{2}{*}{$\begin{array}{c}\text { Sistemas } \\
\text { de } \\
\text { Preparo }\end{array}$} & \multicolumn{11}{|c|}{ Profundidades, $\mathrm{cm}$} \\
\hline & 5 & 10 & 15 & 20 & 25 & 30 & 45 & 60 & 75 & 90 & 120 \\
\hline & \multicolumn{11}{|c|}{ Densidade do solo, $\mathrm{g} \mathrm{cm}^{-3}$} \\
\hline PD & $1,26 a$ & $1,34 a$ & $1,31 \mathrm{a}$ & $1,29 a$ & $1,31 a$ & $1,29 a$ & $1,20 a$ & $1,18 \mathrm{a}$ & $1,07 a$ & $1,07 \mathrm{a}$ & $1,08 \mathrm{a}$ \\
\hline$P E$ & $1,17 \mathrm{a}$ & $1,22 a$ & $1,23 \mathbf{a}$ & $1,32 \mathrm{a}$ & $1,31 \mathrm{a}$ & $1,30 a$ & $1,21 \mathrm{a}$ & 1,06 & b $1,07 a$ & $1,04 a$ & $0.96 a$ \\
\hline PC & $1,18 \mathrm{a}$ & $1,29 a$ & $1,33 \mathbf{a}$ & 1,42 & b $1,32 \mathrm{a}$ & $1,33 a$ & $1,21 \mathrm{a}$ & 1,01 & b $1,01 a$ & $0,99 a$ & $1,01 \mathrm{a}$ \\
\hline CV\% & 5,4 & 5,8 & 6,9 & 4,5 & 4,4 & 5,5 & 6,2 & 4,4 & 6,4 & 6,1 & 5,9 \\
\hline
\end{tabular}

Números seguidos pela mesma letra não diferem entre si, na mesma profundidade, ao nível de 5\% de probabilidade (Duncan). 
A maior densidade no preparo convencional a $20 \mathrm{~cm}$ caracteriza muito bem a compactação ocasionada pela ação do arado, o chamado "pé-de-arado". Estes dados estão de acordo com as observações de VIEIRA \& MUZILLI (1984), SIDIRAS et al. (1982) e CASTRO et al. (1987b), porém diferem quanto às camadas mais superficiais, pois neste estudo não foram obtidas diferenças significativas entre preparos, sendo que nos trabalhos citados o plantio direto apresentou valores de densidade mais altos. Isto pode ser explicado pela época de amostragem, pois tendo sido realizada já no final do ciclo da cultura não detectou grandes diferenças do solo não mobilizado do PD para aqueles que foram revolvidos, caso do $\mathrm{PE}$ e PC, pois nestes, com $O$ tempo há o acomodamento do solo superficial, levando a valores de densidade semelhantes entre os sistemas, conforme foi demonstrado por DERPSCH et al. (1991). Outra explicação, seguindo o que foi demonstrado por DERPSCH et al. (1991), é que sendo a plantadeira provida de sulcador na adubadeira, ela realiza, por ocasião de cada plantio, uma espécie de escarificação até $12 \mathrm{~cm}$ de profundidade, o que contribui para reduzir o efeito da compactação superficial no PD.

As determinações de resistência à penetração com penetrômetro de bolso, realizadas na mesma época e local da coleta dos anéis volumétricos, revelaram a mesma tendência dos dados de densidade do solo, mas com grau de diferenciação maior, conforme pode ser visto na figura 3 e na análise estatística da Tabela 10, a partir dos dados do Apêndice 3. 


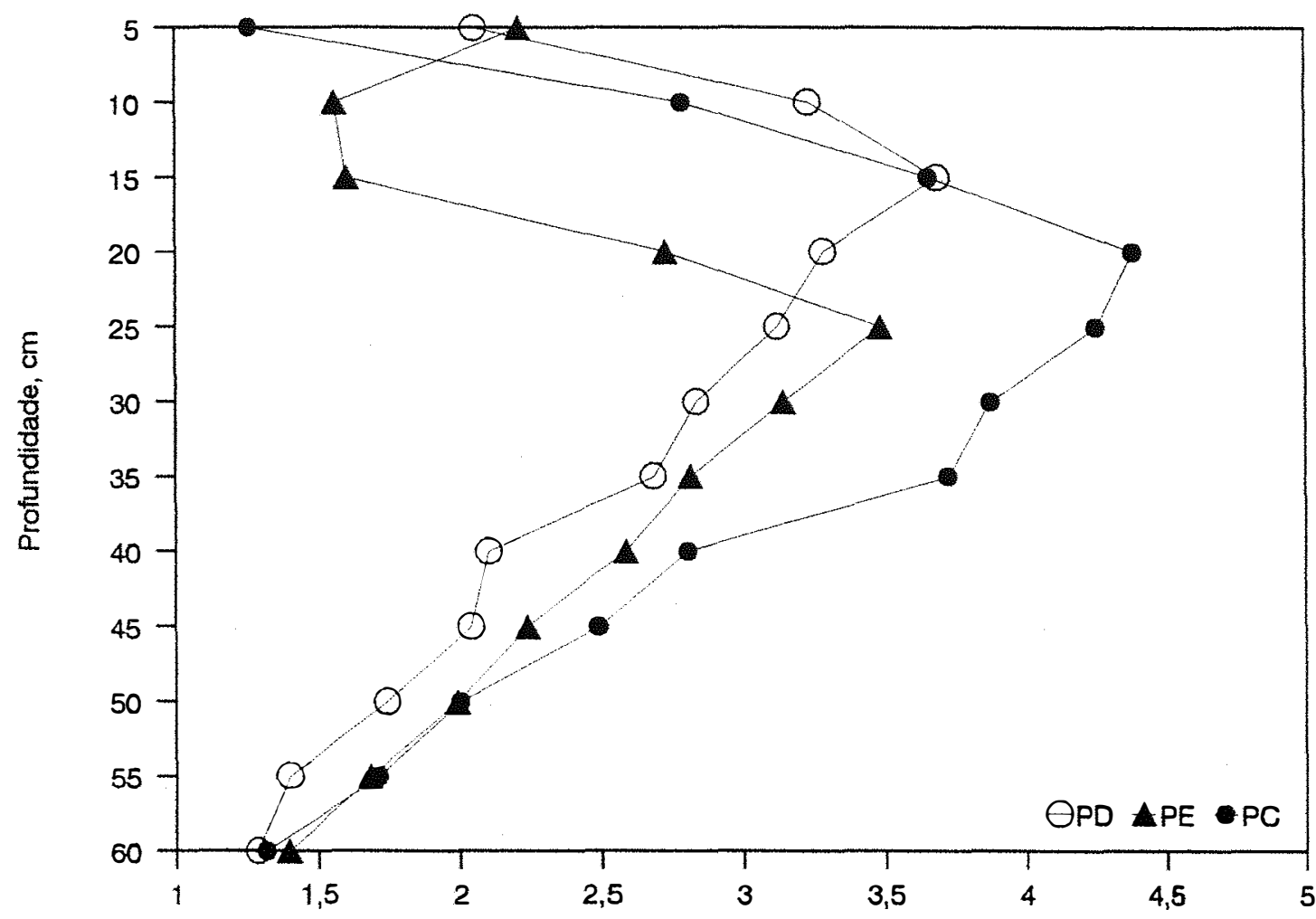

Resistência, kgf . cm-2

Figura 3. Valores de resistência à penetração, com penetrômetro de bolso, em diferentes profundidades, nos três sistemas de preparo de solo.

Tabela 10. Análise estatistica dos valores de resistência à penetração, com penetrômetro de bolso, em diferentes profundidades, nos três sistemas de preparo do solo e umidade volumétrica no momento da avaliação, a 10, 30 e $60 \mathrm{~cm}$.

\begin{tabular}{|c|c|c|c|c|c|c|c|c|c|c|c|c|}
\hline \multirow{3}{*}{$\begin{array}{c}\text { Sistemas } \\
\text { de } \\
\text { Preparo }\end{array}$} & \multicolumn{12}{|c|}{ Profundidades, $\mathrm{cm}$} \\
\hline & 5 & 10 & 15 & 20 & 25 & 30 & 35 & 40 & 45 & 50 & 55 & 60 \\
\hline & \multicolumn{12}{|c|}{ Resistência, kgf. $\mathrm{cm}^{-2}$} \\
\hline PD & $2,05 a$ & $3,23 a$ & $3,68 \mathrm{a}$ & $3,28 \mathrm{ab}$ & $3,12 \mathrm{~b}$ & $2,83 a$ & $2,68 a$ & $2,10 a$ & $2,04 a$ & $1,74 a$ & $1,40 a$ & $1,29 a$ \\
\hline$P E$ & $2,21 \mathrm{a}$ & $1,56 \mathrm{~b}$ & $1,60 \mathrm{~b}$ & $2,72 \mathrm{~b}$ & $3,48 \mathrm{~b}$ & $3,14 a$ & $2,81 \mathrm{a}$ & $2,58 a$ & $2,24 a$ & $1,99 a$ & $1,68 \mathbf{a}$ & $1,40 a$ \\
\hline PC & $1,26 a$ & $2,78 a$ & $3,65 a$ & $4,38 a$ & $4,25 a$ & $3,87 a$ & $3,72 \mathrm{a}$ & $2,80 a$ & $2,49 a$ & $2,00 \mathrm{a}$ & $1,71 \mathrm{a}$ & $1,32 a$ \\
\hline \multirow[t]{2}{*}{ CV\% } & 41,08 & 8,37 & 19,65 & 18,49 & 7,50 & 15,03 & 15,27 & 12,86 & 18,72 & 12,56 & 5,34 & 7,94 \\
\hline & \multicolumn{12}{|c|}{ Umidade $-\mathrm{cm}^{3} \cdot \mathrm{cm}^{-3}$} \\
\hline PD & & 0,251 & & & & 0,260 & & & & & & 0,276 \\
\hline$P E$ & & 0,247 & & & & 0,256 & & & & & & 0,285 \\
\hline PC & & 0,245 & & & & 0,251 & & & & & & 0,297 \\
\hline
\end{tabular}

Números seguidos de mesma letra, na mesma profundidade não diferem entre si ao nivel de 5 을 de probabilidade - teste de Duncan. 
Pela figura 3 é evidente a menor dureza do solo no PE, consequiência da atuação das hastes que rasgam 0 solo anualmente até $25-30 \mathrm{~cm}$ de profundidade, enquanto que $O$ PC de 20 a $35 \mathrm{~cm}$ apresenta resistência distinta dos demais. Na análise estatistica da Tabela 10 o solo do PE apresenta valores mais baixos de 10 a $20 \mathrm{~cm}$ e $O$ PD e PC apresentam valores iguais até $20 \mathrm{~cm}$, sendo que a $25 \mathrm{~cm}$ ○ PC apresenta a maior resistência. Mas o que chama a atenção nestes dados é - gradiente mais acentuado de resistência que o solo do PC apresenta, crescendo 3,5 vezes da profundidade $5 \mathrm{~cm}$ para $20 \mathrm{~cm}$ (maior valor), enquanto os demais tratamentos têm crescimento de apenas 1,7 vezes.

Este gradiente de resistência é importante, pois estudos de DE MARIA et al. (1993) mostram uma alta correlação entre gradiente de resistência e crescimento radicular de soja em solo argiloso, sendo que o plantio direto, embora apresentasse valores de resistência mais altos, estes eram mais uniformes em profundidade, não apresentando descontinuidade significativa no crescimento das raízes.

Na Tabela 10 também são apresentadas as umidades volumétricas nas profundidades de 10,30 e $60 \mathrm{~cm}$, fator determinante nas leituras de resistência. Estes valores, com diferenciação mínima entre tratamentos, estão por volta de $75-80 \%$ da capacidade de campo para este solo. Esta umidade está dentro da faixa ideal para avaliação de resistência segundo MATA (1988) e, portanto, as diferenças de resistência não são devidas a diferenças de umidade. 
A maior densidade do solo e resistência à penetração observada na faixa de $20-25 \mathrm{~cm}$ de profundidade, afetou significativamente o crescimento radicular do milho no sistema PC, conforme pode ser visto na Figura 4 e Tabela 11. No Apêndice 4 estão os dados de cada parcela. Nas camadas de 20-30 cm e 30-40 cm a densidade de raiz no $P C$ é menos da metade daquela observada nos outros tratamentos, mostrando que a compactação existente nesta faixa afetou diretamente 0 desenvolvimento das raizes, confirmando resultados obtidos por VIEIRA (1981) e DE MARIA et al. (1993) também em latossolo roxo, mas com a cultura de soja. Embora o PD apresente valores altos de resistência nas camadas acima dos $20 \mathrm{~cm}$, o desenvolvimento radicular não foi afetado pois, conforme relatado por CANNEI (1981) os solos não mobilizados mantêm a continuidade dos poros, o que facilita o crescimento das raizes por estes poros. Por outro lado, o acúmulo de fósforo e matéria orgânica na camada mais superficial do PD estimulou a abundância de raízes nesta situação, embora a diferença não tenha sido significativa em relação aos demais sistemas.

\subsection{Infiltração e condutividade hidráulica do solo saturado - permeâmetro de Guelph}

Os valores de infiltração e condutividade hidráulica do solo saturado, medidas com permeâmetro de Guelph na superficie, a $20 \mathrm{~cm}$ e a $40 \mathrm{~cm}$ de profundidade, estão na Tabela 12, e os dados individuais no Apêndice 5. 


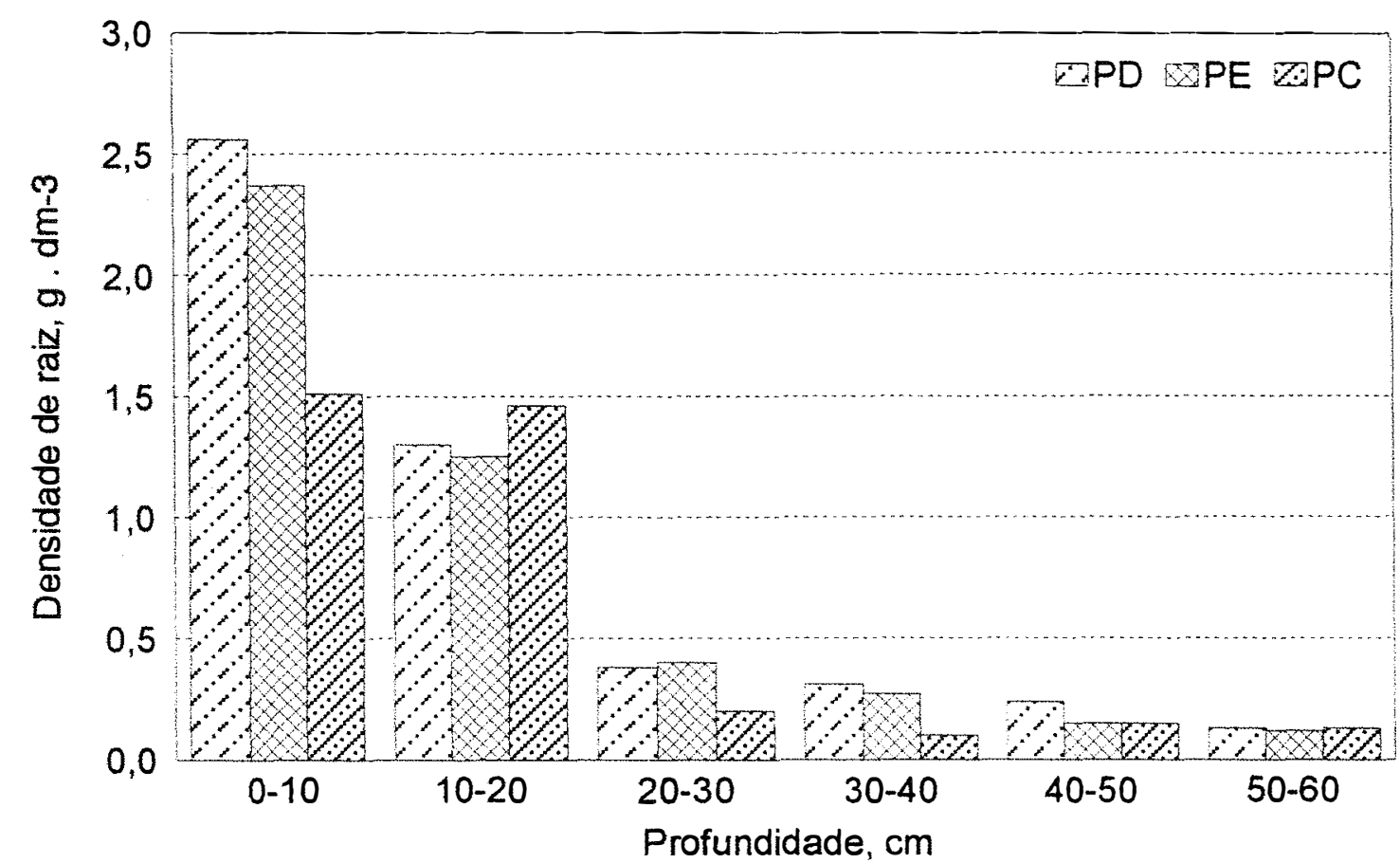

Figura 4. Densidade de raiz de milho, em diferentes profundidades, nos três sistemas de preparo do solo.

Tabela 11. Análise estatística dos dados de densidade de raiz de milho, em diferentes profundidades, nos três sistemas de preparo do solo.

\begin{tabular}{|c|c|c|c|c|c|c|}
\hline \multirow{2}{*}{$\begin{array}{c}\text { Sistemas } \\
\text { de } \\
\text { Preparo }\end{array}$} & \multicolumn{6}{|c|}{ Profundidades, $\mathrm{cm}$} \\
\hline & $0-10$ & $10-20$ & $20-30$ & $30-40$ & $40-50$ & $50-60$ \\
\hline & \multicolumn{6}{|c|}{ Densidade de raiz, g.dm ${ }^{-3}$} \\
\hline PD & $2,56 a$ & $1,30 a$ & $0,38 a$ & $0,31 \mathrm{a}$ & $0,24 a$ & $0,13 a$ \\
\hline$P E$ & $2,37 a$ & $1,25 a$ & $0,40 a$ & $0,27 a$ & $0,15 b$ & $0,12 a$ \\
\hline PC & $1,51 \mathrm{a}$ & $1,46 \mathrm{a}$ & $0,20 \mathrm{~b}$ & $0,10 b$ & $0,15 \mathrm{~b}$ & $0,13 a$ \\
\hline CV\% & 46,47 & 32,43 & 23,38 & 21,37 & 4,81 & 17,92 \\
\hline
\end{tabular}

Números seguidos pela mesma letra não diferem entre si, na mesma profundidade, a $5 \%$ de probabilidade (Duncan). 
Tabela 12. Valores de infiltração e condutividade hidráulica do solo saturado (Kfs), determinadas com permeâmetro de Guelph, na superficie, a $20 \mathrm{~cm}$ e a $40 \mathrm{~cm}$ de profundidade, nos três sistemas de preparo do solo.

\begin{tabular}{|c|c|c|c|c|c|}
\hline \multirow{2}{*}{$\begin{array}{l}\text { Sistemas } \\
\text { de } \\
\text { Preparo }\end{array}$} & \multicolumn{3}{|c|}{ Infiltração, $m m \cdot h^{-1}$} & \multicolumn{2}{|c|}{$\mathrm{Kfs}, \mathrm{cm} \cdot \mathrm{h}^{-1}$} \\
\hline & Superficie & $20 \mathrm{~cm}$ & $40 \mathrm{~cm}$ & $20 \mathrm{~cm}$ & $40 \mathrm{~cm}$ \\
\hline PD & $111,37 \mathrm{a}$ & $112,15 a$ & $86,26 a$ & $2,33 a$ & $1,25 \mathrm{a}$ \\
\hline$P E$ & 62,88 a & $54,56 \quad b$ & $73,32 a$ & $1,08 \quad b$ & $1,04 \mathrm{a}$ \\
\hline PC & $11,88 \quad b$ & $46,15 \quad b$ & 73,09 a & $0,92 b$ & $1,04 \mathrm{a}$ \\
\hline $\mathrm{CV} \%$ & 33,14 & 13,74 & 22,89 & 14,75 & 23,60 \\
\hline
\end{tabular}

Números seguidos pela mesma letra não diferem entre si, na mesma profundidade, ao nível de 5: de probabilidade (Duncan).

Por serem os pontos de amostragem muito pequenos em relação à superfície considerada e devido à variabilidade espacial dos fatores do solo que regem a infiltração de água, o coeficiente de variação dos dados é alto, especialmente das medições superficiais. Como as medições com permeâmetro de Guelph são simples e rápidas, em relação aos outros métodos de campo, é recomendável que se façam várias repetições dentro da parcela de interesse para se obter um dado final médio, que será posteriormente utilizado para comparação estatística com outros tratamentos, se for o caso. 
55.

É como se fosse uma amostragem composta, à semelhança do que se tem para fertilidade do solo. Ao se fazer dois pontos por parcela, parte deste problema é amenizado, pois obtem-se um CV menor. ARZENO (1990) e SARVASI (1994) que trabalharam com um ponto por repetição, neste mesmo tipo de solo, obtiveram um CV muito superior.

Em que pese esta variabilidade, os dados obtidos revelam que 0 solo dos tratamentos PD e PE apresentaram maior infiltração que o PC na superfície e a $20 \mathrm{~cm}$ de profundidade. A $40 \mathrm{~cm}$ de profundidade não houve diferença significativa entre tratamentos, pois nesta camada já não se tem influência dos implementos de preparo.

A condutividade hidráulica do solo saturado Kfs, que rege a infiltração básica do solo, apresenta a mesma tendência de diferenciação entre sistemas.

valores mais altos de infiltração e condutividade hidráulica nos sistemas com menor mobilização do solo, especialmente do plantio direto, podem ser explicados pela continuidade dos poros e pela maior atividade biológica da micro e mesofauna. Apesar dos dados de densidade do solo terem mostrado pouca diferenciação entre PD e PC próximo à superfície, deve-se lembrar que no PC, devido à mobilização do solo predomina a descontinuidade dos poros, enquanto que no PD, embora a porosidade total possa até ser menor, ela apresenta um contínuo de poros que facilita a movimentação tridimensional da água; situação semelhante foi encontrada por SARVASI (1994) trabalhando com diferentes sistemas de preparo. 
Neste caso cabe lembrar a colocação de HILLEL (1971), que as caracteristicas do solo que modificam 0 valor da condutividade são porosidade total, distribuição de tamanho dos poros e a tortuosidade dos intersticios. Este último aspecto pode explicar o valor de infiltração e condutividade cerca de 10 vezes maior no PD em relação ao PC.

outro aspecto importante que se observa nos dados da Tabela 12 é que, enquanto $O$ PD e PE apresentaram pouca variação de infiltração entre camadas, no PC houve um aumento mais acentuado, especialmente da superficie para a camada de $20 \mathrm{~cm}$, consequiência possivelmente da descontinuidade estrutural ao longo do perfil deste sistema, já caracterizado pelos dados de densidade do solo e da resistência ao penetrômetro. Estas observações coincidem com as de DALLA ROSA (1981), obtidas em solo argiloso do Rio Grande do Sul.

Não se determinou, no presente estudo, a Kfs para as leituras de superfície por ser discutivel a aplicação do conceito de condutividade hidráulica a partir do contato solo-atmosfera, com este tipo de equipamento. Os modelos para este tipo de determinação ainda não estão perfeitamente estabelecidos.

\subsection{Potencial matricial da água no solo}

- potencial matricial da água no solo no período compreendido entre a emergência do milho e a sua maturação estão apresentados nas Figuras 5, 6, 7, 8, 9 e 10, respectivamente para as profundidades 10, 20, 30, 60, 90 e $120 \mathrm{~cm}$. Os valores observados no campo estão nos Apêndices 6, 7 e 8. Na Figura 11 estão registrados os dados de precipitação ocorridos no local do experimento, durante o ciclo do milho. 


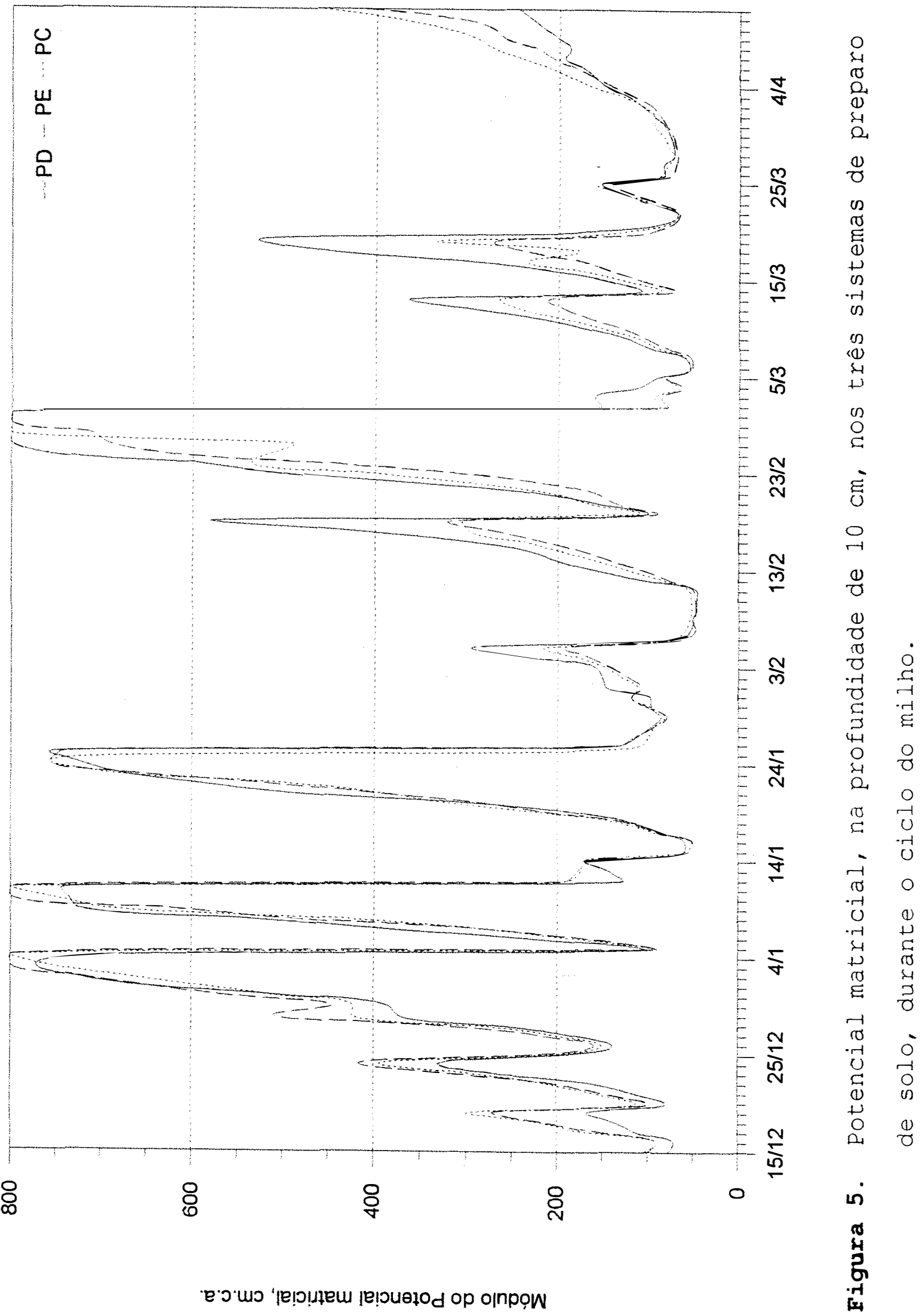




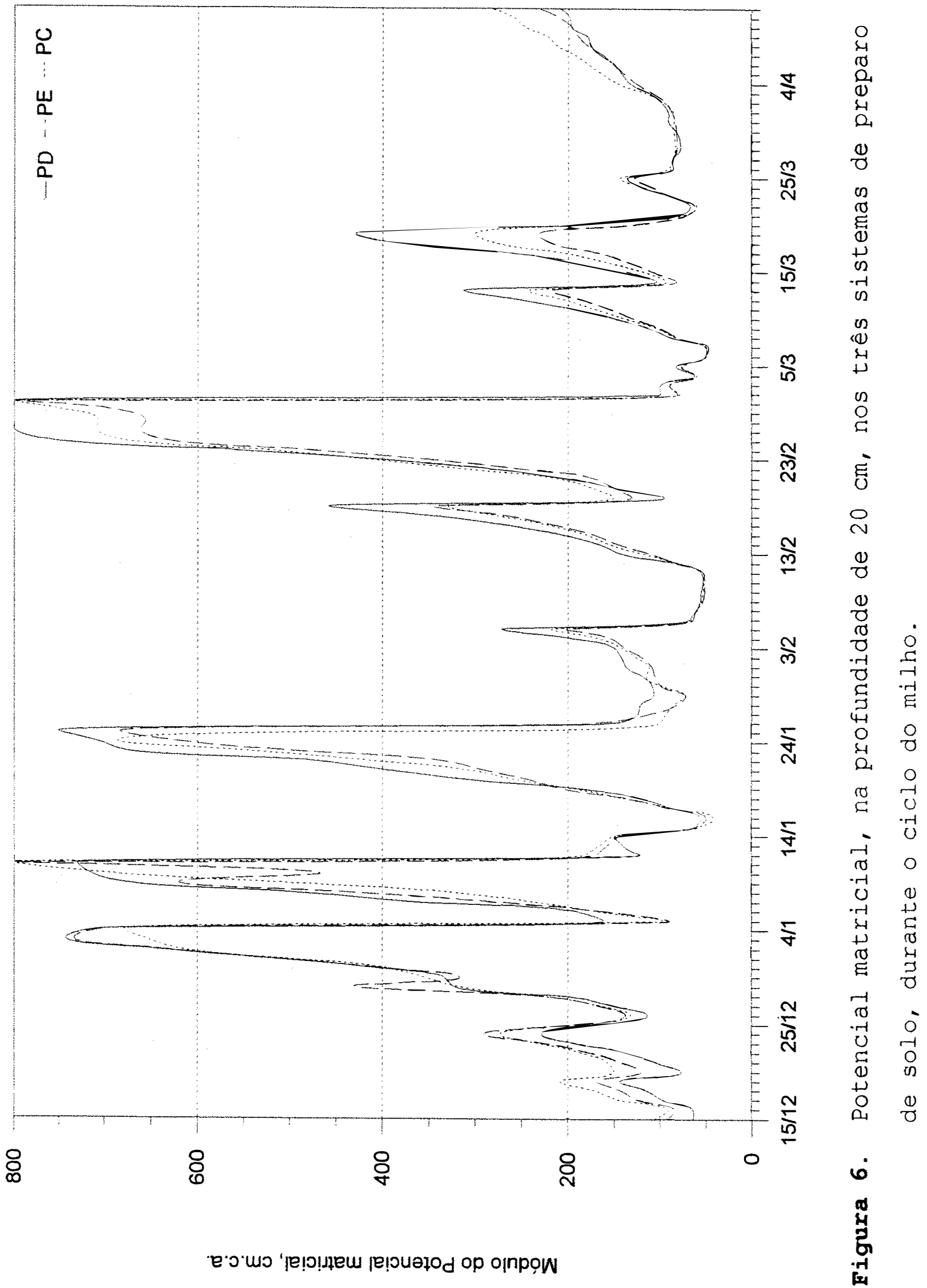




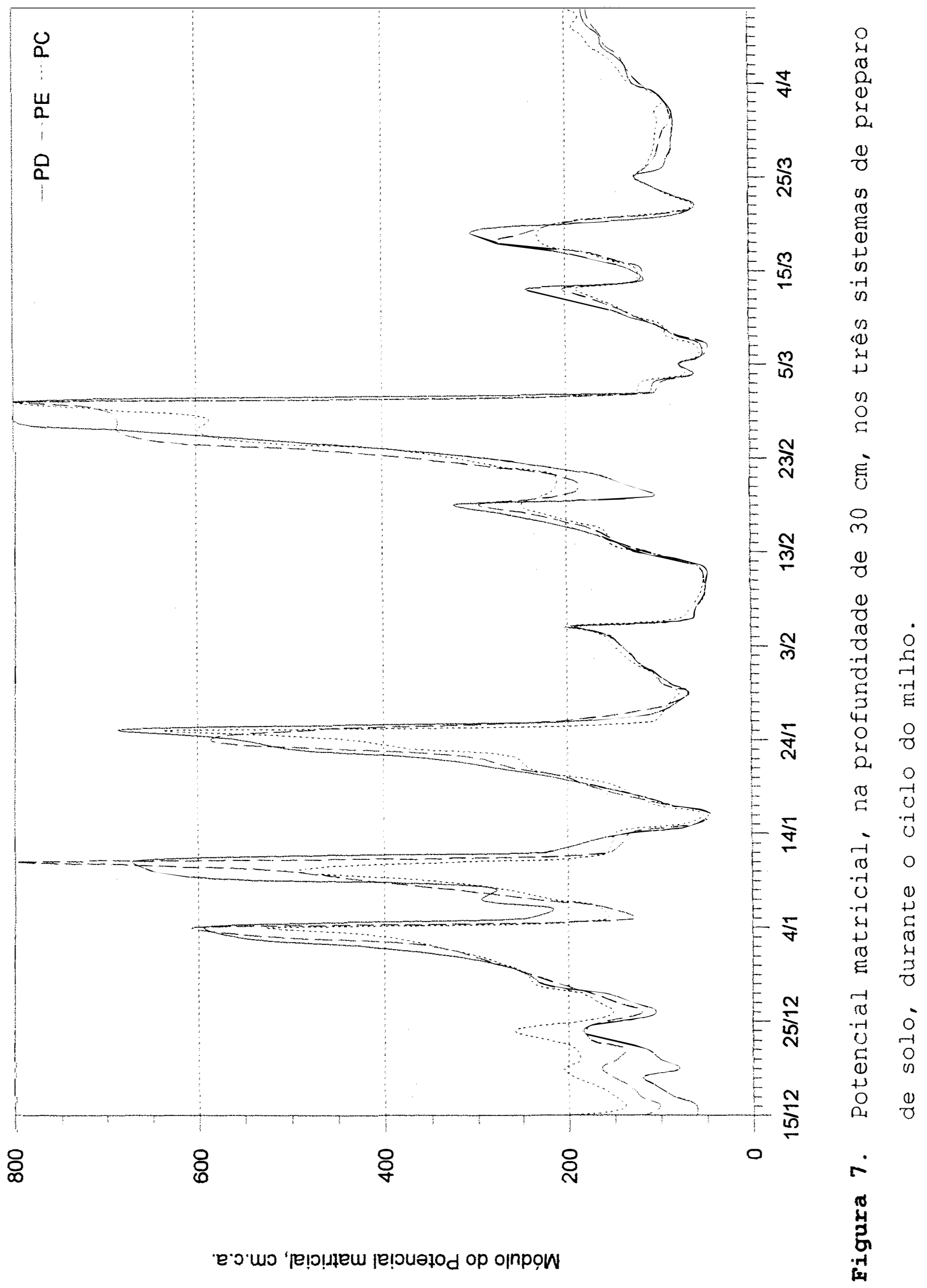




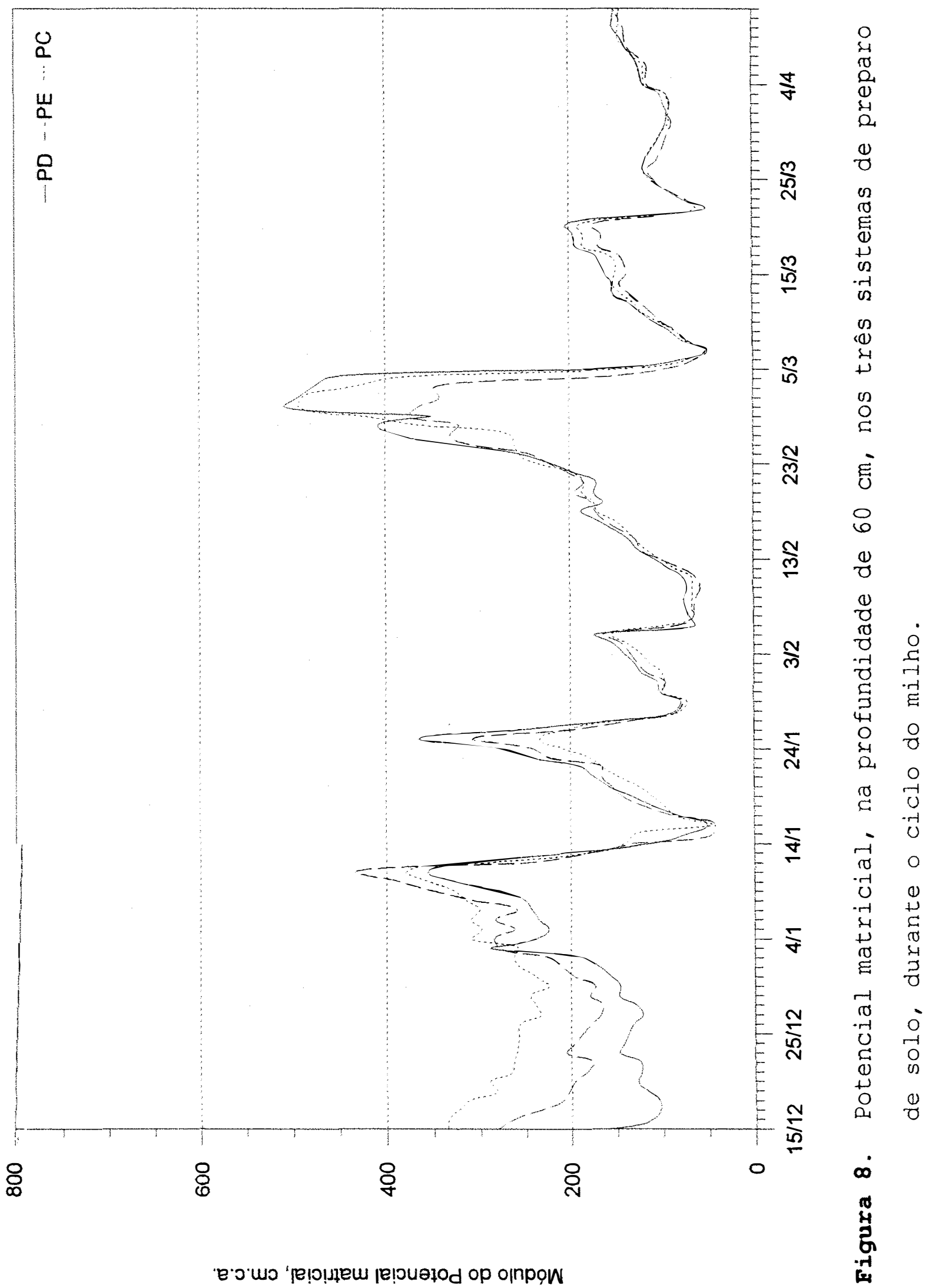


61.

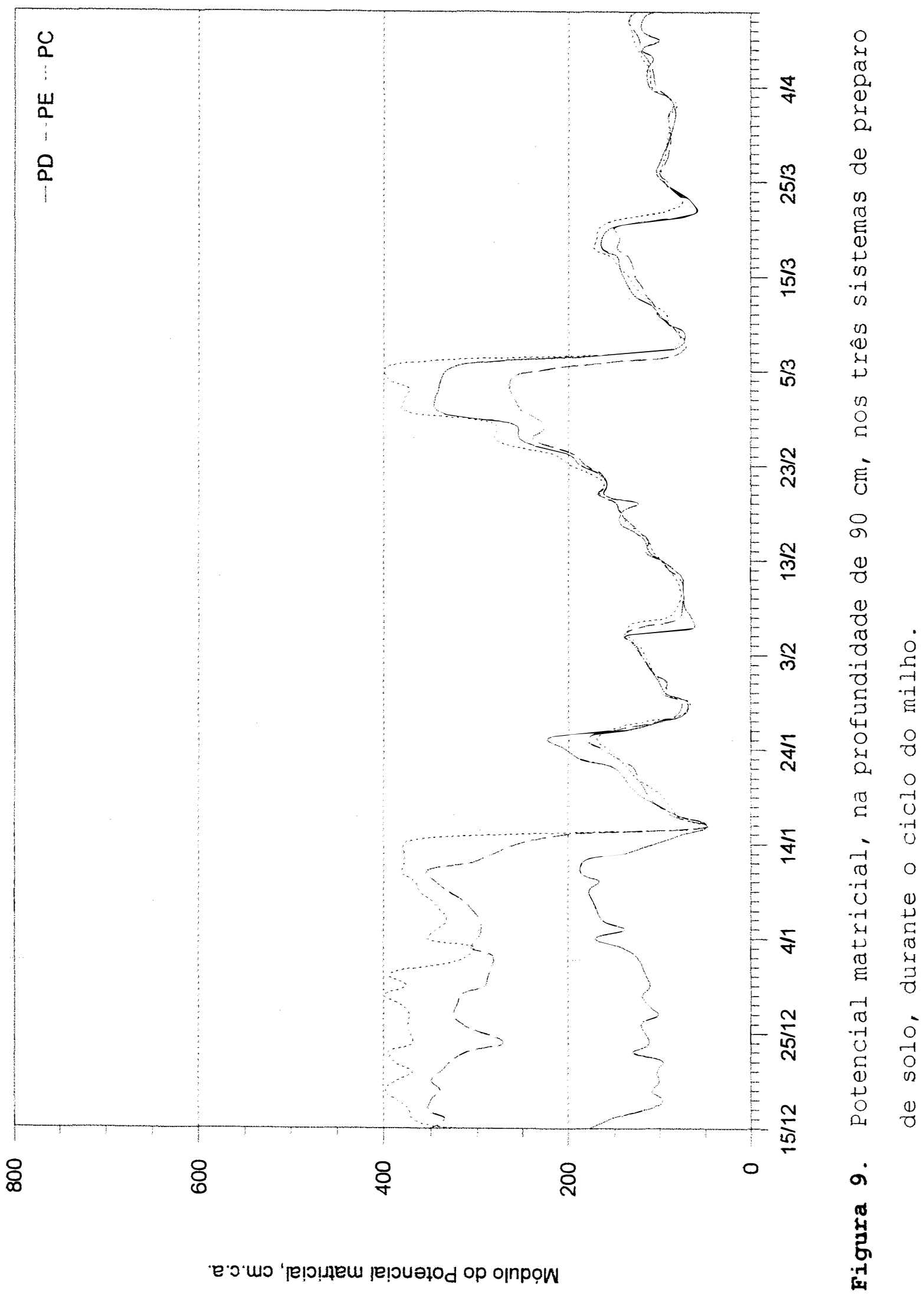




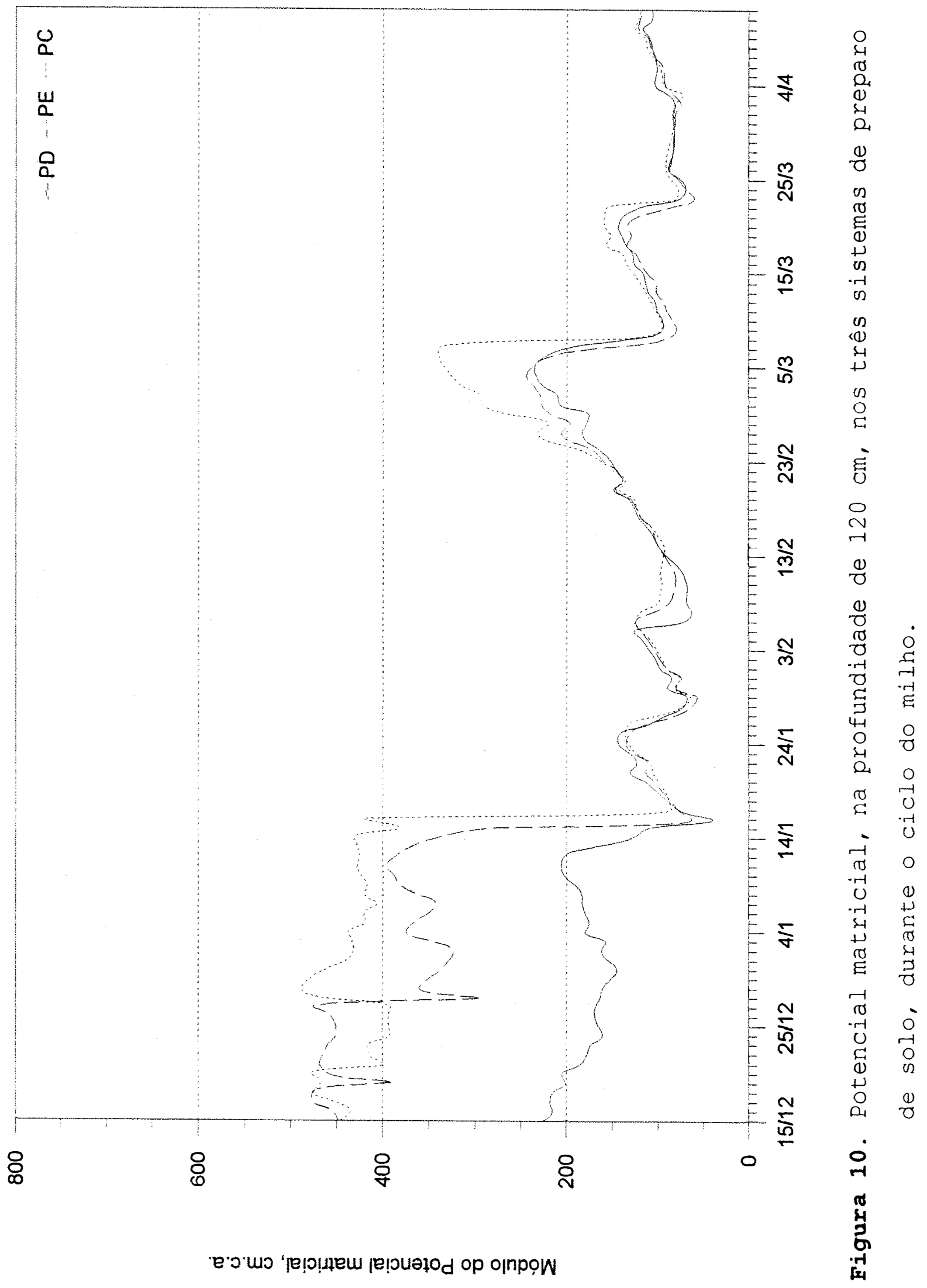




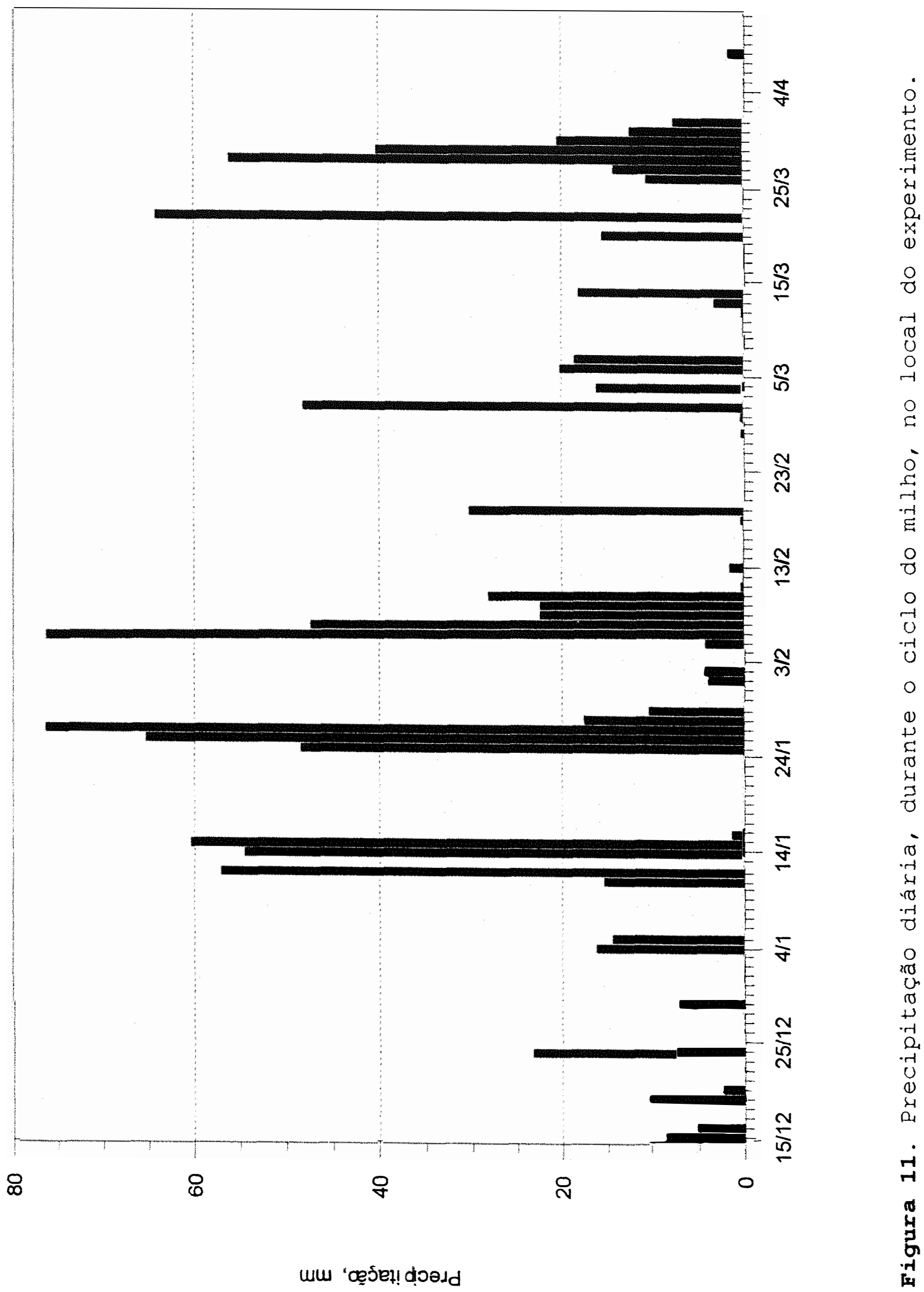


64.

Para efeito de construção dos gráficos de potencial matricial ao longo do ciclo do milho, quando ocorreu rompimento da coluna de mercúrio devido a tensões superiores a $800 \mathrm{~cm}$ de coluna d'água, estes valores foram considerados como iguais a 800 , conforme pode ser visto nos gráficos das profundidades 10,20 e $30 \mathrm{~cm}$. Nas demais profundidades não ocorreu tal situação.

De forma geral verificou-se a tendência do PD apresentar um potencial matricial maior que os demais tratamentos na fase inicial da cultura. Em dois momentos de seca no mês de dezembro, isto ficou mais evidente, observando-se uma diferença de até $130 \mathrm{~cm} . c . a$. entre PD e PC na profundidade de $10 \mathrm{~cm}$ (Figura 5). Nas demais profundidades observou-se a mesma tendência, com diferenciação menos acentuada nas camadas intermediárias para depois aumentar e ficar em torno de $300 \mathrm{~cm} . \mathrm{c} . \mathrm{a}$. a $120 \mathrm{~cm}$ de profundidade, até meados de janeiro. A partir de meados de fevereiro observou-se, nas profundidades de 10, 20 e $30 \mathrm{~cm}$, potenciais mais baixos no PD, em relação ao PC, com diferenças máximas em torno de $275 \mathrm{~cm} . c . a$. (em 18/02) a $10 \mathrm{~cm}$. Abaizo de $60 \mathrm{~cm}$ de profundidade não se observaram tais diferenças havendo uma proximidade maior entre as curvas de potencial matricial.

Se for considerado que o potencial matricial reflete a umidade do solo e também a água disponível às plantas, pode-se dizer que estes dados concordam parcialmente com os trabalhos que mostram o sistema de plantio direto sempre com umidade maior que os sistemas convencionais, como VIEIRA (1981); SIDIRAS et al. (1983); DERPSCH et al. (1986) e ARZENO (1990). 
Uma explicação para esta tendência do PD apresentar potenciais mais altos no início do ciclo da cultura e a partir de meados de fevereiro apresentar valores mais baixos que os outros sistemas, pode estar na cobertura do solo.

$\mathrm{Na}$ Eigura 12 pode-se observar que $\bigcirc \mathrm{PD}$ iniciou com uma cobertura morta de $70 \%$, O PE com $30 \%$ e o PC com 11\%. Com o tempo esta cobertura foi diminuindo, fruto da decomposição da palha de aveia, até se estabilizar em torno de 40\% no PD a partir de fins de fevereiro, ou 70 dias após emergência. Por outro lado, a cobertura proporcionada pelo milho neste mesmo período já atingia cerca de 50 - 60\%, até atingir um máximo de 90\% aos 100 dias após a emergência. Como o maior potencial matricial no PD em relação ao PC passou a ocorrer a partir desta redução da cobertura morta, há uma evidência portanto que esta cobertura já não era suficiente para amenizar a evaporação de água do solo no PD, que nos demais sistemas é amenizada pelo encrostamento superficial. A continuidade dos poros que facilita a infiltração no PD, por ocasião das chuvas, nos momentos de seca passa a atuar como facilitadora de evaporação, diminuindo a umidade do solo nas camadas mais superficiais. Outro aspecto que favorece a redução da umidade nas camadas superficiais do PD, é - maior volume de raiz presente neste sistema, conforme apresentado na Eigura 4. Isto significa que, a partir de 60 - 80 dias da emergência, quando a planta de milho apresenta alta demanda hídrica, o maior volume de raiz presente acelera o secamento do solo nestas camadas consideradas. 

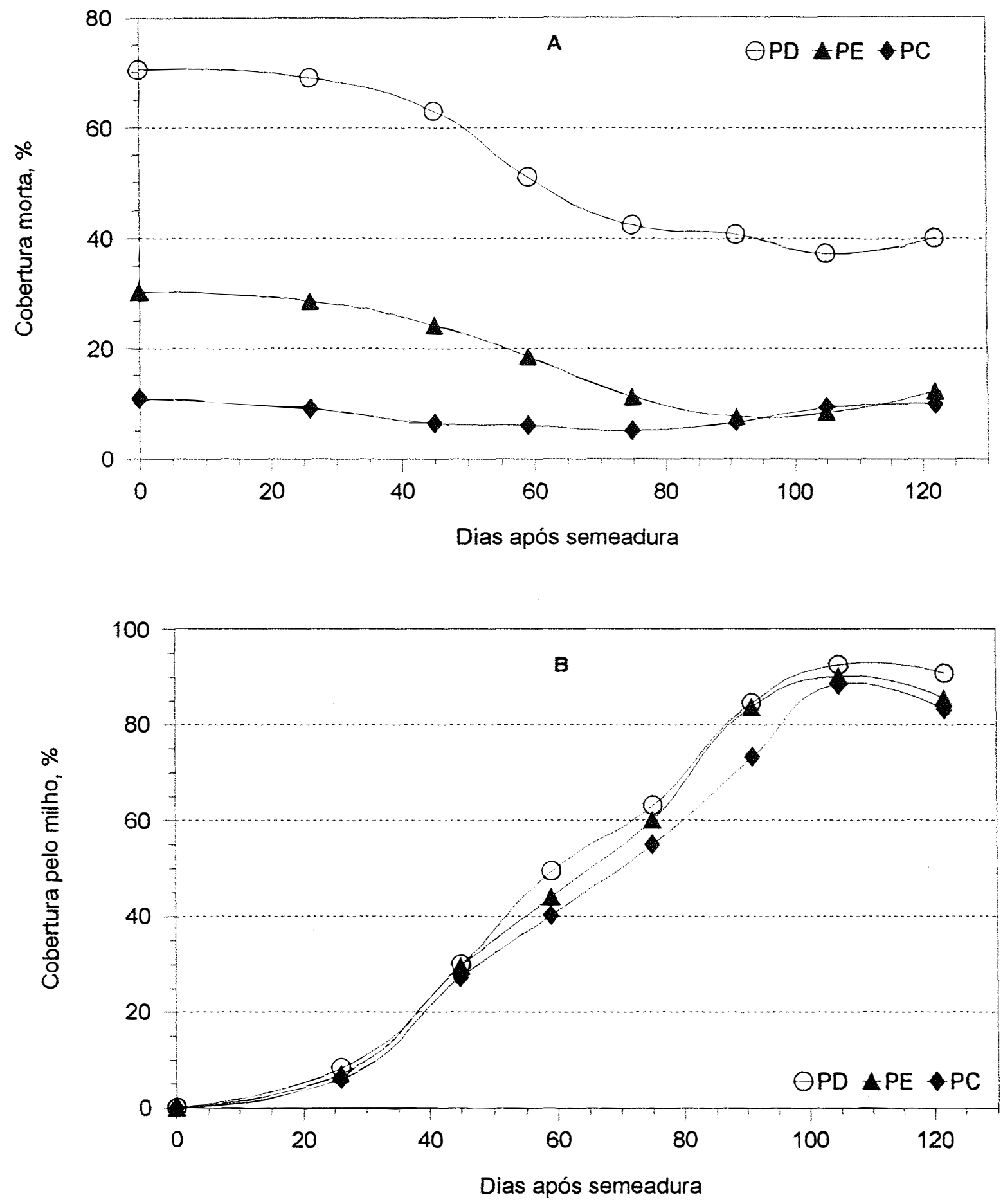

Figura 12. Cobertura morta do solo (A) e cobertura pelo milho ao longo do ciclo (B), nos três sistemas de preparo do solo. 
Estes períodos mais secos no PD não significam que pode ter havido comprometimento para a planta, pois chegou-se a potenciais inferiores a $600 \mathrm{~cm} . c . a$. Em fins de fevereiro, num período de seca mais severo, ultrapassou-se $800 \mathrm{~cm} . \mathrm{c} . \mathrm{a}$. (limite dos tensiômetros) nos três sistemas, quando pode ter ocorrido déficit hídrico nestas profundidades consideradas. Neste momento é que as raízes presentes em maior volume abaixo de $30 \mathrm{~cm}$ no $P D$ e $P E$ podem suprir parte das necessidades hídricas da planta, tendo em vista a água disponível abaixo desta camada, conforme ilustrado nas Figuras 8, 9 e 10 .

Fica evidente nestas figuras, que representam - potencial matricial nas profundidades 60,90 e $120 \mathrm{~cm}$, a maior quantidade de água nestas camadas, especialmente até meados de janeiro, dos sistemas PD e PE em relação ao PC. Isto mostra que estes sistemas em períodos de menor precipitação, que é o caso, mantiveram uma reserva maior de água no solo, conseqüência da maior infiltração por ocasião das chuvas. No PC como a enxurrada é acentuada, ocasionando maior erosão, conforme já destacado por HARROLD (1972); BENATTI Jr. et al. (1977); VIEIRA et al. (1978); MONDARDO et al. (1979) e CASTRO et al (1986), a água armazenada em profundidade é menor, o que em períodos de secamento longo pode levar ao déficit hídrico no solo, comprometendo o desenvolvimento das plantas. 
68.

\subsection{Retenção de água do solo.}

No Apêndice 9 estão colocados os dados da umidade volumétrica de cada tratamento em cada profundidade trabalhada. Estes dados deram origem às Figuras 13 a 23, representando os valores de umidade volumétrica $(\boldsymbol{\theta})$ da saturação até $1.500 \mathrm{KPa}$, para todas as profundidades amostradas.

$\mathrm{Na}$ profundidade de $5 \mathrm{~cm}$ (Figura 13) houve maior umidade no PE em relação ao PD até $2 \mathrm{KPa}$, possivelmente porque este sistema apresenta maior macroporosidade. Embora não se tenha determinado porosidade neste trabalho, os dados da Tabela 9 mostram que a densidade do solo no PE foi menor que os do PD a 5,10 e $15 \mathrm{~cm}$ de profundidade, embora não seja significativa. Mas, em termos de retenção de água isto pode estar implicando numa diferença a mais no PE de 3 a 6\%, dependendo da profundidade e da tensão aplicada, conforme Figuras 13, 14 e 15. Esses resultados concordam com os de SARVASI (1994), onde o solo preparado com arado escarificador apresentava maior macroporosidade e retenção de água que os sistemas convencionais e plantio direto nas tensões até $2 \mathrm{KPa}$.

Conforme se aumenta a tensão aplicada, até $100 \mathrm{KPa}$, valor normalmente dentro da faixa ótima de água disponivel para as plantas, $O$ PE passou a apresentar menor volume de água retida em relação ao PD a $5 \mathrm{~cm}$ e em relação ao PD e PC a 10 e $15 \mathrm{~cm}$ de profundidade. Nesta faixa de tensão aplicada predominam a ação dos meso e microporos que passam a regular a retenção da água, após drenagem dos macroporos. 


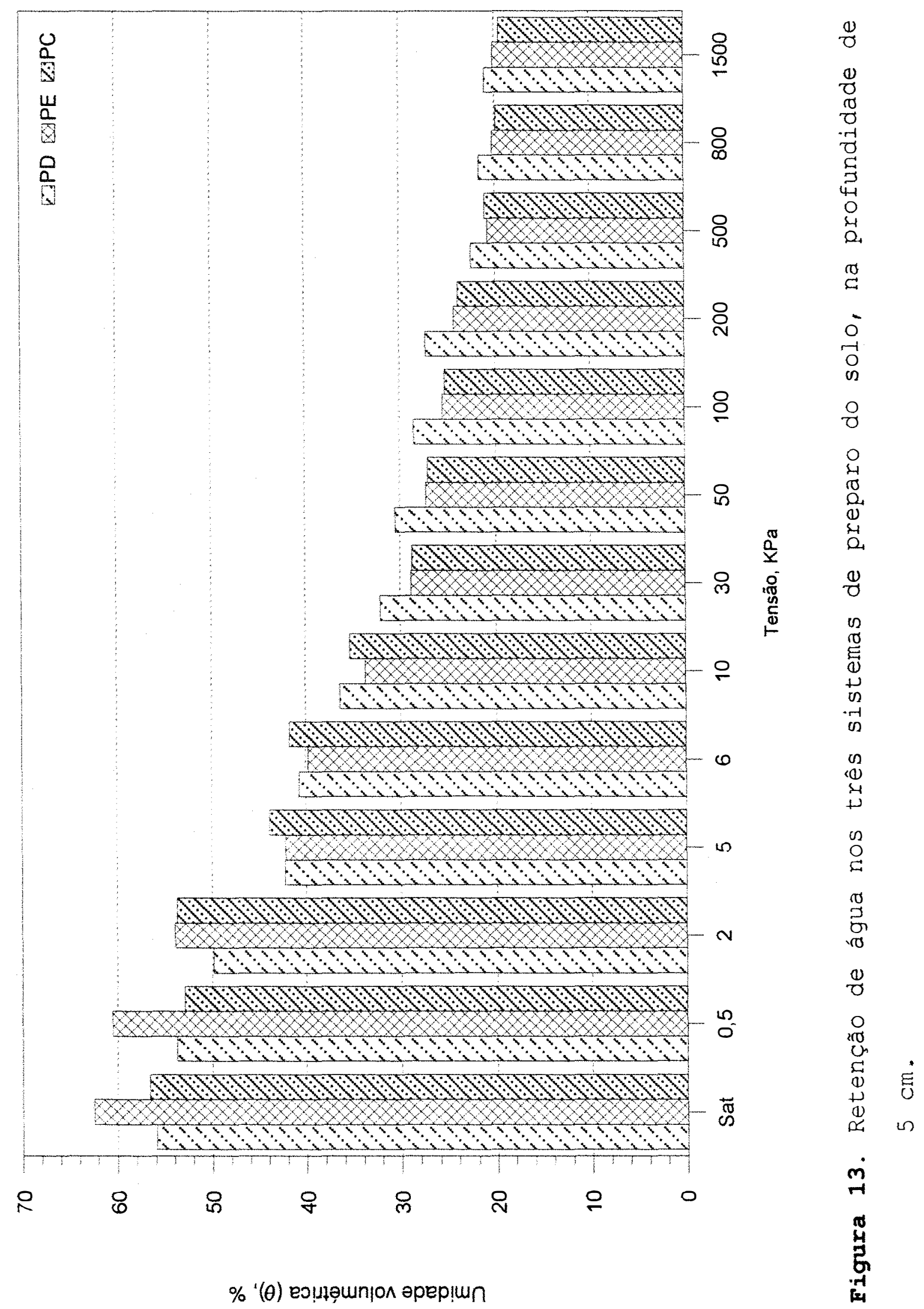




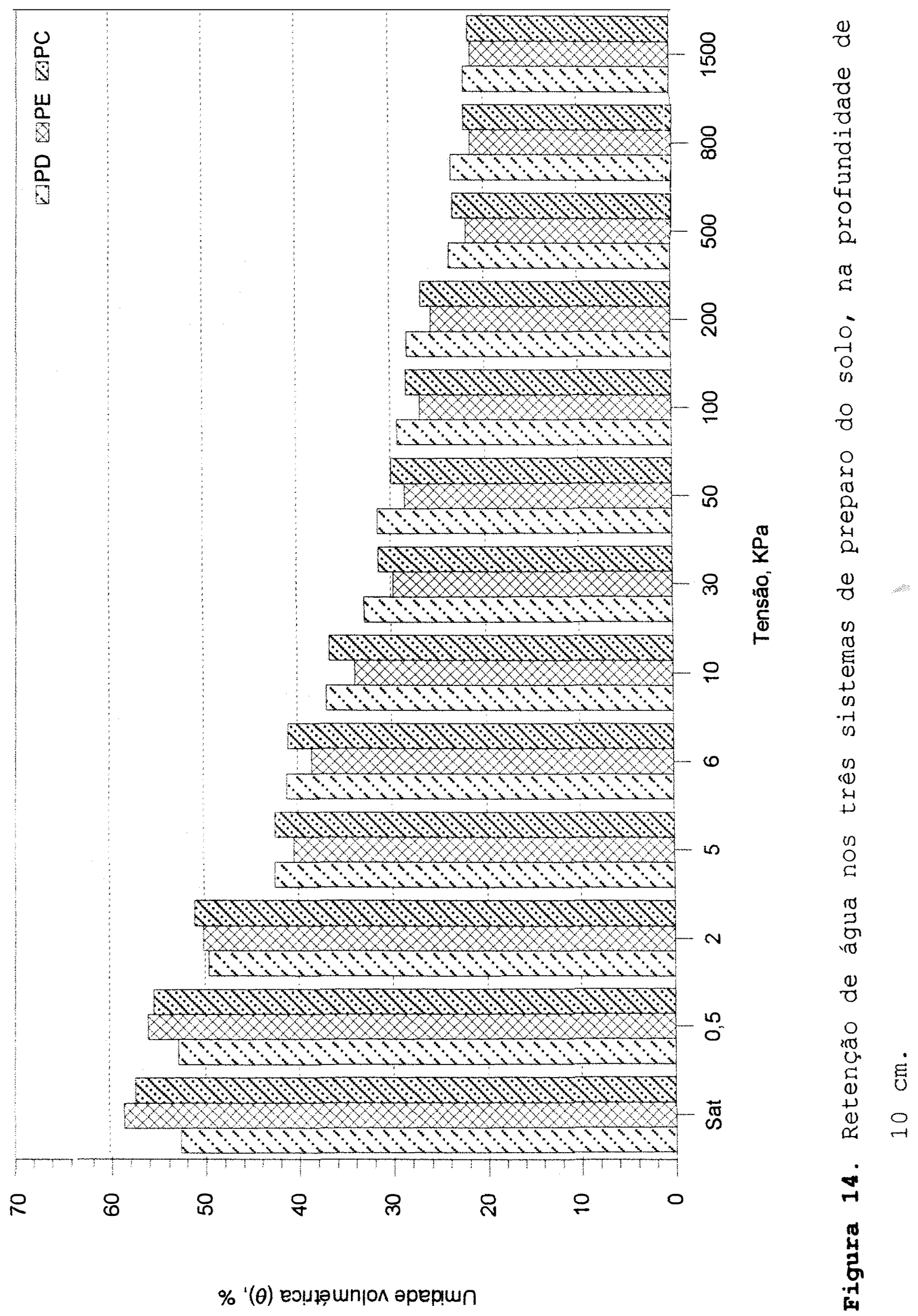




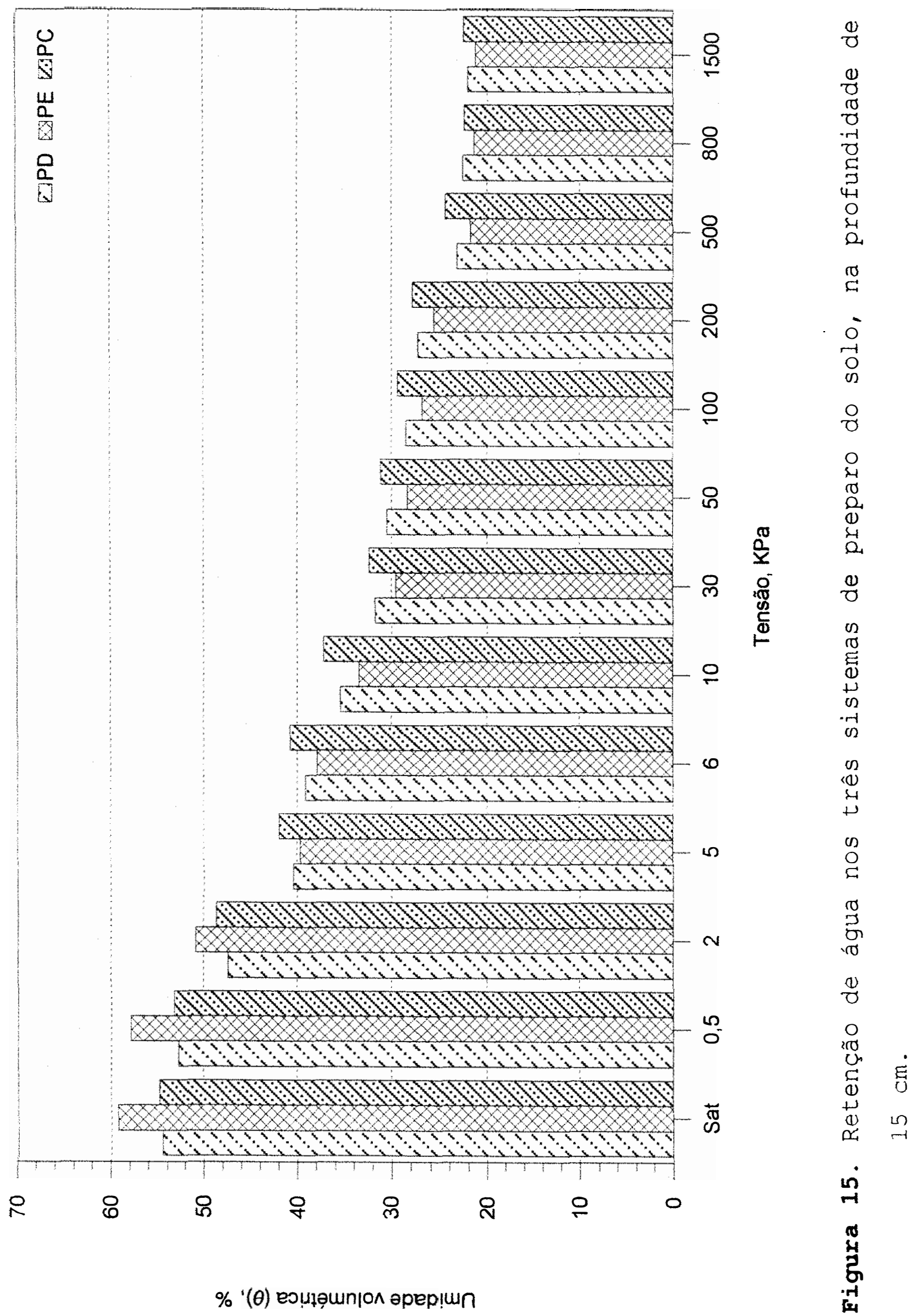


A $20 \mathrm{~cm}$ de profundidade (Figura 16), embora 0 PC se apresentasse mais compactado nesta camada que $\bigcirc \mathrm{PD}$ e $\bigcirc \mathrm{PE}$, isto não implicou em diferenças quanto à retenção de água, apenas nos pontos acima de $500 \mathrm{KPa}$, faixa de retenção onde as plantas já podem entrar em murcha permanente. Nas demais profundidades (Figuras 17, 18, 19, 20, 21, 22 e 23) observou-se alguma diferença apenas na profundidade de $60 \mathrm{~cm}$ (Figura 20) onde O PD apresentou maior retenção de água, acima de $5 \mathrm{KPa}$, coincidindo com a maior densidade do solo (Tabela 9).

Pelos resultados obtidos verifica-se que a retenção de água foi maior no sistema de plantio direto na faixa de 60 a $100 \mathrm{KPa}$, na zona de influência dos sistemas de preparo e também onde se concentra $\circ$ maior volume de raízes. Estes dados coincidem com os de ELTZ et al. (1989) e de SIDIRAS et al. (1983), que obtiveram em latossolo roxo até 5\% a mais de umidade no plantio direto a $33 \mathrm{KPa}$ em relação ao sistema convencional, significando maior disponibilidade de água às plantas, segundo estes autores. Esta maior retenção de água no PD se deve naturalmente à maior densidade do solo, mas sem contudo ser impedimento para a infiltração e crescimento radicular conforme já verificado.

A partir dos dados de retenção de água do Apêndice 10 fez-se o ajuste pela equação (2) de GENUCHTEN \& NIELSEN (1985). Os parâmetros da equação assim obtidos, apresentados na Tabela 13, foram utilizados no cálculo da condutividade hidráulica pelo método de HILLEL et al. (1972). 


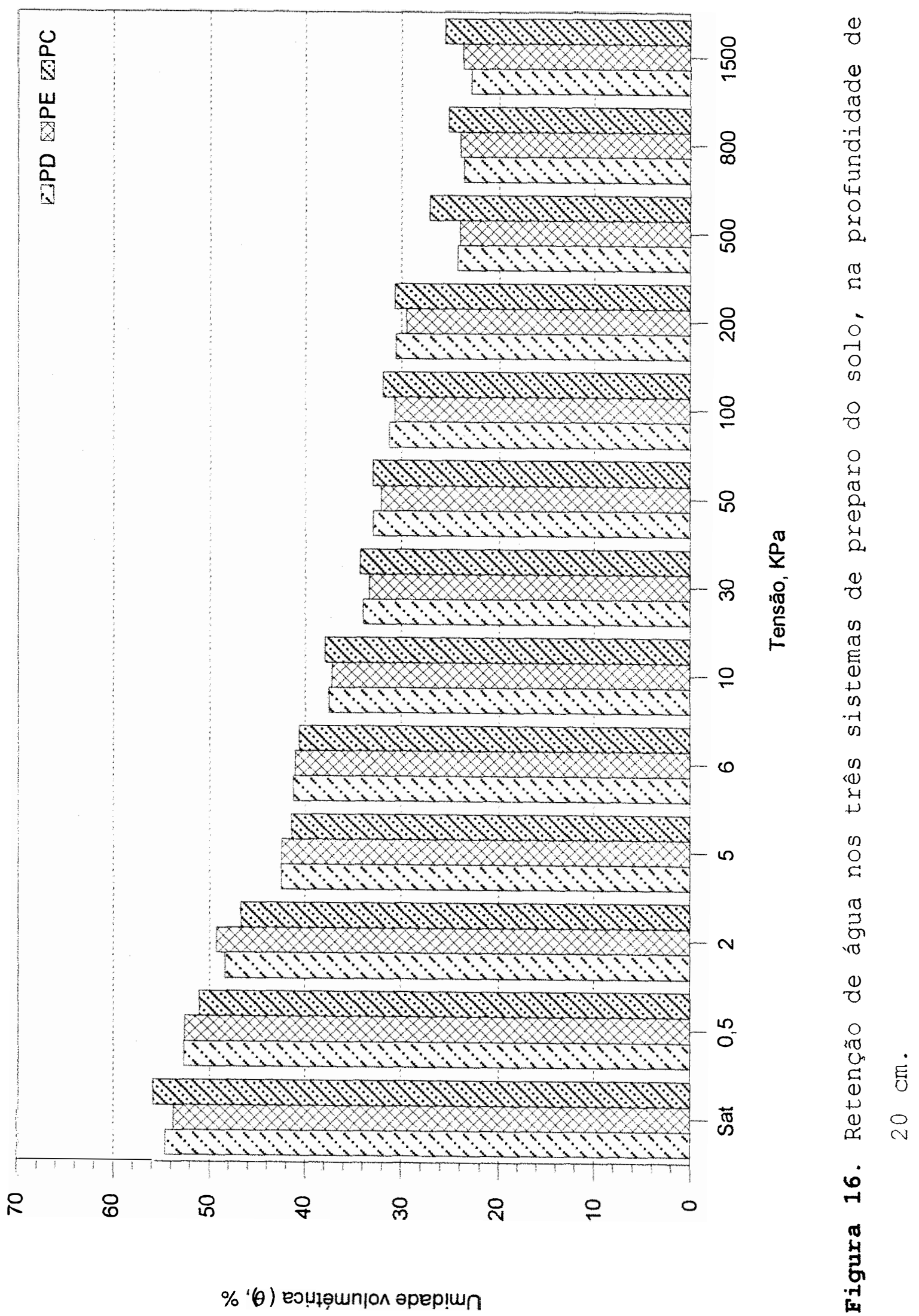




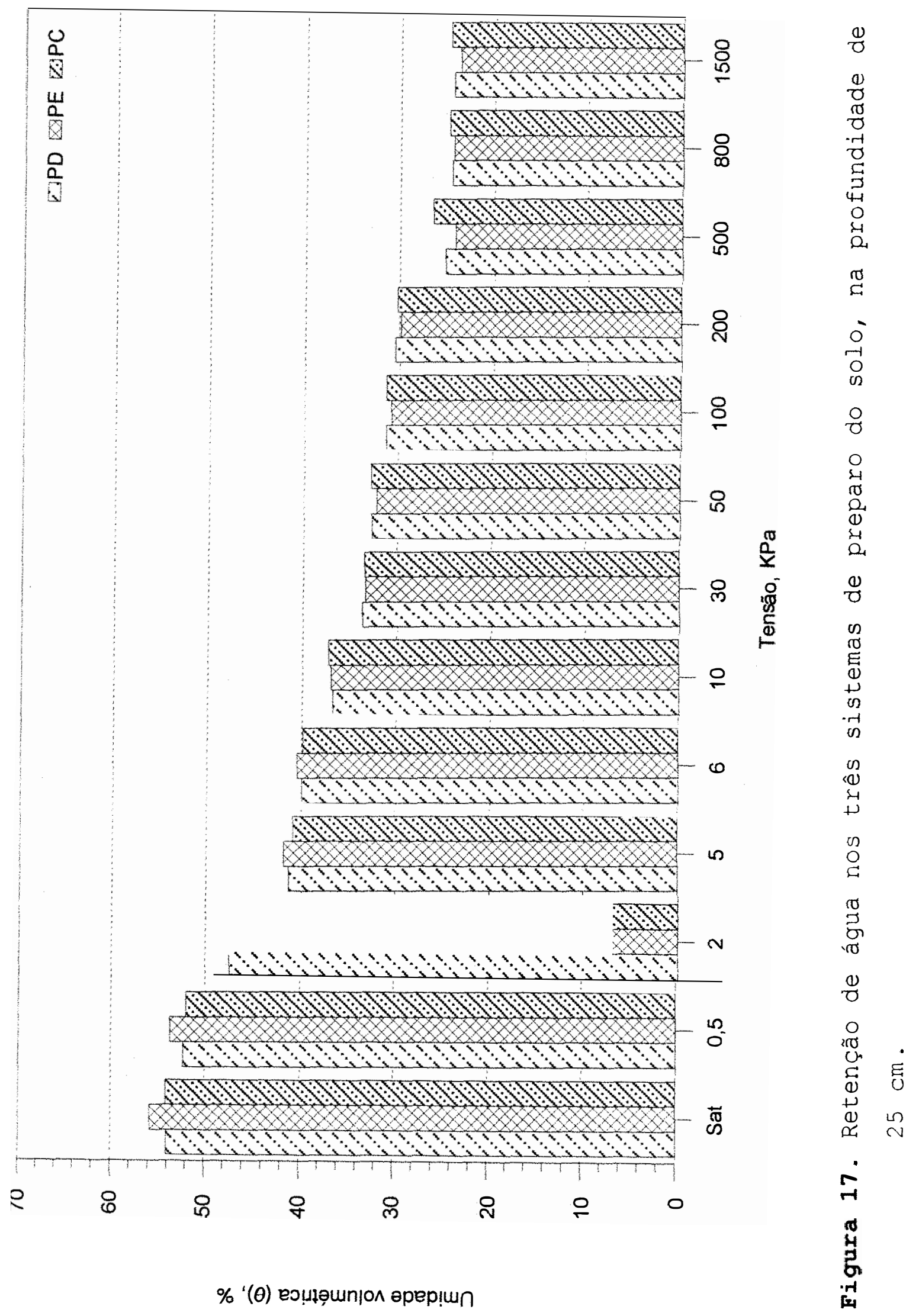




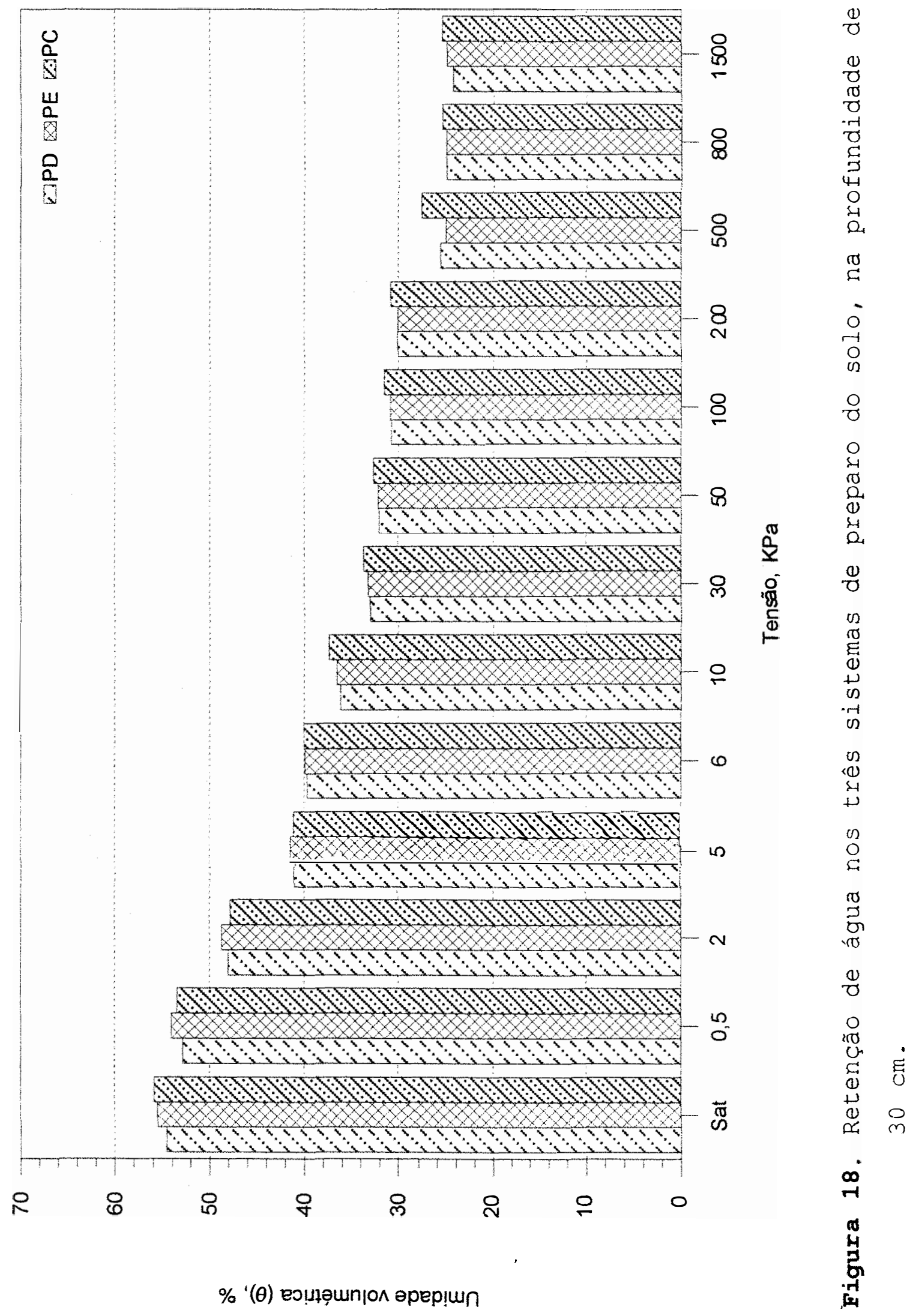




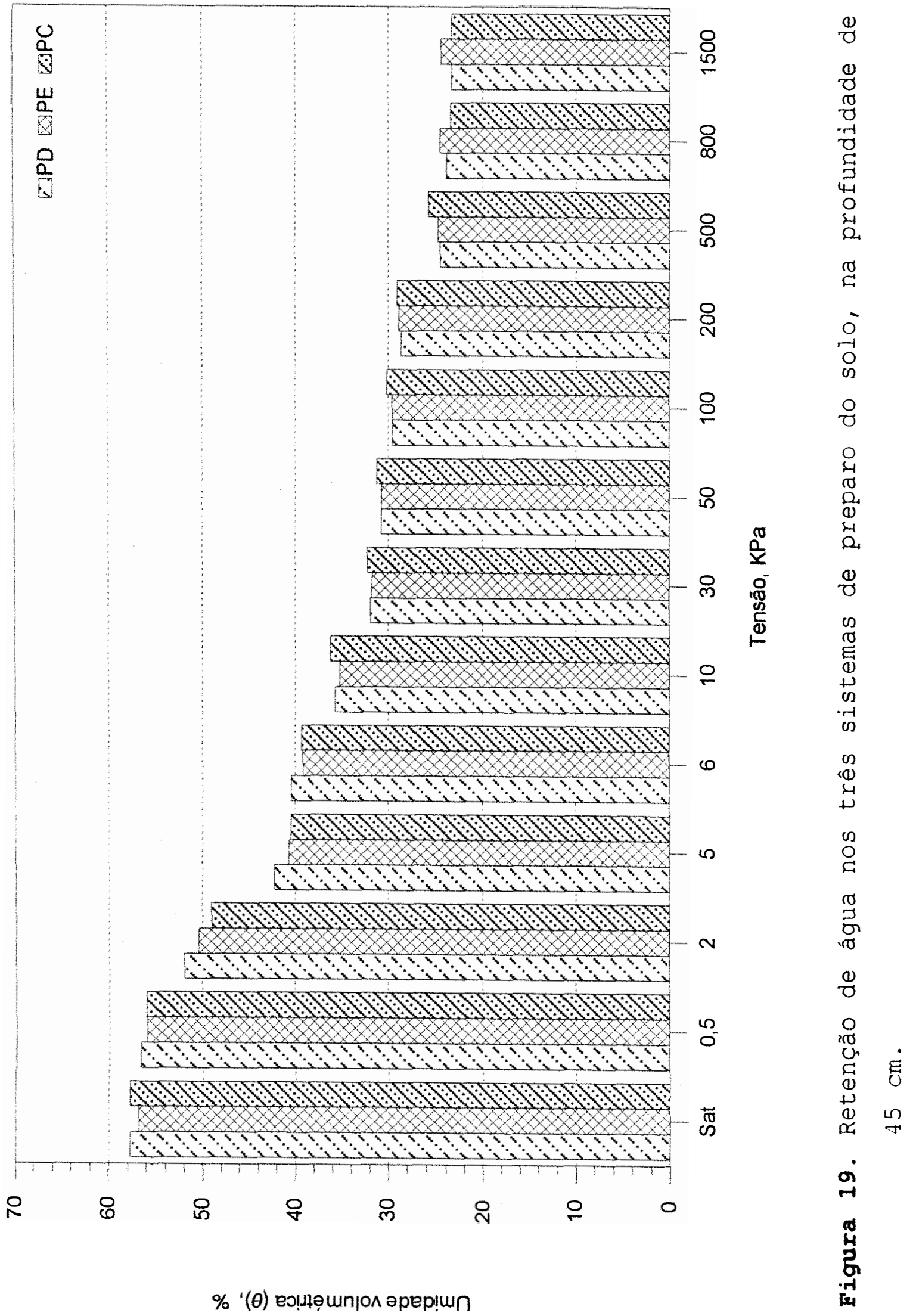




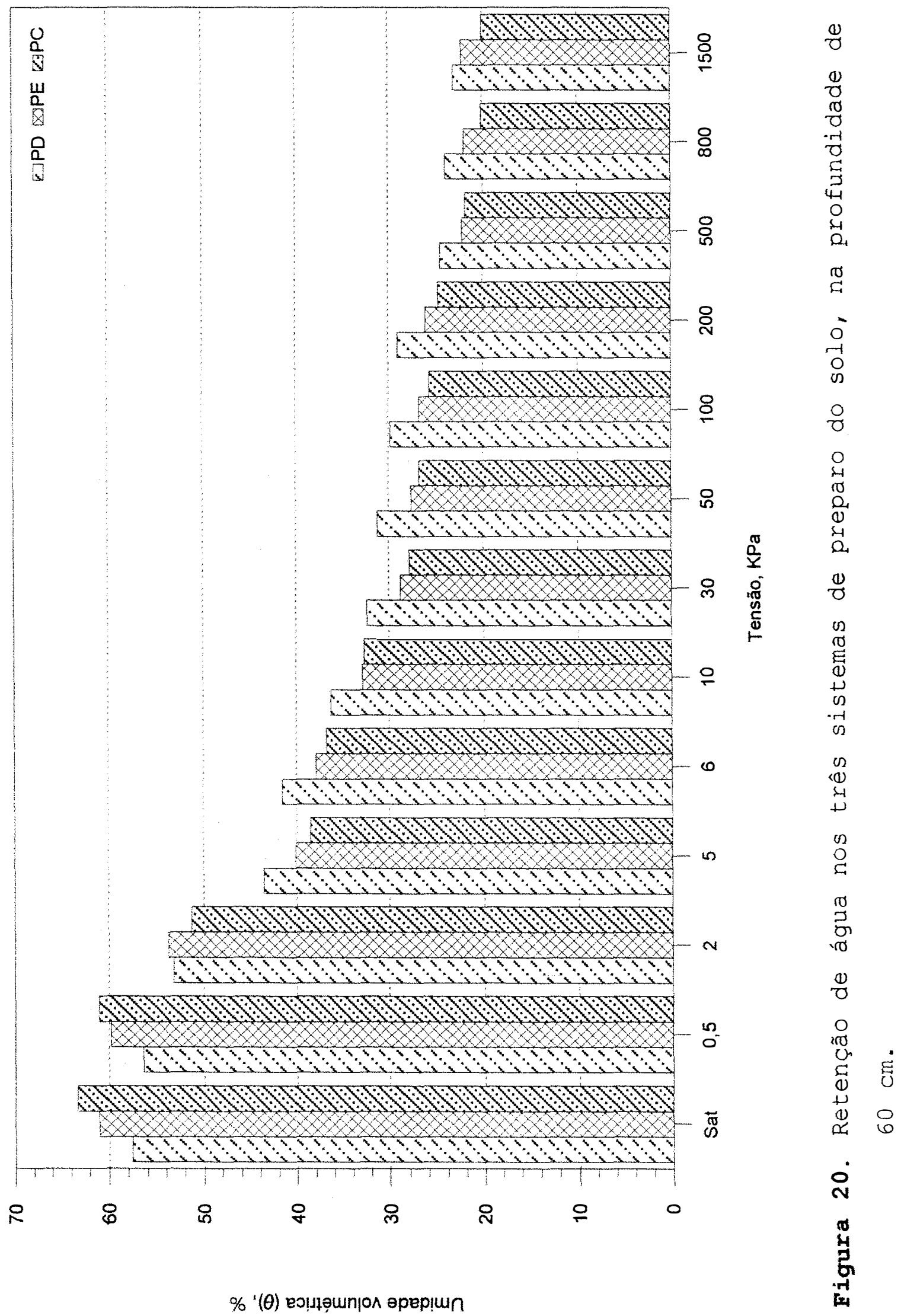




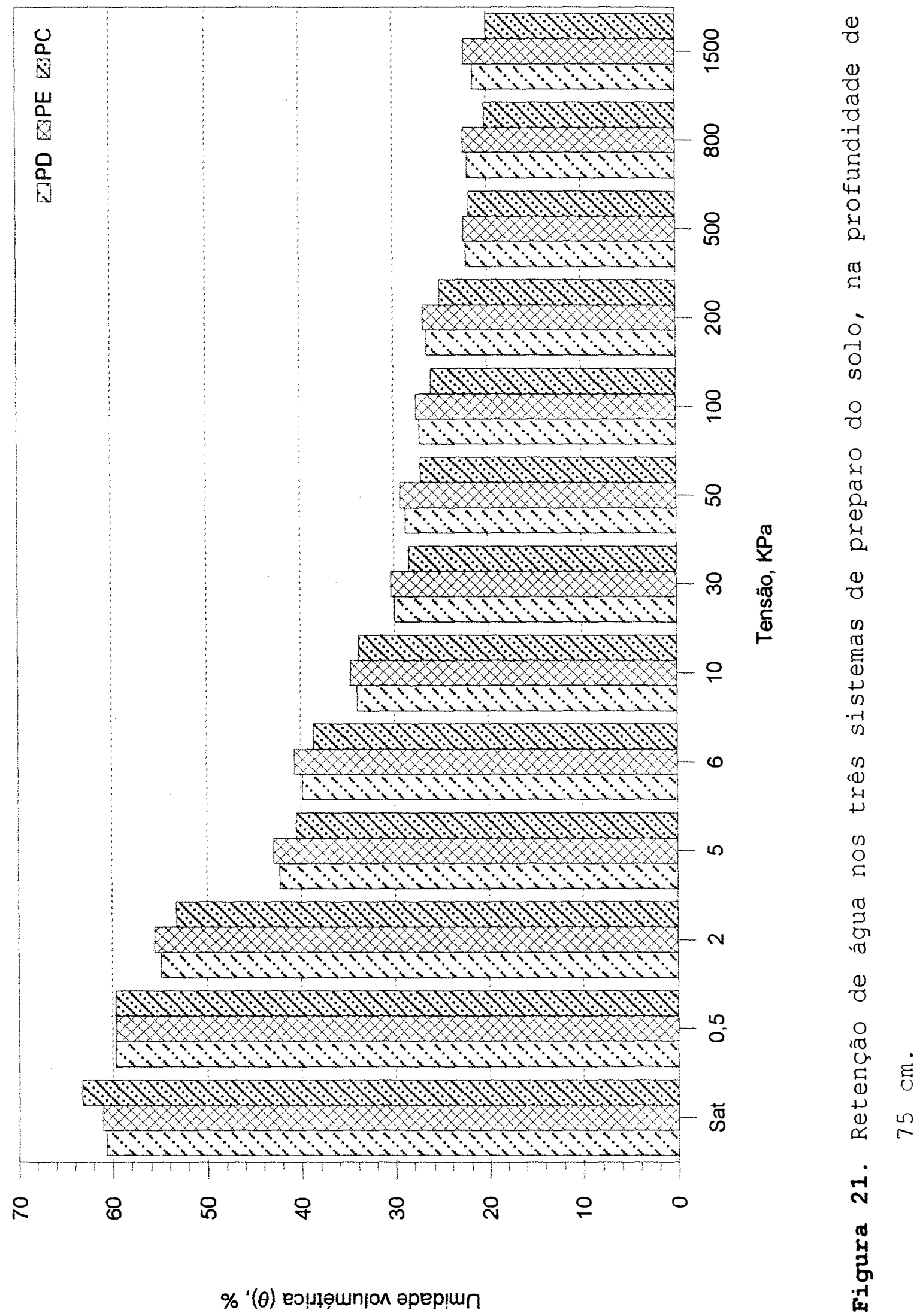




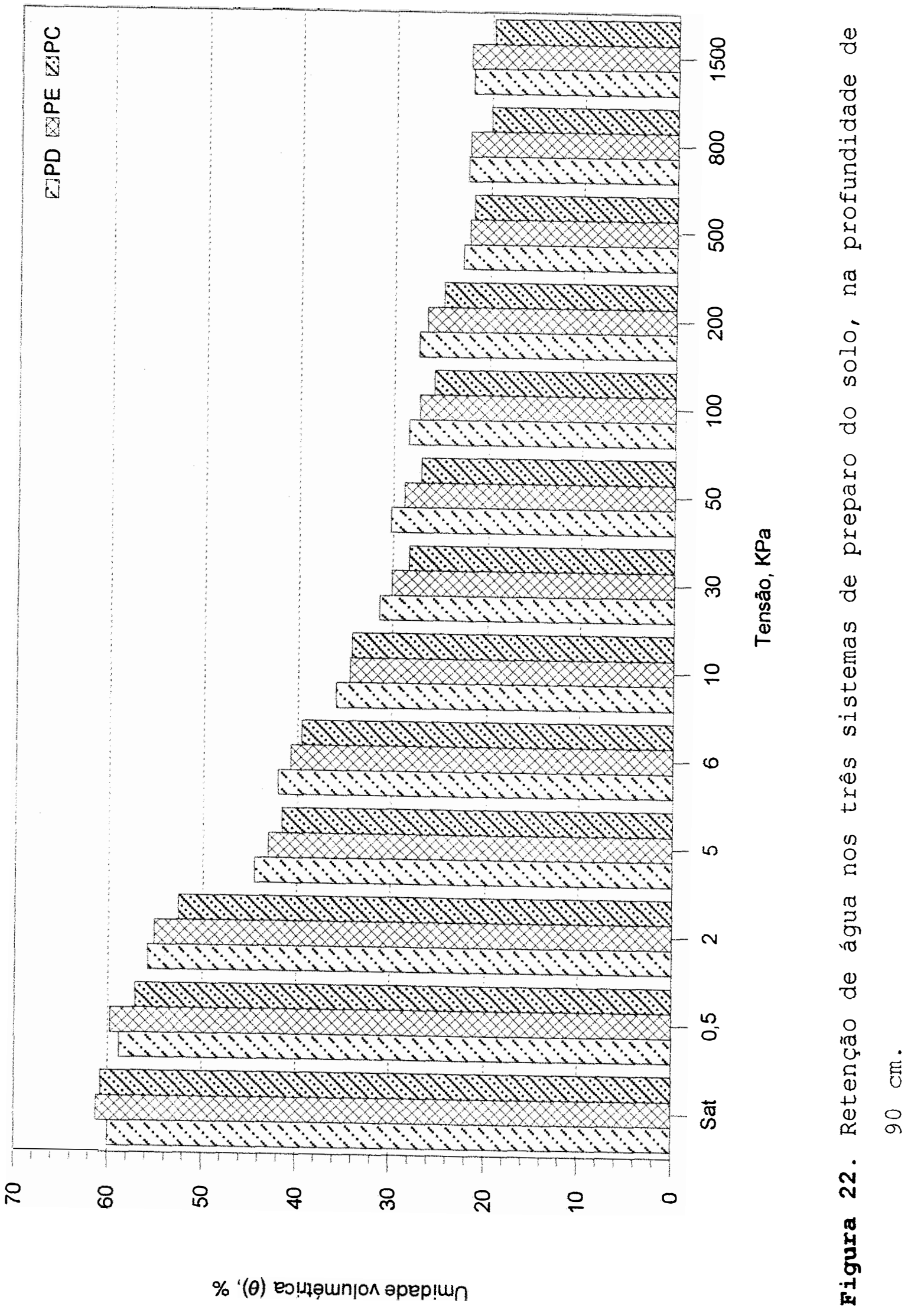




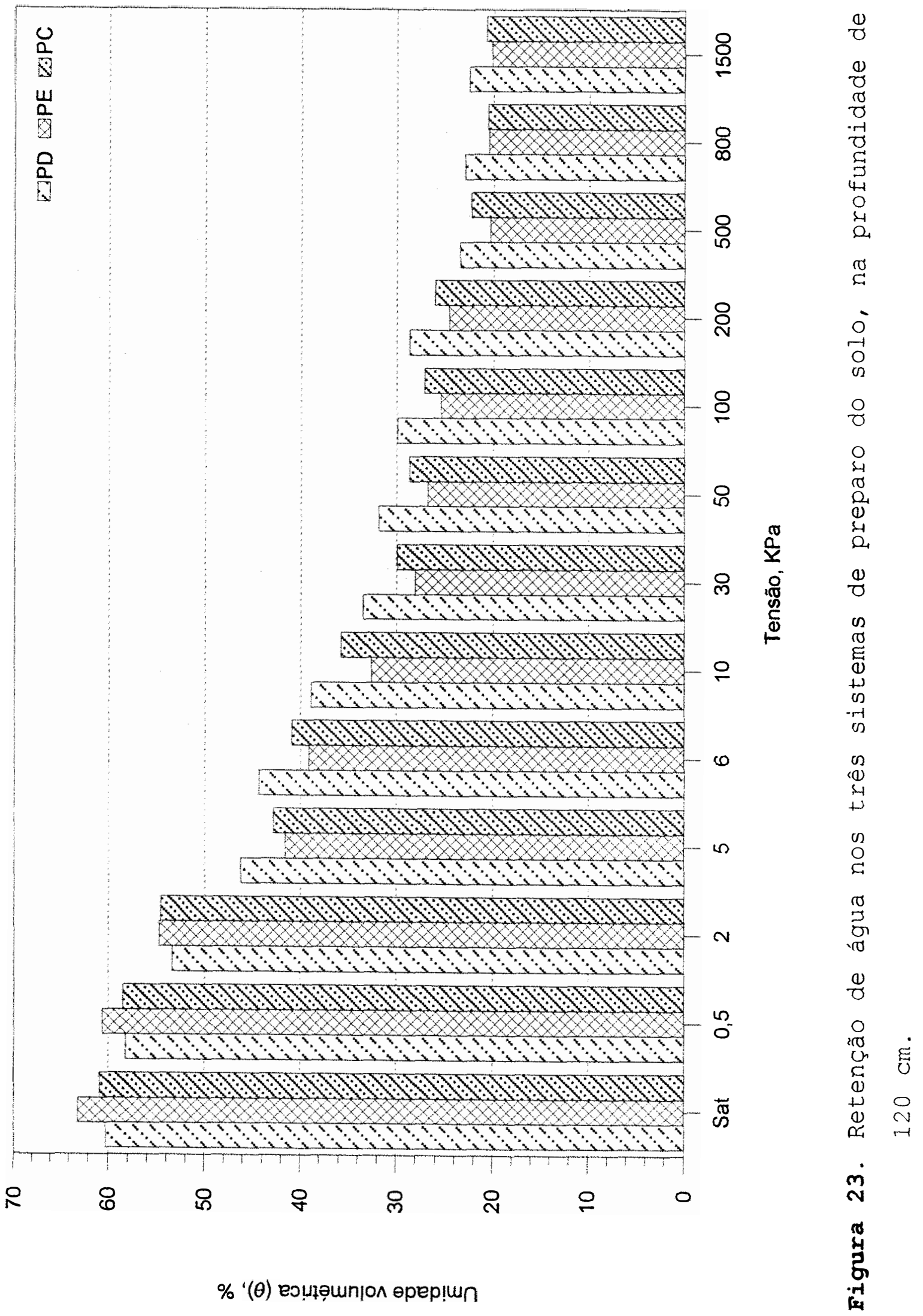


81.

Tabela 13. Parâmetros da equação de GENUCHTEN \& NIELSEN (1985), para cada profundidade, nos três sistemas de preparo do solo.

\begin{tabular}{|c|c|c|c|c|c|c|c|c|}
\hline $\begin{array}{l}\text { Sistemas } \\
\text { de } \\
\text { Preparo }\end{array}$ & $\begin{array}{l}\text { Profundidade } \\
\mathrm{cm}\end{array}$ & Alfa & $M$ & $\mathrm{~N}$ & $\theta R$ & $\theta S$ & Coef. Cor. & Interações \\
\hline \multirow{11}{*}{ PD } & 5 & 0,0751 & 0,2232 & 1,2873 & 0,160 & 0,562 & 0,993 & 131 \\
\hline & 10 & 0,0536 & 0,2411 & 1,3176 & 0,185 & 0,537 & 0,992 & 119 \\
\hline & 15 & 0,0920 & 0,2301 & 1,2988 & 0,181 & 0,549 & 0,994 & 128 \\
\hline & 20 & 0,1243 & 0,1468 & 1,1720 & 0,110 & 0,551 & 0,989 & 179 \\
\hline & 25 & 0,1179 & 0,1911 & 1,2362 & 0,184 & 0,546 & 0,989 & 149 \\
\hline & 30 & 0,1002 & 0,2343 & 1,3059 & 0,214 & 0,551 & 0,989 & 127 \\
\hline & 45 & 0,0599 & 0,3248 & 1,4810 & 0,231 & 0,582 & 0,989 & 85 \\
\hline & 60 & 0,0517 & 0,3224 & 1,4757 & 0,229 & 0,581 & 0,987 & 85 \\
\hline & 75 & 0,0466 & 0,3986 & 1,6627 & 0,225 & 0,612 & 0,989 & 55 \\
\hline & 90 & 0,0442 & 0,3549 & 1,5501 & 0,220 & 0,606 & 0,988 & 71 \\
\hline & 120 & 0,0599 & 0,2560 & 1,3441 & 0,187 & 0,604 & 0,995 & 114 \\
\hline \multirow{11}{*}{$P E$} & 5 & 0,0540 & 0,3676 & 1,5814 & 0,200 & 0,626 & 0,995 & 67 \\
\hline & 10 & 0,0712 & 0,3159 & 1,4617 & 0,202 & 0,588 & 0,994 & 90 \\
\hline & 15 & 0,0667 & 0,3474 & 1,5324 & 0,212 & 0,598 & 0992 & 77 \\
\hline & 20 & 0,0702 & 0,2197 & 1,2815 & 0,187 & 0,542 & 0,990 & 129 \\
\hline & 25 & 0,1016 & 0,2139 & 1,2721 & 0,189 & 0,562 & 0,990 & 137 \\
\hline & 30 & 0,0923 & 0,2520 & 1,3368 & 0,222 & 0,561 & 0,989 & 117 \\
\hline & 45 & 0,0643 & 0,3425 & 1,5208 & 0,244 & 0,574 & 0,990 & 78 \\
\hline & 60 & 0,0476 & 0,4401 & 1,7860 & 0,232 & 0,613 & 0,990 & 39 \\
\hline & 75 & 0,0443 & 0,4029 & 1,6748 & 0,231 & 0,614 & 0,990 & 52 \\
\hline & 90 & 0,0457 & 0,3929 & 1,6471 & 0,225 & 0,615 & 0,991 & 56 \\
\hline & 120 & 0,0490 & 0,4060 & 1,6836 & 0,209 & 0,630 & 0,992 & 52 \\
\hline \multirow{11}{*}{ PC } & 5 & 0,0297 & 0,3786 & 1,6092 & 0,195 & 0,558 & 0,991 & 59 \\
\hline & 10 & 0,0616 & 0,2797 & 1,3884 & 0,195 & 0,576 & 0,995 & 104 \\
\hline & 15 & 0,0773 & 0,2231 & 1,2872 & 0,177 & 0,551 & 0,995 & 129 \\
\hline & 20 & 0,2321 & 0,1487 & 1,1747 & 0,157 & 0,558 & 0,995 & 197 \\
\hline & 25 & 0,1258 & 0,1966 & 1,2448 & 0,195 & 0,545 & 0,992 & 148 \\
\hline & 30 & 0,1254 & 0,2279 & 1,2951 & 0,224 & 0,562 & 0,992 & 134 \\
\hline & 45 & 0,1048 & 0,2636 & 1,3580 & 0,217 & 0,584 & 0,990 & 116 \\
\hline & 60 & 0,0746 & 0,3725 & 1,5937 & 0,208 & 0,637 & 0,993 & 70 \\
\hline & 75 & 0,0638 & 0,3606 & 1,5639 & 0,204 & 0,629 & 0,993 & 73 \\
\hline & 90 & 00555 & 0,3445 & 1,5256 & 0,196 & 0,602 & 0,993 & 78 \\
\hline & 120 & 0,0515 & 0,3410 & 1,5175 & 0,204 & 0,609 & 0,992 & 78 \\
\hline
\end{tabular}




\subsection{Capacidade de aeração (Car) e de água disponivel (Cad)}

Os dados referentes à capacidade de aeração (Car) estão colocados na Eigura 24, determinados segundo a equação (3). Observa-se que a maior diferença ocorreu nas profundidades de 5,10 e $15 \mathrm{~cm}$ onde $O \mathrm{PE}$ apresentou até 8,5\% de umidade (a $5 \mathrm{~cm}$ ) superior aos demais tratamentos, o que confirma a predominância de macroporos neste sistema já destacada quando da análise dos dados de retenção de água. Nas demais profundidades cabe destacar apenas a maior Car do PC a $20 \mathrm{~cm}$, situação que contradiz a maior densidade do solo obtida nesta profundidade para este sistema. De qualquer modo, estes valores estão acima do índice de 5\%, considerado crítico para a aeração por THOMASSON (1978), e estão também acima daqueles obtidos por SARVASI (1994) em latossolo roxo com sistemas de preparo semelhantes a estes. Pela equação (4) foi calculada a capacidade de água disponível (Cad) também para as profundidades de $5,10,15,20,25$ e $30 \mathrm{~cm}$. Os resultados obtidos estão na Figura 25. Não se observaram diferenças muito altas entre sistemas de preparo, apenas uma tendência geral de queda nos valores obtidos conforme se aumenta a profundidade de amostragem. Considere que estes valores devam ser visto com certa reserva, pois estão num intervalo que já considera como água disponivel a água retida abaixo da capacidade de campo, mas esta é momentânea, pois ocorrendo drenagem já se altera este valor, que pode ser grande dependendo da umidade na capacidade de campo. 


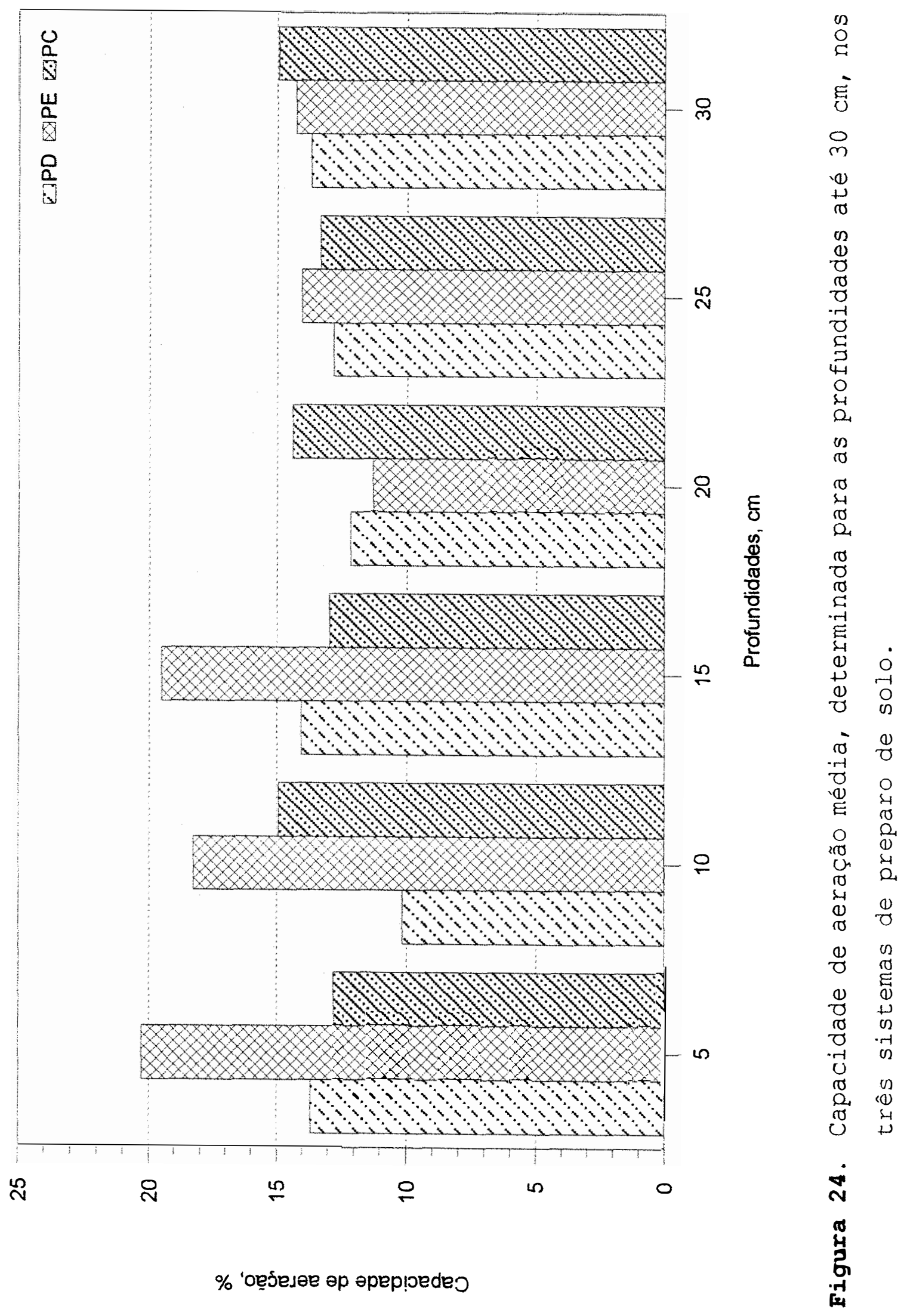


84.

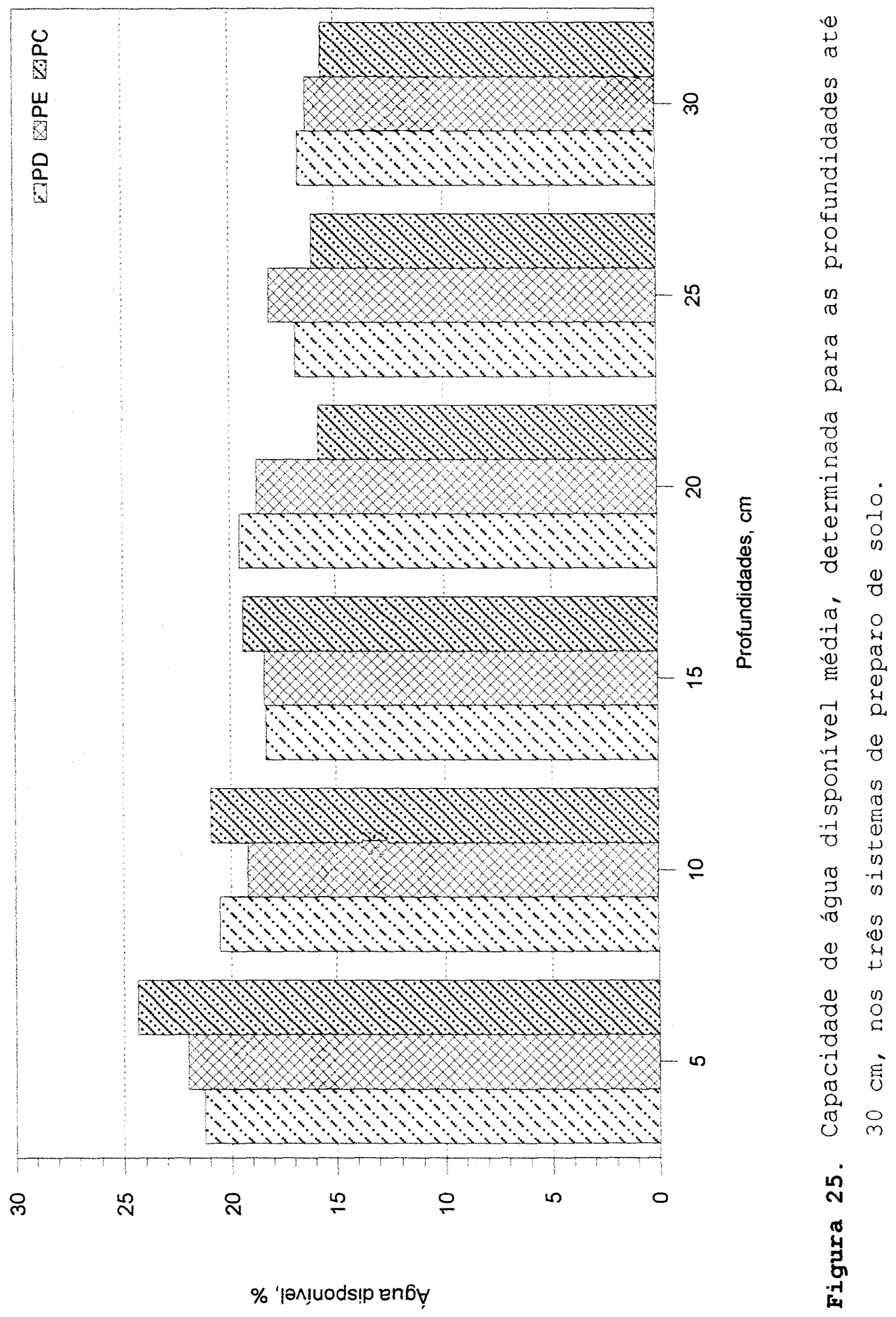


85.

No outro extremo tem-se o valor de $1.500 \mathrm{KPa}$, considerado ponto de murcha permanente, que pode ser atingido em tensões menores dependendo da planta e condição de perda de água.

Os conceitos de car e cad anteriormente discutidos, são mais bem interpretados quando analisados de forma conjunta. THOMASSON (1978), propôs uma forma de classificação da condição estrutural do solo, onde os dados de Car e Cad são confrontados em um gráfico composto por faixas de qualificação com os conceitos de pobre, regular, bom e muito bom. Nas Figuras 26, 27 e 28 são apresentados os gráficos obtidos respectivamente para O PD, PE e PC.

$\mathrm{Na}$ Figura 26 verifica-se que o sistema de plantio direto teve, em todas as profundidades estudadas, um indice classificado como bom, sendo que o valor obtido para $10 \mathrm{~cm}$ está no limite de bom para regular. Esta situação revela a necessidade de se adotar medidas para aumentar a Car nesta camada, como uma escarificação superficial, por exemplo. Os demais pontos, especialmente aqueles abaixo de $10 \mathrm{~cm}$, estão mais agrupados, o que revela uma condição de homogeneidade proporcionada por este tipo de preparo.

O preparo do solo com arado escarificador levou a uma distribuição dos pontos mais dispersa que $O$ PD, conforme se observa na Figura 27 , inclusive com a profundidade $5 \mathrm{~cm}$ caindo na faixa muito bom e as demais na faixa bom. Esta dispersão é normal neste sistema em função do preparo mais grosseiro do solo, com presença de agregados e torrões de diversos tamanhos. 


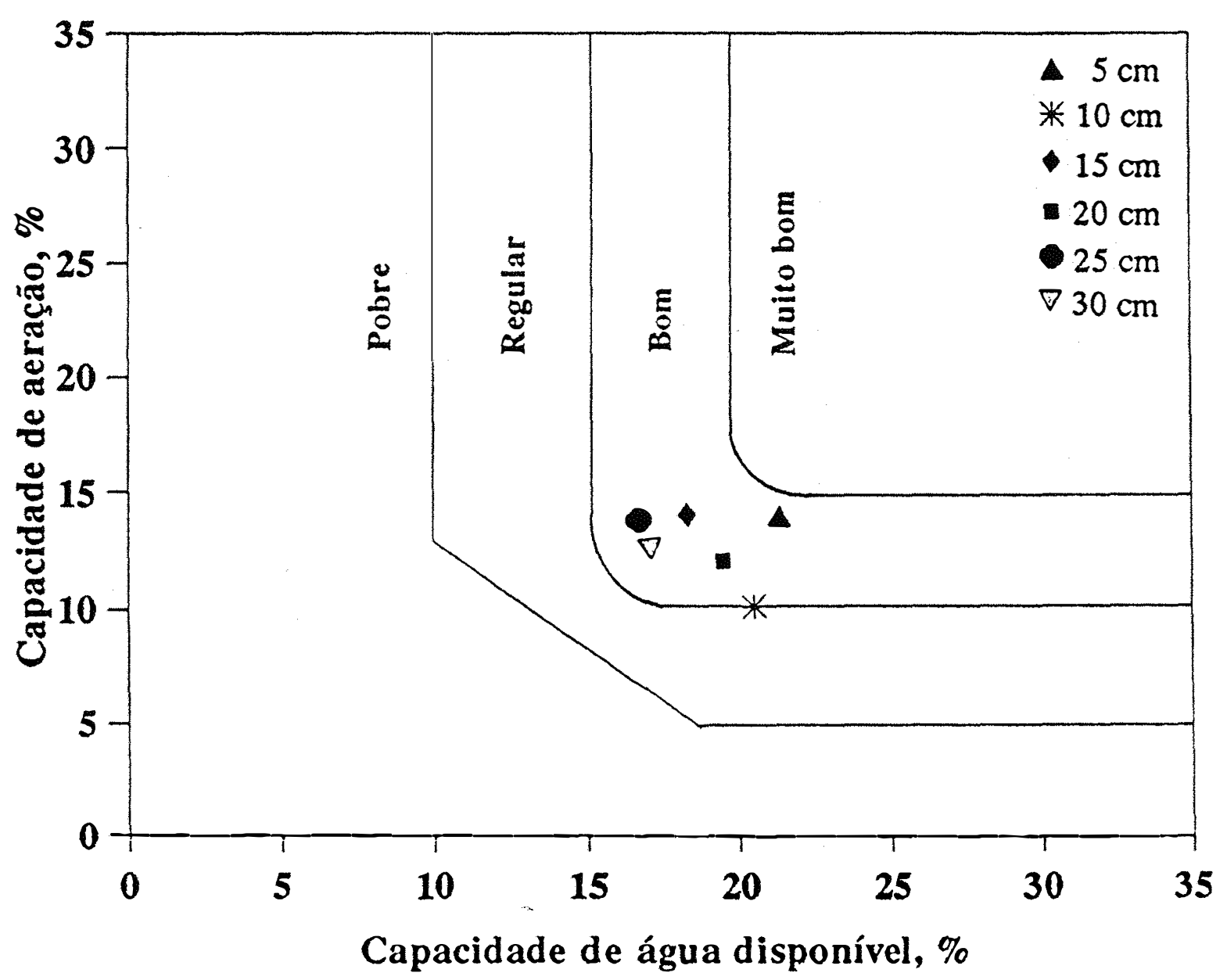

Figura 26. Classificação da condição estrutural do solo, em termos de capacidade de aeração (Car) e de água disponivel (Cad), para o plantio direto. 
87.

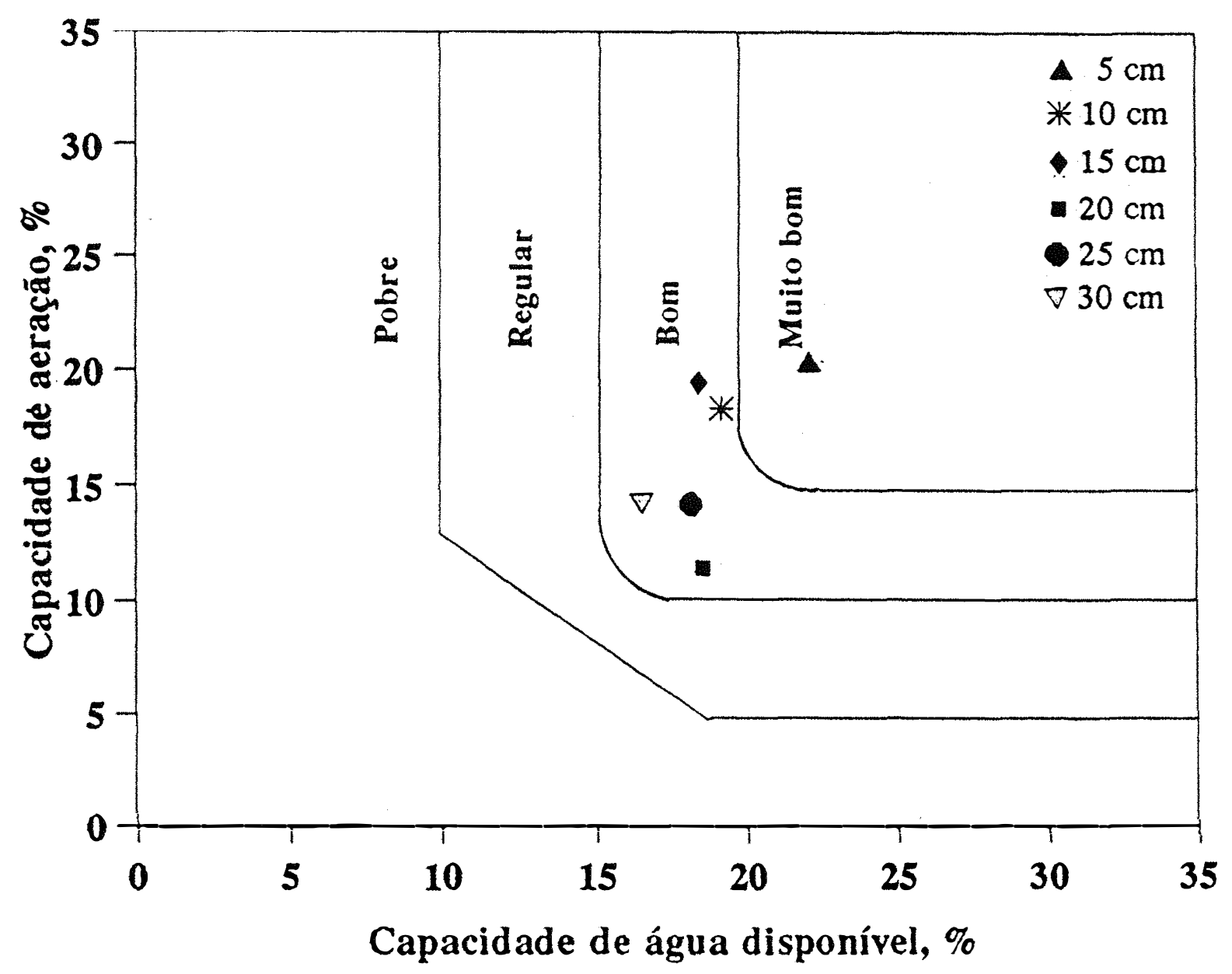

Figura 27. Classificação da condição estrutural do solo, em termos de capacidade de aeração (Car) e de água disponível (Cad), para o preparo com escarificador. 


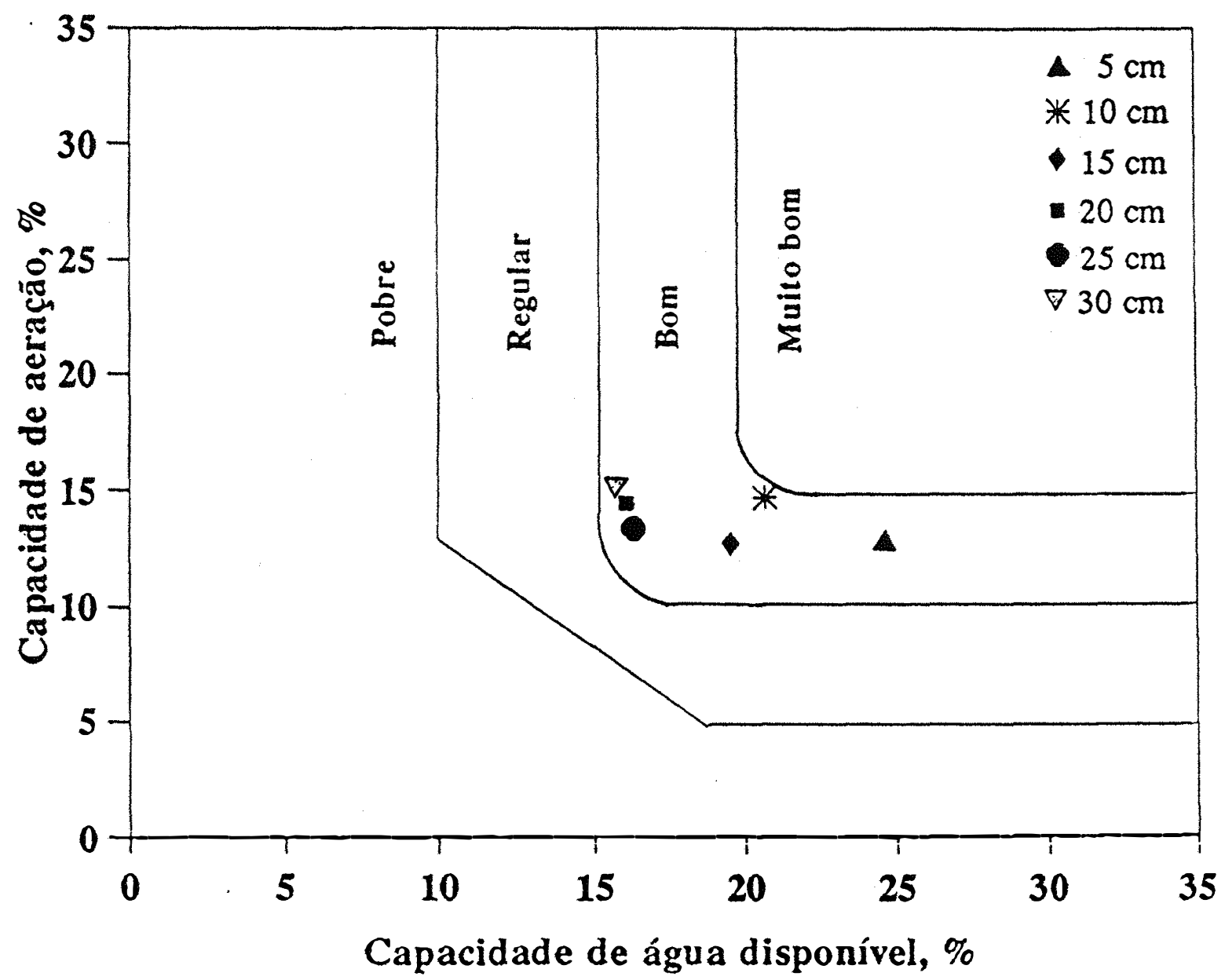

Figura 28. Classificação da condição estrutural do solo, em termos de capacidade de aeração (Car) e de água disponível (Cad), para o preparo convencional. 
O sistema de preparo convencional também apresentou uma dispersão dos pontos obtidos nas profundidades de 5, 10 e $15 \mathrm{~cm}$, conseqüência da desestruturação provocada pelas arações e gradagens. Nas profundidades abaixo de $15 \mathrm{~cm}$ houve um agrupamento próximo do limite de bom para regular, que reflete a homogeneidade destas camadas e pode ser conseqüência do "pé-de-arado". Resultados semelhantes foram obtidos por SARVASI (1994), com estes sistemas de preparo. Esta situação obtida no PC revela que a continuidade deste sistema de preparo pode levar a uma mudança da classe bom para regular, quando então outro sistema de preparo deve ser utilizado para recuperar a estrutura deste solo. Pelo resultados apresentados no $\mathrm{PE}$, este pode ser uma alternativa para "consertar" os efeitos do uso contínuo do arado de discos.

Como a utilização desta classificação nas condições deste trabalho é recente, pode ser que, com seu uso, os valores que separam as diferentes classes possam ser modificados. No presente trabalho já se verificou que, abaixo de $15-20 \mathrm{~cm}$, o crescimento radicular e a infiltração de água no solo foram prejudicadas no PC, fruto talvez desta homogeneidade mais compacta apresentada na Figura 28, que está no limite para a classe regular. Dessa forma, a associação de efeitos na planta e na dinâmica da água podem levar a mudanças nos valores de separação de classes destes solos, dando mais segurança para sugerir medidas de recuperação do solo, quando possível. 


\subsection{Condutividade hidráulica da água do solo}

A determinação da condutividade hidráulica pelo método de HILLEL et al. (1972) permite que se obtenham outras informações sobre a dinâmica da água no solo a partir dos dados que são obtidos nos cálculos até se chegar na função $K(\boldsymbol{\theta})$. Nos Apêndices 10, 11 e 12 estão os valores das leituras obtidas nas três baterias de tensiômetros instaladas em cada parcela de inundação, para cada tratamento. As determinações realizadas a partir dos parâmetros de GENUCHTEN \& NIELSEN (1985) e das leituras dos tensiômetros instalados na parcela de inundação estão colocadas nos Apêndices 13, 14 e 15, respectivamente para O PD, PE e PC.

Uma relação que se obtém neste processo é de $\theta$ em função do tempo, caracterizando a drenagem de água no solo. Na profundidade de $10 \mathrm{~cm}$ (Eigura 29) observou-se uma umidade de saturação, no tempo zero, maior no PE e PC que no PD, conseqüência da estrutura já discutida em outros pontos. Mas, na estabilização, os valores de $\theta$ no PD foram maiores que no PC, refletindo maior retenção de água. Nas profundidades de $20 \mathrm{~cm}$ (Figura 30 ) e de $30 \mathrm{~cm}$ (Figura 31 ) não houve diferenciação entre as curvas dos três sistemas de preparo, apesar das diferenças de estrutura verificadas anteriormente. Nas demais profundidades, apresentadas nas Figuras 32,33 e 34, O PD nitidamente se estabilizou com uma umidade mais alta que os demais, embora nestas profundidades seja dificil encontrar uma razão para explicar tais diferenças como resultado dos sistemas de preparo do solo. 
91.

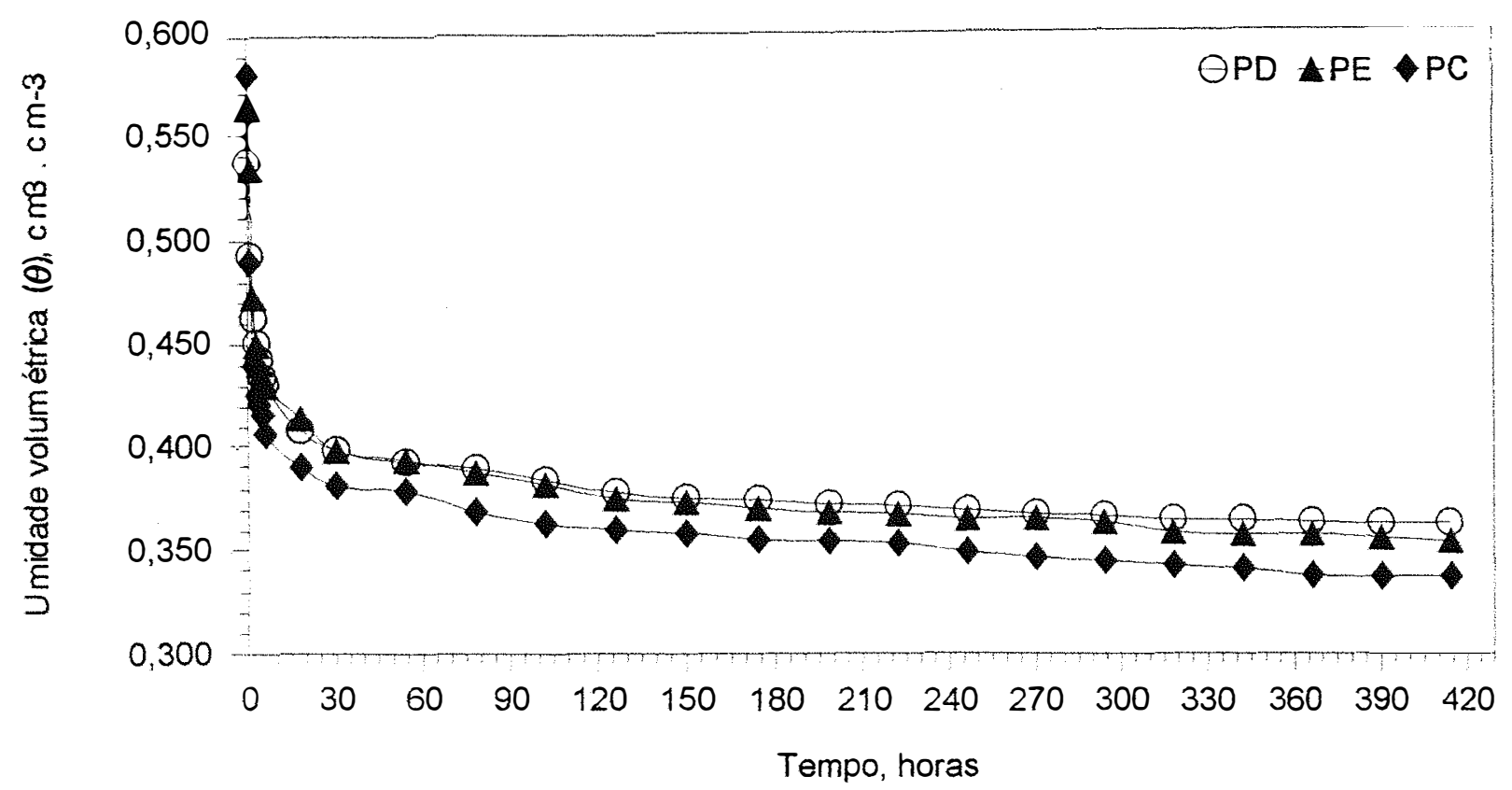

Figura 29. Umidade volumétrica $(\theta)$, em função do tempo de drenagem, para os três sistemas de preparo de solo, na profundidade de $10 \mathrm{~cm}$.

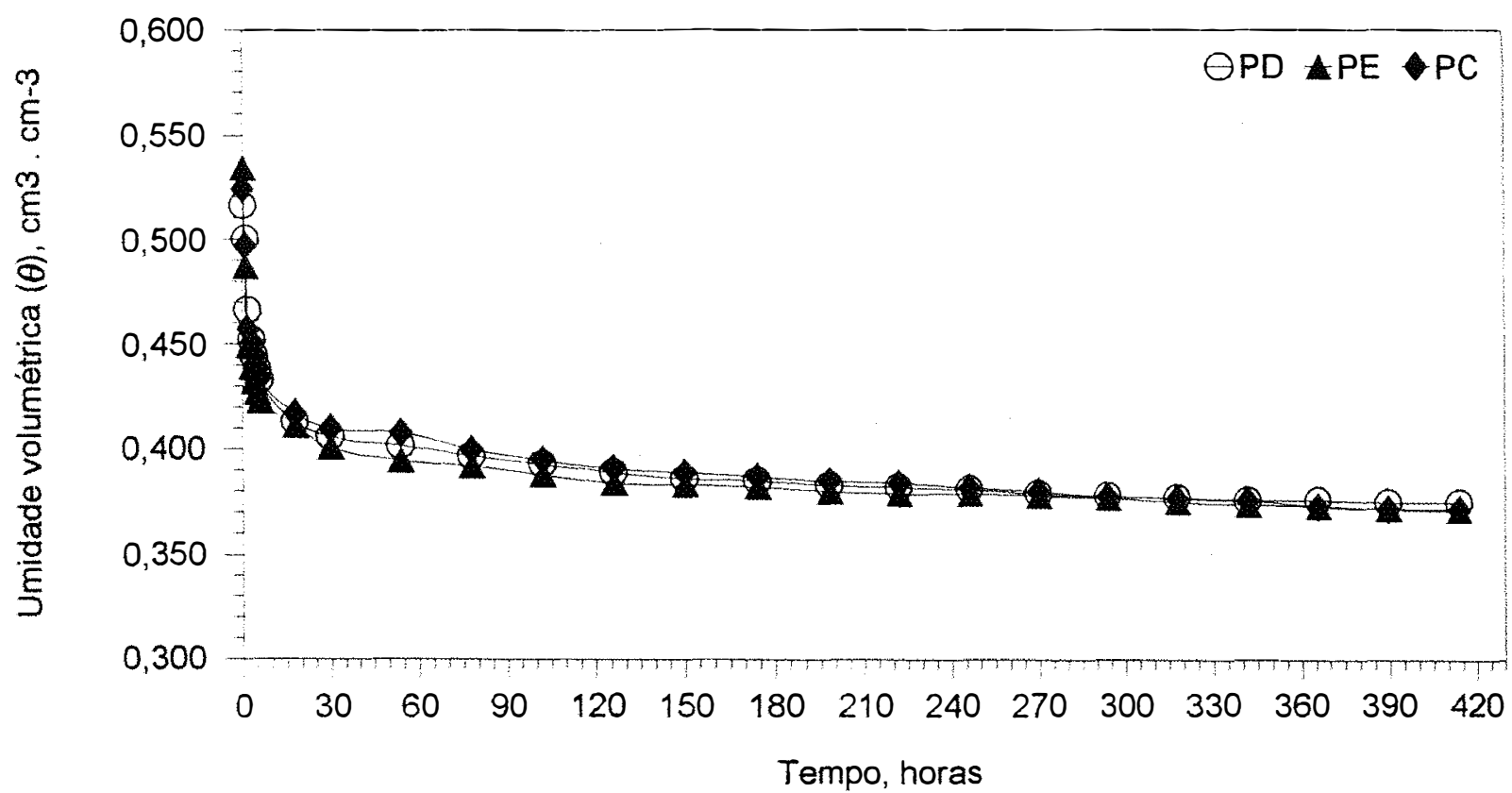

Figura 30. Umidade volumétrica $(\boldsymbol{\theta})$, em função do tempo de drenagem, para os três sistemas de preparo de solo, na profundidade de $20 \mathrm{~cm}$. 


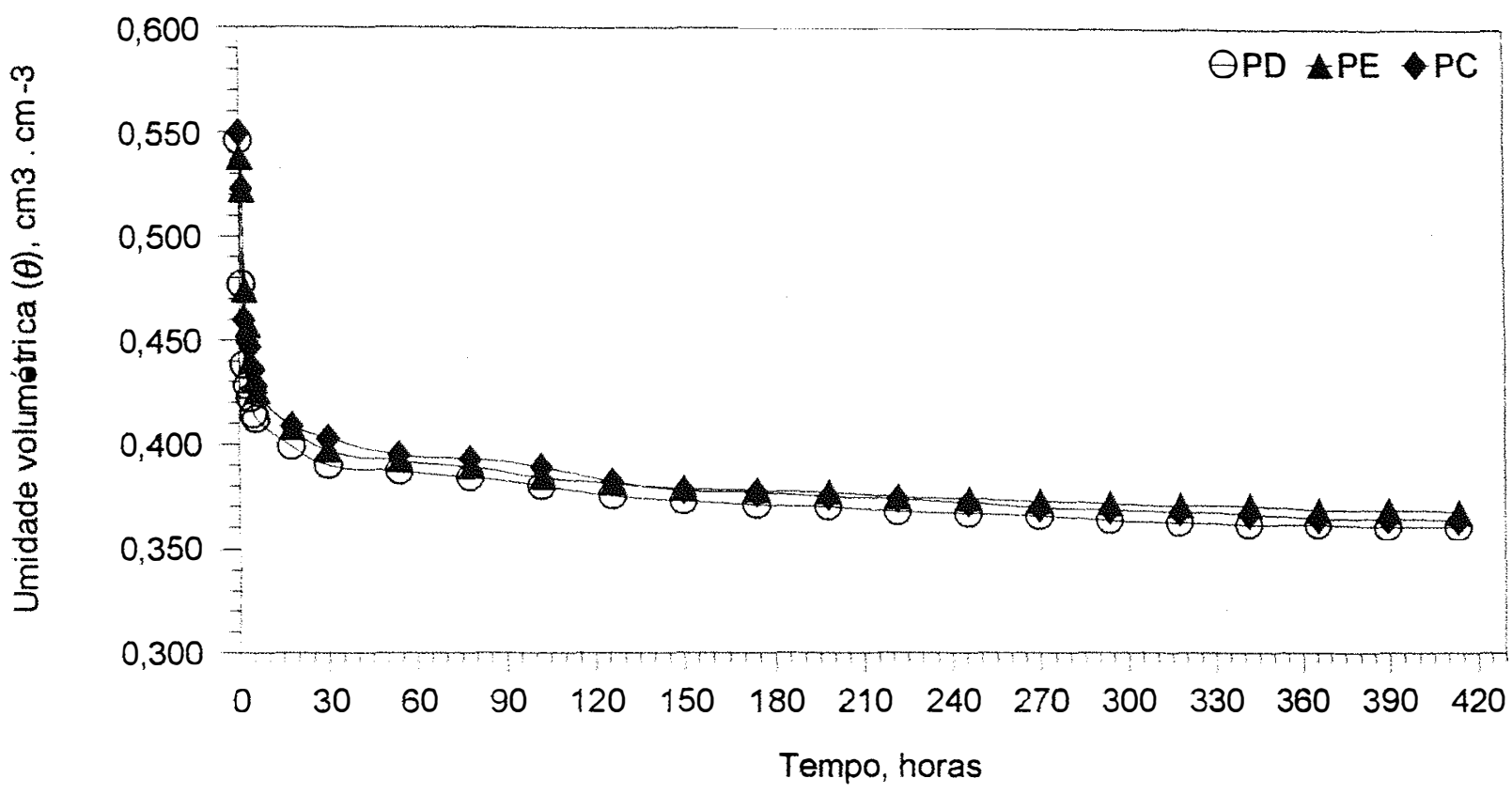

Figura 31. Umidade volumétrica $(\boldsymbol{\theta})$, em função do tempo de drenagem, para os três sistemas de preparo de solo, na profundidade de $30 \mathrm{~cm}$.

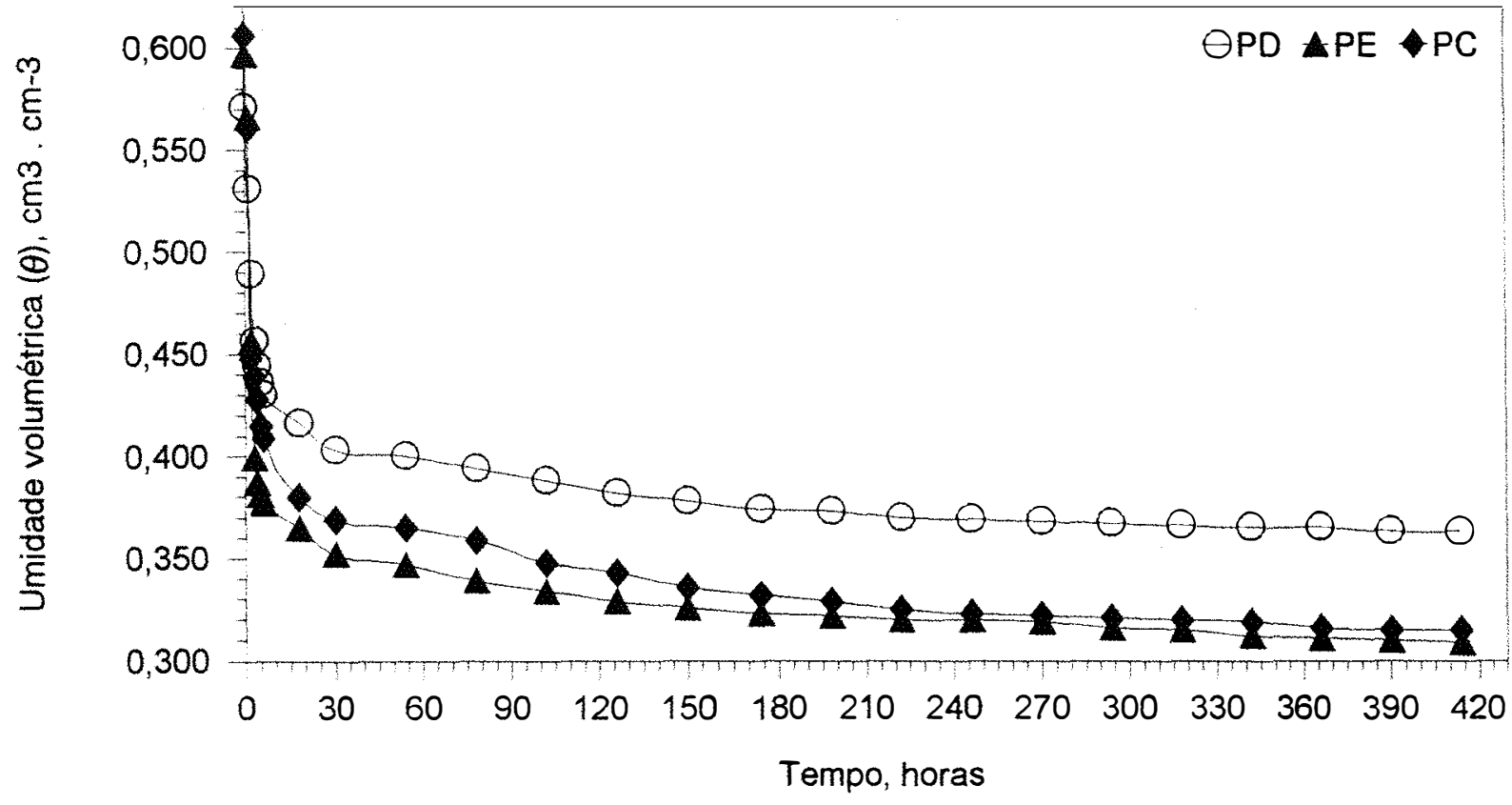

Figura 32. Umidade volumétrica $(\boldsymbol{\theta})$, em função do tempo de drenagem, para os três sistemas de preparo de solo, na profundidade de $60 \mathrm{~cm}$. 
93.

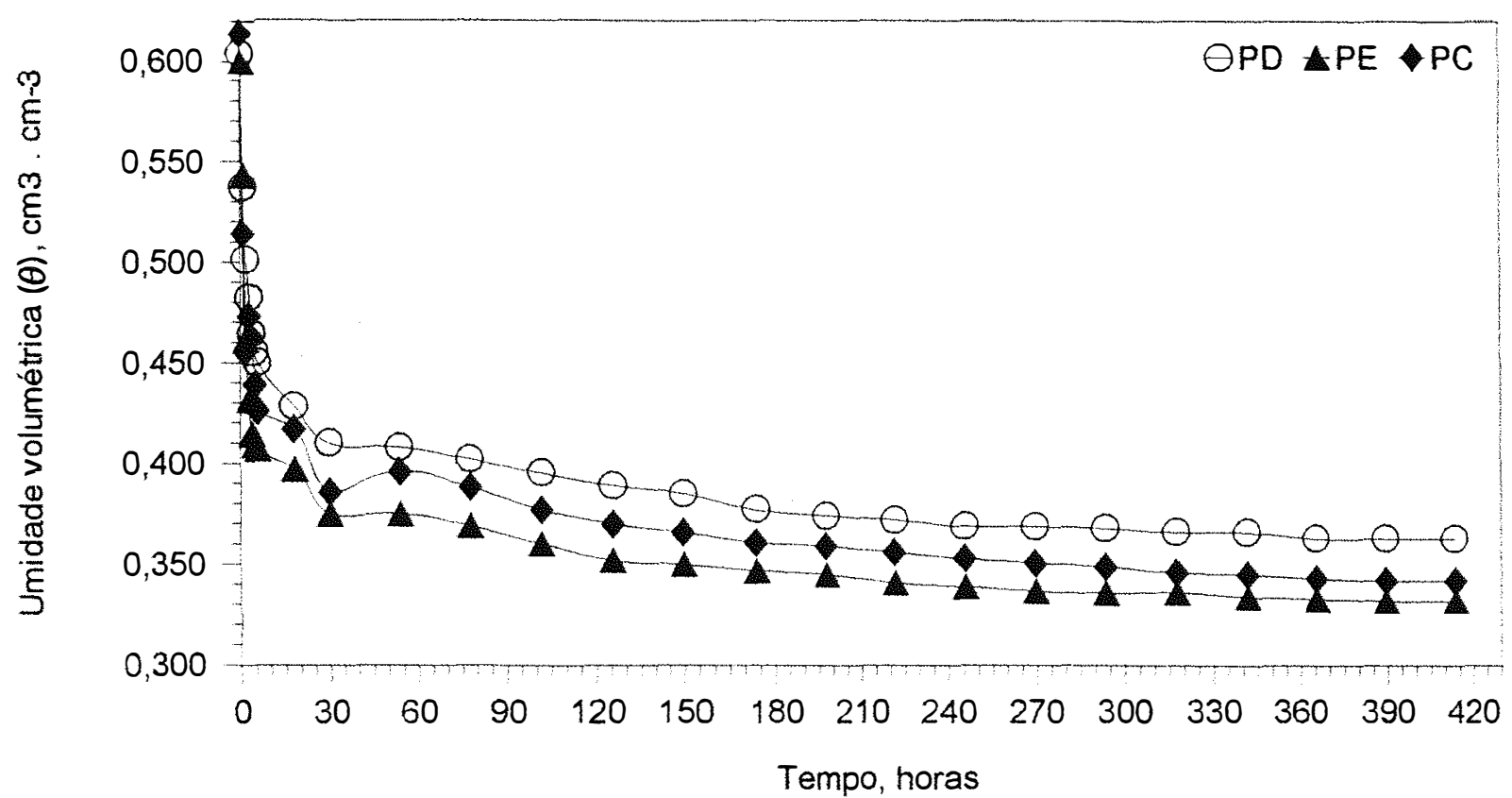

Figura 33. Umidade volumétrica $(\theta)$, em função do tempo de drenagem, para os três sistemas de preparo de solo, na profundidade de $90 \mathrm{~cm}$.

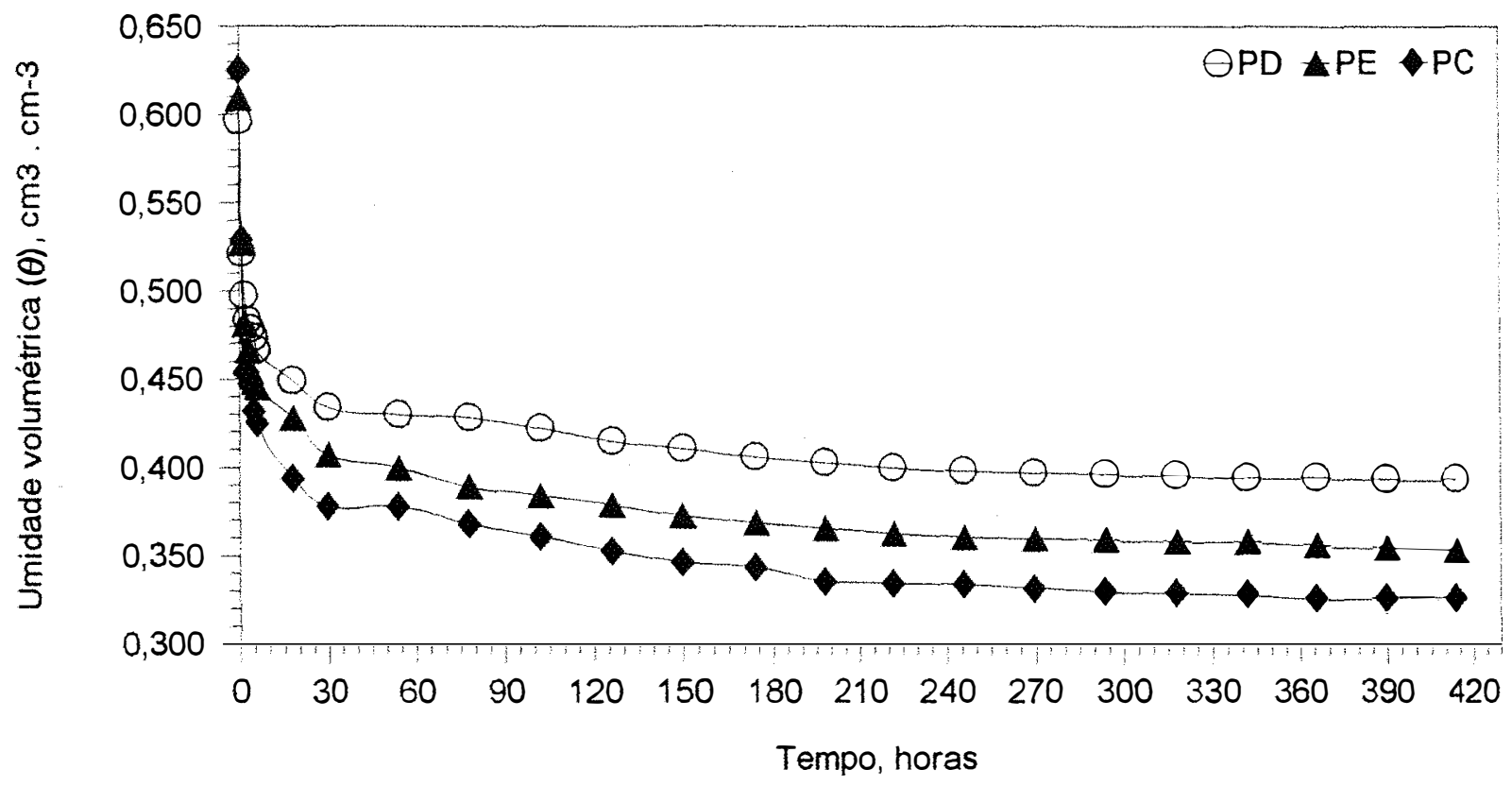

Figura 34. Umidade volumétrica $(\boldsymbol{\theta})$, em função do tempo de drenagem, para os três sistemas de preparo de solo, na profundidade de $120 \mathrm{~cm}$. 
- que se observa numa análise geral destas figuras é uma pequena variação na parte final da curva para - PD, O que revela a maior homogeneidade deste tratamento, diferente do que mostram SIDIRAS et al. (1984) também em latossolo roxo onde se observou grande diferenciação entre PD e PC e entre camadas do mesmo tratamento.

A relação de $\theta$ com 0 tempo ao longo de todo 0 perfil, pode ser mais bem caracterizada colocando todas as profundidades juntas em cada sistema de preparo do solo. o perfil de umidade do PD, apresentado na Figura 35 mostrou uma concavidade para a direita entre 10 e $30 \mathrm{~cm}$, 0 que indica maior retenção de água nesta camada. Abaixo dos $30 \mathrm{~cm}$ houve a tendência de maior retenção em profundidade de maneira bem homogênea, semelhante aos resultados de SIDIRAS et al. (1984). Os perfis obtidos para O PE (Eigura 36) e para O PC (Figura 37) apresentaram mudança de sentido das curvas na fase inicial, na $1 .^{\circ}$ e $2 .^{\circ}$ horas, para depois definir também uma curvatura à direita nas camadas mais superficiais e nas profundidades maiores um comportamento irregular, indicando uma descontinuidade estrutural que afeta $\circ$ fluxo de drenagem ao longo do perfil.

Ao se determinar a condutividade hidráulica (K) em função do tempo, e tendo a umidade volumétrica $(\boldsymbol{\theta})$ correspondente, pode-se fazer a relação $K$ em função de $\theta$ para cada profundidade estudada. 


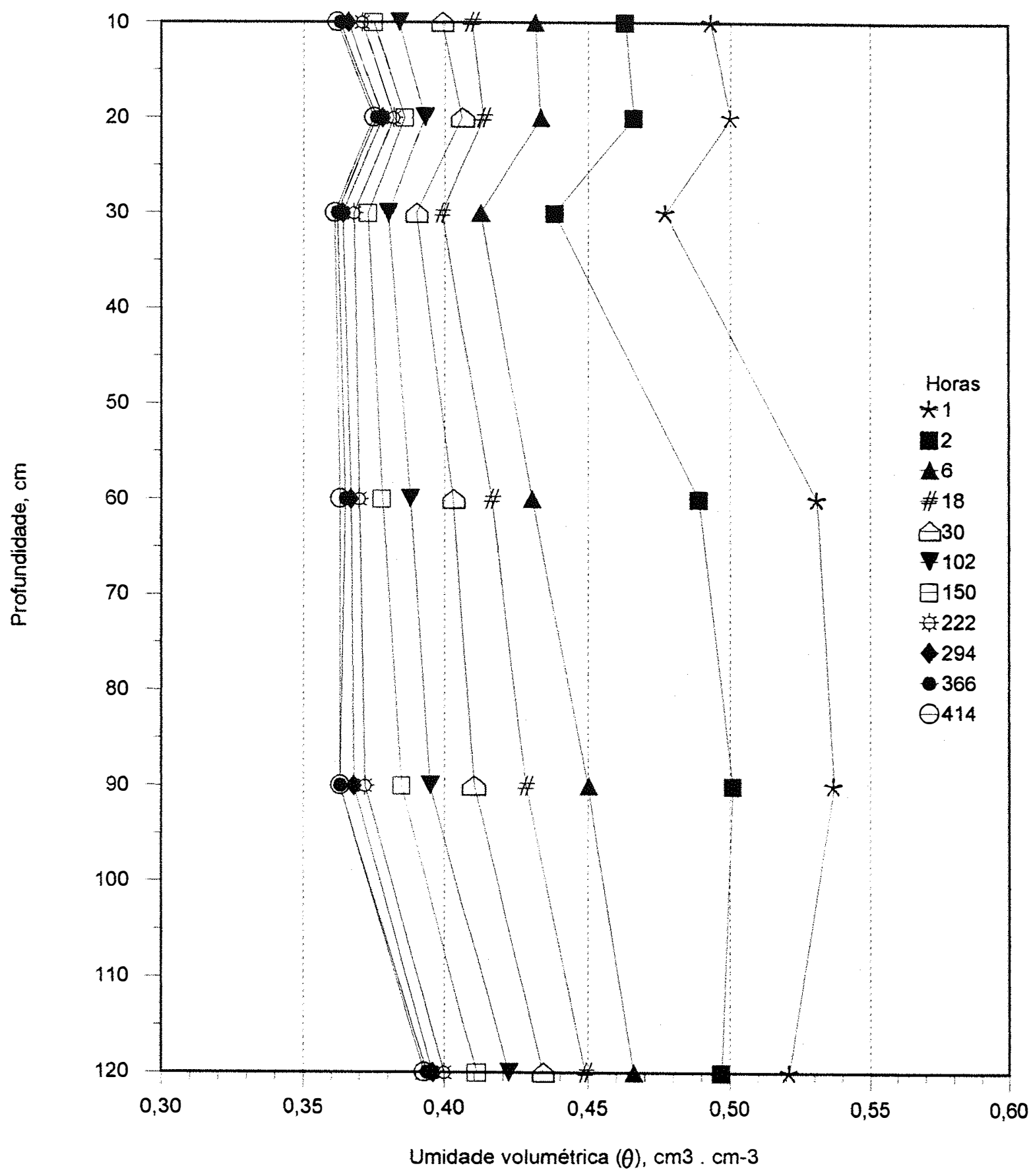

Figura 35. Perfil de umidade do solo no sistema de plantio direto, em vários tempos e após inundação. 


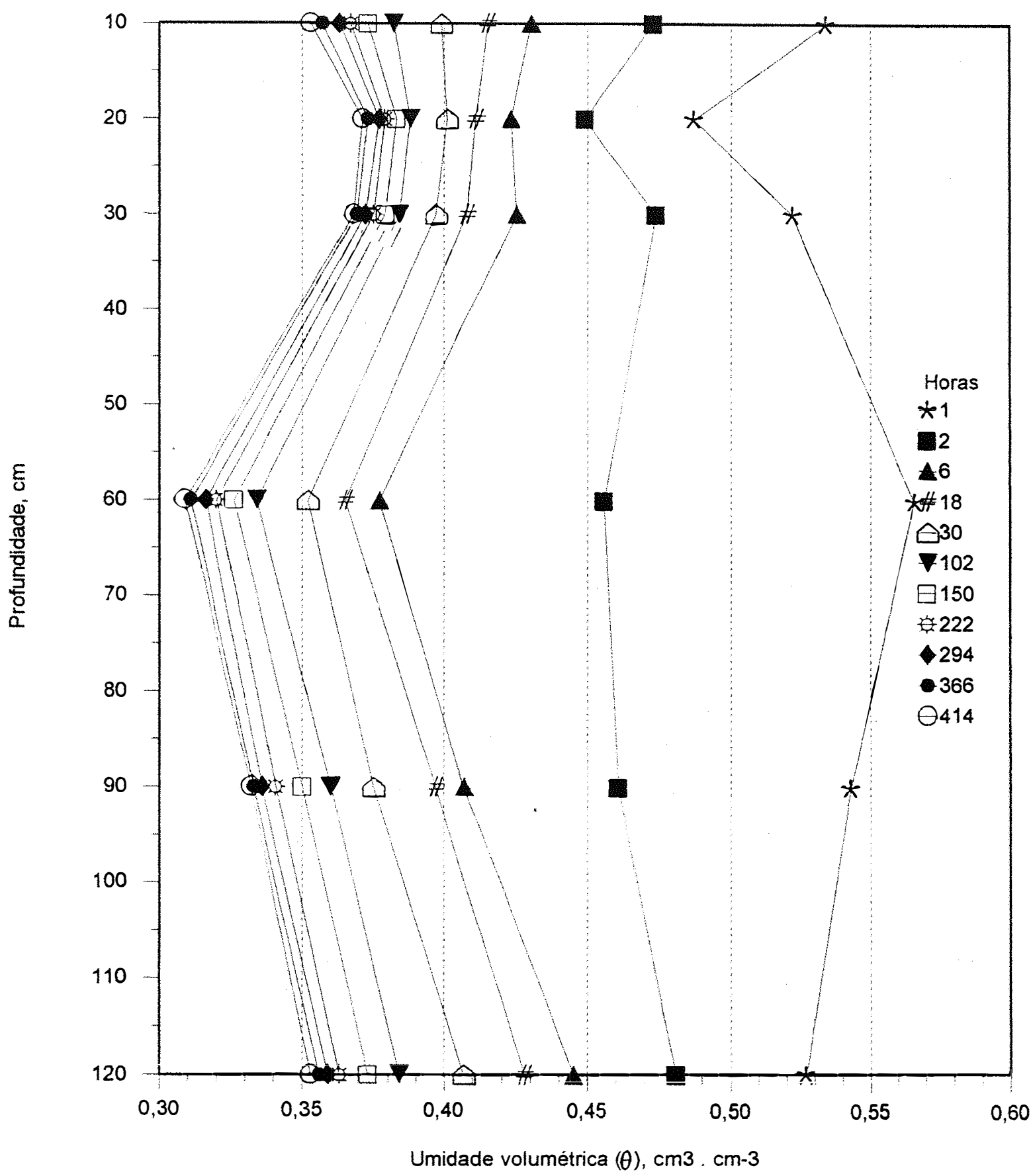

Figura 36. Perfil de umidade do solo no sistema de preparo com escarificador, em vários tempos e após inundação. 


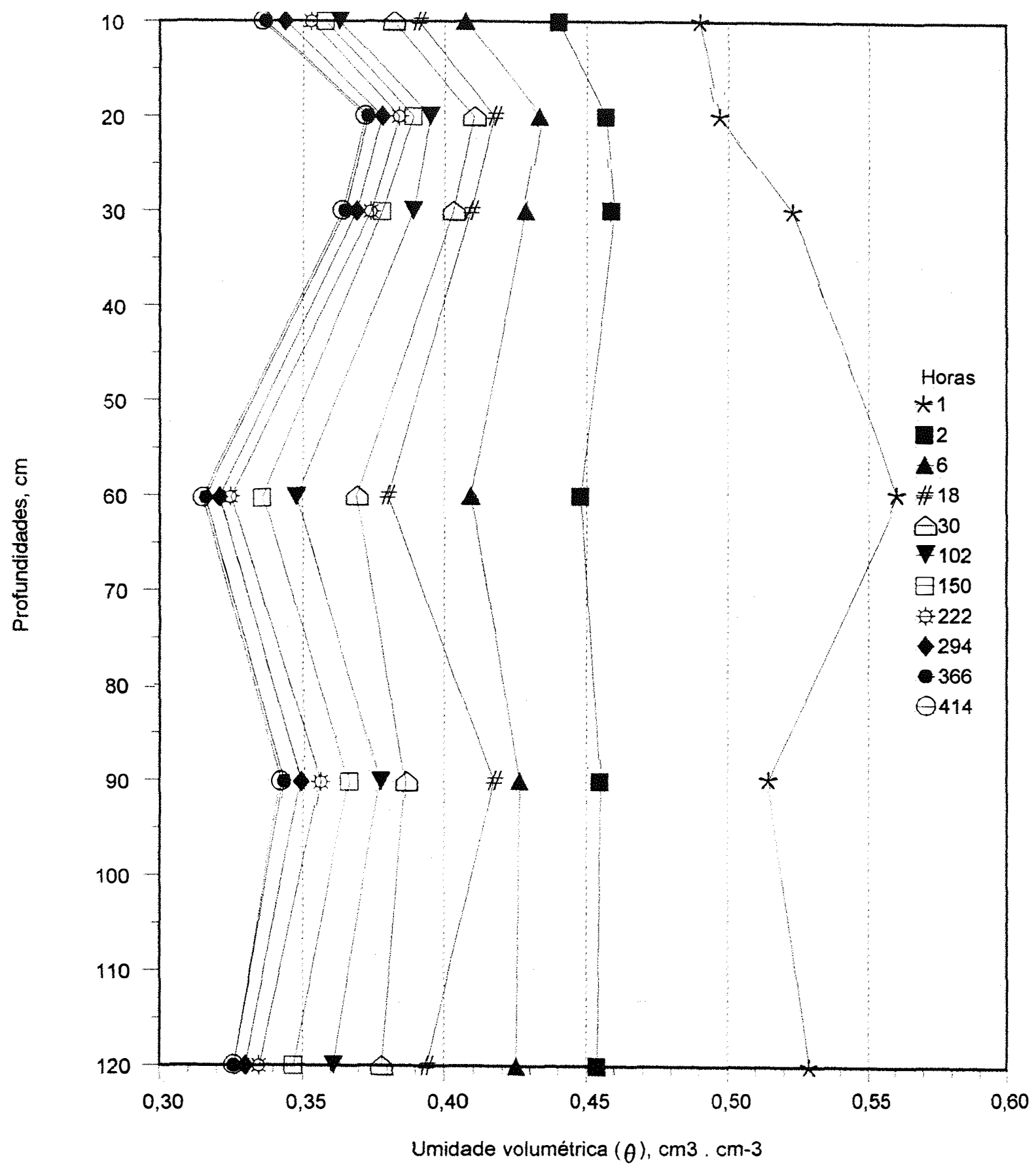

Figura 37. Perfil de umidade do solo no sistema de preparo convencional, em vários tempos e após inundação. 
Nas Figuras 38, 39, 40,41, 42 e 43 estão colocadas as curvas de $K(\theta)$ com os dados determinados para cada profundidade. O que se observa nas Figuras 38, 39 e 40, que representam, respectivamente, as profundidades 10,20 e $30 \mathrm{~cm}$ é uma pequena diferenciação entre tratamentos na condutividade hidráulica. Embora a diferença entre tratamentos seja pequena, na Figura $38 \circ$ PC apresentou valores mais altos de $K$ para um mesmo $\theta$ até este chegar a $0,50 \mathrm{~cm}^{3} \cdot \mathrm{cm}^{-3}$, quando então $\circ \mathrm{PD}$ apresentou maior valor de K. Como a densidade do solo foi maior no PD nesta profundidade (Tabela 9) pode-se considerar que isto reduziu - K do solo não saturado, conforme já definido por HILLEL (1971). Isto fica mais claro na profundidade de $60 \mathrm{~cm}$ (Figura 41) onde são evidentes os menores valores de $\mathrm{K}$ para baixos valores de $\theta$ no PD em relação aos demais preparos, mas - $K_{0}$ é igual entre sistemas. Nas profundidades de $90 \mathrm{~cm}$ (Figura 42) e $120 \mathrm{~cm}$ (Figura 43) esta mesma tendência é mantida, porém sem a correspondente diferenciação na densidade do solo como na profundidade de $60 \mathrm{~cm}$.

A partir das relações $K$ versus $\theta$ apresentadas anteriormente se estabeleceu a equação $K(\boldsymbol{\theta})$ para cada profundidade em cada tratamento de preparo, segundo o modelo exponencial apresentado na equação 12 , ou seja:

$$
\mathrm{K}(\boldsymbol{\theta})=\mathrm{K}_{0} \cdot e^{\gamma\left(\boldsymbol{\theta}-\boldsymbol{\theta}_{0}\right)}
$$

Os parâmetros desta equação para cada profundidade nos três sistemas de preparo estão colocados na Tabela 14. 
99.

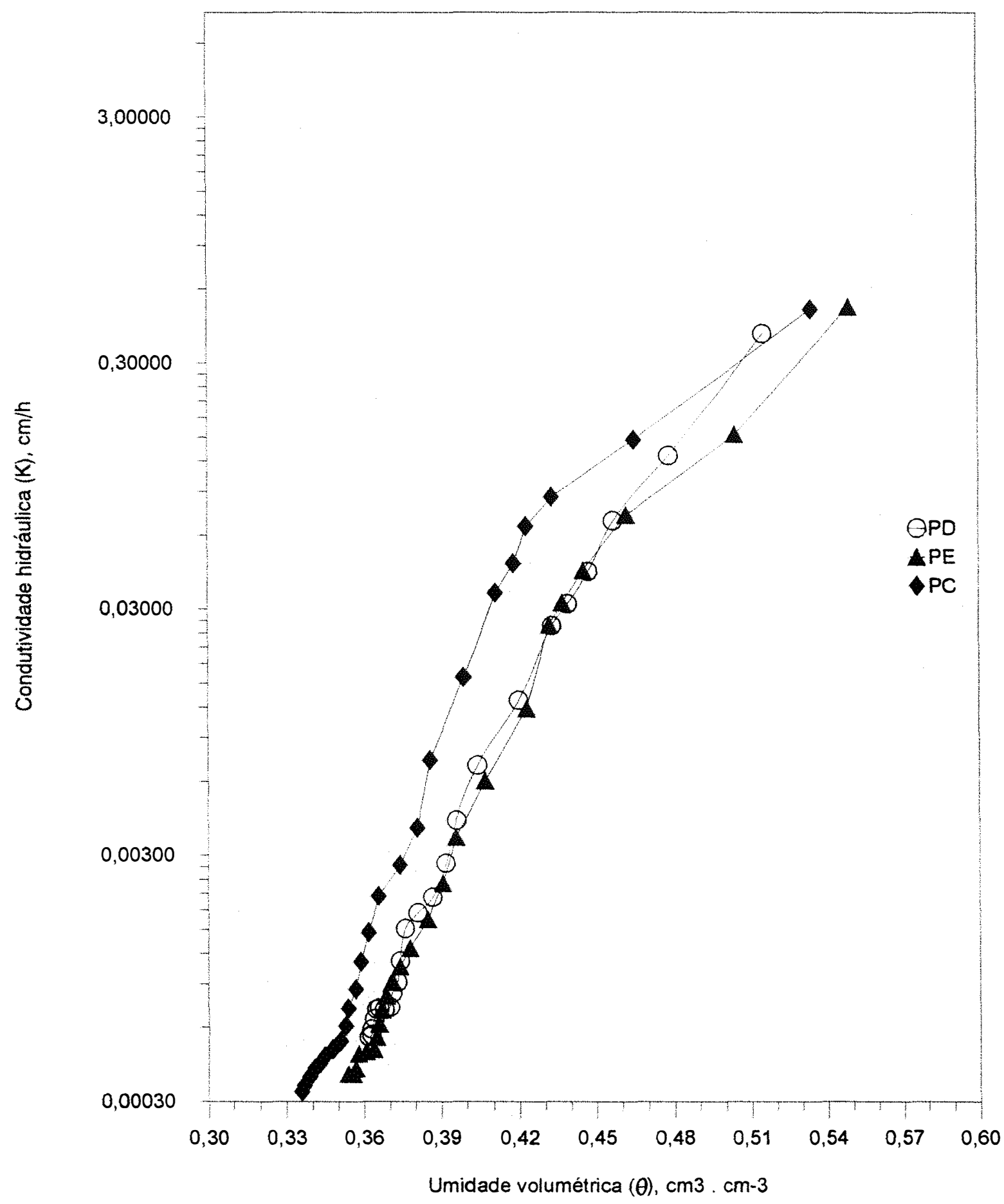

Figura 38. Condutividade hidráulica (K), em função da umidade do solo $(\boldsymbol{\theta})$, para os três sistemas de preparo de solo, na profundidade de $10 \mathrm{~cm}$. 


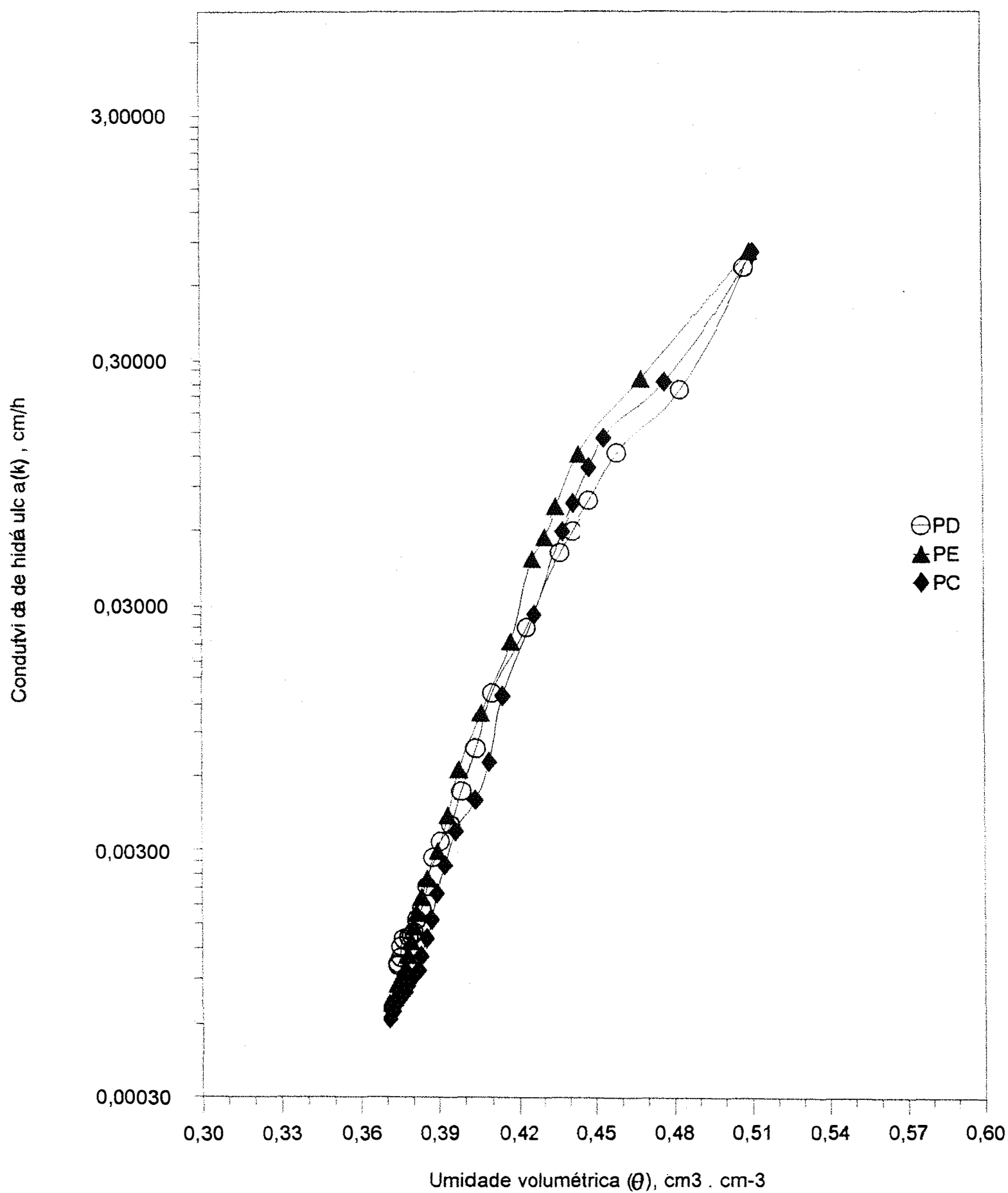

Figura 39. Condutividade hidráulica (K), em função da umidade do solo $(\theta)$, para os três sistemas de preparo de solo, na profundidade de $20 \mathrm{~cm}$. 


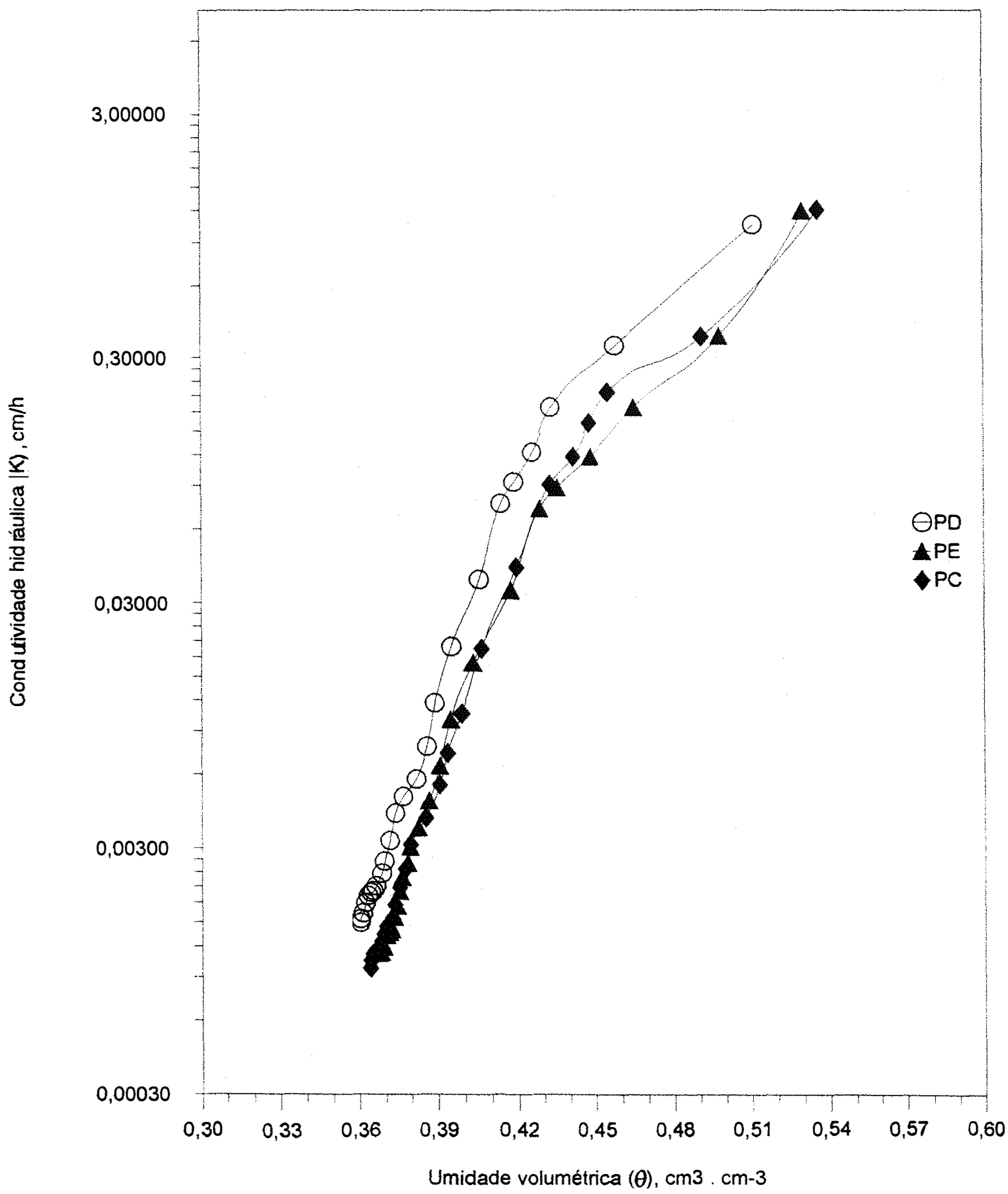

Figura 40. Condutividade hidráulica (K), em função da umidade do solo $(\boldsymbol{\theta})$, para os três sistemas de preparo de solo, na profundidade de $30 \mathrm{~cm}$. 


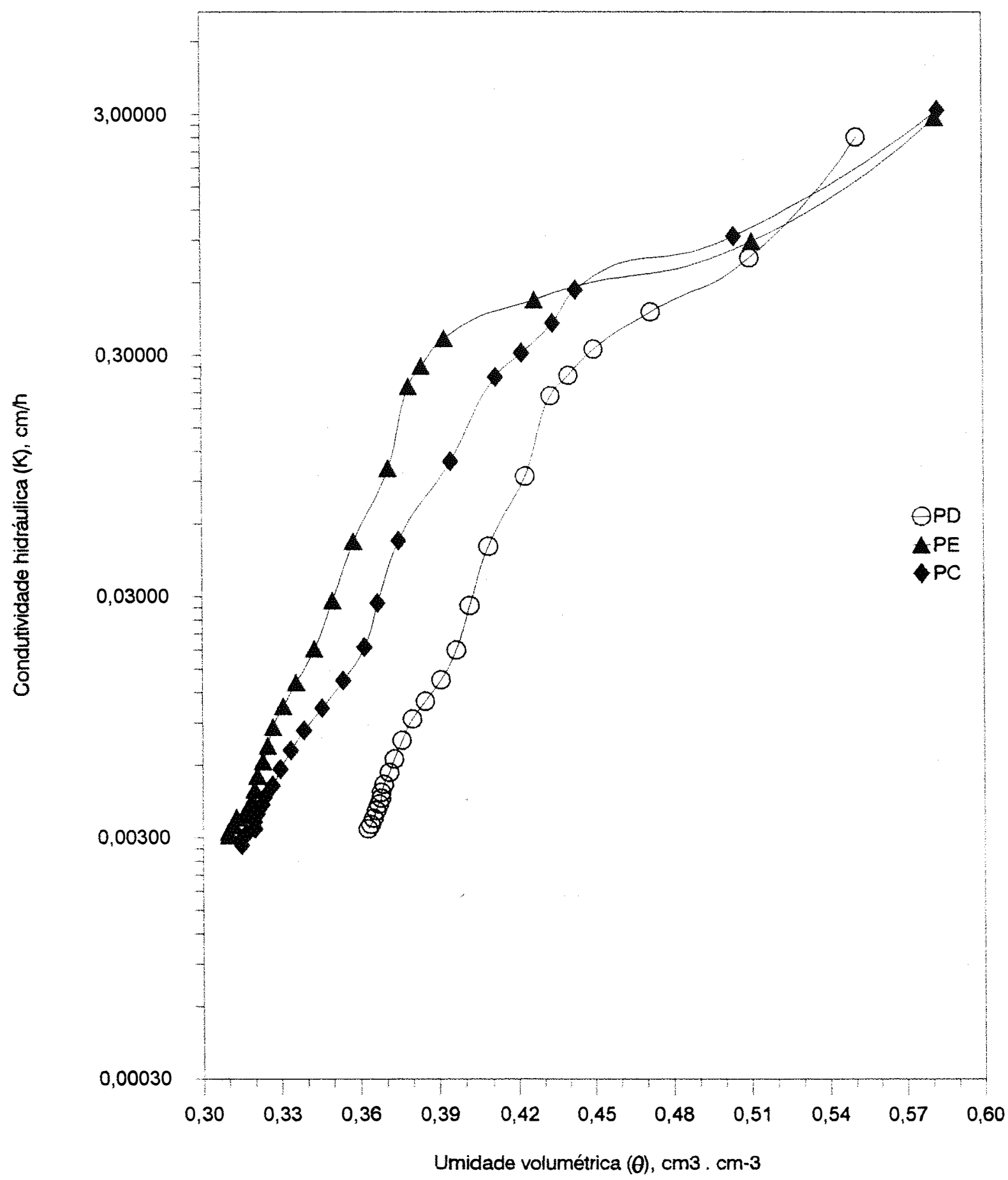

Figura 41. Condutividade hidráulica (K), em função da umidade do solo $(\boldsymbol{\theta})$, para os três sistemas de preparo de solo, na profundidade de $60 \mathrm{~cm}$. 


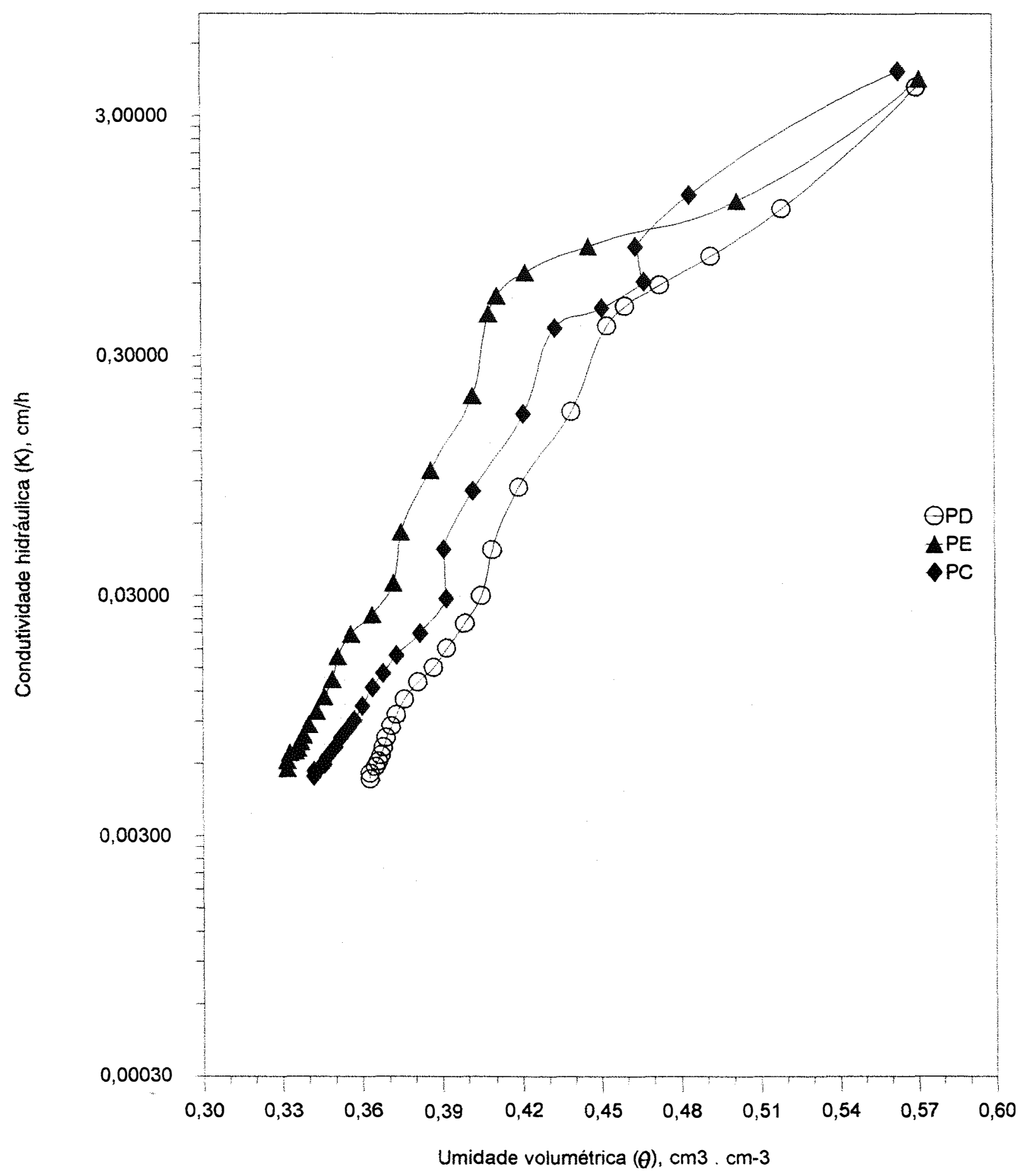

Figura 42. Condutividade hidráulica (K), em função da umidade do solo $(\boldsymbol{\theta})$, para os três sistemas de preparo de solo, na profundidade de $90 \mathrm{~cm}$. 


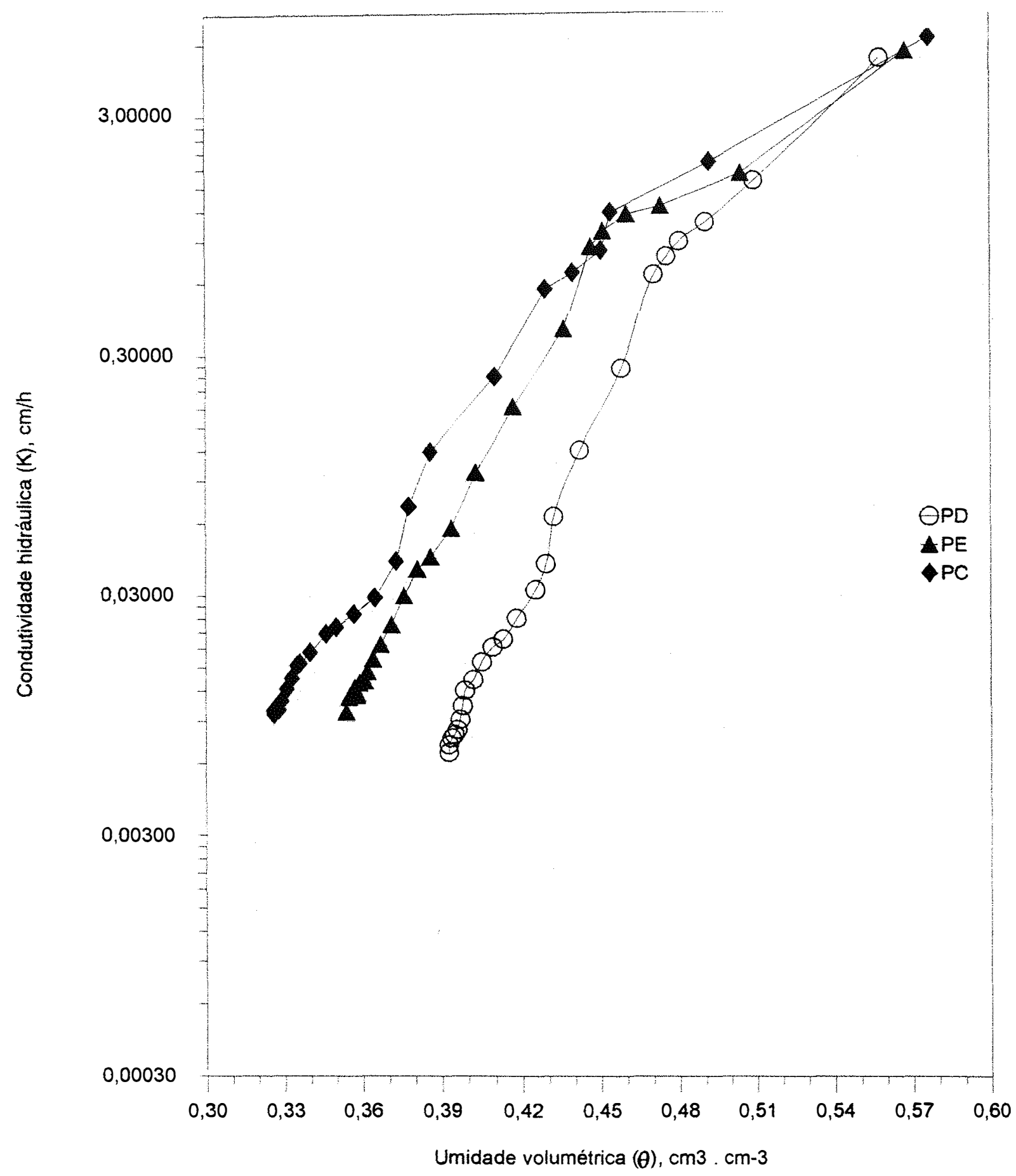

Figura 43. Condutividade hidráulica (K), em função da umidade do solo $(\boldsymbol{\theta})$, para os três sistemas de preparo de solo, na profundidade de $120 \mathrm{~cm}$. 
105.

Tabela 14. Parâmetros da equação $K(\boldsymbol{\theta})$ e $r^{2}$, para cada profundidade, nos três sistemas de preparo de solo.

\begin{tabular}{|c|c|c|c|c|c|c|c|}
\hline \multirow{2}{*}{$\begin{array}{l}\text { Sistemas } \\
\text { de } \\
\text { Preparo }\end{array}$} & & \multicolumn{6}{|c|}{ Profundidade, $\mathrm{cm}$} \\
\hline & & 10 & 20 & 30 & 60 & 90 & 120 \\
\hline \multirow{4}{*}{ PD } & $\gamma$ & 46,7762 & 52,5370 & 52,0055 & 39,0911 & 35,7123 & 46,0513 \\
\hline & $\theta_{0}$ & 0,537 & 0,551 & 0,551 & 0,581 & 0,606 & 0,604 \\
\hline & $\mathrm{K}_{0}$ & 2,3254 & 13,2814 & 41,2989 & 23,7545 & 41,0458 & 147,8826 \\
\hline & $r^{2}$ & 0,9834 & 0,9768 & 0,9271 & 0,9366 & 0,9602 & 0,9616 \\
\hline \multirow{4}{*}{$P E$} & $\gamma$ & 41,7077 & 59,2054 & 46,7026 & 28,6767 & 32,4957 & 34,8198 \\
\hline & $\theta_{0}$ & 0,576 & 0,558 & 0,562 & 0,637 & 0,602 & 0,609 \\
\hline & $\mathrm{K}_{0}$ & 4,8912 & 58,0853 & 14,5846 & 71,2231 & 61,6564 & 97,6086 \\
\hline & $r^{2}$ & 0,9599 & 0,9498 & 0,9407 & 0,8215 & 0,8753 & 0,9394 \\
\hline \multirow{4}{*}{ PC } & $\gamma$ & 45,1836 & 59,5452 & 47,9788 & 30,7495 & 35,8217 & 30,2975 \\
\hline & $\theta_{0}$ & 0,588 & 0,542 & 0,561 & 0,613 & 0,615 & 0,630 \\
\hline & $K_{0}$ & 38,4591 & 17,3642 & 17,8749 & 40,9477 & 109,3835 & 120,2322 \\
\hline & $r^{2}$ & 0,9178 & 0,9674 & 0,9361 & 0,9175 & 0,9598 & 0,9525 \\
\hline
\end{tabular}

$\theta_{0}: \mathrm{cm}^{3} \cdot \mathrm{cm}^{-3}$

$\mathrm{K}_{\mathrm{n}}: \mathrm{cm} \cdot \mathrm{h}^{-1}$ 
Inicialmente se observa um $r^{2}$ superior a 0,9 , exceto para as profundidades de 60 e $90 \mathrm{~cm}$ do $\mathrm{PE}$, o que garante uma precisão alta para os parâmetros obtidos. Comparando-se os valores de condutividade hidráulica saturada $\left(K_{0}\right)$ entre tratamentos, observa-se que $O P D$ e $P E$ apresentaram valores menores que $O$ PC na profundidade de $10 \mathrm{~cm}$, sendo que $O P D$ a $20 \mathrm{~cm}$ apresenta 0 valor mais baixo, para superar os demais a $30 \mathrm{~cm}$. Este menor $\mathrm{Ko}$ do $\mathrm{PD}$ nas camadas superficiais de certo modo contradiz a melhor infiltração deste sistema apresentado na Tabela 12 e também os vários trabalhos já citados anteriormente, que definem este sistema como o mais eficiente no controle da erosão hídrica, que ocorre em condições de solo saturado. Acontece que, num processo de infiltração a partir da superfície, outros fatores interferem, principalmente o encrostamento superficial pelo impacto das gotas de chuvas, como destacado por ROTH et al. (1988) e ARZENO (1990) em trabalhos com chuva simulada. Além disso, até que ocorra a saturação, quem rege o processo é a condutividade com o solo não saturado $(K)$ e pela Tabela 15, verifica-se que até $60 \mathrm{~cm}$ de profundidade $O P D$ apresentou uma superioridade acima de $50 \%$ em relação ao PC para $\circ K(\boldsymbol{\theta})$, na umidade de capacidade de campo. Isto significa que no PD, devido a melhor condutividade, o solo demora mais tempo para saturar e portanto para iniciar o escorrimento superficial. Isto é evidenciado em curvas de infiltração com chuva simulada como de ROTH \& MEYER (1983), DERPSCH et al. (1986) e ARZENO (1990). 
Tabela 15. Valores de condutividade hidráulica na capacidade de campo ( $\mathrm{KCC})$, em $\mathrm{cm} \cdot \mathrm{h}^{-1}$ para os três sistemas de preparo do solo, em cada profundidade.

\begin{tabular}{|c|c|c|c|c|c|c|}
\hline \multirow{2}{*}{$\begin{array}{c}\text { Sistemas } \\
\text { de } \\
\text { Preparo }\end{array}$} & \multicolumn{6}{|c|}{ Profundidade, $\mathrm{cm}$} \\
\hline & 10 & 20 & 30 & 60 & 90 & 120 \\
\hline & \multicolumn{6}{|c|}{$\mathrm{Kcc}, \mathrm{cm} \cdot \mathrm{h}^{-1}$} \\
\hline$P D$ & 0,00055 & 0,00102 & 0,00150 & 0,00326 & 0,00516 & 0,00668 \\
\hline$P E$ & 0,00039 & 0,00072 & 0,00113 & 0,00306 & 0,00572 & 0,00976 \\
\hline PC & 0,00033 & 0,00062 & 0,00098 & 0,00279 & 0,00530 & 0,00953 \\
\hline
\end{tabular}

Esta maior condutividade hidráulica no PD pode ter sido significativa no movimento descendente do cálcio e magnésio (ou do calcário) aplicados na superfície deste sistema alguns anos antes, levando aos menores teores destes elementos no solo do PD, conforme resultados das Tabelas 5 e 6 .

com relação aos dados de condutividade hidráulica do solo saturado obtida com 0 método do permeâmetro de Guelph, apresentados na Tabela 12, se forem comparados com os de Ko da Tabela 14 para a profundidade de $20 \mathrm{~cm}$ observa-se que são muito distintos, mostrando que a definição de um valor de condutividade deve vir sempre acompanhado do método utilizado na sua determinação. 
Além disso, há que se considerar o tamanho da área amostrada, pois, enquanto no método de inundação a área utilizada é de $9 \mathrm{~m}^{2}$, no método do permeâmetro utiliza-se um orifício de $5 \mathrm{~cm}$ de diâmetro, embora se trabalhe com várias repetições.

Outro parâmetro que pode ser obtido a partir dos dados dos Apêndices 13, 14 e 15 é a capacidade de campo para cada tratamento. Tomando-se os valores de potencial matricial quando da estabilização das leituras dos tensiômetros, amostras de solo coletados neste momento ( $\boldsymbol{\theta}$ medido) e o valor de $\theta$ calculado pelo ajuste de GENUCHTEN \& NIELSEN (1985) montou-se a Tabela 16. Verifica-se por estes dados que houve pouca diferenciação entre os valores obtidos em cada profundidade, podendo-se fazer um valor médio para cada preparo. A diferença entre $\theta$ medido e $\theta$ calculado também é pequena, dando uma diferença máxima de 10,7\%, na profundidade de $120 \mathrm{~cm}$ do PD. Isto significa que as equações obtidas a partir dos dados experimentais conseguem representar satisfatoriamente os fenômenos que se propôs determinar.

Os valores de $\theta$ obtidos na estabilização da drenagem correspondem a uma tensão média determinada pelos tensiômetros de $14 \mathrm{KPa}$, que é a tensão na capacidade de campo para este solo, muito inferior ao valor usual de $33 \mathrm{KPa}$ utilizado para fins de irrigação. Isto mostra a necessidade de se determinar no campo este parâmetro, conforme já sugerido por SIDIRAS et al. (1984) quando trabalharam com Latossolos do Paraná. 
Tabela 16. Valores de umidade volumétrica $(\theta)$ em amostras de solo ( $\theta$ medido) retiradas nas parcelas de drenagem após estabilização das leituras dos tensiômetros, valores calculados ( $\theta$ calculado) pela equação de GENUCHTEN \& NIELSEN (1985) e tensão correspondente, para os três sistemas de preparo do solo.

\begin{tabular}{|c|c|c|c|c|c|c|c|c|}
\hline \multirow{2}{*}{$\begin{array}{c}\text { Sistemas } \\
\text { de } \\
\text { Preparo }\end{array}$} & & \multicolumn{6}{|c|}{ Profundidade, $\mathrm{cm}$} & \multirow[b]{2}{*}{ Média } \\
\hline & & 10 & 20 & 30 & 60 & 90 & 120 & \\
\hline & $\theta m$ & 0,348 & 0,334 & 0,330 & 0,337 & 0,318 & 0,355 & 0,337 \\
\hline \multirow[t]{3}{*}{ PD } & $\theta c$ & 0,362 & 0,375 & 0,361 & 0,363 & 0,363 & 0,393 & 0,369 \\
\hline & Tensão & 16 & 15 & 15 & 14 & 13 & 12 & 14 \\
\hline & $\theta m$ & 0,312 & 0,344 & 0,328 & 0,311 & 0,320 & 0,329 & 0,324 \\
\hline \multirow[t]{3}{*}{$\mathrm{PE}$} & $\theta c$ & 0,353 & 0,371 & 0,368 & 0,309 & 0,332 & 0,353 & 0,348 \\
\hline & Tensão & 15 & 15 & 14 & 15 & 14 & 13 & 14 \\
\hline & $\theta m$ & 0,322 & 0,358 & 0,332 & 0,319 & 0,324 & 0,322 & 0,329 \\
\hline \multirow[t]{2}{*}{ PC } & $\theta c$ & 0,336 & 0,372 & 0,364 & 0,315 & 0,342 & 0,326 & 0,342 \\
\hline & Tensão & 14 & 14 & 14 & 14 & 14 & 13 & 14 \\
\hline
\end{tabular}

$\theta \mathrm{m}$ e $\theta \mathrm{c}$ em $\mathrm{cm}^{3} . \mathrm{cm}^{-3}$

Tensão em $\mathrm{KPa}$ 


\subsection{Produção das culturas}

A resposta das culturas a cada sistema de preparo significa uma síntese do que cada um permitiu que ela realizasse dentro das limitações e benefícios de cada preparo, considerando que outros fatores de produção como clima, pragas e doenças foram iguais para as três situações propostas. Na Tabela 17 estão os dados de produção da aveia e do milho, originados a partir dos dados apresentados nos Apêndices 16 e 17. São apresentados, também, a produtividade média do milho dos sete anos que antecederam as determinações deste estudo, de 1983/84 a 1989/90.

Tabela 17. Valores de produção de palha de aveia preta, estande, palha e grãos de milho nos três sistemas de preparo do solo e produção média de milho de $1983 / 84$ a $1989 / 90$.

\begin{tabular}{|c|c|c|c|c|c|}
\hline \multirow{3}{*}{$\begin{array}{c}\text { Sistemas } \\
\text { de } \\
\text { Preparo }\end{array}$} & \multirow{3}{*}{$\begin{array}{l}\text { Aveia preta } \\
\text { palha seca }\end{array}$} & \multicolumn{4}{|c|}{ Milho } \\
\hline & & $\begin{array}{l}\text { estande } \\
\text { planta.ha }{ }^{-1}\end{array}$ & \multirow[t]{2}{*}{ palha seca } & \multicolumn{2}{|c|}{ grãos } \\
\hline & & & & $90 / 91$ & $83 / 84$ a $89 / 90$ \\
\hline \multicolumn{3}{|c|}{$\mathrm{kg} \cdot \mathrm{ha}^{-1}$} & \multicolumn{3}{|c|}{$\mathrm{kg}^{\mathrm{h} \mathrm{ha}^{-1}}$} \\
\hline PD & 4270 a & $59623 a$ & $7964 a$ & $6248 a$ & 5634 \\
\hline PE & $4479 a$ & $46313 \quad b$ & $5478 \quad b$ & $4666 \quad b$ & 5802 \\
\hline$P C$ & 4452 a & 38181 & $7205 a$ & $4589 \quad b$ & 5687 \\
\hline CV\% & 3,96 & 7,22 & 10,24 & 7,34 & \\
\hline
\end{tabular}

Números seguidos pela mesma letra não diferem entre si, na mesma profundidade, ao nível de 5\% de probabilidade (Duncan). 
A produção de palha de aveia, que garantiu a cobertura morta de $70 \%$ no PD, foi igual nos três sistemas de preparo e pode-se dizer que é satisfatória para as condições de inverno seco, predominante na região. Com relação ao milho, objeto do presente estudo, há uma diferença significativa com relação ao estande, sendo que se contou apenas as plantas que tinham espigas, o que significa que no $P E$ e $P C$ muitas plantas se desenvolveram mas não emitiram espigas. Com relação à produção, O PD foi superior aos demais tratamentos na produção de grãos. Mas na média dos sete anos que antecederam este estudo, tem-se uma diferença inferior a 3\% entre a maior e menor produção, respectivamente $\mathrm{PE} e \mathrm{PD}$. Isto mostra que na média de vários anos a diferenciação entre sistemas é muito pequena, podendo ser mais significativa em anos que ocorra algum fenômeno que favoreça um ou outro sistema. 


\section{CONCLUSÕES}

Dentro das condições do estudo e com as metodologias propostas pode-se concluir que:

- o sistema de plantio direto levou a acúmulos significativos de matéria orgânica, fósforo e maior acidificação do solo próximo à superfície.

- os sistemas de plantio direto e escarificador levaram a uma condição estrutural que permitiu melhor desenvolvimento do sistema radicular, maior infiltração e condutividade hidráulica.

- o preparo convencional apresentou uma camada compactada a $20 \mathrm{~cm}$ de profundidade, que implicou numa redução significativa do sistema radicular abaixo desta camada.

- o plantio direto conservou mais umidade nas camadas superficiais na primeira metade do ciclo do milho, sendo que posteriormente foi inferior aos demais tratamentos. 
- abaixo de $60 \mathrm{~cm}$ o plantio direto apresentou mais água no solo que os demais preparos.

- a tensão na umidade de capacidade de campo para este solo é $14 \mathrm{KPa}$, não havendo diferenças entre sistemas de preparo.

- o plantio direto levou a produção de milho significativamente maior que os demais preparos. 


\section{CONSIDERAÇÕES FINAIS}

A avaliação de atributos físicos do solo para caracterizar sistemas de manejo sempre apresenta limitações quanto a época de amostragem, ao método e tipo de equipamento utilizados. Métodos mais pontuais, que trabalham com amostras menores, normalmente são mais fáceis e rápidos, porém ficam mais sujeitos à variabilidade espacial dos solos, embora possa se fazer maior número de repetições. Assim é, por exemplo, com a avaliação de condutividade hidráulica, feita com permeâmetro de Guelph e pelo método de inundação. O primeiro é rápido e simples de se fazer, mas

utiliza uma parcela de $5 \mathrm{~cm}$ de diâmetro. O segundo é lento e complexo, mas é feito em uma parcela de $9 \mathrm{~m}^{2}$, o que garante maior representatividade do solo. Neste estudo ficou evidente a diferença entre resultados de condutividade hidráulica obtidos pelos dois métodos. Isto não invalida os resultados. Apenas põe em evidência a necessidade de se definir o resultado com o método utilizado.

Outro aspecto importante a se considerar nestes estudos é a época de amostragem. Na tentativa de realizar as determinações relativas à estrutura do solo o 
mais próximo daquelas de condutividade hidráulica, realizadas após a colheita, pode-se ter coletado as amostras numa época em que já não se tinha uma grande diferenciação entre tratamentos. Esta diferenciação deve ter ocorrido do preparo do solo até o início da maturação do milho, de acordo com outros estudos já citados (DERPSCH, 1991). Portanto a avaliação de parâmetros relacionados com infiltração e estrutura do solo devem ser realizados neste período, pois mostram o real efeito dos sistemas num período importante do desenvolvimento vegetativo da planta.

Em função disto, destacar um fator, entre os muitos que foram avaliados, como responsável por esta superioridade do PD é muito difícil, pois este apresentou vários fatores positivos que colaboraram para isto, como maior teor de fósforo, matéria orgânica, maior sistema radicular, menor gradiente de resistência à penetração, maior umidade no início do desenvolvimento da cultura, melhor drenagem interna, para destacar alguns. Por outro lado apresentou também alguns fatores que podem ser creditados como prejudiciais, como o baixo pH, menor teor de cálcio e magnésio e menor umidade nas camadas superficiais na segunda metade do ciclo do milho. Pode-se dizer que a conjugação destes fatores associados à condição climática do ano foram favoráveis a este sistema. Tanto que ao se considerar a média de sete anos do experimento, a diferenciação entre sistemas é insignificante. 
Por outro lado, o solo sob preparo com arado escarificador apresentou alguns parâmetros melhores que $O P D$, como maior teor de potássio, cálcio e magnésio no solo, menor resistência à penetração e potencial matricial semelhante ao PD. A favor do preparo com arado escarificador há o fato de ser um sistema de mais simples adoção, principalmente no que diz respeito ao manejo de ervas invasoras, que no plantio direto é mais complexo. Além disso, por implicar em poucas alterações quanto a máquinas e manejo das culturas em relação ao convencional, sua adoção é mais fácil e de menor custo que - plantio direto. O uso do escarificador é recomendável antes da adoção do plantio direto, para "consertar" os problemas deixados pelo sistema convencional, principalmente para eliminar a compactação sub-superficial deixada pelos arados e grades, como caracterizado neste trabalho.

De qualquer forma podemos dizer com segurança que tanto 0 sistema de plantio direto como o escarificador são sistemas conservacionistas possiveis de serem utilizados para a cultura de milho, nas condições climáticas em que 0 trabalho foi conduzido, com produção igual ou superior ao sistema convencional. 


\section{REFERÊNCIAS BIBLIOGRÁFICAS}

ALLMARAS, R.R. \& DOWDY, R.H. Conservation tillage systems and their adoption in the United States. Soil \& Tillage Research, Amsterdam, 5: 197-222, 1985.

ALMEIDA, F.S. de \& RODRIGUES, B.N. Guia de herbicidas: recomendações para o uso adequado em plantio direto e convencional. Londrina, Instituto Agronômico do Paraná, 1985. 482p.

ALVES, M.C. Sistemas de rotação de culturas com plantio direto em latossolo roxo: efeitos nas propriedades físicas e químicas. Piracicaba, 1992. 173p. Tese (Doutorado) ESALQ-USP, 1992 .

ARZENo, J.L. Avaliação física de diferentes manejos de solo em latossolo roxo distrófico. Piracicaba, 1990. 259p. Tese (Doutorado) ESALQ/USP, 1990.

BENATTI JR., R.; BERTONI, J. \& MOREIRA, C.A. Perdas por erosão em plantio direto e convencional de milho em dois solos de São Paulo. Revista Brasileira de Ciência do Solo, Campinas, 1: 121-123, 1977.

BLEVINS, R.L.; COOK, D.; PHILLIPS, S.H.; PHILLIPS, R.E. Influence of no-tillage on soil moisture. Agronomy Journal, Madison, 63: 593-596, 1971. 
BLEVINS, R.L.; MURDOCK, L.W. \& THOMAS, G.W. Effect of time application on no-tillage and conventionally tilled corn. Agronomy Journal, Madison, 70: 322-326, 1978.

BLEVINS, R.L.; SMITH, M.S.; THOMAS, G.W. \& FRYE, W.W. Influence of conservation tillage on soil properties. Journal of Soil Water Conservation, Ankeny, 38: 301-305, 1983.

BOND, J.J. \& WILLIS, W.O. Soil water conservation: surface residue rate and placement effects. Soil Science Society of America Proceedings, Madison, 33: 445-448, 1969.

BOND, J.J. \& WILLIS, W.O. Soil water evaporation: first stage drying as influenced by surface residue and evaporation potential. Soil Science Society of America Proceedings, Madison, 34: 924-928, 1970.

BOONE, E.R. Weather and other environmental factors influencing crop responses to tillage and traffic. Soil \& Tillage Research, Amsterdam, 11: 283-324, 1988.

CAMARGO, O.A. de. Compactação do solo e desenvolvimento das plantas. Campinas, Fundação Cargill, 1983. 44p.

CAMARGO, O.A. de; MONIZ, A.C.; JORGE, J.A.; VALADARES, J.M.A.S. Métodos de análise química, mineralógica e física de solos do Instituto Agronômico de Campinas. Campinas, Instituto Agronômico, 1986. 94p. (Boletim técnico, 106)

CANNEL, R.Q. Soil cultural practices related to root development. In: RUSSEL, R.S.; IGUE, K.; MENTA, Y.R., eds. The soil/root system in relation to brazilian agriculture. Londrina, Fundação Instituto Agronômico do Paraná, 1981. p. 61-80. 
CASTRO, O.M. de. Preparo do solo para a cultura do milho. Campinas, Fundação Cargill, 1989. 41p. (Série técnica,3)

CASTRO, O.M. de; CAMARGO, O.A. de; VIEIRA, S.R.; DECHEN, S.C.F. \& CANTARELLA, H. Caracterização química e física de dois latossolos em plantio direto e convencional. Campinas, Instituto Agronômico, 1987b. 23p. (Boletim cientifico, 11)

CASTRO, O.M. de; LOMBARDI NETO, F.; QUAGGIO, J.A.; DE MARIA, I.C.; VIEIRA, S.R. \& DECHEN, S.C.F. Perdas por erosão de nutrientes vegetais na sucessão soja/trigo em diferentes sistemas de manejo. Revista Brasileira de Ciência do Solo, Campinas, 10: 293-297, 1986a.

CASTRO, O.M. de; LOMBARDI NETO, F.; VIEIRA, S.R.; DECHEN, S.C.F. Sistemas convencionais e reduzidos de preparo do solo e as perdas por erosão. Revista Brasileira de Ciência do Solo, Campinas, 10: 167-171, 1986b.

CASTRO, O.M. de; VIEIRA, S.R. \& DE MARIA, I.C. Sistemas de preparo do solo e disponibilidade de água. In: VIEGAS, G.P, ed. Simpósio sobre o manejo de água na agricultura, Campinas, Fundação Cargill, 1987a. p. 27-51.

CENTURION, J.F. \& DEMATTÊ, J.L.I. Efeitos de sistemas de preparo nas propriedades físicas de um solo sob cerrado cultivado com soja. Revista Brasileira de Ciência do Solo, Campinas, 9: 263-266, 1985.

CENTURION, J.F.; DEMATTÊ, J.L.I. \& FERNANDES, F.M. Efeitos de sistemas de preparo nas propriedades químicas de um solo sob cerrado cultivado com soja. Revista Brasileira de Ciência do Solo, Campinas, 9: 267-270, 1985. 
DALLA ROSA, A. Práticas mecânicas e culturais na recuperação de caracteristicas físicas de solos degradados pelo cultivo - solo Santo Ângelo (Latossolo Roxo distrófico). Porto Alegre, 1981. 136p. (Dissertação Mestrado) Faculdade de Agronomia/Universidade Federal do Rio Grande do Sul, 1981.

DE MARIA, I.C. \& CASTRO, O.M. de. Fósforo, potássio e matéria orgânica em um latossolo roxo, sob sistemas de manejo com milho e soja. Revista Brasileira de Ciência do Solo, Campinas, 17: 471-477, 1993.

DE MARIA, I.C.; CASTRO, O.M. de \& SOUZA DIAS, H. Atributos físicos e desenvolvimento radicular de soja em solo argiloso sob diferentes métodos de preparo. In: CONGRESSO BRASILEIRO DE CIÊNCIA DO SOLO, 24., Goiânia, 1993. Goiânia, SBCS, 1993. Resumos. v.3, p.41-42.

DERPSCH, R. Alguns resultados sobre adubação verde no Paraná. In: Adubação verde no Brasil. Campinas, Fundação Cargill, 1984. p. 268-279.

DERPSCH, R.; ROTH, C.H.; SIDIRAS, N. \& KOPKE, U. Controle da erosão no Paraná, Brasil: sistemas de cobertura do solo, plantio direto e preparo conservacionista do solo. Dt. Ges. für Techn. Zusammenarbeit (GTZ) GmbH, Eschuborn, 1991. 272p.

DERPSCH, R.; SIDIRAS, N. \& ROTH, C.H. Results of studies made from 1977 to 1984 to control erosion by cover crops and tillage techniques in Paraná, Brazil. Soil \& Tillage Research, Amsterdam, 8: 253-263, 1986.

DOREN, JR., D.M. van. Influence of plowing, disking, cultivation, previous crop, and surface residues on corn yield. Soil Science Society of America Proceedings, Madison, 29: 595-597, 1965. 
DOREN JR., D.M. van., TRIPLETT JR., G.B. \& HENRY, J.E. Influence of long term tillage, crop rotation and soil type combinations an corn yield. Soil science Society of America Journal, Madison, 40:100-105, 1976.

DREW, M.C. \& SAKER, L.R. Effects of direct drilling and ploughing on root distribution in spring barley, and on the concentration of extractable phosphate and potassium in the upper horizons of a clay soil. Journal of the Science of Food and Agriculture, Londres, 29: 201-206, 1978 .

DREW, M.C. \& SAKER, L.R. Direct drilling and ploughing: their effects on the distribution of extractable phosphorus and potassium and of roots, in the upper horizons of two clay soils under winter wheat and spring barley. Journal of Agricultural Science, Londres, 94: 411-423, 1980 .

EHLERS, W. Observation on earthworm channels and infiltration on tilled and untilled loess soil. Soil Science, Baltimore, 11: 242-249, 1975.

ELTZ, F.L.F.; PEIXOTO, R.T.G. \& JASTER, F. Efeitos de sistemas de preparo do solo nas propriedades físicas e químicas de um latossolo bruno álico. Revista Brasileira de Ciência do Solo, Campinas, 13: 259-267, 1989.

ELWELL, H.A. \& WENDELAAR, F.E. To initiate a vegetal cover data bank for soil loss estimation. Salisbury, Departament of Conservation e Extension, 1977. 12p. (Research Bulletin, 23)

GENUCHTEN, M.T. van \& NIELSEN, D.R. On describing and predicting the hydraulic properties of unsaturated soils. Annales Geophysicae, s.1.p., 3: 615-628, 1985. 
HARROLD, L.L. SOil erosion by water affected by reduced tillage systems. In: NATIONAL NO-TILLAGE SYSTEMS SYMPOSIUM, Columbus, 1972, Proceedings. Columbus, Ohio State University Ohio Agriculture Research, Development Center, Chevron. Chemical Company, 1972. p.21-29.

HILLEL, D. Soil and water: physical principles and processes. New York, Academic Press, 1971. 228p.

HILLEL, D.; KRENTOS, V.D. \& STYLIANOU, Y. Procedure and test of an internal drainage method for measuring soil hydraulic characteristics in situ. Soil science, Baltimore, 114: 395-400, 1972.

HUDSON, N. Soil conservation. London, BT Batsford Ltd., 1971. $304 \mathrm{p}$.

JUO, A.S.R. \& LAL, R. Nutrient profile in a tropical Alfisol under conventional and no-till systems. Soil Science, Baltimore, 127: 168-173, 1979.

LAL, R. Rate of mulching techniques in tropical soil and water management. Ibadan, IITA, 1975. 38p. (Bulletin, 1)

LAL, R. Influence of within-and between-row mulching on soil temperature, soil moisture, root development and yield of maize (zea mays L.) in a tropical soil. Field Crops Research, Amsterdam, 1: 127-129, 1978.

LAL, R. Influence of tillage methods and residue mulches on soil structure and infiltration rates. In: LAL, $R$. \& GREENLAND, eds. Soil physical properties and crop production in the tropics, Chichester, John whiley and Sons, 1979. 551p.

LAL, R. Management of clay soils for erosion control. Tropical Agriculture, Trinidad, 59: 133-138, 1982. 
LEITE, J.A. \& MEDINA, B.F. Efeito dos sistemas de manejo sobre as propriedades físicas de um latossolo amarelo do Amazonas. Pesquisa Agropecuária Brasileira, Brasília, 19: 1417-1422, 1984 .

LETEY, J. The study of soil structure: science on art. Australian Journal of Soil Research, East Melbourne, 29: 699-707, 1991.

LOMBARDI NETO, F.; DE MARIA, I.C.; CASTRO, O.M. de; DECHEN, S.C.F. \& VIEIRA, S.R. Efeito da quantidade de resíduos culturais de milho nas perdas de solo e água. Revista Brasileira de Ciência do Solo, Campinas, 12: 71-75, 1988.

MACHADO, J.A. \& BRUM, A.C.R. Efeito do sistema de cultivo em algumas propriedades físicas do solo. Revista Brasileira de Ciência do Solo, Campinas, 2: 81-84, 1978.

MANNERING, J.V. \& BURWELL, R.E. Tillage methods to reduce runoff and erosion in the Corn Belt. Washington, USDA, Agricultural Research Service, 1968. 14p. (Bulletin, 330)

MANNERING, J.V. \& MEYER, L.D. The effects of varius rates of surface mulch on infiltration and erosion. Soil Science Society of America Proceedings, Madison, 27: 84-86, 1963.

MATA, J. de D.V. da. Relações entre as características físicas e os níveis de compactação de alguns latossolos paranaenses. Curitiba, 1988.105p. (Dissertação Mestrado) - Universidade Federal do Paraná, 1988.

MEDEIROS, J.C.; MIELNICZUK, J. \& PEDO, F. Sistemas de culturas adaptadas à produtividade, recuperação e conservação do solo. Revista Brasileira de Ciência do Solo, Campinas, 11: 199-204, 1987. 
MONDARDO, A.; VIEIRA, M.J.; BISCAIA, R.M.; CASTRO FILHO, C. \& RUEINO, R.L. Erosion studies for different tillage and crop systems in the state of Paraná, Brazil. In: PROCEEDINGS OF INTERNATIONAL SOIL \& TILLAGE RESEARCH ORGANIZATION, 8., Hohenheim, 1979. p. 159-163.

MUZILLI, 0 . A influência do sistema de plantio direto, comparado ao convencional sobre a fertilidade da camada arável do solo. Revista Brasileira de Ciência do Solo, Campinas, 7: 95-102, 1983.

OLIVEIRA, E.F. de; BAIRRÃO, J.F.M.; CARRARO, I.M. \& BALBINO, L.C. Efeito do sistema de preparo do solo nas suas características físicas e químicas e no rendimento de trigo e soja em latossolo roxo. I. Resultados obtidos de 1982 a 1988. Cascavel, OCEPAR, 1990. 54p. (Resultados de pesquisa, 4)

PHILLIPS, R.E. No-tillage research, research reports and reviews. Lexington, University of Kentuky/College of Agriculture and Agricultural Experiment Station, 1984 p. 23-42.

RAIJ, B. van \& QUAGGIO, J.A. Métodos de análise de solo para fins de fertilidade. Campinas, Instituto Agronômico, 1983. 31p. (Boletim técnico, 81)

RAIJ, B. van; SILVA, N.M.; BATAGLIA, O.C.; QUAGGIO, J.A.; HIROCE, R.; CANTARELLA, H.; BELLINAZZI JR., R.; DECHEN, A.R. \& TRANI, P.E. Recomendação de adubação e calagem o Estado de São Paulo. Campinas, Instituto Agronômico, 1985. 107p. (Boletim técnico, 100)

REYNOLDS, W.D. \& ELRICK, D.E. In situ measurement of fieldsatured hydraulic conductivity, sorptivity and the $\alpha$-parameters using the Guelph permeameter. Soil Science, Baltimore, 140: 292-302, 1985. 
RICHARDS, L.A. Physical condition of water in soil. In: BLACK, C.A., Eds. Methods of soil analysis. I. Physical and mineralogical properties including statistical of measuring and sampling. Americam Society of Agronomy, Madison, 1965. p. 128-151. (Agronomy Series, 9)

ROBBINS, S.G. \& VOSS, R.D. Phosphorus and potassium stratifiction in conservation tillage systems. Journal of Soil and Water Conservation, Ankeny, 46: 298-300, 1991.

ROTH, C.H. \& MEYER, B. Infiltrabilidade de um latossolo roxo distrófico durante o periodo vegetativo da soja sob o preparo convencional, escarificação e plantio direto. In: CONGRESSO BRASILEIRO DE CIÊNCIA DO SOLO, 19., Curitiba. 1983. Programa e Resumos. Campinas, SBCS, 1983. p.101-102

ROTH, C.H.; MEYER, B.; EREDE, M.-G. \& DERPSCH, R. Effect of mulch rates and tillage systems on infiltrability and other soil physical properties of an Oxisol in Paraná, Brazil. Soil \& Tillage Research, Amsterdam, 11: 81-91, 1988 .

SARVASI, F. de O.C. Dinâmica da água, erosão hídrica e produtividade das culturas em função do preparo do solo. Piracicaba, 1994. 147p. (Dissertação Mestrado) ESALQUSP, 1994.

SHANHOLTZ, V.O. \& LILLARD, J.H. Tillage system effects on water use efficiency. Journal of soil and Water Conservation, Ankeny, 24: 186-189, 1969.

SHEAR, G.M. \& MOSCHLER, W.W. Continuous corn by the no tillage and conventional tilled methods. Agronomy Journal, Madison, 61: 524-526, 1969. 
SIDIRAS, N.; DERPSCH, R. \& MONDARDO, A. Influência de diferentes sistemas de preparo do solo na variação da umidade e rendimento da soja, em latossolo roxo distrófico (Oxisol). Revista Brasileira de Ciência do Solo, Campinas, 7: 103-106, 1983.

SIDIRAS, N.; HENKLAIN, J.C. \& DERPSCH, R. Comparation of three different tillage systems with respect to aggregate stability, the soil and water conservation and the yields of soybean and wheat on an oxisol. In: CONFERENCE OF THE INTERNATIONAL SOIL TILLAgE RESEARCH ORGANIZATION, 9., Osijek, 1982. p. 537-544.

SIDIRAS, N. \& ROTH, C.H. Infiltration measurements with double-ring infiltrometers and a rainfall simulator under different surface conditions on an Oxisol. Soil \& Tillage Research, Amsterdam, 9: 161-168. 1987.

SIDIRAS, N.; ROTH, C.H. \& FARIAS, G.S. Efeito da intensidade de chuva na desagregação por impacto de gotas em três sistemas de preparo do solo. Revista Brasileira de Ciência do Solo, Campinas, 8(2): 251-254, 1984.

SIDIRAS, N. \& VIEIRA, M.J. Compactação em latossolo roxo provocada pelas rodas do trator na semeadura: comportamento físico do solo e rendimento de três culturas. Pesquisa Agropecuária Brasileira, Brasília, 19: 1285-1293, 1984.

SIDIRAS, N.; VIEIRA, S.R. \& ROTH, C.H. Determinação de algumas características físicas de um Latossolo roxo distrófico sob plantio direto e preparo convencional. Revista Brasileira de Ciência do Solo, Campinas, 8: 265-268, 1984. 
THOMASSON, A.J. Towards and objective classification of soil structure. The Journal of Soil Science, Oxford, 29: $38-46,1978$.

THORNTHWAITE, C.W. \& MATHER, J.R. The water balance publications in climatology, vol. III. New Jersey, Diwxel Institute of Technology, Laboratory of Climatology Centerton. 1955. 104p.

TRIPLETT JR., G.B. \& DOREN JR., D.M. van. Nitrogen, phosphurus and potassium fertilization of non-tilled maize. Agronomy Journal, Madison, 61: 637-639, 1969.

VIEIRA, M.J. Propriedades físicas do solo. In: Plantio direto no Estado do Paraná. Londrina, Fundação Instituto Agronômico do Paraná, 1981. p. 19-32. (Circular IAPAR, 23)

VIEIRA, M.J.; COGO, N.P. \& CASSOL, E.A. Perdas por erosão, em diferentes sistemas de preparo do solo, para a cultura da soja (Glycine max (I.) Merr.) em condições de chuva simulada. Revista Brasileira de Ciência do Solo, Campinas, 2: 209-214, 1978.

VIEIRA, M.J. \& MUZILLI, O. Características físicas de um latossolo vermelho-escuro sob diferentes sistemas de manejo. Pesquisa Agropecuária Brasileira, Brasilia, 19: 873-882, 1984 . 
VIEIRA, S.R.; REYNOLDS, W.D. \& TOPP, G.C. Spatial variability of hidraulic properties in a righly structured clay soil. In: WIERENGA, P.J. \& BACHALET, D., Eds. Validation of Flow and Transport Models for the Unsaturated zone: Conference Proceedings. Las Cruces, Department of Agronomy and Horticulture, New Mexico University, 1988. p. 471-483. (Research Report 88-55-04; Conference of Validation of Flow and Transport Models for the Unsaturated Zone, Ruidoso, Novo Méxiico, 1988). 
129.

APENNDICES 
Apêndice 1. Valores de pH, matéria orgânica, fósforo, potássio, cálcio, magnésio e saturação por bases.

\begin{tabular}{|c|c|c|c|c|c|c|c|}
\hline \multirow{2}{*}{$\begin{array}{l}\text { Sistemas } \\
\text { de } \\
\text { Preparo }\end{array}$} & \multirow[b]{2}{*}{ Repetições } & \multicolumn{6}{|c|}{ Profundidades, $\mathrm{cm}$} \\
\hline & & $0-10$ & $10-20$ & $20-30$ & $30-40$ & $40-50$ & $50-60$ \\
\hline & & & & & & & \\
\hline & 1 & 4,7 & 4,3 & 4,0 & 4,0 & 4,3 & 4,7 \\
\hline \multirow[t]{3}{*}{ PD } & 2 & 5,0 & 5,1 & 4,2 & 4,5 & 4,6 & 4,9 \\
\hline & 3 & 4,8 & 4,3 & 4,3 & 4,5 & 4,7 & 4,8 \\
\hline & 1 & 4,8 & 5,5 & 5,2 & 4,7 & 4,9 & 5,2 \\
\hline \multirow[t]{3}{*}{ PE } & 2 & 5,1 & 4,9 & 5,0 & 4,7 & 4,7 & 4,9 \\
\hline & 3 & 4,8 & 4,9 & 4,7 & 4,5 & 4,7 & 4,8 \\
\hline & 1 & 5,2 & 5,0 & 5,7 & 5,0 & $5 ; 0$ & 4,9 \\
\hline \multirow[t]{4}{*}{ PC } & 2 & 5,1 & 5,7 & 5,6 & 5,7 & 4,8 & 5,3 \\
\hline & 3 & 4,9 & 5,3 & 5,4 & 5,4 & 5,3 & 5,1 \\
\hline & & \multicolumn{6}{|c|}{ Matéria Orgânica, g/kg } \\
\hline & 1 & 33 & 27 & 23 & 28 & 20 & 17 \\
\hline \multirow[t]{3}{*}{ PD } & 2 & 29 & 23 & 17 & 19 & 17 & 16 \\
\hline & 3 & 32 & 24 & 20 & 19 & 16 & 17 \\
\hline & 1 & 28 & 21 & 20 & 19 & 18 & 17 \\
\hline \multirow[t]{3}{*}{$P E$} & 2 & 29 & 24 & 22 & 17 & 19 & 17 \\
\hline & 3 & 29 & 27 & 19 & 18 & 17 & 18 \\
\hline & 1 & 23 & 21 & 14 & 17 & 18 & 17 \\
\hline \multirow[t]{4}{*}{ PC } & 2 & 26 & 20 & 20 & 20 & 18 & 19 \\
\hline & 3 & 27 & 23 & 20 & 19 & 19 & 16 \\
\hline & & \multicolumn{6}{|c|}{ Fósforo, $\mathrm{mg} / \mathrm{dm}^{3}$} \\
\hline & 1 & 40 & 24 & 6 & 4 & 2 & 3 \\
\hline \multirow[t]{3}{*}{ PD } & 2 & 42 & 20 & 4 & 2 & 2 & 2 \\
\hline & 3 & 38 & 28 & 4 & 3 & 3 & 2 \\
\hline & 1 & 24 & 29 & 4 & 2 & 3 & 2 \\
\hline \multirow[t]{3}{*}{ PE } & 2 & 35 & 30 & 8 & 3 & 3 & 2 \\
\hline & 3 & 24 & 19 & 6 & 2 & 2 & 4 \\
\hline & 1 & 18 & 20 & 4 & 2 & 2 & 3 \\
\hline \multirow[t]{2}{*}{$P C$} & 2 & 26 & 18 & 5 & 4 & 3 & 3 \\
\hline & 3 & 24 & 29 & 4 & 3 & 2 & $\begin{array}{l}2 \\
\ldots\end{array}$ \\
\hline
\end{tabular}


Apêndice 1. (Continuação)

\begin{tabular}{|c|c|c|c|c|c|c|c|}
\hline & & \multicolumn{6}{|c|}{ Potássio, $\mathrm{cmol} / \mathrm{kg}$} \\
\hline & 1 & 2,1 & 1,3 & 0,6 & 0,7 & 0,7 & 0,6 \\
\hline \multirow[t]{3}{*}{ PD } & 2 & 2,6 & 1,0 & 0,8 & 0,8 & 0,9 & 0,7 \\
\hline & 3 & 2,8 & 0,8 & 0,4 & 0,4 & 0,3 & 0,4 \\
\hline & 1 & 3,0 & 1,9 & 0,7 & 0,6 & 0,5 & 0,5 \\
\hline \multirow[t]{3}{*}{ PE } & 2 & 4,3 & 2,4 & 1,0 & 0,9 & 0,8 & 0,5 \\
\hline & 3 & 2,7 & 2,3 & 0,8 & 0,7 & 0,6 & 0,5 \\
\hline & 1 & 2,6 & 1,8 & 0,5 & 0,6 & 0,3 & 0,3 \\
\hline \multirow[t]{4}{*}{ PC } & 2 & 2,0 & 1,3 & 0,4 & 0,6 & 0,2 & 0,2 \\
\hline & 3 & 2,2 & 1,1 & 0,4 & 0,5 & 0,2 & 0,2 \\
\hline & & \multicolumn{6}{|c|}{ Cálcio, $\mathrm{cmol} / \mathrm{kg}$} \\
\hline & 1 & 22 & 9 & 6 & 5 & 6 & 6 \\
\hline \multirow[t]{3}{*}{ PD } & 2 & 29 & 19 & 5 & 6 & 8 & 11 \\
\hline & 3 & 27 & 14 & 9 & 8 & 8 & 8 \\
\hline & 1 & 29 & 25 & 11 & 7 & 7 & 9 \\
\hline \multirow[t]{3}{*}{ PE } & 2 & 23 & 20 & 13 & 6 & 6 & 8 \\
\hline & 3 & 18 & 25 & 14 & 7 & 9 & 13 \\
\hline & 1 & 24 & 27 & 16 & 8 & 11 & 7 \\
\hline \multirow[t]{4}{*}{ PC } & 2 & 24 & 28 & 25 & 15 & 8 & 11 \\
\hline & 3 & 22 & 23 & 23 & 12 & 8 & 9 \\
\hline & & \multicolumn{6}{|c|}{ Magnésio, $\mathrm{cmol} / \mathrm{kg}$} \\
\hline & 1 & 7,0 & 3,0 & 2,0 & 3,0 & 3,0 & 3,0 \\
\hline \multirow[t]{3}{*}{ PD } & 2 & 9,0 & 5,0 & 1,0 & 2,0 & 3,0 & 4,0 \\
\hline & 3 & 9,0 & 4,0 & 3,0 & 4,0 & 4,0 & 4,0 \\
\hline & 1 & 9,0 & 8,0 & 4,0 & 4,0 & 4,0 & 6,0 \\
\hline \multirow[t]{3}{*}{ PE } & 2 & 8,0 & 5,0 & 5,0 & 3,0 & 2,0 & 4,0 \\
\hline & 3 & 7,0 & 5,0 & 5,0 & 3,0 & 4,0 & 6,0 \\
\hline & 1 & 9,0 & 9,0 & 6,0 & 4,0 & 6,0 & 4,0 \\
\hline \multirow[t]{4}{*}{ PC } & 2 & 9,0 & 10,0 & 9,0 & 7,0 & 5,0 & 7,0 \\
\hline & 3 & 8,0 & 11,0 & 6,0 & 6,0 & 6,0 & 5,0 \\
\hline & & \multicolumn{6}{|c|}{ Saturação por bases, \% } \\
\hline & 1 & 43 & 16 & 16 & 10 & 19 & 23 \\
\hline \multirow[t]{3}{*}{ PD } & 2 & 59 & 45 & 14 & 21 & 26 & 34 \\
\hline & 3 & 53 & 29 & 22 & 24 & 28 & 26 \\
\hline & 1 & 59 & 61 & 39 & 28 & 26 & 41 \\
\hline \multirow[t]{3}{*}{ PE } & 2 & 53 & 47 & 42 & 24 & 24 & 32 \\
\hline & 3 & 41 & 50 & 37 & 22 & 31 & 39 \\
\hline & 1 & 56 & 58 & 53 & 34 & 38 & 28 \\
\hline \multirow[t]{2}{*}{ PC } & 2 & 58 & 64 & 65 & 52 & 32 & 45 \\
\hline & 3 & 51 & 52 & 53 & 46 & 39 & 36 \\
\hline
\end{tabular}


Apêndice 2. Valores de densidadade do solo.

\begin{tabular}{|c|c|c|c|c|c|c|c|c|c|c|c|c|}
\hline \multirow{2}{*}{$\begin{array}{c}\text { Sistemas } \\
\text { de } \\
\text { Preparo }\end{array}$} & \multirow{2}{*}{ Repetiçōes } & \multicolumn{11}{|c|}{ Profundidades, $\mathrm{cm}$} \\
\hline & & 5 & 10 & 15 & 20 & 25 & 30 & 45 & 60 & 75 & 90 & 120 \\
\hline & & \multicolumn{11}{|c|}{ Densidade do solo, $\mathrm{g} . \mathrm{cm}^{-3}$} \\
\hline & 1 & 1,36 & 1,38 & 1,30 & 1,20 & 1,20 & 1,23 & 1,23 & 1,15 & 1,00 & 1,13 & 1,10 \\
\hline \multirow[t]{3}{*}{ PD } & 2 & 1,19 & 1,30 & 1,27 & 1,33 & 1,38 & 1,34 & 1,16 & 1,23 & 1,06 & 1,02 & 1,15 \\
\hline & 3 & 1,23 & 1,35 & 1,36 & 1,34 & 1,34 & 1,31 & 1,20 & 1,18 & 1,14 & 1,06 & 1,00 \\
\hline & 1 & 1,26 & 1,29 & 1,23 & 1,25 & 1,20 & 1,21 & 1,21 & 1,10 & 1,15 & 1,10 & 0,90 \\
\hline \multirow[t]{3}{*}{ PE } & 2 & 1,18 & 1,27 & 1,35 & 1,38 & 1,37 & 1,35 & 1,29 & 1,01 & 0,99 & 1,04 & 1,05 \\
\hline & 3 & 1,08 & 1,10 & 1,11 & 1,32 & 1,28 & 1,33 & 1,14 & 1,07 & 1,08 & 0,99 & 0,93 \\
\hline & 1 & 1,17 & 1,41 & 1,40 & 1,44 & 1,30 & 1,30 & 1,16 & 0,99 & 1,04 & 1,02 & 0,96 \\
\hline \multirow[t]{2}{*}{ PC } & 2 & 1,17 & 1,20 & 1,33 & 1,47 & 1,29 & 1,32 & 1,34 & 1,05 & 0,99 & 0,96 & 1,02 \\
\hline & 3 & 1,20 & 1,27 & 1,27 & 1,35 & 1,36 & 1,36 & 1,13 & 1,00 & 1,00 & 1,00 & 1,05 \\
\hline
\end{tabular}


Apêndice 3. Valores das leituras de resistência à penetração, com penetrômetro de bolso.

\begin{tabular}{|c|c|c|c|c|c|c|c|c|c|c|c|c|c|}
\hline \multirow{2}{*}{$\begin{array}{l}\text { Sistemas } \\
\text { de } \\
\text { Preparo }\end{array}$} & \multirow{2}{*}{ Repetiçōes } & \multicolumn{12}{|c|}{ Profundidades, $\mathrm{cm}$} \\
\hline & & 5 & 10 & 15 & 20 & 25 & 30 & 35 & 40 & 45 & 50 & 55 & 60 \\
\hline & & \multicolumn{12}{|c|}{ Resistência à penetração, $\mathrm{kgf} . \mathrm{cm}^{2}$} \\
\hline & 1 & 1,58 & 3,92 & 3,25 & 2,42 & 2,42 & 2,67 & 2,50 & 2,04 & 2,08 & 1,75 & 1,42 & 1,21 \\
\hline \multirow[t]{3}{*}{ PD } & 2 & 1,79 & 3,08 & 3,17 & 3,87 & 3,79 & 3,67 & 3,50 & 2,47 & 2,33 & 2,04 & 1,39 & 1,29 \\
\hline & 3 & 2,79 & 2,71 & 4,63 & 3,54 & 3,17 & 2,17 & 2,04 & 1,79 & 1,71 & 1,42 & 1,38 & 1,38 \\
\hline & 1 & 1,25 & 1,79 & 1,96 & 3,29 & 3,04 & 2,50 & 2,63 & 2,29 & 2,17 & 1,71 & 1,71 & 1,38 \\
\hline \multirow[t]{3}{*}{$P E$} & 2 & 1,42 & 1,67 & 1,50 & 2,50 & 3,96 & 3,38 & 3,13 & 2,50 & 1,92 & 2,08 & 1,63 & 1,50 \\
\hline & 3 & 1,00 & 1,21 & 1,33 & 2,37 & 3,46 & 3,54 & 2,67 & 2,96 & 2,62 & 2,17 & 1,71 & 1,33 \\
\hline & 1 & 1,33 & 3,17 & 3,71 & 4,42 & 3,96 & 3,33 & 3,13 & 2,46 & 1,96 & 2,00 & 1,63 & 1,42 \\
\hline \multirow[t]{2}{*}{$P C$} & 2 & 1,17 & 2,67 & 3,71 & 4,25 & 4,33 & 4,21 & 3,92 & 2,92 & 2,67 & 2,00 & 1,63 & 1,25 \\
\hline & 3 & 1,29 & 2,50 & 3,54 & 4,46 & 4,46 & 4,08 & 4,13 & 3,04 & 2,83 & 2,00 & 1,88 & 1,29 \\
\hline
\end{tabular}


Apêndice 4. Densidade de raiz do milho.

\begin{tabular}{|c|c|c|c|c|c|c|c|}
\hline \multirow{2}{*}{$\begin{array}{c}\text { Sistemas } \\
\text { de } \\
\text { Preparo }\end{array}$} & \multirow{2}{*}{ Repetições } & \multicolumn{6}{|c|}{ Profundidade, $\mathrm{cm}$} \\
\hline & & $0-10$ & $10-0$ & $20-30$ & $30-40$ & $40-50$ & $50-60$ \\
\hline & & \multicolumn{6}{|c|}{ Densidade de raiz, g.dm } \\
\hline & 1 & 2,104 & 1,158 & 0,306 & 0,364 & 0,212 & 0,154 \\
\hline \multirow[t]{3}{*}{ PD } & 2 & 2,026 & 1,170 & 0,312 & 0,308 & 0,252 & 0,126 \\
\hline & 3 & 3,553 & 1,481 & 0,519 & 0,260 & 0,256 & 0,118 \\
\hline & 1 & 3,870 & 1,113 & 0,416 & 0,282 & 0,130 & 0,130 \\
\hline \multirow[t]{3}{*}{ PE } & 2 & 1,688 & 1,332 & 0,390 & 0,323 & 0,180 & 0,078 \\
\hline & 3 & 1,569 & 1,319 & 0,394 & 0,208 & 0,152 & 0,156 \\
\hline & 1 & 1,481 & 1,922 & 0,204 & 0,078 & 0,124 & 0,156 \\
\hline \multirow[t]{2}{*}{ PC } & 2 & 1,506 & 1,688 & 0,208 & 0,108 & 0,162 & 0,108 \\
\hline & 3 & 1,558 & 0,379 & 0,182 & 0,130 & 0,160 & 0,130 \\
\hline
\end{tabular}


Apêndice 5. Valores de condutividade hidráulica saturada (Kfs) e de infiltração obtidas pelo permeâmetro de Guelph.

\begin{tabular}{|c|c|c|c|c|c|c|}
\hline \multirow{3}{*}{$\begin{array}{c}\text { Sistemas } \\
\text { de } \\
\text { Preparo }\end{array}$} & \multirow{3}{*}{ Repetiçōes } & \multirow{3}{*}{$\begin{array}{c}\begin{array}{c}\text { Superfi cie } \\
\text { Infiltração }\end{array} \\
\mathrm{mm} \cdot \mathrm{h}^{-1}\end{array}$} & \multicolumn{2}{|c|}{$20 \mathrm{~cm}$} & \multicolumn{2}{|c|}{$40 \mathrm{~cm}$} \\
\hline & & & Kfs & Infiltração & $\mathrm{Kfs}$ & Infiltração \\
\hline & & & $\mathrm{cm} \cdot \mathrm{h}^{-1}$ & $\mathrm{~mm} \cdot \mathrm{h}^{-1}$ & $\mathrm{~cm} \cdot \mathrm{h}^{-1}$ & $m m \cdot h^{-1}$ \\
\hline & 1 & 103,96 & 2,3367 & 110,00 & 0,6912 & 48,52 \\
\hline \multirow[t]{3}{*}{$P D$} & 2 & 111,36 & 2,6404 & 122,95 & 1,6521 & 113,22 \\
\hline & 3 & 118,80 & 2,1742 & 103,50 & 1,4096 & 97,05 \\
\hline & 1 & 18,81 & 1,2362 & 60,16 & 0,7392 & 51,76 \\
\hline \multirow[t]{3}{*}{ PE } & 2 & 70,80 & 1,3087 & 64,70 & 0,9312 & 64,70 \\
\hline & 3 & 99,02 & 0,7487 & 38,82 & 1,5062 & 103,50 \\
\hline & 1 & 10,89 & 0,8154 & 41,41 & 0,7387 & 51,76 \\
\hline \multirow[t]{2}{*}{$P C$} & 2 & 14,85 & 0,8933 & 45,29 & 0,9292 & 64,70 \\
\hline & 3 & 9,90 & 1,0250 & 51,76 & 1,5042 & 102,80 \\
\hline
\end{tabular}




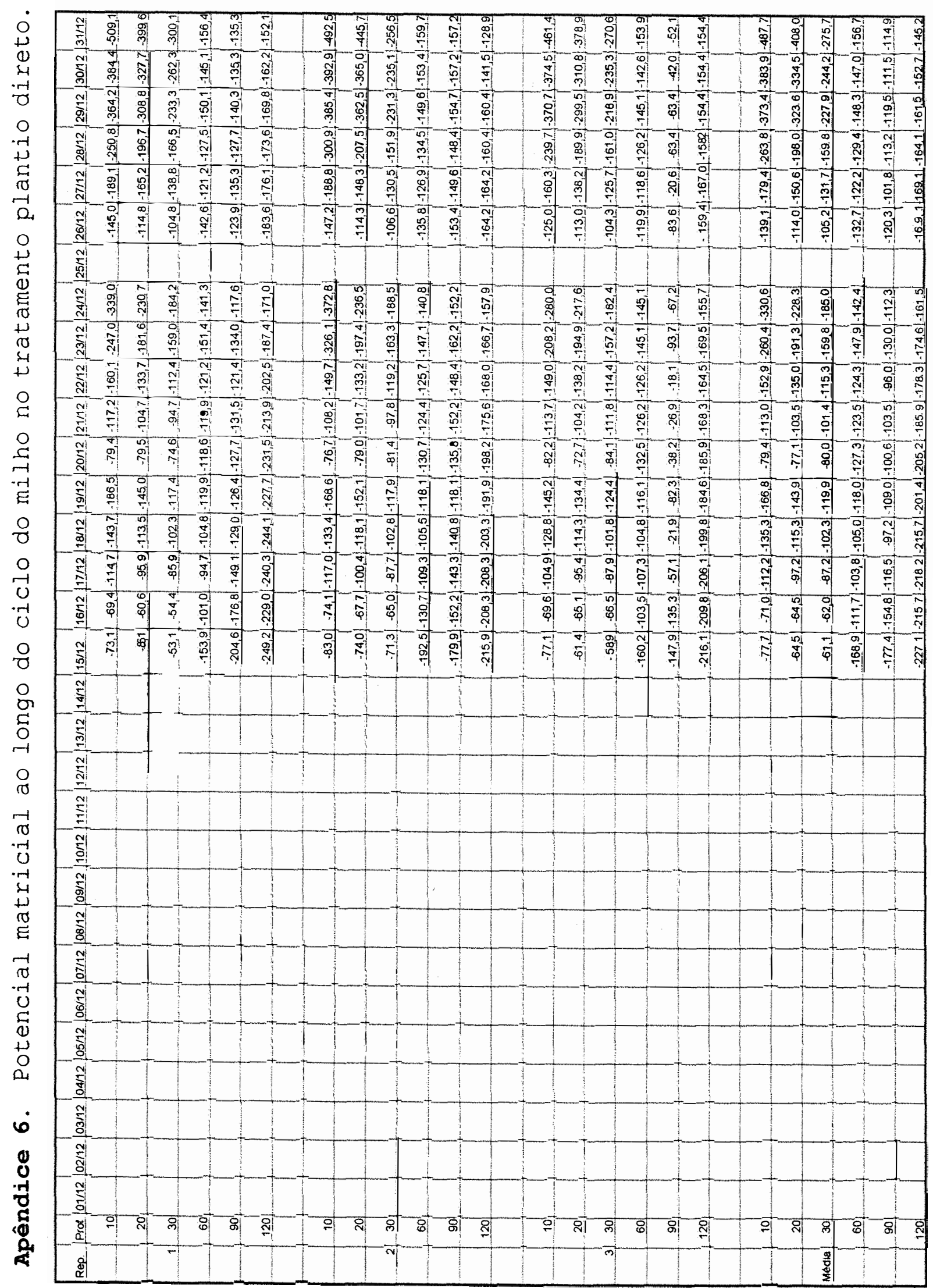




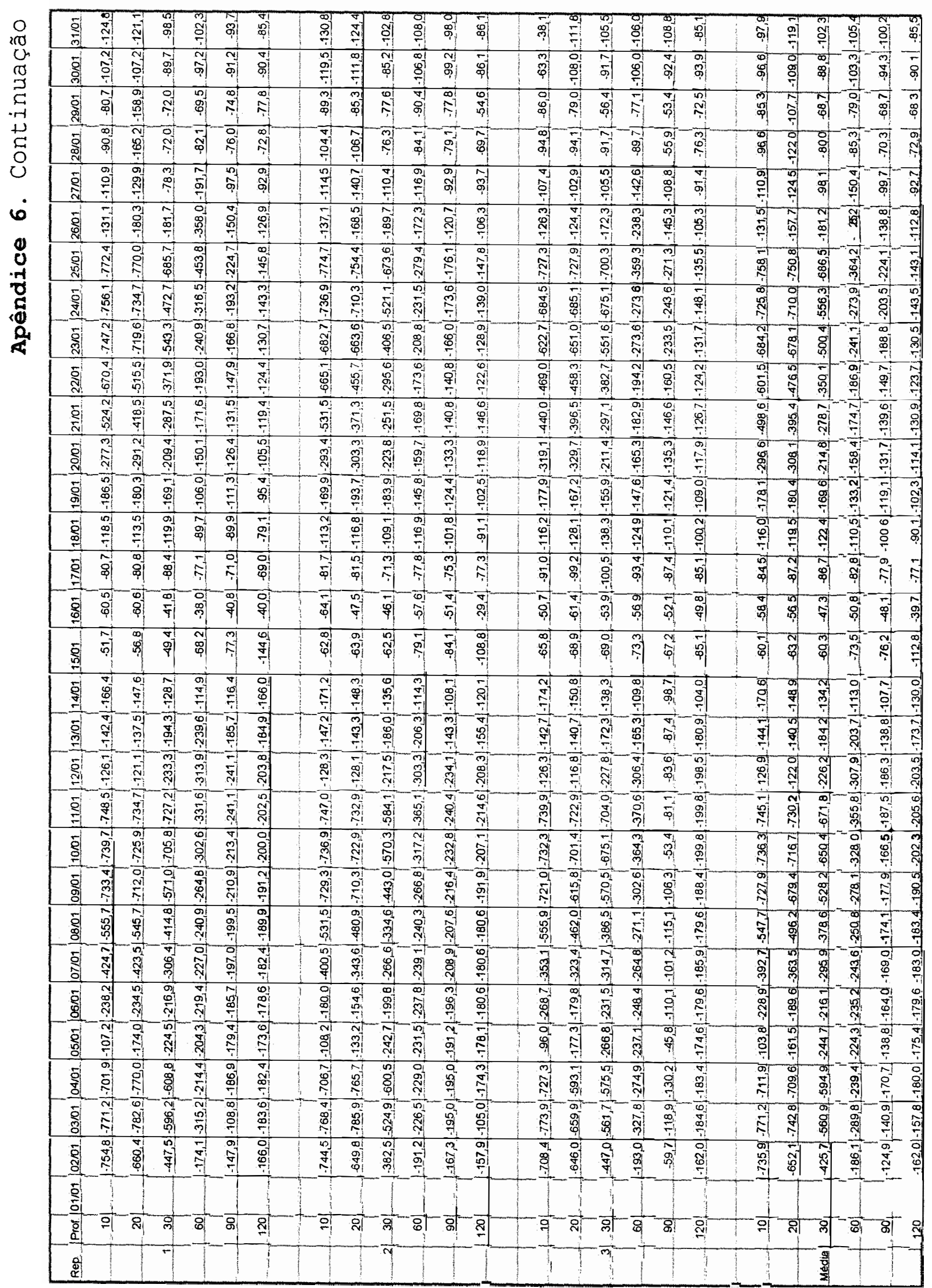




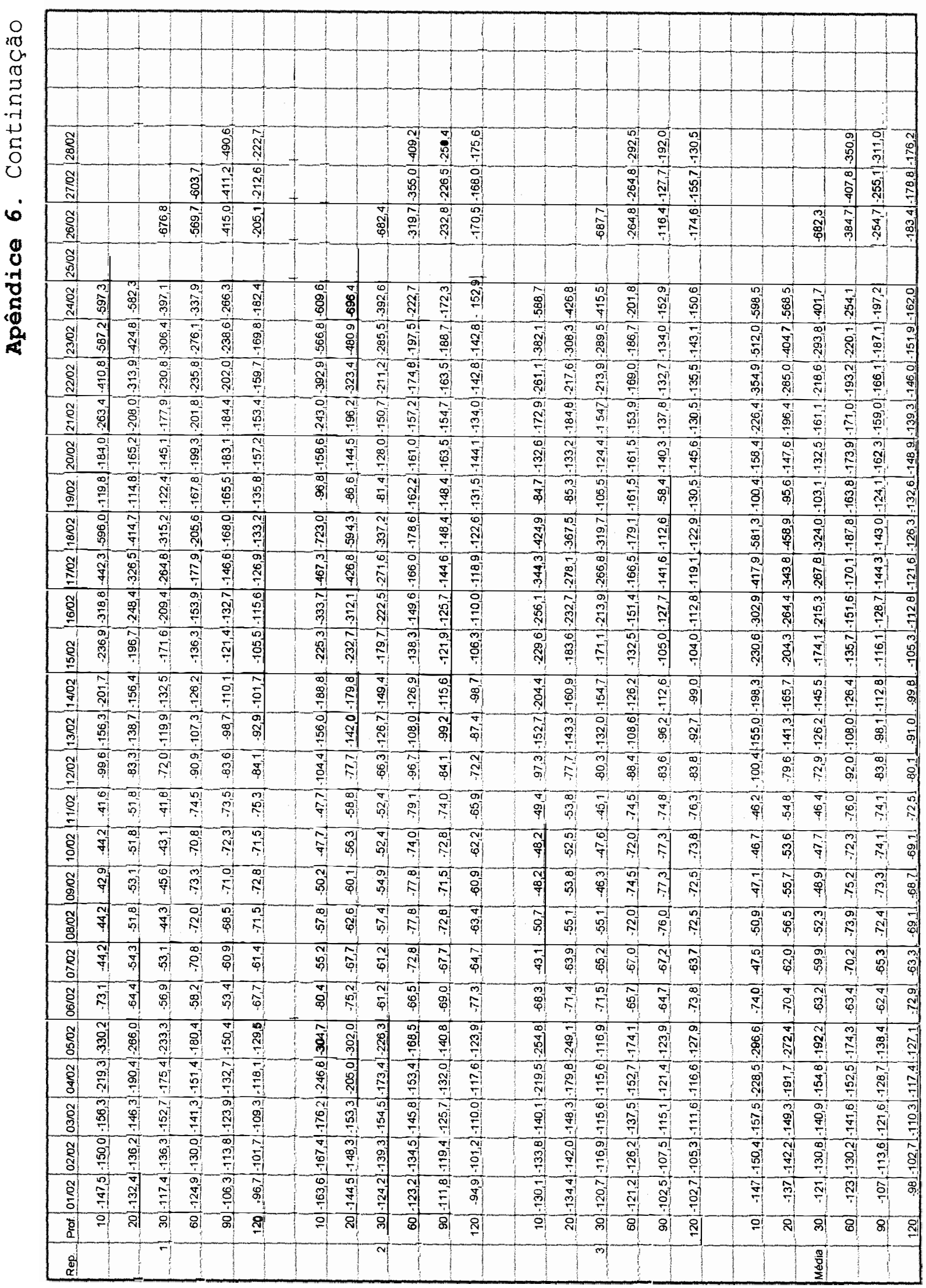




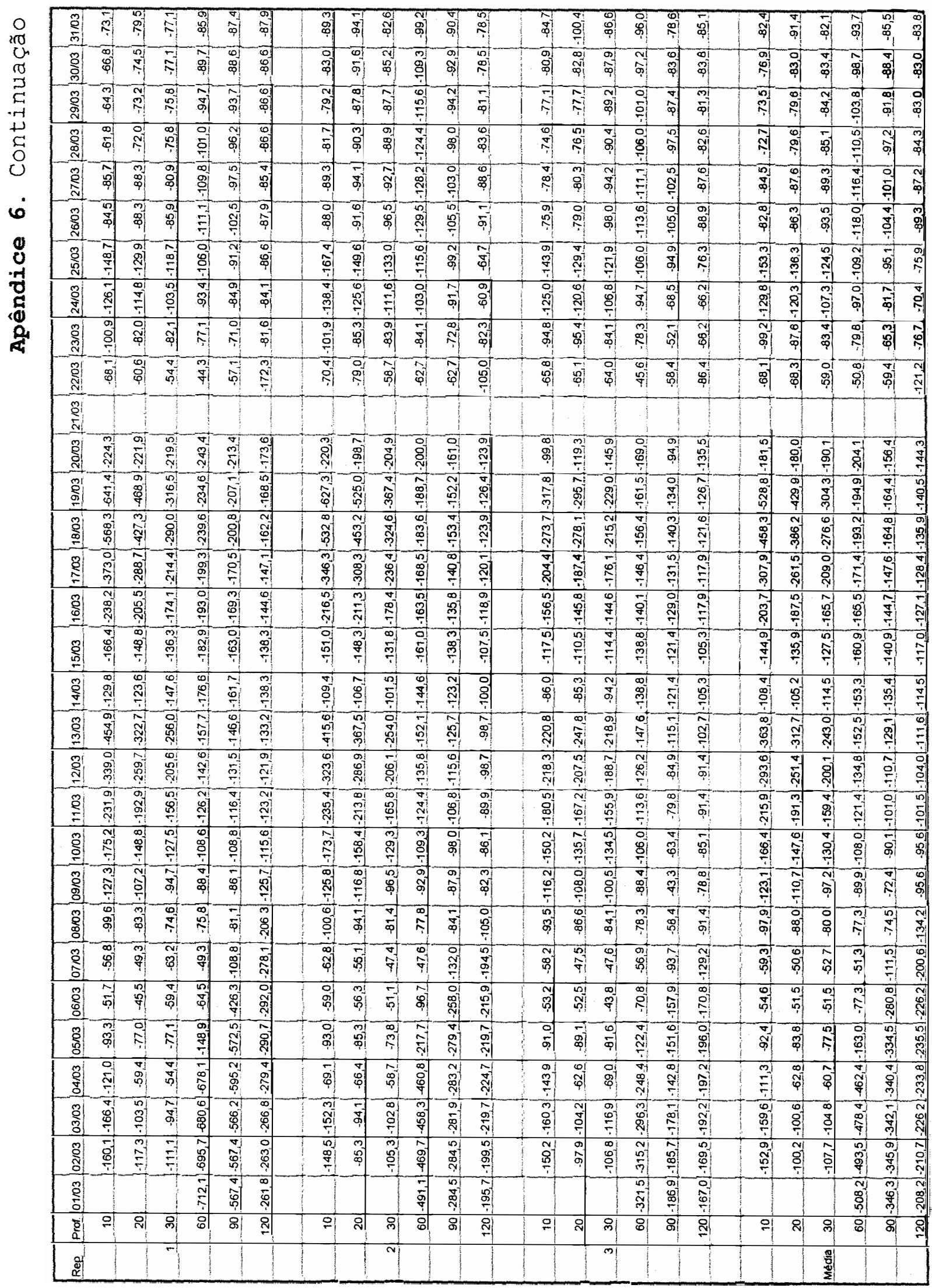




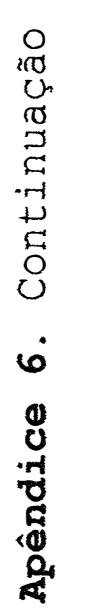

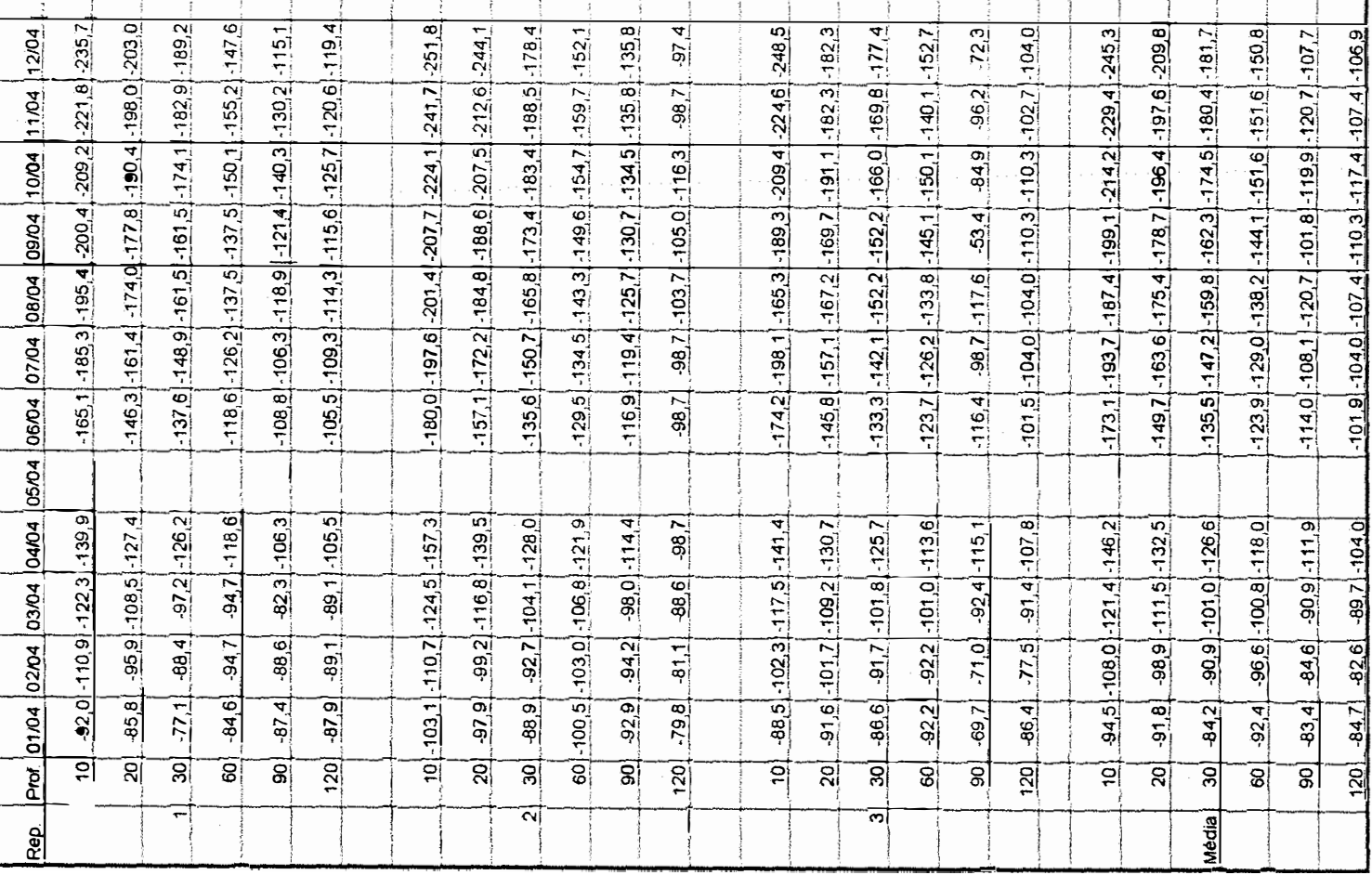




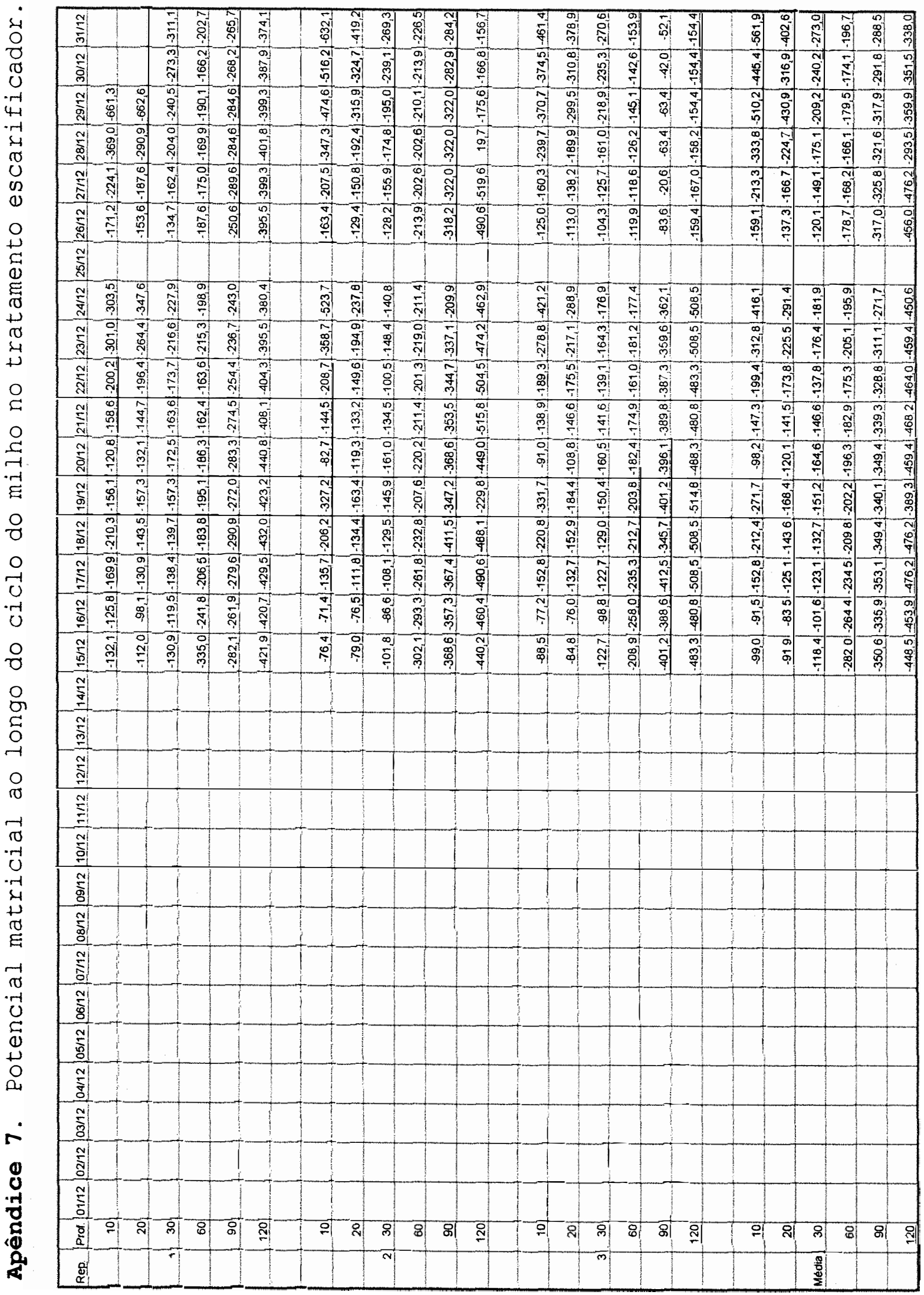




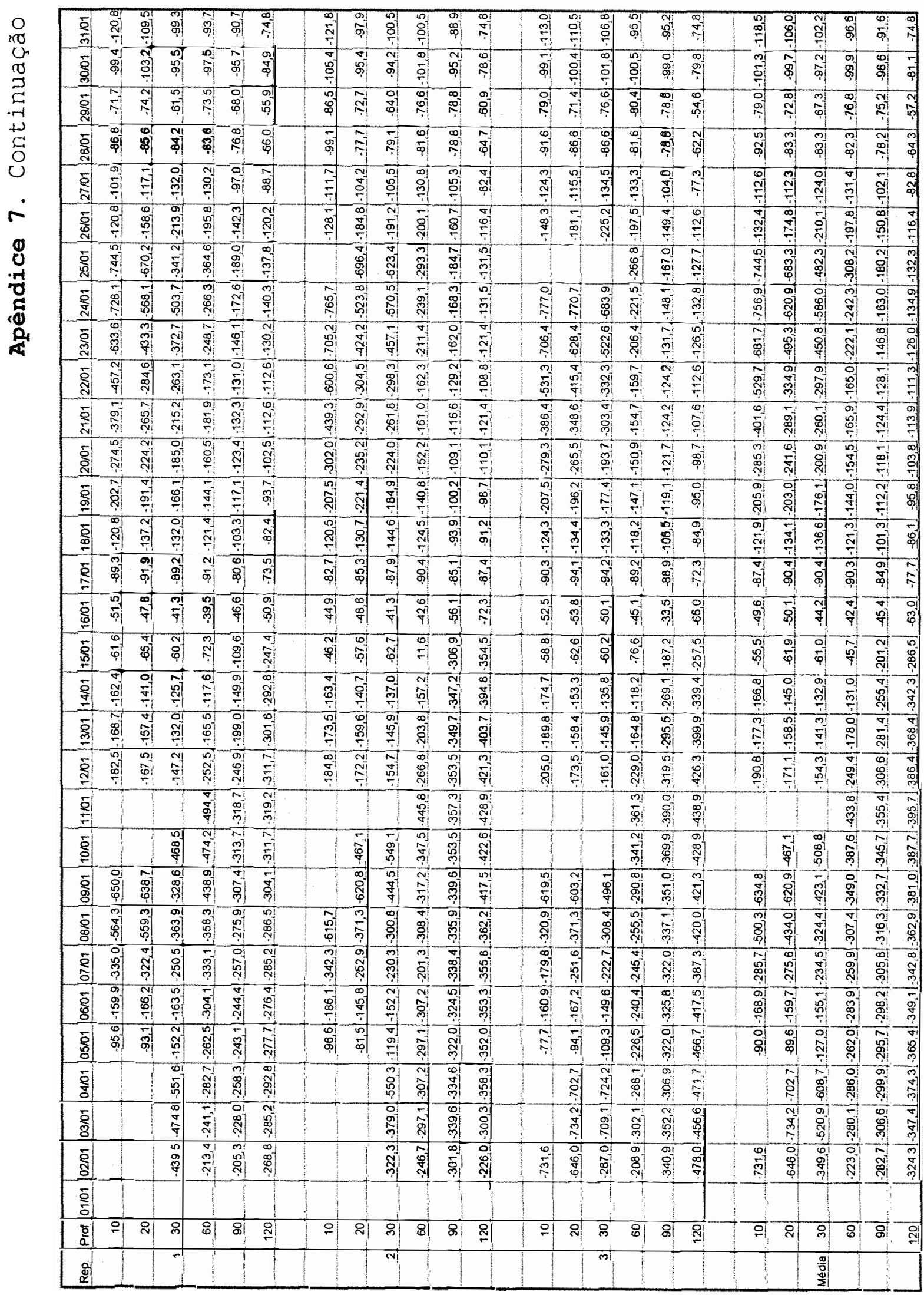




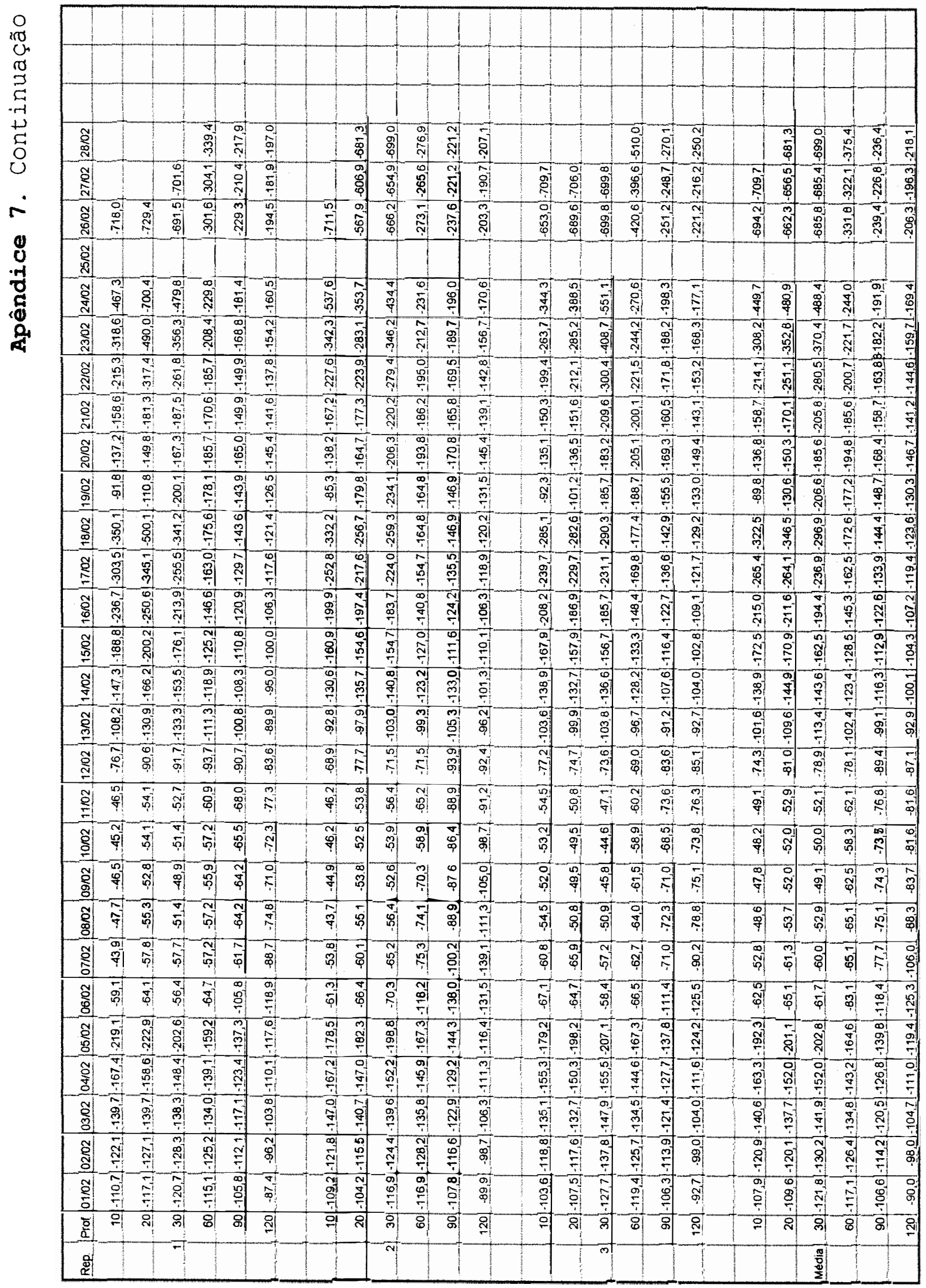




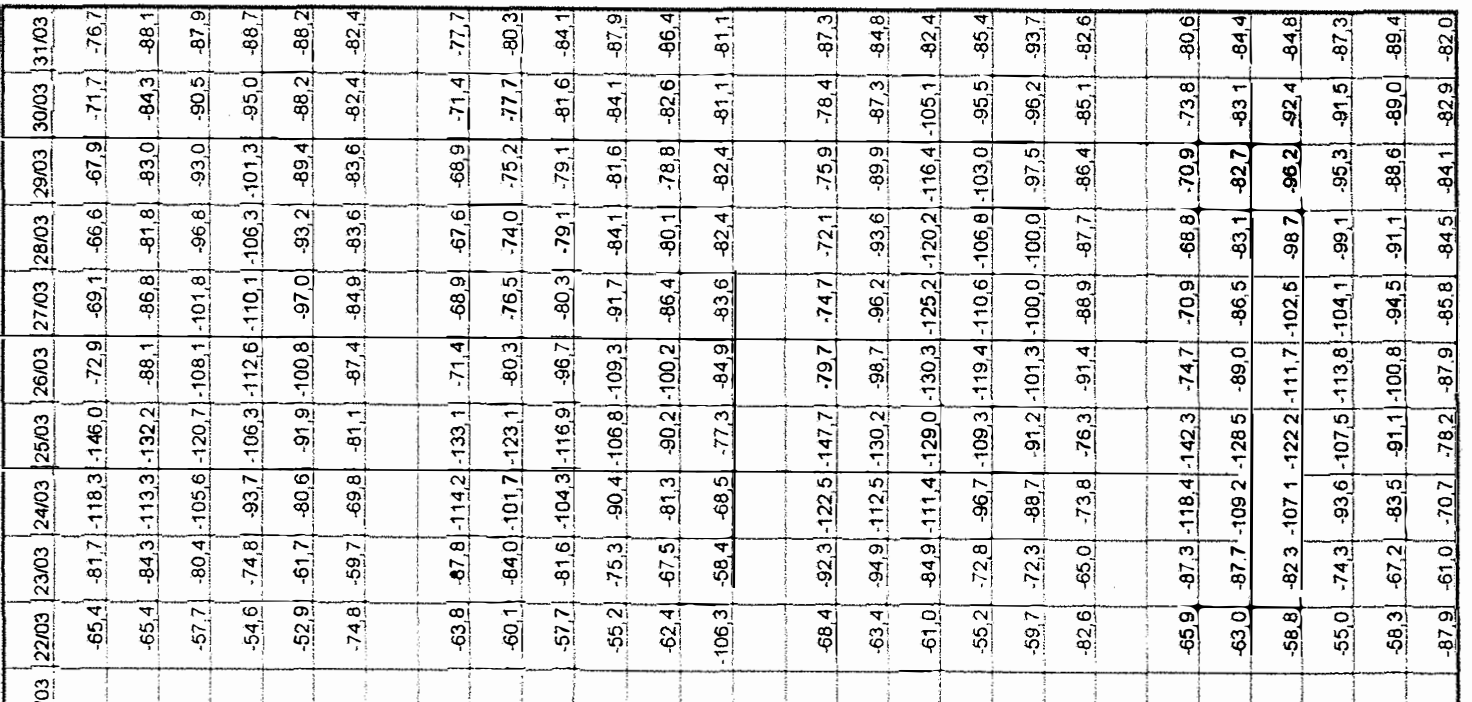

?.:

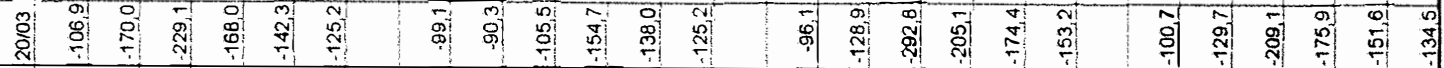

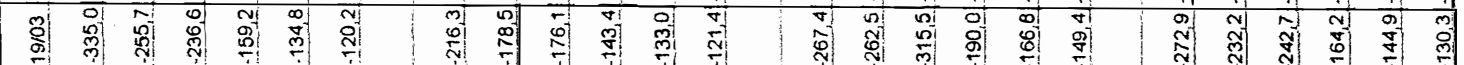

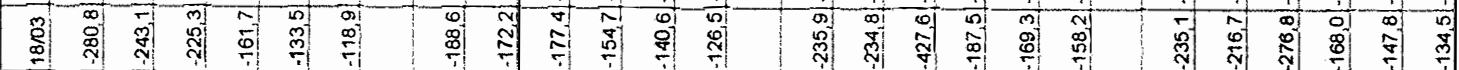

रु

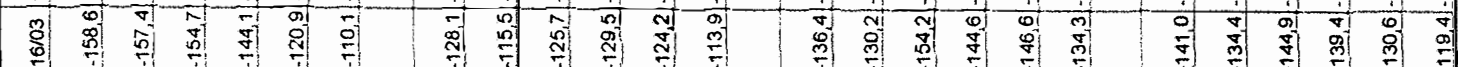

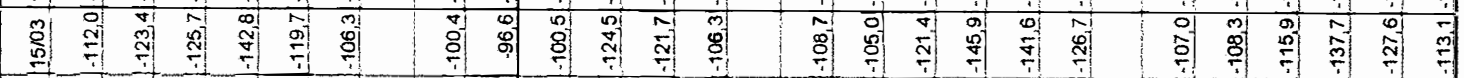

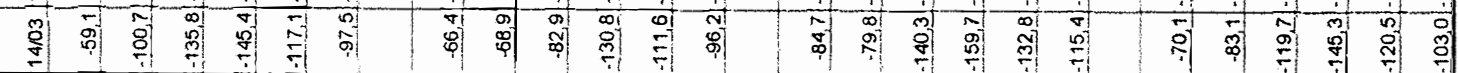

कै तै क्षी

क्ञ

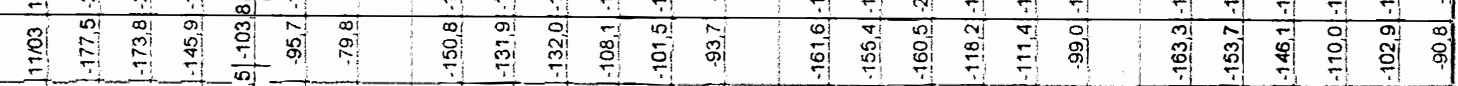

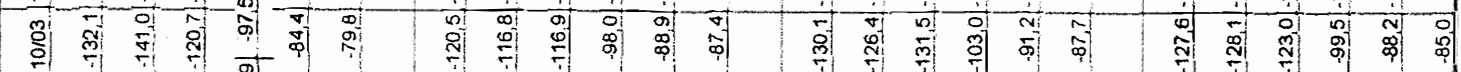

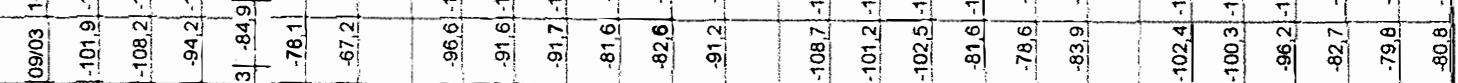

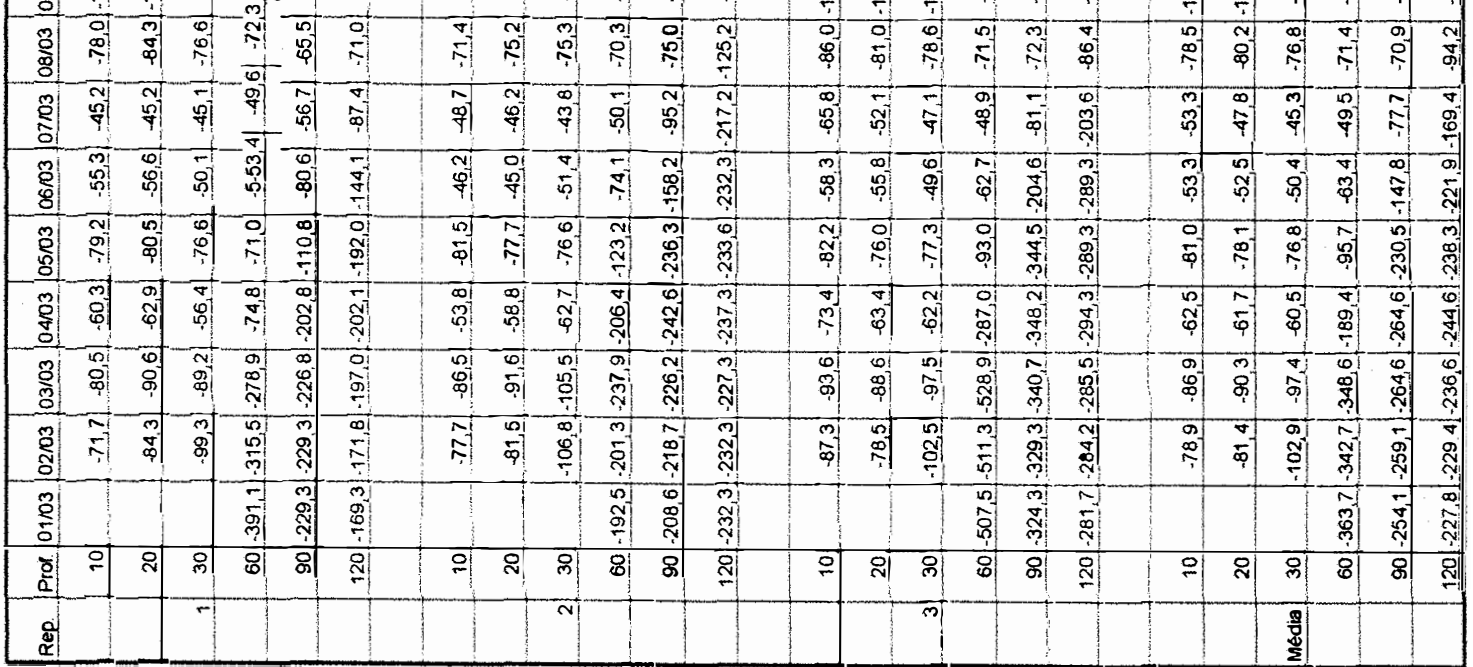




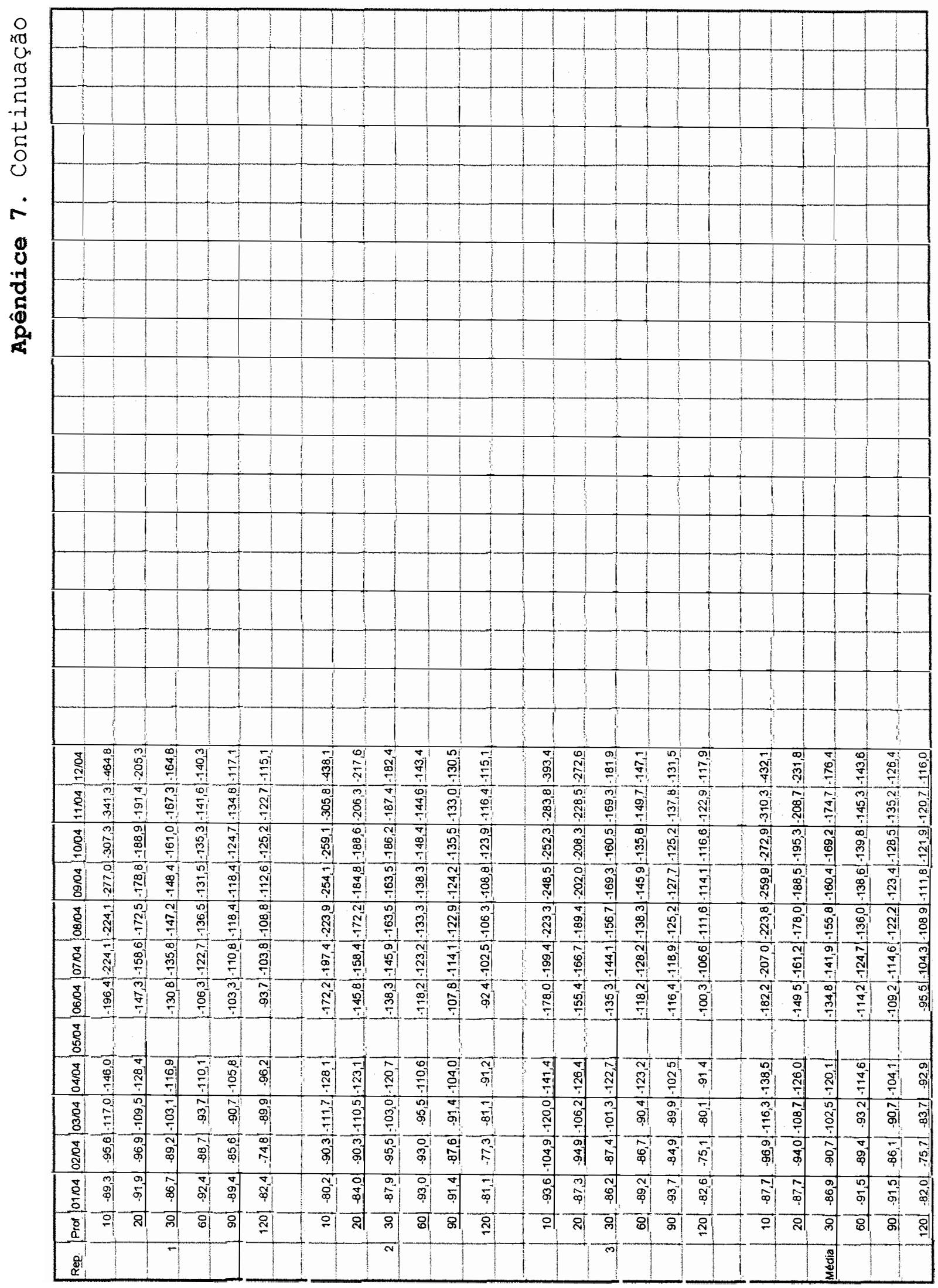




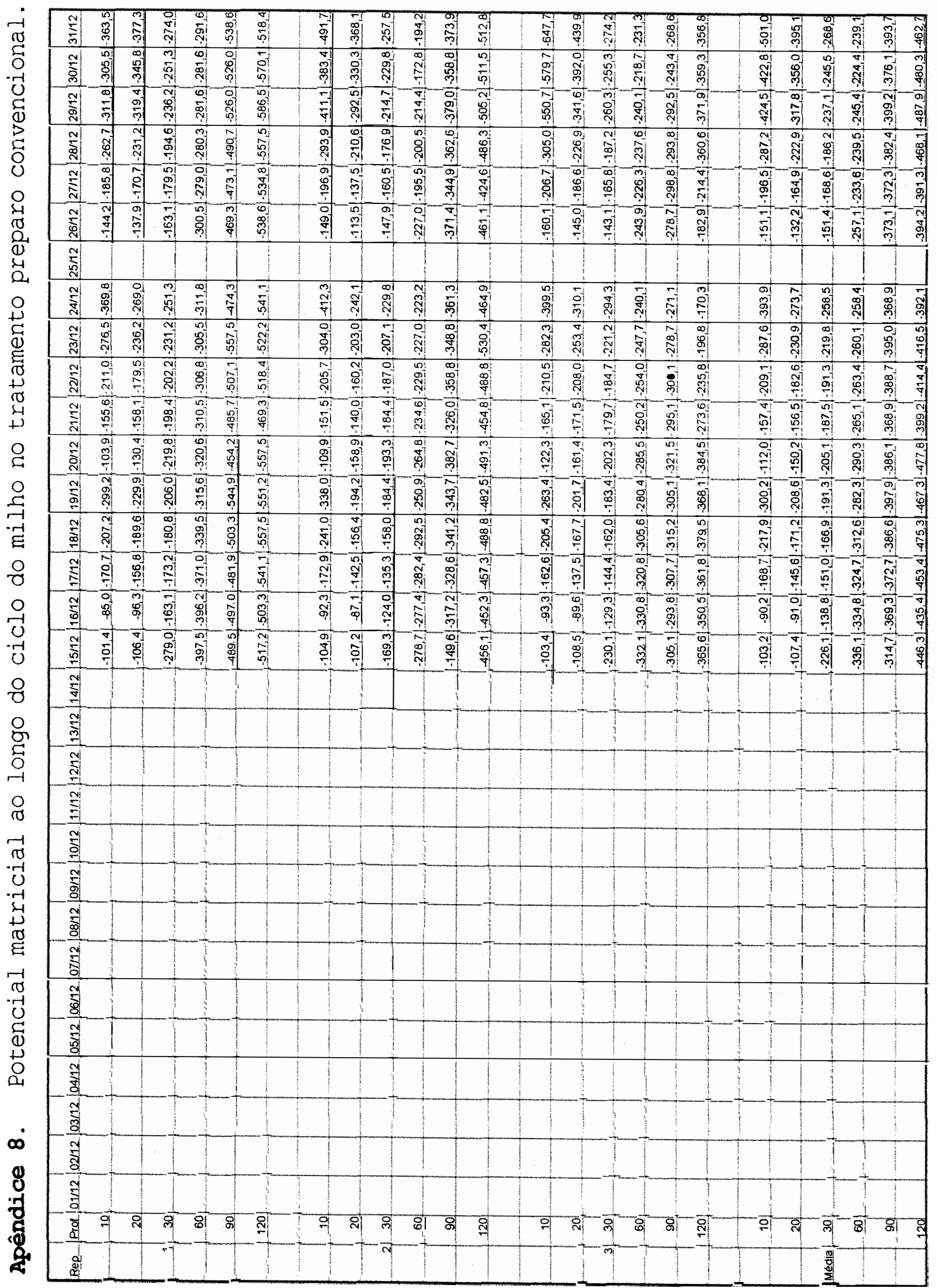




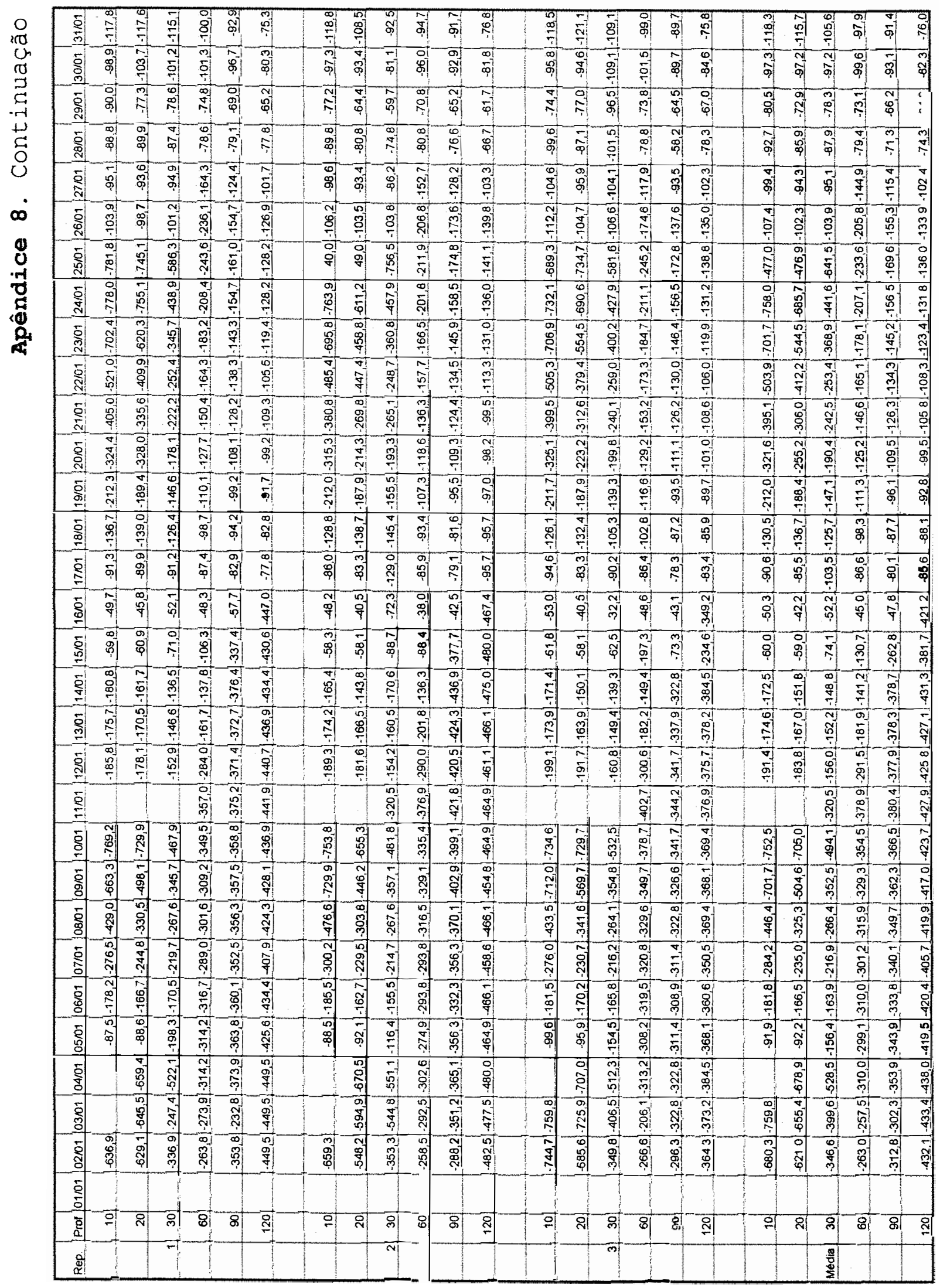




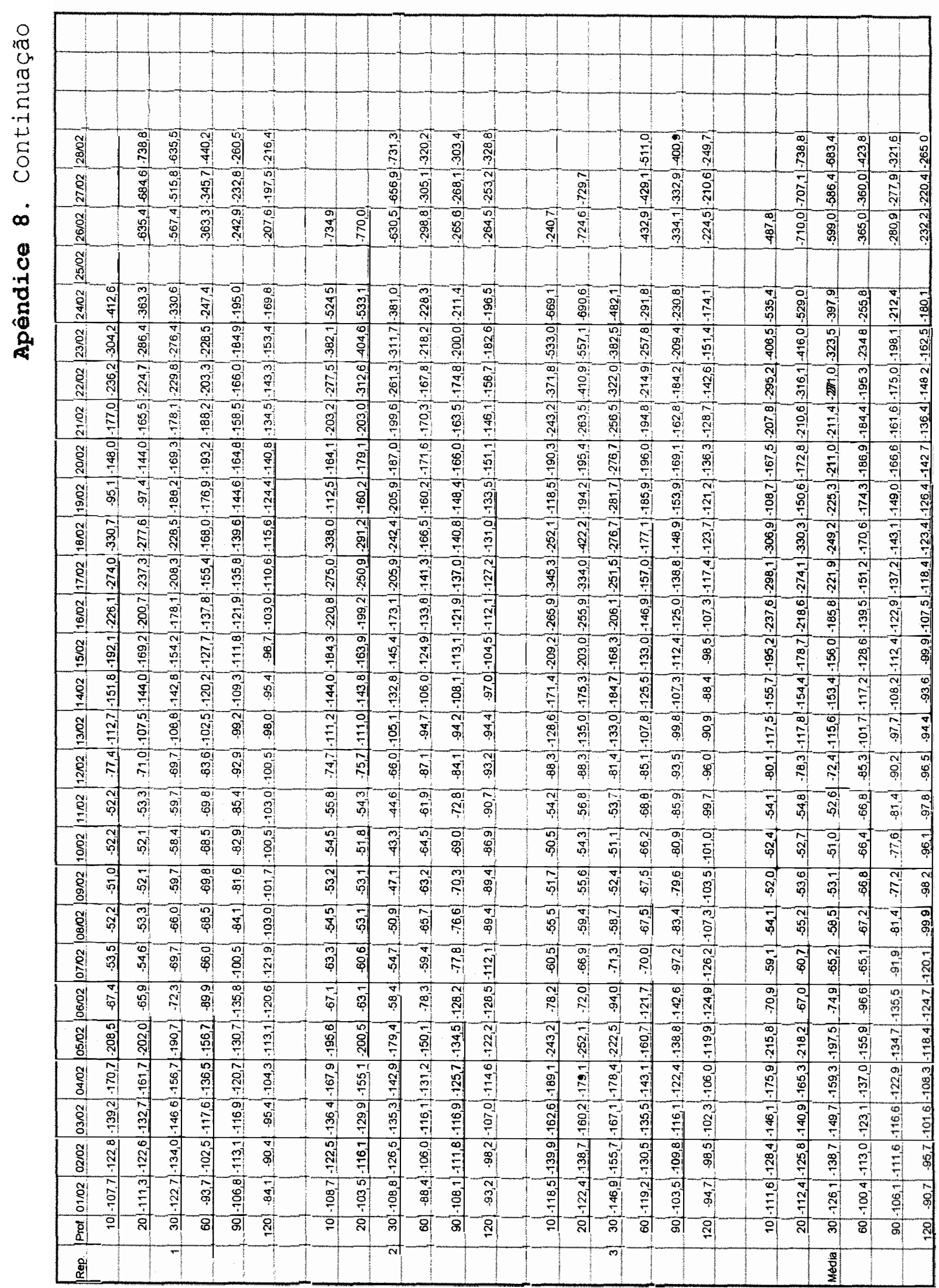




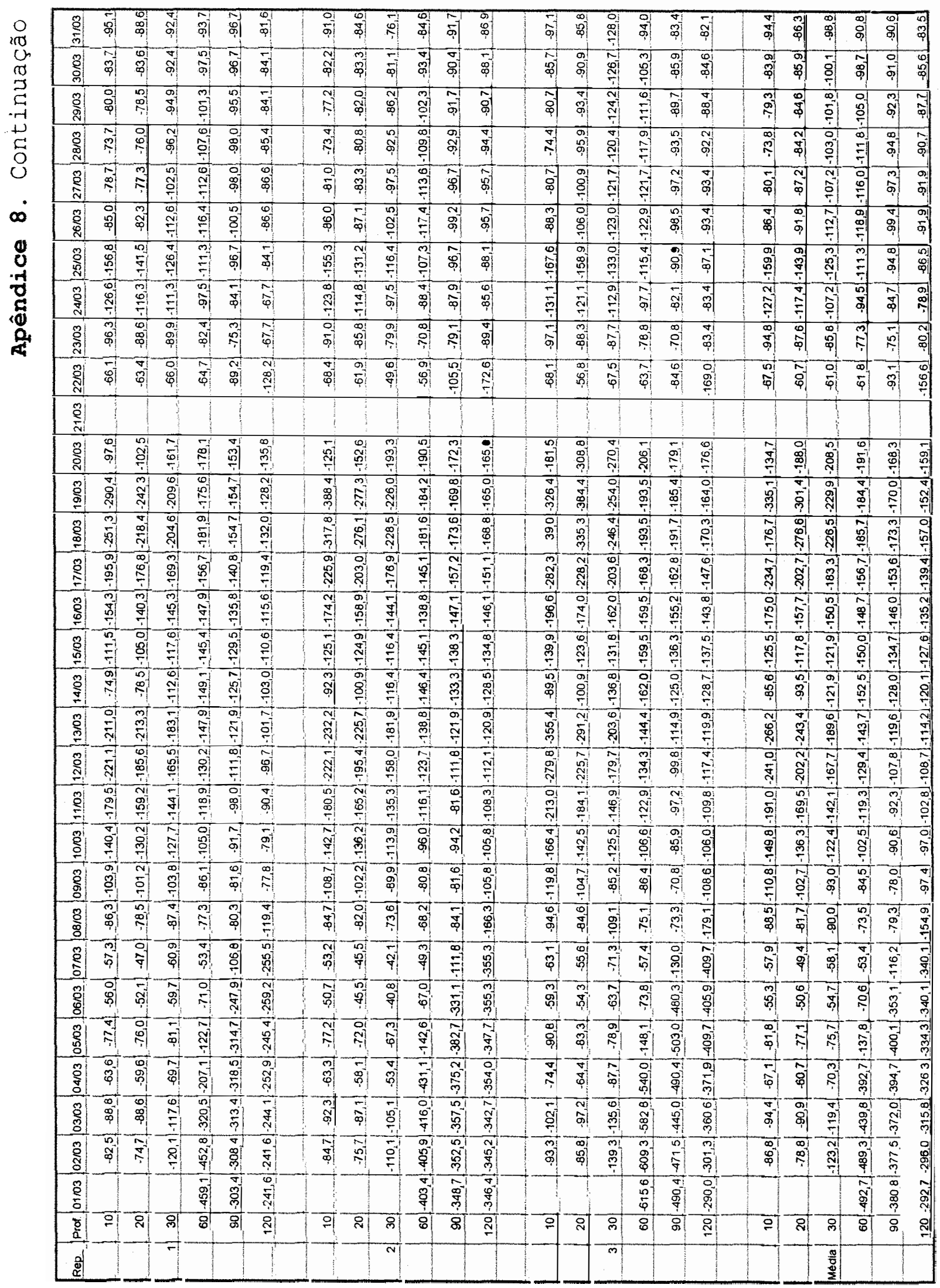




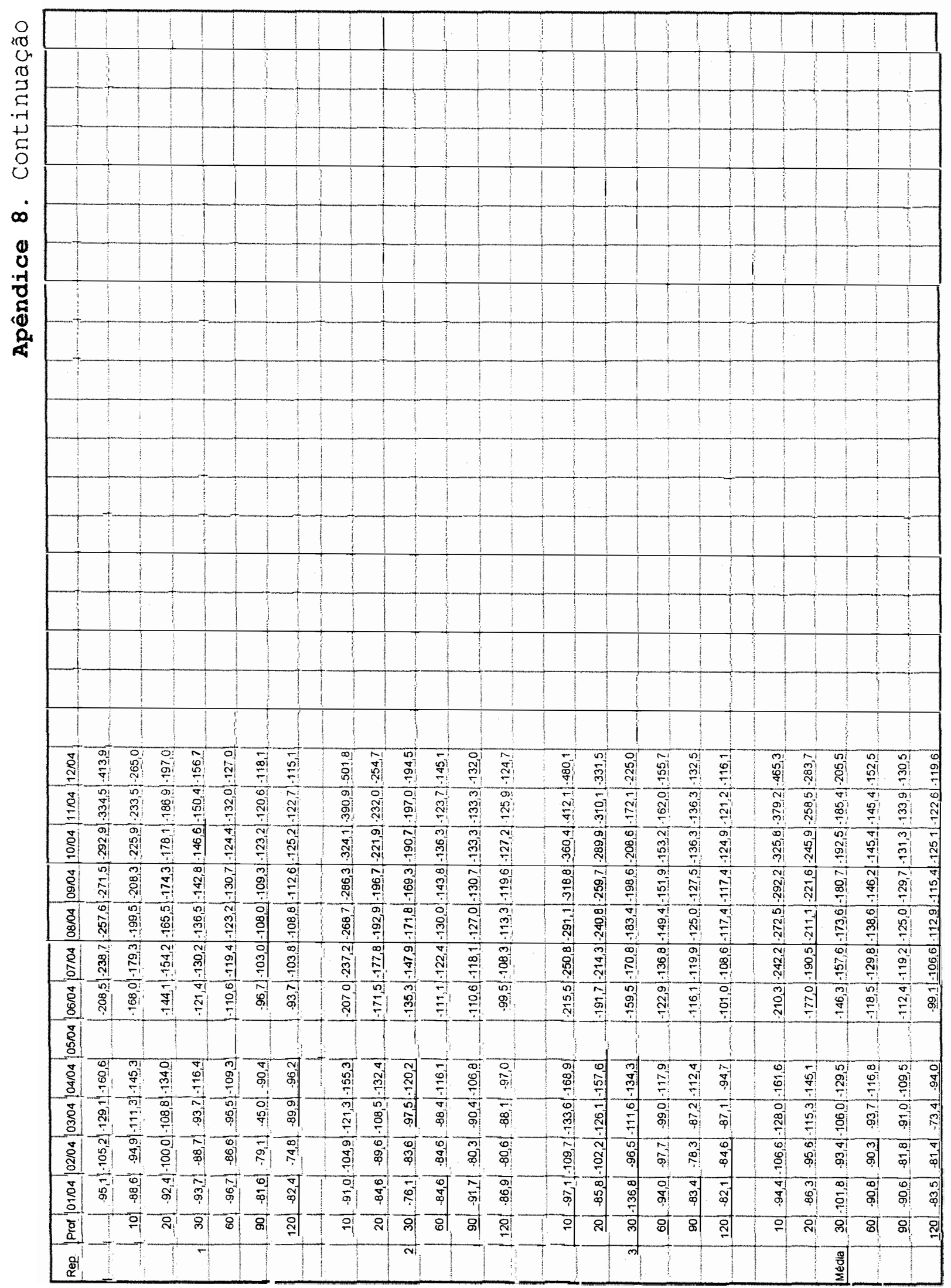




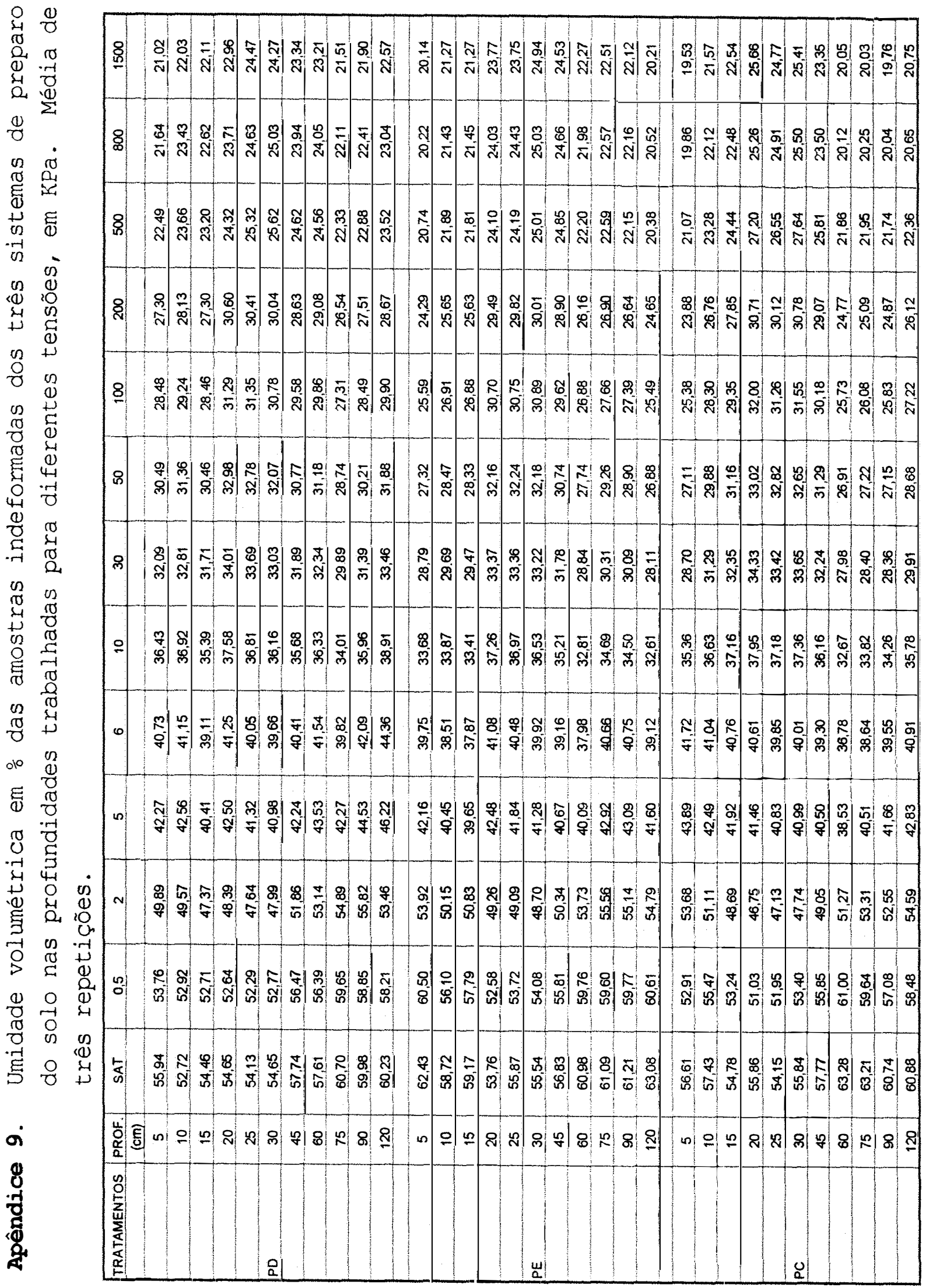


152.

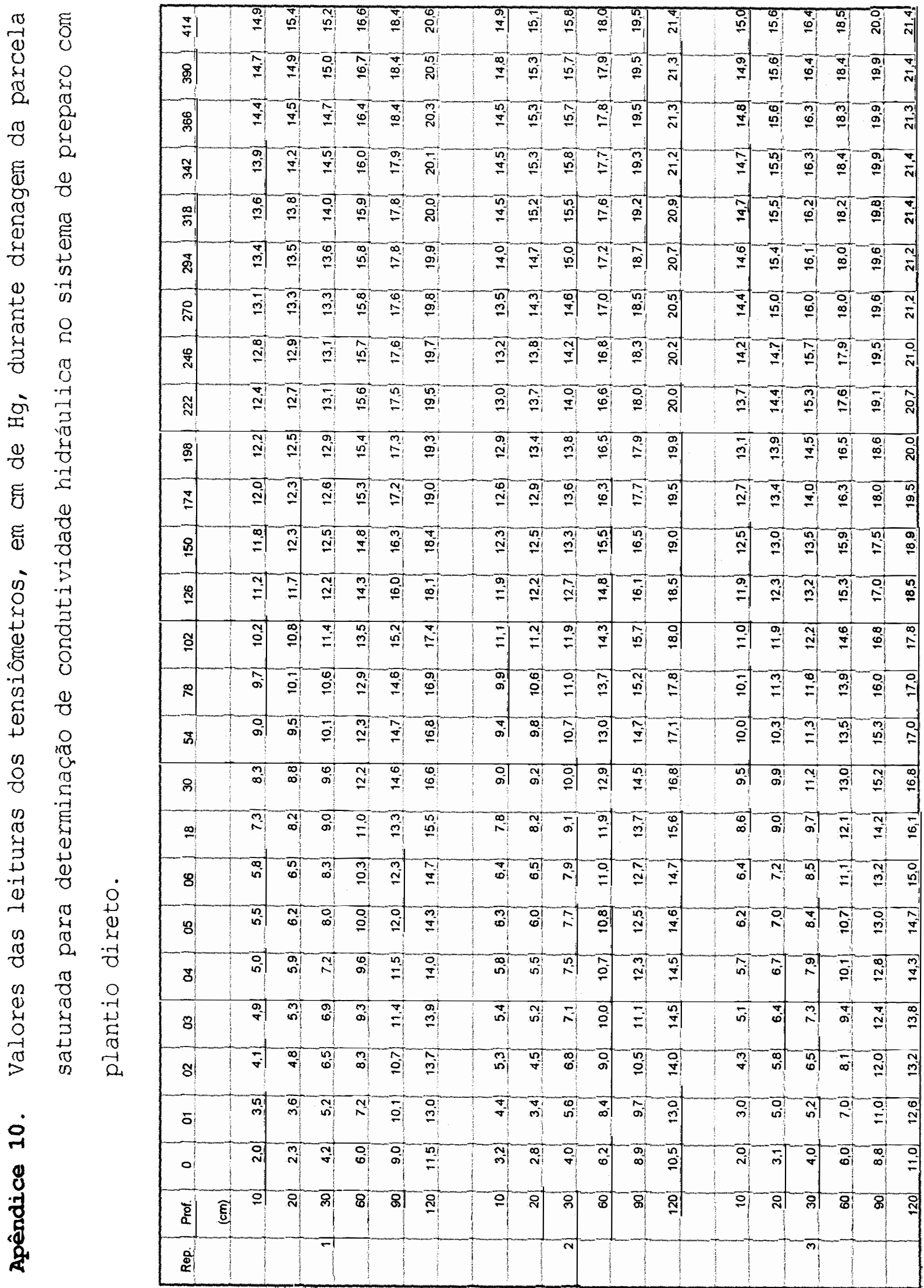




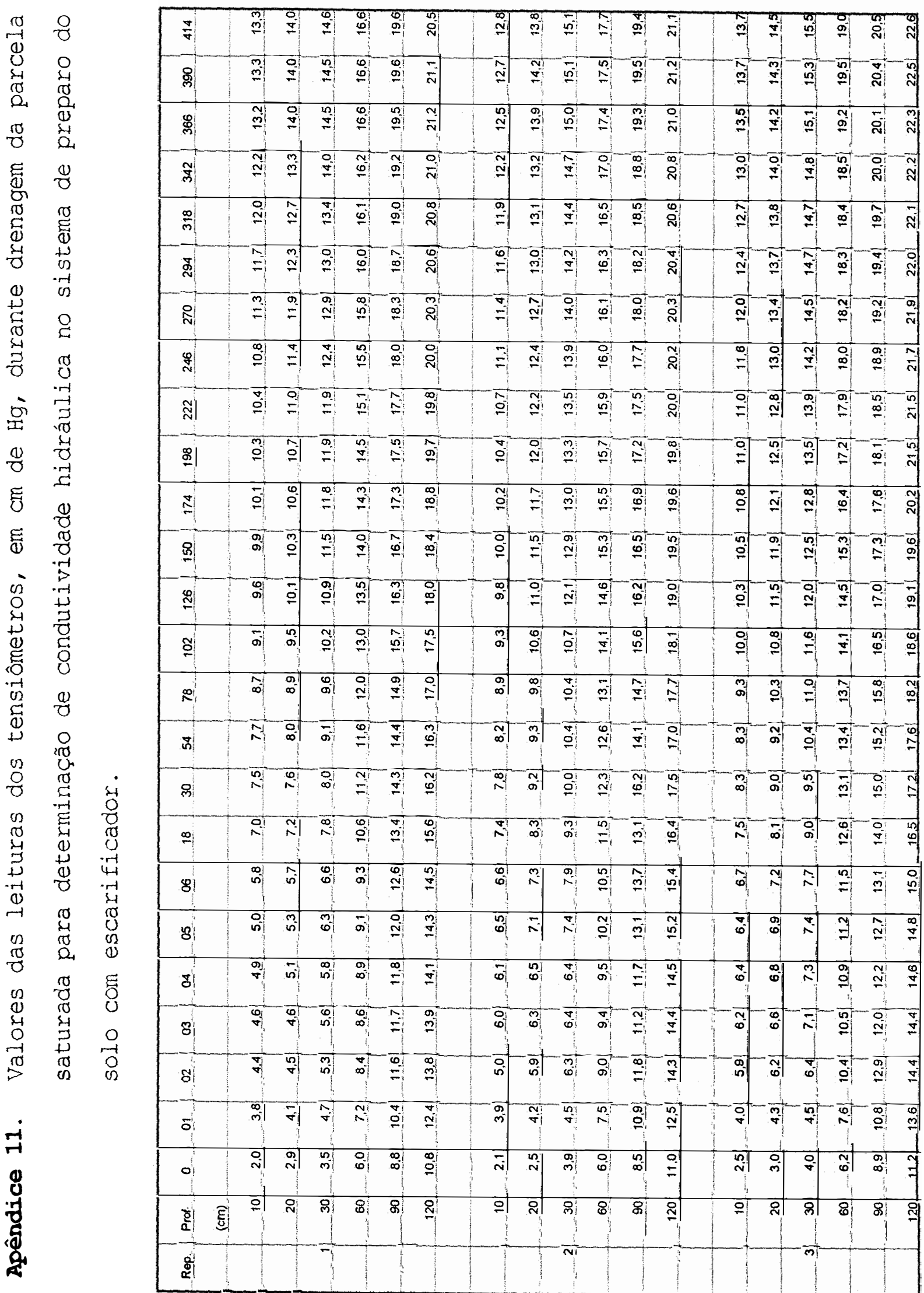


154.

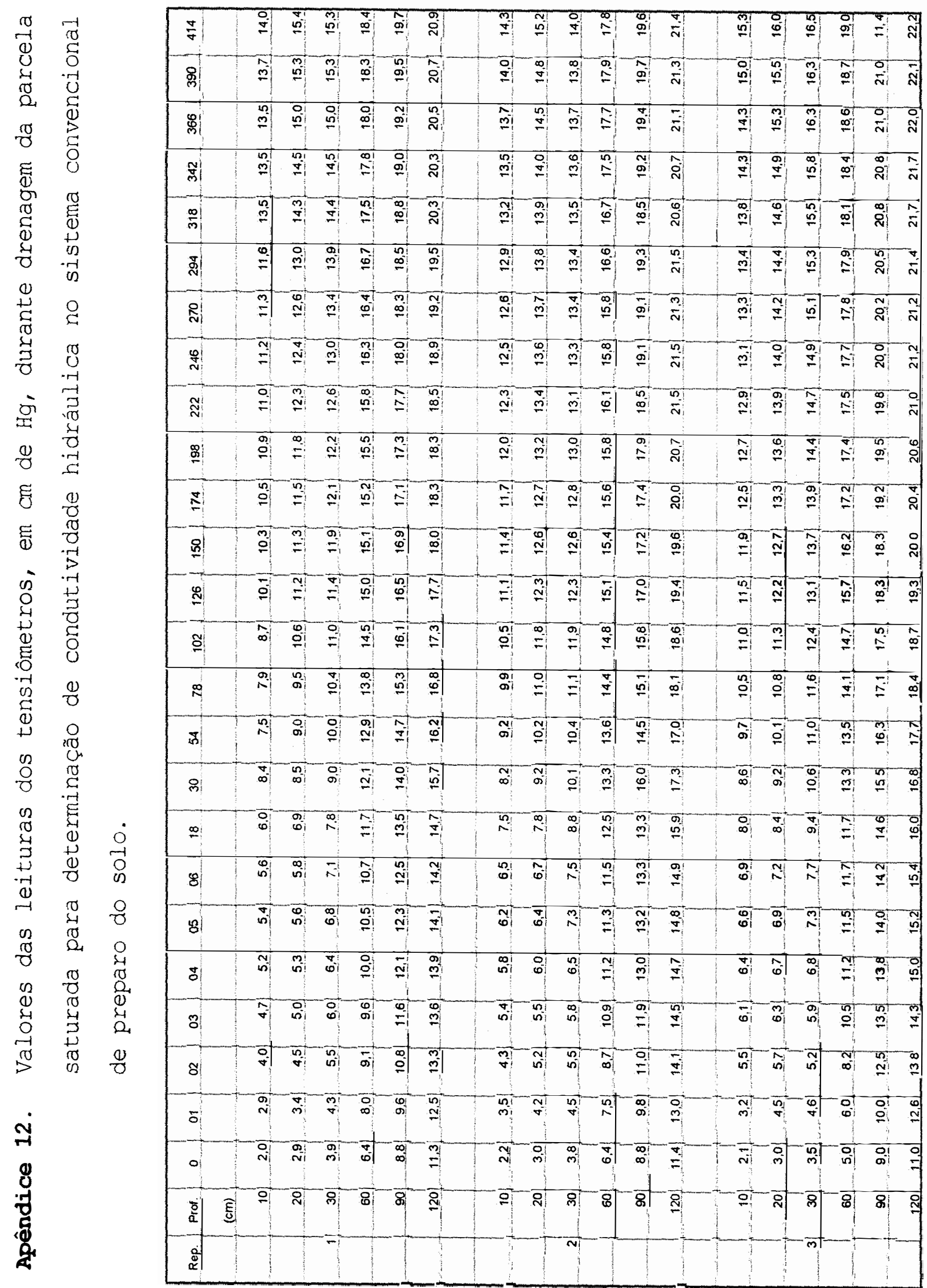


Apêndice 13. Dados utilizados e seqüência de cálculos para determinação da condutividade hidráulica no plantio direto.

DADOS UTILIZADOS:

$\begin{array}{llccccc}\text { Prof. } & 10 \mathrm{~cm} & 20 \mathrm{~cm} & 30 \mathrm{~cm} & 60 \mathrm{~cm} & 90 \mathrm{~cm} & 120 \mathrm{~cm} \\ \text { Alfa } & 0.0536 / \mathrm{cm} & 0.1243 / \mathrm{cm} & 0.1002 / \mathrm{cm} & 0.0517 / \mathrm{cm} & 0.0442 / \mathrm{cm} & 0.0599 / \mathrm{cm} \\ \text { Eme } & 0.2411 & 0.1468 & 0.2343 & 0.3224 & 0.3549 & 0.2560 \\ \text { Ene } & 1.3176 & 1.1720 & 1.3059 & 1.4757 & 1.5501 & 1.3441 \\ \text { TETAr } & 0.1850 & 0.1100 & 0.2140 & 0.2290 & 0.2200 & 0.1870 \\ \text { TETAs } & 0.5370 & 0.5510 & 0.5510 & 0.5810 & 0.6060 & 0.6040 \\ \text { H cuba } & 20.0 \mathrm{~cm} & 20.0 \mathrm{~cm} & 20.0 \mathrm{~cm} & 20.0 \mathrm{~cm} & 20.0 \mathrm{~cm} & 20.0 \mathrm{~cm}\end{array}$

Leitura tensiômetros (cm de ascensão de mercúrio)

$\begin{array}{rr}\text { tempo }(\mathrm{h}) & 10 \mathrm{~cm} \\ 0.0 & 2 . \\ 1.0 & 3 . \\ 2.0 & 4 . \\ 3.0 & 5 . \\ 4.0 & 5.5 \\ 5.0 & 6 . \\ 6.0 & 6.2 \\ 18.0 & 7.9 \\ 30.0 & 8.9 \\ 54.0 & 9.5 \\ 78.0 & 9.9 \\ 102.0 & 10.8 \\ 126.0 & 11.7 \\ 150.0 & 12 . \\ 174.0 & 12.4 \\ 198.0 & 12.7 \\ 222.0 & 13.0 \\ 246.0 & 13.4 \\ 270.0 & 13.7 \\ 294.0 & 14.0 \\ 318.0 & 14.3 \\ 342.0 & 14.4 \\ 366.0 & 14.6 \\ 390.0 & 14.8 \\ 414.0 & 14.9\end{array}$

$\begin{array}{rrr}\text { cm } & 20 \text { cm } & 30 \mathrm{~cm} \\ 2.4 & 2.7 & 4.1 \\ 3.6 & 4.0 & 5.3 \\ 4.6 & 5.0 & 6.6 \\ 5.1 & 5.6 & 7.1 \\ 5.5 & 6.0 & 7.5 \\ 6.0 & 6.4 & 8.0 \\ 6.2 & 6.7 & 8.2 \\ 7.9 & 8.5 & 9.3 \\ 8.9 & 9.3 & 10.3 \\ 9.5 & 9.9 & 10.7 \\ 9.9 & 10.7 & 11.1 \\ 10.8 & 11.3 & 11.8 \\ 11.7 & 12.1 & 12.7 \\ 12.2 & 12.6 & 13.1 \\ 12.4 & 12.9 & 13.4 \\ 12.7 & 13.3 & 13.7 \\ 13.0 & 13.6 & 14.1 \\ 13.4 & 13.8 & 14.3 \\ 13.7 & 14.2 & 14.6 \\ 14.0 & 14.5 & 14.9 \\ 14.3 & 14.8 & 15.2 \\ 14.4 & 15.0 & 15.5 \\ 14.6 & 15.1 & 15.6 \\ 14.8 & 15.3 & 15.7 \\ 14.9 & 15.4 & 15.8\end{array}$

Método Hillel

Potencial mátrico (cca)

$\begin{array}{rr}\text { tempo (h) } & 10 \mathrm{~cm} \\ 0.0 & -0.0 \\ 1.0 & -15.0 \\ 2.0 & -27.5 \\ 3.0 & -33.8 \\ 4.0 & -38.8 \\ 5.0 & -45.0 \\ 6.0 & -47.5 \\ 18.0 & -68.8 \\ 30.0 & -81.2 \\ 54.0 & -88.8 \\ 78.0 & -93.7\end{array}$

$20 \mathrm{~cm}$
6.2
-10.0
-22.5
-30.0
-35.0
-40.0
-43.7
-66.3
-76.3
-83.7
-93.8

$30 \mathrm{~cm}$
-1.2
-16.3
-32.5
-38.8
-43.8
-50.0
-52.5
-66.3
-78.8
-83.8
-88.8

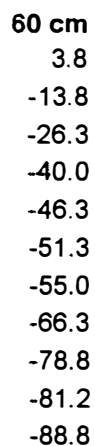

$90 \mathrm{~cm}$

$120 \mathrm{~cm}$ 2.5 $-21.2$ $-30.0$ $-36.3$ $-38.8$ $-41.3$ $-45.0$ $-56.2$ $-68.8$ $-72.5$ $-75.0$ 
Apêndice 13. Continuação

$\begin{array}{lll}102.0 & -105.0 & -101.3 \\ 126.0 & -116.3 & -111.3 \\ 150.0 & -122.5 & -117.5 \\ 174.0 & -125.0 & -121.2 \\ 198.0 & -128.8 & -126.3 \\ 222.0 & -132.5 & -130.0 \\ 246.0 & -137.5 & -132.5 \\ 270.0 & -141.3 & -137.5 \\ 294.0 & -145.0 & -141.3 \\ 318.0 & -148.8 & -145.0 \\ 342.0 & -150.0 & -147.5 \\ 366.0 & -152.5 & -148.8 \\ 390.0 & -155.0 & -151.3 \\ 414.0 & -156.3 & -152.5\end{array}$

$$
\begin{array}{r}
-97.5 \\
-108.8 \\
-113.8 \\
-117.5 \\
-121.3 \\
-126.3 \\
-128.8 \\
-132.5 \\
-136.3 \\
-140.0 \\
-143.8 \\
-145.0 \\
-146.3 \\
-147.5
\end{array}
$$

\section{$-96.3$}

$-105.0$

$-112.5$

$-120.0$

$-121.3$

$-127.5$

$-130.0$

$-131.3$

$-132.5$

$-135.0$

$-137.5$

$-138.8$

$-141.3$

$-141.3$

$\begin{array}{rr}-88.7 & -81.3 \\ -95.0 & -90.0 \\ -100.0 & -95.0 \\ -110.0 & -101.2 \\ -113.7 & -106.3 \\ -117.5 & -111.3 \\ -121.3 & -113.7 \\ -122.5 & -116.3 \\ -123.8 & -117.5 \\ -126.2 & -120.0 \\ -127.5 & -121.2 \\ -131.2 & -122.5 \\ -131.2 & -123.8 \\ -131.2 & -123.8\end{array}$

Umidade volumétrica

tempo (h)

0.0
1.0

$$
2.0
$$$$
3.0
$$$$
4.0
$$$$
5.0
$$$$
6.0
$$

18.0

30.0

54.0

78.0

102.0

126.0

150.0

174.0

198.0

222.0

246.0

270.0

294.0

318.0

342.0

366.0

390.0

414.0
$10 \mathrm{~cm}$
0.537
0.493
0.463
0.451
0.443
0.434
0.431
0.409
0.399
0.393
0.390
0.384
0.378
0.375
0.374
0.372
0.371
0.369
0.367
0.366
0.364
0.364
0.363
0.362
0.362

Ajuste à equaçāo TETA $=a \cdot$ tempo^b

$10 \mathrm{~cm}$
0.46497
-0.04166
0.96704

\section{$20 \mathrm{~cm}$}

0.516

0.500

0.466

0.452

0.444

0.438

0.433

0.413

0.406

0.402

0.397

0.393

0.389

$$
0.386
$$$$
0.385
$$

$$
0.383
$$$$
0.382
$$$$
0.381
$$

0.379

0.378

0.377

$$
0.376
$$

0.376

0.375

0.375

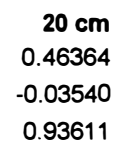
$30 \mathrm{~cm}$
$-0.03864$
0.97736

0.371

0.361

0.361

\section{$30 \mathrm{~cm}$}

0.546
0.477

0.438

0.428

0.422
0.414

0.412

0.399

0.390

0.387

0.384

0.380

0.375

0.373

0.370

0.368

0.367

0.366

0.364

0.363

0.362

0.362

\section{$60 \mathrm{~cm}$}

0.571
0.531

0.489

0.456

0.444

0.436

0.430

0.416

0.403

0.400

0.394

0.388

0.382

0.378

0.374

0.373

0.370

0.369

0.368

0.367

0.366

0.365

0.365

0.363

0.363

$60 \mathrm{~cm}$
0.48112
-0.04737
0.94338

$90 \mathrm{~cm}$
0.50054
-0.05321
0.96590

$90 \mathrm{~cm}$

$120 \mathrm{~cm}$

0.521

$0.501 \quad 0.497$

$0.482 \quad 0.483$

$0.464 \quad 0.478$

$0.455 \quad 0.473$

$0.450 \quad 0.466$

$0.428 \quad 0.449$

$0.410 \quad 0.434$

$0.408 \quad 0.430$

$0.402 \quad 0.428$

$0.395 \quad 0.422$

$0.389 \quad 0.415$

$0.385 \quad 0.411$

$0.377 \quad 0.406$

$0.374 \quad 0.403$

$0.372 \quad 0.400$

$0.369 \quad 0.398$

$0.369 \quad 0.397$

$0.368 \quad 0.396$

$0.366 \quad 0.395$

$0.366 \quad 0.394$

$0.363 \quad 0.394$

$0.363 \quad 0.393$

$\begin{array}{ll}0.363 & 0.393\end{array}$

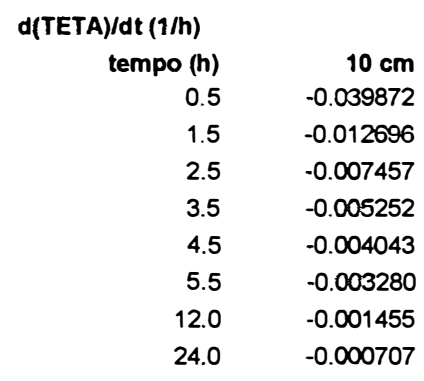

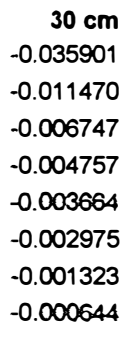

$90 \mathrm{~cm}$
-0.055274
-0.017378
-0.010147
-0.007120
-0.005464
-0.004423
-0.001945
-0.000937

$120 \mathrm{~cm}$
-0.043307
-0.013790
-0.008100
-0.005705
-0.004391
-0.003563
-0.001581
-0.000768

$120 \mathrm{~cm}$ 0.50498

$-0.04166$

0.98853 


$\begin{array}{rr}42.0 & -0.000395 \\ 66.0 & -0.000246 \\ 90.0 & -0.000178 \\ 114.0 & -0.000139 \\ 138.0 & -0.000114 \\ 162.0 & -0.000097 \\ 186.0 & -0.000084 \\ 210.0 & -0.000074 \\ 234.0 & -0.000066 \\ 258.0 & -0.000060 \\ 282.0 & -0.000054 \\ 306.0 & -0.000050 \\ 330.0 & -0.000046 \\ 354.0 & -0.000043 \\ 378.0 & -0.000040 \\ 402.0 & -0.000038\end{array}$

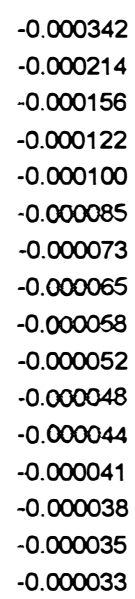

$-0.000360$ $-0.000225$ $-0.000163$ $-0.000128$ $-0.000105$ $-0.000089$ $-0.000077$

$-0.000068$ $-0.000060$ $-0.000055$ $-0.000050$ $-0.000046$ $-0.000042$ $-0.000039$ $-0.000037$ $-0.000034$

$d$ (TETA)/dt $x d z(\mathrm{~cm} / \mathrm{h})$ tempo (h)

$10 \mathrm{~cm}$
-0.398718
-0.126961
-0.074573
-0.052525
-0.040427
-0.032801
-0.014553
-0.007070
-0.003947
-0.002465
-0.001784
-0.001395
-0.001143
-0.000967
-0.000838
-0.000738
-0.000659
-0.000596
-0.000543
-0.000499
-0.000461
-0.000428
-0.000400
-0.000375

$30 \mathrm{~cm}$
$-0,359014$
$-0,114697$
$-0,067473$
$-0,047572$
$-0,036643$
$-0,029749$
$-0,013230$
$-0,006440$
$-0,003601$
$-0,002252$
$-0,001632$
$-0,001277$
$-0,001047$
$-0,000886$
$-0,000768$
$-0,000677$
$-0,000605$
$-0,000547$
$-0,000498$
$-0,000458$
$-0,000423$
$-0,000393$
$-0,000368$
$-0,000345$
$-0,000330$
Apêndice 13.

$-0.000455$ $-0.000283$ $-0.000205$ $-0.000160$ $-0.000131$ $-0.000111$ $-0.000096$ $-0.000084$ $-0.000075$ $-0.000068$ $-0.000062$ $-0.000057$ $-0.000052$ $-0.000049$ $-0.000046$ $-0.000043$

$60 \mathrm{~cm}$ $-1,413010$ $-0,447120$

$-0,261859$ $-0,184084$ $-0,141483$

$-0,114663$ $-0,050647$ $-0,024506$ $-0,013637$ $-0,008494$ $-0,006138$ $-0,004792$ $-0,003923$ $-0,003317$ $-0,002870$ $-0,002527$ $-0,002256$ $-0,002037$ $-0,001856$

$-0,001704$ $-0,001574$ $-0,001463$ $-0,001365$ $-0,001280$

\section{$q=$ Somatório $[d(T E T A) / d t \times d z](c m / h)$}

$\begin{array}{rr}\text { tempo }(\mathrm{h}) & 10 \mathrm{~cm} \\ 0.5 & -0.398718 \\ 1.5 & -0.126961 \\ 2.5 & -0.074573 \\ 3.5 & -0.052525 \\ 4.5 & -0.040427 \\ 5.5 & -0.032801 \\ 12.0 & -0014553 \\ 24.0 & -0.007070 \\ 42.0 & -0.003947 \\ 66.0 & -0.002465 \\ 90.0 & -0.001784 \\ 114.0 & -0.001395 \\ 138.0 & -0.001143 \\ 162.0 & -0.000967\end{array}$

$\begin{array}{ll}-0.000520 & -0.000429 \\ -0.000323 & -0.000268 \\ -0.000233 & -0.000194 \\ -0.000182 & -0.000151 \\ -0.000148 & -0.000124 \\ -0.000125 & -0.000105 \\ -0.000108 & -0.000091 \\ -0.000095 & -0.000080 \\ -0.000085 & -0.000072 \\ -0.000077 & -0.000065 \\ -0.000070 & -0.000059 \\ -0.000064 & -0.000054 \\ -0.000059 & -0.000050 \\ -0.000055 & -0.000047 \\ -0.000051 & -0.000043 \\ -0.000048 & -0.000041\end{array}$

$120 \mathrm{~cm}$ $-1,299223$ $-0,413700$ $-0,242994$ $-0,171151$ $-0,131731$ $-0,106883$ $-0,047421$ $-0,023036$ $-0,012860$ $-0,008031$ $-0,005814$ $-0,004545$ $-0,003725$ $-0,003152$ $-0,002729$ $-0,002405$ $-0,002149$ $-0,001941$ $-0,001769$ $-0,001625$ $-0,001502$ $-0,001396$ $-0,001304$ $-0,001223$

$120 \mathrm{~cm}$ $-5.464 .609$ $-1.731 .694$ $-1.014 .879$ $-0.713780$ $-0.548782$ $-0.444880$ $-0.196720$ $-0.095277$ $-0.053063$ $-0.033074$ $-0.023911$ $-0.018674$ $-0.015292$ $-0.012931$ 


$\begin{array}{lll}186.0 & -0.000838 & -0.001571 \\ 210.0 & -0.000738 & -0.001385 \\ 234.0 & -0.000659 & -0.001238 \\ 258.0 & -0.000596 & -0.001118 \\ 282.0 & -0.000543 & -0.001020 \\ 306.0 & -0.000499 & -0.000937 \\ 330.0 & -0.000461 & -0.000866 \\ 354.0 & -0.000428 & -0.000805 \\ 378.0 & -0.000400 & -0.000752 \\ 402.0 & -0.000375 & -0.000706\end{array}$

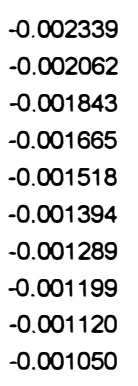

Apêndice 13. Continuação

-0.005209
-0.004589
-0.004099
-0.003702
-0.003374
-0.003098
-0.002863
-0.002661
-0.002485
-0.002331

$-0.008462$

$-0.007452$

$-0.006653$

$-0.006007$

$-0.005473$

$-0.005024$

$-0.004642$

$-0.004313$

$-0.004027$

$-0.003775$

-0.011191
-0.009857
-0.008802
-0.007948
-0.007242
-0.006649
-0.006144
-0.005709
-0.005331
-0.004998

PSIt (cca)

$\begin{array}{rr}\text { tempo }(\mathrm{h}) & 10 \mathrm{~cm} \\ 0.5 & -17.5 \\ 1.5 & -31.2 \\ 2.5 & -40.6 \\ 3.5 & -46.3 \\ 4.5 & -51.9 \\ 5.5 & -56.3 \\ 12.0 & -68.1 \\ 24.0 & -85.0 \\ 42.0 & -95.0 \\ 66.0 & -101.3 \\ 90.0 & -109.4 \\ 114.0 & -120.6 \\ 138.0 & -129.4 \\ 162.0 & -133.8 \\ 186.0 & -136.9 \\ 210.0 & -140.6 \\ 234.0 & -145.0 \\ 258.0 & -149.4 \\ 282.0 & -153.1 \\ 306.0 & -156.9 \\ 330.0 & -159.4 \\ 354.0 & -161.3 \\ 378.0 & -163.8 \\ 402.0 & -165.6\end{array}$

$\begin{array}{rrrrr}20 \mathrm{~cm} & 30 \mathrm{~cm} & \mathbf{6 0} \mathrm{cm} & 90 \mathrm{~cm} & 120 \mathrm{~cm} \\ -21.9 & -38.8 & -65.0 & -100.0 & -129.4 \\ -36.3 & -54.4 & -80.0 & -113.8 & -145.6 \\ -46.3 & -65.6 & -93.1 & -121.9 & -153.1 \\ -52.5 & -71.3 & -103.1 & -128.8 & -157.5 \\ -57.5 & -76.9 & -108.8 & -134.4 & -160.0 \\ -61.9 & -81.3 & -113.1 & -137.5 & -163.1 \\ -75.0 & -89.4 & -120.6 & -145.0 & -170.6 \\ -91.3 & -102.5 & -132.5 & -158.1 & -182.5 \\ -100.0 & -111.3 & -140.0 & -165.6 & -190.6 \\ -108.8 & -116.3 & -145.0 & -168.8 & -193.8 \\ -117.5 & -123.1 & -152.5 & -175.0 & -198.1 \\ -126.3 & -133.1 & -160.6 & -181.9 & -205.6 \\ -134.4 & -141.3 & -168.8 & -187.5 & -212.5 \\ -139.4 & -145.6 & -176.3 & -195.0 & -218.1 \\ -143.8 & -149.4 & -180.6 & -201.9 & -223.8 \\ -148.1 & -153.8 & -184.4 & -205.6 & -228.8 \\ -151.3 & -157.5 & -188.8 & -209.4 & -232.5 \\ -155.0 & -160.6 & -190.6 & -211.9 & -235.0 \\ -159.4 & -164.4 & -191.9 & -213.1 & -236.9 \\ -163.1 & -168.1 & -193.8 & -215.0 & -238.8 \\ -166.3 & -171.9 & -196.3 & -216.9 & -240.6 \\ -168.1 & -174.4 & -198.1 & -219.4 & -241.9 \\ -170.0 & -175.6 & -200.0 & -221.2 & -243.1 \\ -171.9 & -176.9 & -201.3 & -221.2 & -243.8\end{array}$

Ajuste à equaçāo PSIT $=a+b . z+c . z^{2}$

$\begin{array}{rrrrr}\text { tempo }(\mathrm{h}) & a(\mathbf{c c a}) & b(\mathbf{c c a} / \mathbf{c m}) & c\left(\mathbf{c c a} / \mathbf{c m}^{2}\right. & r^{2} \\ 0.5 & -5.6458 & -1.00255 & -0.00028 & 0.997 \\ 1.5 & -20.1642 & -0.99683 & -0.00041 & 0.997 \\ 2.5 & -28.6638 & -1.11267 & 0.00067 & 0.996 \\ 3.5 & -32.1793 & -1.27356 & 0.00196 & 0.996 \\ 4.5 & -36.7043 & -1.33451 & 0.00259 & 0.996 \\ 5.5 & -41.1856 & -1.33221 & 0.00268 & 0.996 \\ 12.0 & -55.0612 & -1.17302 & 0.00178 & 0.998 \\ 24.0 & -72.9215 & -103809 & 0.00103 & 0.999 \\ 42.0 & -83.4542 & -0.95821 & 0.00052 & 0.999 \\ 66.0 & -91.4054 & -0.89011 & 0.00031 & 0.999 \\ 90.0 & -99.5307 & -0.89089 & 0.00057 & 0.998 \\ 114.0 & -111.1256 & -0.80125 & 0.00011 & 0.998 \\ 138.0 & -120.3086 & -0.75826 & -0.00006 & 0.997 \\ 162.0 & -123.0471 & -0.87734 & 0.00072 & 0.996 \\ 186.0 & -125.7418 & -0.93317 & 0.00095 & 0.997 \\ 210.0 & -130.2069 & -0.90888 & 0.00072 & 0.997 \\ 234.0 & -133.9522 & -0.91518 & 0.00078 & 0.996 \\ 258.0 & -138.9362 & -0.84217 & 0.00033 & 0.997 \\ 282.0 & -144.2933 & -0.75277 & -0.00017 & 0.998 \\ 306.0 & -148.9089 & -0.69809 & -0.00043 & 0.999\end{array}$




$\begin{array}{ll}330.0 & -151.9540 \\ 354.0 & -153.5527 \\ 378.0 & -155.6875 \\ 402.0 & -158.0188\end{array}$

$d(P S \mid t) / d z$ (cca/cm)

$\begin{array}{rr}\text { tempo }(\mathbf{h}) & 10 \mathrm{~cm} \\ 0.5 & -1.008 \\ 1.5 & -1.005 \\ 2.5 & -1.099 \\ 3.5 & -1.234 \\ 4.5 & -1.283 \\ 5.5 & -1.279 \\ 12.0 & -1.138 \\ 24.0 & -1.018 \\ 42.0 & -0.948 \\ 66.0 & -0884 \\ 90.0 & -0.880 \\ 114.0 & -0.799 \\ 138.0 & -0.759 \\ 162.0 & -0.863 \\ 186.0 & -0.914 \\ 210.0 & -0.894 \\ 234.0 & -0.900 \\ 258.0 & -0.836 \\ 282.0 & -0.756 \\ 306.0 & -0.707 \\ 330.0 & -0.705 \\ 354.0 & -0.727 \\ 378.0 & -0.719 \\ 402.0 & -0.687 \\ & \end{array}$

$20 \mathrm{~cm}$
-1.014
-1.013
-1.086
-1.195
-1.231
-1.225
-1.103
-0.997
-0.937
-0.878
-0.868
-0.797
-0.761
-0.849
-0.805
-0.880
-0.884
-0.829
-0.759
-0.715
-0.711
-0.729
-0.721
-0.693

Apêndice

$\begin{array}{lll}-0.69820 & -0.00033 & 0.999 \\ -0.72489 & -0.00009 & 1.000 \\ -0.71652 & -0.00012 & 0.999 \\ -0.68156 & -0.00028 & 0.999\end{array}$

$\mathrm{K}$ (condutividade hidráulica, $\mathrm{cm} / \mathrm{h}$ )

$\begin{array}{rrrrrrr}\text { tempo }(\mathbf{h}) & \mathbf{1 0} \mathbf{~ c m} & \mathbf{2 0} \mathbf{~ c m} & \mathbf{3 0} \mathbf{~ c m} & \mathbf{6 0} \mathbf{c m} & \mathbf{9 0} \mathbf{c m} & 120 \mathrm{~cm} \\ 0.5 & 0.39547 & 0.72508 & 1,07319 & 2.41884 & 3,95386 & 5,10482 \\ 1.5 & 0.12632 & 0.23175 & 0,34216 & 0.76147 & 1,23077 & 1,58066 \\ 2.5 & 0.06784 & 0.12723 & 0,19175 & 0.45307 & 0.77864 & 1,06730 \\ 3.5 & 0.04255 & 0.08149 & 0,12542 & 0.31699 & 0.58964 & 0.88944 \\ 4.5 & 0.03152 & 0.06094 & 0,09470 & 0.24729 & 0.48035 & 0.76991 \\ 5.5 & 0.02565 & 0.04971 & 0,07737 & 0.20308 & 0.39748 & 0.64501 \\ 12.0 & 0.01279 & 0.02456 & 0,03778 & 0.09474 & 0.17500 & 0.26363 \\ 24.0 & 0.00595 & 0.01322 & 0,02009 & 0.04823 & 0.08466 & 0.12034 \\ 42.0 & 0.00416 & 0.00786 & 0,01184 & 0.02749 & 0.04655 & 0.06376 \\ 66.0 & 0.00279 & 0.00525 & 0,00787 & 0.01799 & 0.02999 & 0.04050 \\ 90.0 & 0.00203 & 0.00385 & 0,00580 & 0.01350 & 0.02293 & 0.03166 \\ 114.0 & 0.00175 & 0.00328 & 0,00489 & 0.01102 & 0.01808 & 0.02410 \\ 138.0 & 0.00151 & 0.00282 & 0,00419 & 0.00929 & 0.01504 & 0.01979 \\ 162.0 & 0.00112 & 0.00214 & 0,00324 & 0.00760 & 0.01306 & 0.01833 \\ 186.0 & 0.00092 & 0.00176 & 0,00267 & 0.00636 & 0.01110 & 0.01587 \\ 210.0 & 0.00083 & 0.00157 & 0,00238 & 0.00558 & 0.00957 & 0.01341 \\ 234.0 & 0.00073 & 0.00140 & 0,00212 & 0.00499 & 0.00858 & 0.01208 \\ 258.0 & 0.00071 & 0.00135 & 0,00202 & 0.00461 & 0.00767 & 0.01041 \\ 282.0 & 0.00072 & 0.00134 & 0,00199 & 0.00437 & 0.00699 & 0.00914 \\ 306.0 & 0.00071 & 0.00131 & 0,00193 & 0.00413 & 0.00648 & 0.00830 \\ 330.0 & 0.00065 & 0.00122 & 0,00180 & 0.00388 & 0.00612 & 0.00790 \\ 354.0 & 0.00059 & 0.00110 & 0,00164 & 0.00361 & 0.00581 & 0.00764 \\ 378.0 & 0.00056 & 0.00104 & 0,00155 & 0.00340 & 0.00546 & 0.00716 \\ 402.0 & 0.00055 & 0.00102 & 0,00150 & 0.00326 & 0.00516 & 0.00668\end{array}$

$\begin{array}{ll}30 \mathrm{~cm} & 60 \mathrm{~cm} \\ -1.020 & -1.037 \\ -1.022 & -1046 \\ -1.072 & -1.032 \\ -1.156 & -1.038 \\ -1.179 & -1.024 \\ -1.172 & -1.011 \\ -1.067 & -0.960 \\ -0.977 & -0.915 \\ -0.927 & -0.895 \\ -0.872 & -0.853 \\ -0.857 & -0.823 \\ -0.795 & -0.788 \\ -0.762 & -0.766 \\ -0.834 & -0.791 \\ -0.876 & -0.819 \\ -0.865 & -0.822 \\ -0.869 & -0.822 \\ -0.822 & -0.803 \\ -0.763 & -0.773 \\ -0.724 & -0.750 \\ -0.718 & -0.738 \\ -0.731 & -0.736 \\ -0.723 & -0.730 \\ -0.698 & -0.715\end{array}$

$90 \mathrm{~cm}$

$120 \mathrm{~cm}$

$-1.053 \quad-1.070$

$-1.071 \quad-1.096$

$-0.991 \quad-0.951$

$-0.920 \quad-0.803$

$-0.868 \quad-0.713$

$-0.850 \quad-0.690$

$-0.853 \quad-0.746$

$-0.853 \quad-0.792$

$-0.864 \quad-0.832$

$\begin{array}{ll}-0.835 & -0.817\end{array}$

$-0.789 \quad-0.755$

$-0.781 \quad-0.775$

$\begin{array}{ll}-0.781 & -0.775 \\ -0.769 & -0.773\end{array}$

$\begin{array}{ll}-0.749 & -0.706\end{array}$

$-0.762 \quad-0.705$

$-0.778 \quad-0.735$

$-0.775 \quad-0.729$

$-0.783 \quad-0.763$

$-0.783 \quad-0.793$

$-0.775 \quad-0.801$

$-0.758 \quad-0.778$

$-0.742 \quad-0.748$
-0.737

$\begin{array}{ll}-0.737 & -0.744\end{array}$

$\begin{array}{ll}-0.731 & -0.748\end{array}$ 
$\ln [\mathrm{K}](\ln [\mathrm{cm} / \mathrm{h}])$

tempo (h)

0.5

1.5

2.5

3.5

4.5

5.5

12.0

24.0

42.0

66.0

90.0

114.0

138.0

162.0

186.0

210.0

234.0

258.0

282.0

306.0

330.0

354.0

378.0

402.0

\begin{abstract}
$10 \mathrm{~cm}$
\end{abstract}

$$
-2.07
$$

$-2.69$

$-3.16$

$-3.46$

$-3.66$

$-4.36$

$-4.97$

$-5.48$

$-5.88$

$-6.20$

$-6.35$

$-6.50$

$-6.79$

$-7.00$

$-7.10$

$-7.22$

$-7.25$

$-7.24$

$-7.26$

$-7.33$

.7 .44

$-7.49$

$-7.51$

Umidade volumetrica

$$
\text { tempo (h) }
$$

0.5

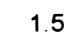

2.5

3.5

4.5

5.5

12.0

24.0

42.0

66.0

90.0

114.0

138.0

162.0

186.0

210.0

234.0

258.0

282.0

306.0

330.0

354.0

378.0

402.0

$\begin{array}{ll}10 \mathrm{~cm} & 20 \mathrm{~cm} \\ 0.515 & 0.508 \\ 0.478 & 0.483 \\ 0.457 & 0.459 \\ 0.447 & 0.448 \\ 0.439 & 0.441 \\ 0.433 & 0.436 \\ 0.420 & 0.423 \\ 0.404 & 0.410 \\ 0.396 & 0.404 \\ 0.392 & 0.399 \\ 0.387 & 0.395 \\ 0.381 & 0.391 \\ 0.376 & 0.388 \\ 0.374 & 0.386 \\ 0.373 & 0.384 \\ 0.371 & 0.382 \\ 0.370 & 0.381 \\ 0.368 & 0.380 \\ 0.366 & 0.379 \\ 0.365 & 0.377 \\ 0.364 & 0.376 \\ 0.363 & 0.376 \\ 0.363 & 0.375 \\ 0.362 & 0.375\end{array}$

\section{$20 \mathrm{~cm}$}

$-0.32$

$-1.46$

$-2.06$

$-2.51$

$-2.80$

$-3.00$

$-3.71$

$-4.33$

$-4.85$

$-5.25$

$-5.56$

$-5.72$

$-5.87$

$-6.15$

$-6.35$

$-6.45$

$-6.57$

$-6.61$

$-6.61$

$-6.64$

$-6.71$

$-6.81$

$-6.87$

$-6.89$

$30 \mathrm{~cm}$

0.511

0.458

0.433

0.425

0.418

0.413

0.405

0.395

0.389

0.386

0.382

0.377

0.374

0.372

0.370

0.369

0.367

0.366

0.365

0.364

0.363

0.362

0.361

0.361

Apêndice 13. Continuação

$60 \mathrm{~cm}$
0.88
-0.27
-0.79
-1.15
-1.40
-1.59

$90 \mathrm{~cm}$

1.37

0.21

$-0.25$

$-0.53$

$-0.73$

$-0.92$

$-1.74$

$-2.47$

$-3.07$

$-3.51$

$-3.78$

$-4.01$

$-4.20$

$-4.34$

$-4.50$

$-4.65$

$-4.76$

$-4.87$

$-4.96$

$-5.04$

$-5.10$

$-5.15$

$-5.21$

$-5.27$

\section{$60 \mathrm{~cm}$}

0.551

0.510

0.472

0.450

0.440

0.433

0.423

0.409

0.402

0.397

0.391

0.385

0.380

0.376

0.373

0.371

0.369

0.368

0.368

0.367

0.366

0.365

0.364

0.363
$90 \mathrm{~cm}$

0.571

0.519

0.492

0.473

0.460

0.453

0.439

0.419

0.409

0.405

0.399

0.392

0.387

0.381

0.376

0.373

0.371

0.369

0.368

0.367

0.366

0.365

0.363

0.363
$120 \mathrm{~cm}$

1.63

0.46

0.07

$-0.12$

$-0.26$

$-0.44$

$-1.33$

$-2.12$

$-2.75$

$-3.21$

$-3.45$

$-3.73$

$-3.92$

$-4.00$

$-4.14$

$-4.31$

$-4.42$

$-4.56$

$-4.70$

$-4.79$

$-4.84$

$-4.87$

$-4.94$

$-5.01$

$120 \mathrm{~cm}$

0.558

0.509

0.490

0.480

0.475

0.470

0.458

0.442

0.432

0.429

0.425

0.418

0.413

0.409

0.405

0.402

0.399

0.398

0.397

0.396

0.395

0.394

0.393

0.393

Regressãolinear: in (K) = gama. (Umidade - UmldadeSat $)+\ln \left(K_{0}\right)$

$\begin{array}{lrrrrrr}\text { gama } & 46.7762 & 52.5370 & 52.0055 & 39.0911 & 35.7123 & 46.0513 \\ K_{0}(\mathrm{~cm} / \mathrm{h}) & 2.3254 & 13.2814 & 41.2989 & 23.7545 & 41.0458 & 147.8826 \\ r^{2} & 0.9834 & 0.9768 & 0.9271 & 0.9366 & 0.9602 & 0.9616\end{array}$


Apêndice 14. Dados utilizados e seqüência de cálculos para determinação da condutividade hidráulica no sistema de preparo do solo com escarificador.

\begin{tabular}{|c|c|c|c|c|c|c|}
\hline Prof. & $10 \mathrm{~cm}$ & $20 \mathrm{~cm}$ & $30 \mathrm{~cm}$ & $60 \mathrm{~cm}$ & $90 \mathrm{~cm}$ & $120 \mathrm{~cm}$ \\
\hline Alfa & $0.0616 / \mathrm{cm}$ & $0.2321 / \mathrm{cm}$ & $0.1254 / \mathrm{cm}$ & $0.0746 / \mathrm{cm}$ & $0.0555 / \mathrm{cm}$ & $0.0515 / \mathrm{cm}$ \\
\hline Eme & 0.2797 & 0.1487 & 0.2279 & 0.3725 & 0.3445 & 0.3410 \\
\hline Ene & 13.884 & 11.747 & 12.951 & 15.937 & 15.256 & 15.175 \\
\hline TETAr & 0.1950 & 0.1570 & 0.2240 & 0.2080 & 0.1960 & 0.2040 \\
\hline TETAs & 0.5760 & 0.5580 & 0.5620 & 0.6370 & 0.6020 & 0.6090 \\
\hline H cuba & $20.0 \mathrm{~cm}$ & $20.0 \mathrm{~cm}$ & $20.0 \mathrm{~cm}$ & $20.0 \mathrm{~cm}$ & $20.0 \mathrm{~cm}$ & $20.0 \mathrm{~cm}$ \\
\hline \multicolumn{7}{|c|}{ Leitura tensiòmetros ( $\mathrm{cm}$ de ascensão de mercúrio) } \\
\hline tempo (h) & $10 \mathrm{~cm}$ & $20 \mathrm{~cm}$ & $30 \mathrm{~cm}$ & $60 \mathrm{~cm}$ & $90 \mathrm{~cm}$ & $120 \mathrm{~cm}$ \\
\hline 0.0 & 21 & 3.0 & 3.7 & 5.9 & 8.9 & 11.2 \\
\hline 1.0 & 3.2 & 4.0 & 4.5 & 7.2 & 9.8 & 12.7 \\
\hline 2.0 & 4.6 & 5.1 & 5.4 & 8.7 & 11.4 & 13.7 \\
\hline 3.0 & 5.4 & 5.6 & 5.9 & 10.3 & 12.3 & 14.1 \\
\hline 4.0 & 5.8 & 6.0 & 6.6 & 10.8 & 13.0 & 14.5 \\
\hline 5.0 & 6.1 & 6.3 & 7.1 & 11.1 & 13.2 & 14.7 \\
\hline 6.0 & 6.3 & 6.6 & 7.4 & 11.3 & 13.3 & 14.8 \\
\hline 18.0 & 7.2 & 7.7 & 8.7 & 12.0 & 13.8 & 15.5 \\
\hline 30.0 & 8.4 & 9.0 & 9.9 & 12.9 & 15.2 & 16.6 \\
\hline 54.0 & 8.8 & 9.8 & 10.5 & 13.3 & 15.2 & 17.0 \\
\hline 78.0 & 9.4 & 10.4 & 11.0 & 14.1 & 15.7 & 17.8 \\
\hline 102.0 & 10.1 & 11.2 & 11.8 & 14.7 & 16.5 & 18.2 \\
\hline 126.0 & 10.9 & 11.9 & 12.3 & 15.3 & 17.3 & 18.6 \\
\hline 150.0 & 112 & 12.2 & 12.7 & 15.6 & 17.5 & 19.2 \\
\hline 174.0 & 11.6 & 12.5 & 12.9 & 16.0 & 17.9 & 19.6 \\
\hline 198.0 & 11.9 & 12.9 & 13.2 & 16.2 & 18.2 & 19.9 \\
\hline 222.0 & 12.1 & 13.2 & 13.5 & 16.5 & 18.7 & 20.3 \\
\hline 246.0 & 12.3 & 13.3 & 13.7 & 16.6 & 19.0 & 20.5 \\
\hline 270.0 & 12.4 & 13.5 & 14.0 & 16.7 & 19.2 & 20.6 \\
\hline 294.0 & 12.6 & 13.7 & 14.2 & 17.1 & 19.4 & 20.8 \\
\hline 318.0 & 13.5 & 14.3 & 14.5 & 17.4 & 19.4 & 20.9 \\
\hline 342.0 & 13.8 & 14.5 & 14.6 & 17.9 & 19.7 & 20.9 \\
\hline 366.0 & 13.8 & 14.9 & 15.0 & 18.1 & 19.9 & 21.2 \\
\hline 390.0 & 14.2 & 15.2 & 15.1 & 18.3 & 20.1 & 21.4 \\
\hline 414.0 & 14.5 & 15.5 & 15.3 & 18.4 & 20.1 & 21.5 \\
\hline
\end{tabular}

\section{Método Hillel}

Potencial mátrico (cca)

$\begin{array}{rr}\text { tempo (h) } & 10 \mathrm{~cm} \\ 0.0 & 3.8 \\ 1.0 & -10.0 \\ 2.0 & -27.5 \\ 3.0 & -37.5 \\ 4.0 & -42.5 \\ 5.0 & -46.3 \\ 6.0 & -48.8 \\ 18.0 & -60.0 \\ 30.0 & -75.0 \\ 54.0 & -80.0 \\ 78.0 & -87.5\end{array}$

$$
\begin{array}{r}
20 \mathrm{~cm} \\
2.5 \\
-10.0 \\
-23.7 \\
-30.0 \\
-35.0 \\
-38.8 \\
-42.5 \\
-56.2 \\
-72.5 \\
-82.5 \\
-90.0
\end{array}
$$

$$
\begin{array}{r}
30 \mathrm{~cm} \\
3.7 \\
-6.3 \\
-17.5 \\
-23.8 \\
-32.5 \\
-38.8 \\
-42.5 \\
-58.7 \\
-73.7 \\
-81.3 \\
-87.5
\end{array}
$$

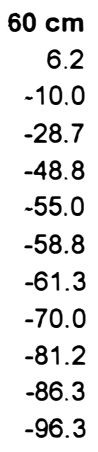

$\begin{array}{rr}90 \mathrm{~cm} & 120 \mathrm{~cm} \\ -1.2 & 0.0 \\ -12.5 & -18.7 \\ -32.5 & -31.2 \\ -43.8 & -36.3 \\ -52.5 & -41.3 \\ -55.0 & -43.7 \\ -56.3 & -45.0 \\ -62.5 & -53.8 \\ -80.0 & -67.5 \\ -80.0 & -72.5 \\ -86.3 & -82.5\end{array}$


Apêndice 14. Continuação

$\begin{array}{lrl}102.0 & -96.3 & -100.0 \\ 126.0 & -106.2 & -108.7 \\ 150.0 & -110.0 & -112.5 \\ 174.0 & -115.0 & -116.3 \\ 198.0 & -118.7 & -121.2 \\ 222.0 & -121.3 & -125.0 \\ 246.0 & -123.8 & -126.3 \\ 270.0 & -125.0 & -128.8 \\ 294.0 & -127.5 & -131.3 \\ 318.0 & -138.8 & -138.8 \\ 342.0 & -142.5 & -141.3 \\ 366.0 & -142.5 & -146.3 \\ 390.0 & -147.5 & -150.0 \\ 414.0 & -151.3 & -153.8\end{array}$

-97.5
-103.8
-108.8
-111.2
-115.0
-118.8
-121.3
-125.0
-127.5
-131.3
-132.5
-137.5
-138.8
-141.3

-103.8
-111.3
-115.0
-120.0
-122.5
-126.3
-127.5
-128.8
-133.8
-137.5
-143.8
-146.3
-148.7
-150.0

$\begin{array}{rr}-96.3 & -87.5 \\ -106.2 & -92.5 \\ -108.8 & -100.0 \\ -113.7 & -105.0 \\ -117.5 & -108.7 \\ -123.8 & -113.7 \\ -127.5 & -116.3 \\ -130.0 & -117.5 \\ -132.5 & -120.0 \\ -132.5 & -121.2 \\ -136.3 & -121.2 \\ -138.8 & -125.0 \\ -141.3 & -127.5 \\ -141.3 & -128.8\end{array}$

Umidade volumetrica

$\begin{array}{rrr}\text { tempo }(\boldsymbol{h}) & \mathbf{1 0} \mathbf{c m} & \mathbf{2 0} \mathbf{~ c m} \\ 0.0 & 0.563 & 0.534 \\ 1.0 & 0.534 & 0.487 \\ 2.0 & 0.473 & 0.449 \\ 3.0 & 0.450 & 0.439 \\ 4.0 & 0.441 & 0.432 \\ 5.0 & 0.434 & 0.427 \\ 6.0 & 0.430 & 0.423 \\ 18.0 & 0.415 & 0.411 \\ 30.0 & 0.399 & 0.401 \\ 54.0 & 0.394 & 0.395 \\ 78.0 & 0.388 & 0.392 \\ 102.0 & 0.382 & 0.388 \\ 126.0 & 0.375 & 0.384 \\ 150.0 & 0.373 & 0.383 \\ 174.0 & 0.370 & 0.382 \\ 198.0 & 0.368 & 0.380 \\ 222.0 & 0.367 & 0.379 \\ 246.0 & 0.365 & 0.379 \\ 270.0 & 0.365 & 0.378 \\ 294.0 & 0.363 & 0.377 \\ 318.0 & 0.358 & 0.375 \\ 342.0 & 0.357 & 0.374 \\ 366.0 & 0.357 & 0.373 \\ 390.0 & 0.355 & 0.372 \\ 414.0 & 0.353 & 0.371\end{array}$

$30 \mathrm{~cm}$

$60 \mathrm{~cm}$

$\begin{array}{lr}90 \mathrm{~cm} & 120 \mathrm{~cm} \\ 0.600 & 0.609 \\ 0.543 & 0.527 \\ 0.461 & 0.481 \\ 0.431 & 0.466 \\ 0.414 & 0.454 \\ 0.409 & 0.448 \\ 0.407 & 0.445 \\ 0.397 & 0.428 \\ 0.375 & 0.407 \\ 0.375 & 0.400 \\ 0.369 & 0.380 \\ 0.360 & 0.384 \\ 0.352 & 0.379 \\ 0.350 & 0.373 \\ 0.347 & 0.369 \\ 0.345 & 0.366 \\ 0.341 & 0.363 \\ 0.339 & 0.361 \\ 0.337 & 0.360 \\ 0.338 & 0.359 \\ 0.336 & 0.358 \\ 0.334 & 0.358 \\ 0.333 & 0.356 \\ 0.332 & 0.354 \\ 0.332 & 0.353\end{array}$

Ajuste à equação TETA $=a \cdot$ tempo^b

$\begin{array}{lrrrrrr} & 10 \mathrm{~cm} & 20 \mathrm{~cm} & 30 \mathrm{~cm} & 60 \mathrm{~cm} & 90 \mathrm{~cm} & 120 \mathrm{~cm} \\ a(1 / \mathrm{h}) & 0.47661 & 0.45824 & 0.46878 & 0.45302 & 0.47007 & 0.49304 \\ b & -0.04845 & -0.03531 & -0.04112 & -0.06519 & -0.05888 & -0.05506 \\ \mathrm{r}^{2} & 0.93649 & 0.97254 & 0.91806 & 0.87839 & 0.93644 & 0.97931\end{array}$

\begin{tabular}{|c|c|c|c|c|c|c|}
\hline $\begin{array}{r}\text { TETA)/dt (1/h) } \\
\text { tempo (h) }\end{array}$ & $10 \mathrm{~cm}$ & $20 \mathrm{~cm}$ & $30 \mathrm{~cm}$ & $60 \mathrm{~cm}$ & $90 \mathrm{~cm}$ & $120 \mathrm{~cm}$ \\
\hline 0.5 & -0.047758 & -0.033164 & -0.039662 & .0 .061797 & -0.057665 & -0.056405 \\
\hline 1.5 & -0.015094 & -0.010634 & -0.012637 & -0.019175 & -0.018018 & -0.017698 \\
\hline 2.5 & -0.008835 & -0.006266 & -0.007425 & -0.011128 & -0.010490 & -0.010324 \\
\hline 3.5 & -0.006209 & -0.004423 & -0.005230 & -0.007776 & -0.007346 & -0.007239 \\
\hline 4.5 & -0.004771 & -0.003410 & -0.004026 & -0.005950 & -0.005630 & .0 .005553 \\
\hline 5.5 & -0.003865 & -0.002770 & -0.003267 & -0.004805 & -0.004552 & -0.004494 \\
\hline 12.0 & -0.001706 & -0.001235 & -0.001450 & -0.002093 & -0.001993 & -0.001973 \\
\hline 24.0 & -0.000825 & -0.000603 & -0.000705 & -0.001000 & -0.000956 & -0.000950 \\
\hline
\end{tabular}


Apêndice 14. Continuação

$\begin{array}{rrr}42.0 & -0.000459 & -0.000338 \\ 66.0 & -0.000286 & -0.000211 \\ 90.0 & -0.000206 & -0.000153 \\ 114.0 & -0.000161 & -0.000120 \\ 138.0 & -0.000132 & -0.000099 \\ 162.0 & -0.000111 & -0.000083 \\ 186.0 & -0.000096 & -0.000072 \\ 210.0 & -0.000085 & -0.000064 \\ 234.0 & -0.000076 & -0.000057 \\ 258.0 & -0.000068 & -0.000052 \\ 282.0 & -0.000062 & -0.000047 \\ 306.0 & -0.000057 & -0.000043 \\ 330.0 & -0.000053 & -0.000040 \\ 354.0 & -0.000049 & -0.000037 \\ 378.0 & -0.000046 & -0.000035 \\ 402.0 & -0.000043 & -0.000033\end{array}$

-0.000394
-0.000246
-0.000178
-0.000139
-0.000114
-0.000097
-0.000084
-0.000074
-0.000066
-0.000059
-0.000054
-0.000050
-0.000046
-0.000043
-0.000040
-0.000037

$-0.000551$

$-0.000341$

$-0.000245$

$-0.000190$

$-0.000155$

$-0.000131$

$-0.000113$

$-0.000099$

$-0.000088$

$-0.000080$

$-0.000072$

$-0.000066$

$-0.000061$

$-0.000057$

$-0.000053$

$-0.000050$

$d(T E T A) / d t \times d z(c m / h)$ tempo (h)

0.5

$10 \mathrm{~cm}$
-0.477580
-0.150942
-0.088351
-0.062088
-0.047706
-0.038655
-0.017060
-0.008248
-0.004587
-0.002856
-0.002063
-0.001610
-0.001318
-0.001114
-0.000964
-0.000849
-0.000758
-0.000684
-0.000623
-0.000572
-0.000528
-0.000491
-0.000458
-0.000430

$20 \mathrm{~cm}$

$-0.331636$

$-0.106339$

$-0.062663$

$-0.044231$

.0 .034098

$-0.027701$

$-0.012351$

$-0.006026$

$-0.003376$

$-0.002115$

$-0.001534$

$-0.001201$

$-0.000985$

$-0.000835$

$-0.000723$

$-0.000638$

$-0.000570$

234.0

258.0

282.0

306.0

330.0

354.0

378.0

402.0

\begin{abstract}
$30 \mathrm{~cm}$
$-0.396623$

$-0.126369$

$-0.074245$

$-0.052304$

$-0.040263$

$-0.032671$

$-0.014502$

$-0.007047$

$-0.003935$

$-0.002458$

$-0.001780$

$-0.001392$

$-0.001141$

$-0.000965$

$-0.000836$

$-0.000737$

$-0.000658$

$-0.000595$

$-0.000542$

$-0.000498$

$-0.000460$

$-0.000428$

$-0.000399$

$-0.000375$
\end{abstract}

$$
\begin{array}{r}
60 \mathrm{~cm} \\
-1.853 .896 \\
-0.575254 \\
-0.333847 \\
-0.233289 \\
-0.178498 \\
-0.144146 \\
-0.062791 \\
-0.030008 \\
-0.016533 \\
-0.010216 \\
-0.007342 \\
-0.005707 \\
-0.004656 \\
-0.003925 \\
-0.003388 \\
-0002977 \\
-0.002653 \\
-0.002391 \\
-0.002175 \\
-0.001994 \\
-0.001840 \\
-0.001707 \\
-0.001592 \\
-0.001491
\end{array}
$$

$\begin{array}{ll}-0.000529 & -0.000526 \\ -0.000328 & -0.000327 \\ -0.000236 & -0.000235 \\ -0.000184 & -0.000183 \\ -0.000150 & -0.000150 \\ -0.000127 & -0.000127 \\ -0.000109 & -0.000109 \\ -0.000096 & -0.000096 \\ -0.000086 & -0.000086 \\ -0.000077 & -0.000078 \\ -0.000070 & -0.000071 \\ -0.000065 & -0.000065 \\ -0.000060 & -0.000060 \\ -0.000055 & -0.000056 \\ -0.000052 & -0.000052 \\ -0.000048 & -0.000049\end{array}$

$-0.000048$ $q=$ Somatório $[d(T E T A) / d t \times d z](\mathrm{cm} / \mathrm{h})$

$\begin{array}{rrr}\text { tempo (h) } & 10 \mathrm{~cm} & 20 \mathrm{~cm} \\ 0.5 & -0.477580 & -0.809216 \\ 1.5 & -0.150942 & -0.257281 \\ 2.5 & -0.088351 & -0.151014 \\ 3.5 & -0.062088 & -0.106318 \\ 4.5 & -0.047706 & -0.081804 \\ 5.5 & -0.038655 & -0.066356 \\ 12.0 & -0.017060 & -0.029411 \\ 24.0 & -0.008248 & -0.014274 \\ 42.0 & -0.004587 & -0.007963 \\ 66.0 & -0.002856 & -0.004970 \\ 90.0 & -0.002063 & -0.003597 \\ 114.0 & -0.001610 & -0.002811 \\ 138.0 & -0.001318 & -0.002303 \\ 162.0 & -0.001114 & -0.001949\end{array}$

$30 \mathrm{~cm}$
1,205839
-0.383650
-0.225260
-0.158622
-0.122066
-0.099027
-0.043913
-0.021322
-0.011899
-0.007429
-0.005377
-0.004203
-0.003444
-0.002914

$60 \mathrm{~cm}$
-3.059735
-0.958904
-0.559107
-0.391911
-0.300564
-0.243173
-0.106703
-0.051330
-0.028432
-0.017644
-0.012718
-0.009910
-0.008100
-0.006839

$$
\begin{array}{r}
90 \mathrm{~cm} \\
-1.729 .960 \\
-0.540531 \\
-0.314708 \\
-0.220382 \\
-0.168890 \\
-0.136560 \\
-0.059780 \\
-0.028694 \\
-0.015865 \\
-0.009831 \\
-0.007079 \\
-0.005511 \\
-0.004502 \\
-0.003799 \\
-0.003282 \\
-0.002886 \\
-0.002574 \\
-0.002321 \\
-0.002112 \\
-0.001937 \\
-0.001788 \\
-0.001660 \\
-0.001549 \\
-0.001451
\end{array}
$$$$
\begin{array}{r}
120 \mathrm{~cm} \\
-1.692 .165 \\
-0.530947 \\
-0.309733 \\
-0.217177 \\
-0.166594 \\
-0.134807 \\
-0.059188 \\
-0.028486 \\
-0.015784 \\
-0.009797 \\
-0.007063 \\
-0.005504 \\
-0.004499 \\
-0.003799 \\
-0.003284 \\
-0.002889 \\
-0.002577 \\
-0.002325 \\
-0.002117 \\
-0.001942 \\
-0.001793 \\
-0.001665 \\
-0.001554 \\
-0.001456
\end{array}
$$

$\begin{array}{rr}90 \mathrm{~cm} & 120 \mathrm{~cm} \\ -4,789696 & -6,481860 \\ -1,499434 & -2,030381 \\ -0.873815 & -1,183548 \\ -0.612292 & -0.829469 \\ -0.469455 & -0.636049 \\ -0.379733 & -0.514539 \\ -0.166483 & -0.225671 \\ -0.080024 & -0.108510 \\ -0.044297 & -0.060081 \\ -0.027475 & -0.037273 \\ -0.019797 & -0.026860 \\ -0.015421 & -0.020925 \\ -0.012602 & -0.017101 \\ -0.010638 & -0.014437\end{array}$




$\begin{array}{ll}186.0 & -0.000364 \\ 210.0 & -0.000849 \\ 234.0 & -0.000758 \\ 258.0 & -0.000684 \\ 282.0 & -0.000623 \\ 306.0 & -0.000572 \\ 330.0 & -0.000528 \\ 354.0 & -0.000491 \\ 378.0 & -0.000458 \\ 402.0 & -0.000430\end{array}$

$\begin{array}{ll}-0.001687 & -0.002523 \\ -0.001487 & -0.002223 \\ -0.001328 & -0.001986 \\ -0.001199 & -0.001794 \\ -0.001093 & -0.001635 \\ -0.001004 & -0.001502 \\ -0.000928 & -0.001388 \\ -0.000862 & -0.001290 \\ -0.000805 & -0.001205 \\ -0.000755 & -0.001130\end{array}$

Apêndice 14. Continuação

$\begin{array}{lll}-0.005911 & -0.009193 & -0.012477 \\ -0.005201 & -0.008087 & -0.010976 \\ -0.004639 & -0.007213 & -0.009790 \\ -0.004185 & -0.006506 & -0.008831 \\ -0.003810 & -0.005922 & -0.008039 \\ -0.003495 & -0.005433 & -0.007375 \\ -0.003228 & -0.005016 & -0.006809 \\ -0.002997 & -0.004657 & -0.006323 \\ -0.002797 & -0.004346 & -0.005899 \\ -0.002621 & -0.004072 & -0.005528\end{array}$

PSit (cca)

\begin{tabular}{|c|c|c|c|c|c|c|}
\hline tempo (h) & $10 \mathrm{~cm}$ & $20 \mathrm{~cm}$ & $30 \mathrm{~cm}$ & $60 \mathrm{~cm}$ & $90 \mathrm{~cm}$ & $120 \mathrm{~cm}$ \\
\hline 0.5 & -13.1 & -23.8 & -31.3 & -61.9 & -96.9 & -129.4 \\
\hline 1.5 & -28.8 & -36.9 & -41.9 & -79.4 & -112.5 & -145.0 \\
\hline 2.5 & -42.5 & -46.9 & -50.6 & -98.8 & -128.1 & -153.8 \\
\hline 3.5 & -50.0 & -52.5 & -58.1 & -111.9 & -138.1 & -158.8 \\
\hline 4.5 & -54.4 & -56.9 & -65.6 & -116.9 & -143.8 & -162.5 \\
\hline 5.5 & -57.5 & -60.6 & -70.6 & -120.0 & -145.6 & -164.4 \\
\hline 12.0 & -64.4 & -69.4 & -80.6 & -125.6 & -149.4 & -169.4 \\
\hline 24.0 & -77.5 & -84.4 & -96.2 & -135.6 & -161.3 & -180.6 \\
\hline 42.0 & -87.5 & -97.5 & -107.5 & -143.8 & -170.0 & -190.0 \\
\hline 66.0 & -93.8 & -106.3 & -114.4 & -151.3 & -173.1 & -197.5 \\
\hline 90.0 & -101.9 & -115.0 & -122.5 & -160.0 & -181.3 & -205.0 \\
\hline 114.0 & -111.3 & -124.4 & -130.6 & -167.5 & -181.3 & -210.0 \\
\hline 138.0 & -118.1 & -130.6 & -136.3 & -173.1 & -197.5 & -216.3 \\
\hline 162.0 & -122.5 & -134.4 & -140.0 & -177.5 & -201.3 & -222.5 \\
\hline 186.0 & -126.9 & -138.8 & -143.1 & -181.3 & -205.6 & -226.9 \\
\hline 210.0 & -130.0 & -143.1 & -146.9 & -184.4 & -210.6 & -231.3 \\
\hline 234.0 & -132.5 & -145.6 & -150.0 & -186.9 & -215.6 & -235.0 \\
\hline 258.0 & -134.4 & -147.5 & -153.1 & -188.1 & -218.8 & -236.9 \\
\hline 282.0 & -136.3 & -150.0 & -156.3 & -191.3 & -221.3 & -238.8 \\
\hline 306.0 & -143.1 & -155.0 & -159.4 & -195.6 & -222.5 & -240.6 \\
\hline 330.0 & -150.6 & -160.0 & -161.9 & -200.6 & -224.4 & -241.3 \\
\hline 354.0 & -152.5 & -163.8 & -165.0 & -205.0 & -227.5 & -243.1 \\
\hline 378.0 & -155.0 & -168.1 & -168.1 & -207.5 & -230.0 & -246.3 \\
\hline 402.0 & -159.4 & -171.9 & -170.0 & -209.4 & -231.3 & -248.1 \\
\hline \multicolumn{7}{|c|}{ AJuste à equaçāo PSIT $=a+b, z+c \cdot z^{2}$} \\
\hline & & tempo (h) & a (cca) & $b(c c a / c m)$ & $c\left(\mathrm{cca} / \mathrm{cm}^{2}\right)$ & 12 \\
\hline & & 0.5 & $-3,9142$ & -0.91295 & -0.00115 & 0.999 \\
\hline & & 1.5 & $-16,8655$ & -0.95915 & -0.00097 & 0.997 \\
\hline & & 2.5 & $-24,0084$ & -1.24427 & 0.00124 & 0.986 \\
\hline & & 3.5 & $-27,0097$ & -1.50761 & 0.00328 & 0.978 \\
\hline & & 4.5 & $-31,0592$ & $-1.57 @ 94$ & 0.00388 & 0.982 \\
\hline & & 5.5 & $-34,8828$ & -1.57921 & 0.00406 & 0.985 \\
\hline & & 12.0 & $-44,1931$ & -1.51753 & 0.00390 & 0.991 \\
\hline & & 24.0 & $-59,7147$ & -1.43809 & 0.00354 & 0.996 \\
\hline & & 42.0 & $-72,3460$ & -1.35316 & 0.00307 & 0.998 \\
\hline & & 66.0 & $-80,7887$ & -1.28554 & 0.00264 & 0.998 \\
\hline & & 90.0 & $-88,8079$ & -1.30834 & 0.00287 & 0.997 \\
\hline & & 114.0 & $-97,3415$ & -1.34052 & 0.00332 & 0.997 \\
\hline & & 138.0 & $-104,2484$ & -1.30396 & 0.00305 & 0.997 \\
\hline & & 162.0 & $-108,9319$ & -1.26043 & 0.00260 & 0.997 \\
\hline & & 186.0 & $-113,3417$ & -1.23671 & 0.00239 & 0.995 \\
\hline & & 210.0 & $-116,8284$ & -1.24382 & 0.00237 & 0.996 \\
\hline & & 234.0 & $-118,8926$ & -1.27397 & 0.00248 & 0.996 \\
\hline & & 258.0 & $-120,7738$ & -1.28807 & 0.00258 & 0.996 \\
\hline & & 282.0 & $-122,4551$ & -1.33574 & 0.00297 & 0.997 \\
\hline & & 306.0 & -129.4360 & -1.24220 & 0.00256 & 0.995 \\
\hline
\end{tabular}


Apêndice 14. Continuação

$\begin{array}{ll}330.0 & -136,0648 \\ 354.0 & -137,6431 \\ 378.0 & -141,2791 \\ 402.0 & -146,3306\end{array}$

-1.18074
-1.26405
$-1,24009$
$-1,14703$

$\begin{array}{ll}0.00245 & 0.989 \\ 0.00313 & 0.989 \\ 0.00298 & 0.989 \\ 0.00242 & 0.985\end{array}$

$d(P S I t) / d z$ (cca/cm)

$\begin{array}{rr}\text { tempo }(\mathrm{h}) & 10 \mathrm{~cm} \\ 0.5 & -0.93 \\ 1.5 & -0.979 \\ 2.5 & -1.22 \\ 3.5 & -1.44 \\ 4.5 & -1.49 \\ 5.5 & -1.49 \\ 12.0 & -1.44 \\ 24.0 & -1.36 \\ 42.0 & -1.29 \\ 66.0 & -1.233 \\ 90.0 & -1.25 \\ 114.0 & -1.274 \\ 138.0 & -1.243 \\ 162.0 & -1.20 \\ 186.0 & -1.189 \\ 210.0 & -1.19 \\ 234.0 & -1.22 \\ 258.0 & -1.23 \\ 282.0 & -1.276 \\ 306.0 & -1.19 \\ 330.0 & -1.13 \\ 354.0 & -1.20 \\ 378.0 & -1.18 \\ 402.0 & -1.099 \\ \end{array}$

$\begin{array}{ll}20 \mathrm{~cm} & 30 \mathrm{~cm} \\ -0.959 & -0.982 \\ -0.998 & -1.017 \\ -1.195 & -1.170 \\ -1.376 & -1.311 \\ -1.422 & -1.344 \\ -1.417 & -1.336 \\ -1.362 & -1.284 \\ -1.297 & -1.226 \\ -1230 & -1.169 \\ -1.180 & -1.127 \\ -1.193 & -1.136 \\ -1.208 & -1.141 \\ -1.182 & -1.121 \\ -1.157 & -1.105 \\ -1.141 & -1.093 \\ -1.149 & -1.102 \\ -1.175 & -1.125 \\ -1.185 & -1.133 \\ -1.217 & -1.157 \\ -1.140 & -1.089 \\ -1.083 & -1.034 \\ -1.139 & -1.076 \\ -1.121 & -1.061 \\ -1.050 & -1.002\end{array}$

$$
\begin{aligned}
& 60 \mathrm{~cm} \\
& -1.050 \\
& -1.075 \\
& -1.096 \\
& -1.114 \\
& -1.111 \\
& -1.092 \\
& -1.050 \\
& -1.014 \\
& -0.985 \\
& -0.968 \\
& -0.964 \\
& -0.942 \\
& -0.938 \\
& -0.949 \\
& -0.950 \\
& -0.959 \\
& -0.977 \\
& -0.978 \\
& -0.979 \\
& -0.935 \\
& -0.887 \\
& -0.888 \\
& -0.883 \\
& -0.857
\end{aligned}
$$

$\begin{array}{ll}90 \mathrm{~cm} & 120 \mathrm{~cm} \\ -1.119 & -1.188 \\ -1.134 & -1.192 \\ -1.022 & -0.947 \\ -0.917 & -0.720 \\ -0.878 & -0.645 \\ -0.848 & -0.604 \\ -0.816 & -0.582 \\ -0.802 & -0.590 \\ -0.801 & -0.617 \\ -0.810 & -0.651 \\ -0.791 & -0.619 \\ -0.742 & -0.543 \\ -0.755 & -0.572 \\ -0.793 & -0.637 \\ -0.807 & -0.664 \\ -0.817 & -0.675 \\ -0.828 & -0.679 \\ -0.824 & -0.669 \\ -0.800 & -0.622 \\ -0.782 & -0.629 \\ -0.740 & -0.594 \\ -0.700 & -0.512 \\ -0.704 & -0.525 \\ -0.712 & -0.567\end{array}$

$\mathrm{K}$ (condutividade hidráulica, $\mathrm{cm} / \mathrm{h}$ )

$\begin{array}{rrr}\text { tempo (h) } & 10 \mathrm{~cm} & 20 \mathrm{~cm} \\ 0.5 & 0.51032 & 0.84403 \\ 1.5 & 0.15425 & 0.25781 \\ 2.5 & 0.07245 & 0.12640 \\ 3.5 & 0.04306 & 0.07724 \\ 4.5 & 0.03182 & 0.05754 \\ 5.5 & 0.02580 & 0.04684 \\ 12.0 & 0.01185 & 0.02160 \\ 24.0 & 0.00603 & 0.01101 \\ 42.0 & 0.00355 & 0.00647 \\ 66.0 & 0.00232 & 0.00421 \\ 90.0 & 0.00165 & 0.00301 \\ 114.0 & 0.00126 & 0.00233 \\ 138.0 & 0.00106 & 0.00195 \\ 162.0 & 0.00092 & 0.00168 \\ 186.0 & 0.00081 & 0.00148 \\ 210.0 & 0.00071 & 0.00129 \\ 234.0 & 0.00062 & 0.00113 \\ 258.0 & 0.00055 & 0.00101 \\ 282.0 & 0.00049 & 0.00090 \\ 306.0 & 0.00048 & 0.00088 \\ 330.0 & 0.00047 & 0.00086 \\ 354.0 & 0.00041 & 0.00076 \\ 378.0 & 0.00039 & 0.00072 \\ 402.0 & 0.00039 & 0.00072\end{array}$

$30 \mathrm{~cm}$
1.22837
0.37712
0.19253
0.12101
0.09082
0.07415
0.03421
0.01739
0.01018
0.00659
0.00473
0.00368
0.00307
0.00264
0.00231
0.00202
0.00176
0.00158
0.00141
0.00138
0.00134
0.00120
0.00114
0.00113

$60 \mathrm{~cm}$
2.91301
0.89159
0.51025
0.35179
0.27050
0.22272
0.10164
0.05063
0.02886
0.01822
0.01320
0.01052
0.00864
0.00721
0.00622
0.00542
0.00475
0.00428
0.00389
0.00374
0.00364
0.00337
0.00317
0.00306

$\begin{array}{rr}90 \mathrm{~cm} & 120 \mathrm{~cm} \\ 4,28004 & 5,45710 \\ 1,32264 & 1,70356 \\ 0.85542 & 1,24946 \\ 0.66753 & 1,15131 \\ 0.53454 & 0.98559 \\ 0.44771 & 0.85119 \\ 0.20405 & 0.38774 \\ 0.09982 & 0.18407 \\ 0.05531 & 0.09740 \\ 0.03394 & 0.05726 \\ 0.02501 & 0.04339 \\ 0.02078 & 0.03856 \\ 0.01670 & 0.02992 \\ 0.01341 & 0.02266 \\ 0.01139 & 0.01880 \\ 0.00990 & 0.01626 \\ 0.00871 & 0.01441 \\ 0.00790 & 0.01320 \\ 0.00740 & 0.01292 \\ 0.00695 & 0.01173 \\ 0.00678 & 0.01147 \\ 0.00665 & 0.01234 \\ 0.00617 & 0.01123 \\ 0.00572 & 0.00976\end{array}$


166.

$\ln [\mathrm{K}](\ln [\mathrm{cm} / \mathrm{h})$

\begin{tabular}{|c|c|c|c|c|c|c|}
\hline & & & & & & \\
\hline tempo (h) & $10 \mathrm{~cm}$ & $20 \mathrm{~cm}$ & $30 \mathrm{~cm}$ & $60 \mathrm{~cm}$ & $90 \mathrm{~cm}$ & $120 \mathrm{~cm}$ \\
\hline 0.5 & -0.67 & -0.17 & 0.21 & 1.07 & 1.45 & 1.70 \\
\hline 1.5 & -1.87 & -1.36 & .0 .98 & -0.11 & 0.28 & 0.53 \\
\hline 2.5 & -2.62 & -2.07 & -1.65 & -0.67 & -0.16 & 0.22 \\
\hline 3.5 & -3.15 & -2.56 & -2.11 & -1.04 & -0.40 & 0.14 \\
\hline 4.5 & -3.45 & -2.86 & -2.40 & -1.31 & -0.63 & -0.01 \\
\hline 5.5 & -3.66 & -3.06 & -2.60 & -1.50 & -0.80 & -0.16 \\
\hline 12.0 & -4.44 & -3.84 & -3.38 & -2.29 & -1.59 & -0.95 \\
\hline 24.0 & -5.11 & -4.51 & -4.05 & -2.98 & -2.30 & -1.69 \\
\hline 42.0 & -5.64 & -5.04 & -4.59 & -3.55 & -2.89 & -2.33 \\
\hline 66.0 & -6.07 & -5.47 & -5.02 & -4.01 & -3.38 & -2.86 \\
\hline 90.0 & -6.41 & -5.80 & -5.35 & -4.33 & -3.69 & -3.14 \\
\hline 114.0 & -6.67 & -6.06 & -5.60 & -4.55 & -3.87 & -3.26 \\
\hline 138.0 & -6.85 & -6.24 & -5.79 & -4.75 & -4.09 & -3.51 \\
\hline 162.0 & -6.99 & -6.39 & -5.94 & -4.93 & -4.31 & -3.79 \\
\hline 186.0 & -7.12 & -6.52 & -6.07 & -5.08 & -4.47 & -3.97 \\
\hline 210.0 & -7.25 & -6.65 & -6.21 & -5.22 & -4.62 & -4.12 \\
\hline 234.0 & -7.39 & -6.79 & -6.34 & -5.35 & -4.74 & -4.24 \\
\hline 258.0 & -7.50 & -6.90 & -6.45 & -5.45 & -4.84 & -4.33 \\
\hline 282.0 & -7.62 & -7.01 & -6.56 & -5.55 & -4.91 & -4.35 \\
\hline 306.0 & -7.64 & -703 & -6.59 & -5.59 & -4.97 & -4.45 \\
\hline 330.0 & -7.67 & -7.06 & -6.61 & -5.62 & -4.99 & -4.47 \\
\hline 354.0 & -7.80 & -7.19 & -6.73 & -5.69 & -5.01 & -4.40 \\
\hline 378.0 & -7.85 & -7.24 & -6.78 & -5.75 & -5.09 & -4.49 \\
\hline 402.0 & -7.85 & -7.24 & -6.79 & -5.79 & -5.16 & -4.63 \\
\hline \multicolumn{7}{|c|}{ Umidade volumétrica } \\
\hline tempo (h) & $10 \mathrm{~cm}$ & $20 \mathrm{~cm}$ & $30 \mathrm{~cm}$ & $60 \mathrm{~cm}$ & $90 \mathrm{~cm}$ & $120 \mathrm{~cm}$ \\
\hline 0.5 & 0.549 & 0.510 & 0.530 & 0.582 & 0.572 & 0.568 \\
\hline 1.5 & 0.504 & 0.468 & 0.498 & 0.511 & 0.502 & 0.504 \\
\hline 2.5 & 0.462 & 0.444 & 0.465 & 0.427 & 0.446 & 0.473 \\
\hline 3.5 & 0.445 & 0.435 & 0.448 & 0.393 & 0.422 & 0.460 \\
\hline 4.5 & 0.437 & 0.430 & 0.435 & 0.384 & 0.411 & 0.451 \\
\hline 5.5 & 0.432 & 0.425 & 0.428 & 0.379 & 0.408 & 0.446 \\
\hline 12.0 & 0.423 & 0.417 & 0.417 & 0.371 & 0.402 & 0.436 \\
\hline 24.0 & 0.407 & 0.406 & 0.403 & 0.358 & 0.386 & 0.417 \\
\hline 42.0 & 0.396 & 0.398 & 0.395 & 0.350 & 0.375 & 0.403 \\
\hline 66.0 & 0.391 & 0.394 & 0.391 & 0.343 & 0.372 & 0.394 \\
\hline 90.0 & 0.385 & 0.390 & 0.387 & 0.336 & 0.364 & 0.386 \\
\hline 114.0 & 0.378 & 0.386 & 0.383 & 0.331 & 0.356 & 0.381 \\
\hline 138.0 & 0.374 & 0.384 & 0.380 & 0.327 & 0.351 & 0.376 \\
\hline 162.0 & 0.371 & 0.382 & 0.379 & 0.325 & 0.349 & 0.371 \\
\hline 186.0 & 0.369 & 0.381 & 0.377 & 0.323 & 0.346 & 0.367 \\
\hline 210.0 & 0.367 & 0.380 & 0.376 & 0.321 & 0.343 & 0.364 \\
\hline 234.0 & 0.366 & 0.379 & 0.375 & 0.320 & 0.340 & 0.362 \\
\hline 258.0 & 0.365 & 0.378 & 0.374 & 0.319 & 0.338 & 0.361 \\
\hline 282.0 & 0.364 & 0.378 & 0.373 & 0.318 & 0.337 & 0.359 \\
\hline 306.0 & 0.361 & 0.376 & 0.372 & 0.316 & 0.336 & 0.358 \\
\hline 330.0 & 0.358 & 0.375 & 0.371 & 0.313 & 0.335 & 0.358 \\
\hline 354.0 & 0.357 & 0.374 & 0.370 & 0.312 & 0.333 & 0.357 \\
\hline 378.0 & 0.356 & 0.373 & 0.369 & 0.310 & 0.332 & 0.355 \\
\hline 402.0 & 0.354 & 0.372 & 0.368 & 0.310 & 0.332 & 0.354 \\
\hline \multicolumn{7}{|c|}{ Regressāo linear: $\operatorname{In}(K)=$ gama. (Umldade-UmldadeSat) $+\ln \left(K_{0}\right)$} \\
\hline & $10 \mathrm{~cm}$ & $20 \mathrm{~cm}$ & $30 \mathrm{~cm}$ & $60 \mathrm{~cm}$ & $90 \mathrm{~cm}$ & $120 \mathrm{~cm}$ \\
\hline gama & 41,7077 & 59,2054 & 46,7026 & 28,6767 & 32.4957 & 34,8198 \\
\hline$K_{0}(\mathrm{~cm} / \mathrm{h})$ & 4,8912 & 58,0853 & 14,5846 & 71,2231 & 61,6564 & 97,6086 \\
\hline$r^{2}$ & 0,9599 & 0.9498 & 0.9407 & 0.8215 & 0.8753 & 0.9394 \\
\hline
\end{tabular}

Apêndice 14. Continuação 
Apêndice 15. Dados utilizados e seqüência de cálculos para determinação da condutividade hidráulica no sistema convencional de preparo do solo.

\section{DADOS UTILIZADOS}

$\begin{array}{lcccccc}\text { Prof. } & 10 \mathrm{~cm} & 20 \mathrm{~cm} & 30 \mathrm{~cm} & 60 \mathrm{~cm} & 90 \mathbf{c m} & 120 \mathrm{~cm} \\ \text { Alfa } & 0.0712 / \mathrm{cm} & 0.0702 / \mathrm{cm} & 0.0923 / \mathrm{cm} & 0.0476 / \mathrm{cm} & 0.0457 / \mathrm{cm} & 0.0490 / \mathrm{cm} \\ \text { Eme } & 0.3159 & 0.2197 & 0.2520 & 0.4401 & 0.3929 & 0.4060 \\ \text { Ene } & 14.617 & 12.815 & 13.368 & 17.860 & 16.471 & 16.836 \\ \text { TETAr } & 0.2020 & 0.1870 & 0.2220 & 0.2320 & 0.2250 & 0.2090 \\ \text { TETAs } & 0.5880 & 0.5420 & 0.5610 & 0.6130 & 0.6150 & 0.6300 \\ \text { H cuba } & 20.0 \mathrm{~cm} & 20.0 \mathrm{~cm} & 20.0 \mathrm{~cm} & 20.0 \mathrm{~cm} & 20.0 \mathrm{~cm} & 20.0 \mathrm{~cm}\end{array}$

Leitura tensiómetros (cm de ascensão de mercúrio)

$\begin{array}{rrrr}\text { tempo (h) } & 10 \mathbf{c m} & 20 \mathbf{c m} & 30 \mathbf{c m} \\ 0.0 & 2.2 & 2.8 & 3.8 \\ 1.0 & 3.9 & 4.2 & 4.6 \\ 2.0 & 5.1 & 5.5 & 6.0 \\ 3.0 & 5.6 & 5.8 & 6.4 \\ 4.0 & 5.8 & 6.1 & 6.5 \\ 5.0 & 6.0 & 6.4 & 7.0 \\ 6.0 & 6.4 & 6.7 & 7.4 \\ 18.0 & 7.3 & 7.9 & 8.7 \\ 30.0 & 7.9 & 8.6 & 9.2 \\ 54.0 & 8.1 & 8.8 & 10.0 \\ 78.0 & 9.0 & 9.7 & 10.3 \\ 102.0 & 9.5 & 10.3 & 10.8 \\ 126.0 & 9.9 & 10.9 & 11.7 \\ 150.0 & 10.1 & 11.2 & 12.3 \\ 174.0 & 10.4 & 11.5 & 12.5 \\ 198.0 & 10.6 & 11.7 & 12.9 \\ 222.0 & 10.7 & 12.0 & 13.1 \\ 246.0 & 11.2 & 12.3 & 13.5 \\ 270.0 & 11.6 & 12.7 & 13.8 \\ 294.0 & 11.9 & 13.0 & 14.0 \\ 318.0 & 12.2 & 13.2 & 14.2 \\ 342.0 & 12.5 & 13.5 & 14.5 \\ 366.0 & 13.1 & 14.0 & 14.9 \\ 390.0 & 13.2 & 14.2 & 15.0 \\ 414.0 & 13.3 & 14.2 & 15.1 \\ & & & \end{array}$

$60 \mathrm{~cm}$
6.1
7.4
9.3
9.5
9.8
10.2
10.4
11.6
12.2
12.5
12.9
13.7
14.2
14.9
15.4
15.8
16.3
16.5
16.7
16.9
17.0
17.2
17.7
17.9
17.9

$90 \mathrm{~cm}$

Método Hillel

Potencial mátrico (cca)

tempo $(\mathbf{h})$
0.0
1.0
2.
3.
4.
5.
6.0
18.
30.
54.
78.

$10 \mathrm{~cm}$
2.5
-18.8
-33.8
-40.0
-42.5
-45.0
-50.0
-61.3
-68.8
-71.3
-82.5

$$
\begin{array}{r}
20 \mathrm{~cm} \\
5.0 \\
-12.5 \\
-28.8 \\
-32.5 \\
-36.3 \\
-40.0 \\
-43.7 \\
-58.8 \\
-67.5 \\
-70.0 \\
-81.3
\end{array}
$$
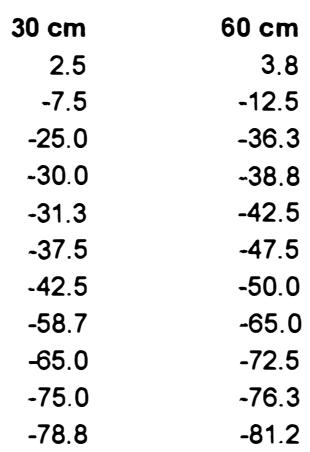

$90 \mathrm{~cm}$
1.3
-23.7
-41.3
-35.0
-38.7
-47.5
-53.8
-58.8
-80.0
-72.5
-78.8

$120 \mathrm{~cm}$
2.5
-20.0
-37.5
-37.5
-40.0
-45.0
-47.5
-62.5
-72.5
-72.5
-80.0


$\ln [\mathrm{K}](\ln [\mathrm{cm} / \mathrm{h}])$

\begin{tabular}{|c|c|c|c|c|c|c|}
\hline \\
\hline tempo (h) & $10 \mathrm{~cm}$ & $20 \mathrm{~cm}$ & $30 \mathrm{~cm}$ & $60 \mathrm{~cm}$ & $90 \mathrm{~cm}$ & $120 \mathrm{~cm}$ \\
\hline 0.5 & -0.70 & -0.18 & 0.22 & 1.14 & 1.53 & 1.83 \\
\hline 1.5 & -1.91 & -1.38 & -0.98 & -0.06 & 0.34 & 0.65 \\
\hline 2.5 & -2.46 & -1.92 & -1.51 & -0.58 & -0.16 & 0.16 \\
\hline 3.5 & -2.73 & -2.19 & -1.80 & -0.90 & .0 .50 & -0.20 \\
\hline 4.5 & -3.08 & -2.53 & -2.12 & -1.18 & -0.75 & -0.41 \\
\hline 5.5 & -3.36 & -2.79 & -2.37 & -1.41 & -0.94 & -0.57 \\
\hline 12.0 & -4.14 & -3.58 & -3.16 & -2.22 & -1.76 & -1.40 \\
\hline 24.0 & -4.92 & -4.35 & -3.92 & -2.97 & -2.50 & -2.13 \\
\hline 42.0 & -5.55 & -4.97 & -4.54 & -3.57 & -3.06 & -2.65 \\
\hline 66.0 & -5.90 & -5.33 & .4 .91 & -3.99 & -3.53 & -3.18 \\
\hline 90.0 & -6.19 & -5.62 & -5.21 & -4.31 & -3.86 & -3.53 \\
\hline 114.0 & -6.53 & -5.94 & -5.51 & -4.57 & -4.08 & -3.69 \\
\hline 138.0 & -6.80 & -6.20 & -5.76 & -4.78 & -4.25 & -3.81 \\
\hline 162.0 & -7.06 & -6.45 & -5.99 & -4.98 & -4.39 & -3.87 \\
\hline 186.0 & -7.23 & -6.62 & -6.17 & -5.15 & -4.56 & -4.05 \\
\hline 210.0 & -7.41 & -6.79 & -6.34 & -5.31 & -4.70 & -4.16 \\
\hline 234.0 & -7.55 & -6.93 & -6.47 & -5.41 & -4.77 & -4.18 \\
\hline 258.0 & -7.61 & -6.99 & -6.53 & -5.49 & -4.87 & -4.30 \\
\hline 282.0 & -7.68 & -7.06 & -6.61 & -5.58 & -4.96 & -4.41 \\
\hline 306.0 & -7.75 & -7.13 & -6.68 & -5.66 & -5.05 & -4.52 \\
\hline 330.0 & -7.81 & -7.19 & -6.74 & -5.72 & -5.12 & -4.60 \\
\hline 354.0 & -7.87 & -7.25 & -6.79 & -5.77 & -5.16 & -4.62 \\
\hline 378.0 & -7.94 & -7.32 & -6.86 & -5.82 & -5.19 & -4.62 \\
\hline 402.0 & -8.02 & -7.39 & -6.93 & -5.88 & -5.24 & -4.65 \\
\hline \multicolumn{7}{|c|}{ Umidade volumétrica } \\
\hline tempo (h) & $10 \mathrm{~cm}$ & $20 \mathrm{~cm}$ & $30 \mathrm{~cm}$ & $60 \mathrm{~cm}$ & $90 \mathrm{~cm}$ & $120 \mathrm{~cm}$ \\
\hline 0.5 & 0.534 & 0.511 & 0.536 & 0.583 & 0.564 & 0.577 \\
\hline 1.5 & 0.465 & 0.477 & 0.491 & 0.504 & 0.484 & 0.492 \\
\hline 2.5 & 0.433 & 0.454 & 0.455 & 0.443 & 0.464 & 0.454 \\
\hline 3.5 & 0.423 & 0.448 & 0.448 & 0.434 & 0.467 & 0.450 \\
\hline 4.5 & 0.418 & 0.442 & 0.441 & 0.422 & 0.451 & 0.439 \\
\hline 5.5 & 0.411 & 0.437 & 0.432 & 0.412 & 0.433 & 0.429 \\
\hline 12.0 & 0.399 & 0.426 & 0.419 & 0.395 & 0.421 & 0.410 \\
\hline 24.0 & 0.386 & 0.414 & 0.406 & 0.375 & 0.402 & 0.386 \\
\hline 42.0 & 0.381 & 0.409 & 0.399 & 0.367 & 0.391 & 0.378 \\
\hline 66.0 & 0.374 & 0.404 & 0.394 & 0.362 & 0.392 & 0.373 \\
\hline 90.0 & 0.366 & 0.397 & 0.391 & 0.354 & 0.382 & 0.365 \\
\hline 114.0 & 0.362 & 0.393 & 0.386 & 0.346 & 0.373 & 0.357 \\
\hline 138.0 & 0.359 & 0.390 & 0.380 & 0.339 & 0.368 & 0.350 \\
\hline 162.0 & 0.357 & 0.388 & 0.378 & 0.334 & 0.364 & 0.346 \\
\hline 186.0 & 0.354 & 0.386 & 0.376 & 0.330 & 0.360 & 0.340 \\
\hline 210.0 & 0.353 & 0.384 & 0.374 & 0.327 & 0.357 & 0.336 \\
\hline 234.0 & 0.351 & 0.383 & 0.373 & 0.324 & 0.355 & 0.335 \\
\hline 258.0 & 0.348 & 0.381 & 0.371 & 0.323 & 0.352 & 0.333 \\
\hline 282.0 & 0.345 & 0.379 & 0.370 & 0.321 & 0.350 & 0.331 \\
\hline 306.0 & 0.343 & 0.378 & 0.369 & 0.320 & 0.347 & 0.329 \\
\hline 330.0 & 0.341 & 0.376 & 0.368 & 0.320 & 0.346 & 0.328 \\
\hline 354.0 & 0.339 & 0.374 & 0.366 & 0.317 & 0.344 & 0.327 \\
\hline 378.0 & 0.337 & 0.373 & 0.365 & 0.315 & 0.342 & 0.326 \\
\hline 402.0 & 0.336 & 0.372 & 0.365 & 0.315 & 0.342 & 0.326 \\
\hline \multicolumn{7}{|c|}{ Regressão linear: In (K) = gama. (Umldade-UmldadeSat) + In $\left(K_{0}\right)$} \\
\hline & $10 \mathrm{~cm}$ & $20 \mathrm{~cm}$ & $30 \mathrm{~cm}$ & $60 \mathrm{~cm}$ & $90 \mathrm{~cm}$ & $120 \mathrm{~cm}$ \\
\hline gama & 45,1836 & 59,5452 & 47,9788 & 30,7495 & 35,8217 & 30,2975 \\
\hline$K_{0}(\mathrm{~cm} / \mathrm{h})$ & 38,4591 & 17,3642 & 17,8749 & 40,9477 & 109,3835 & 120,2322 \\
\hline$r^{2}$ & 0.9178 & 0.9674 & 0.9361 & 0.9175 & 0.9598 & 0.9525 \\
\hline
\end{tabular}

Apêndice 15. Continuação 


$\begin{array}{ll}330.0 & -121.2015 \\ 354.0 & -126.6945 \\ 378.0 & -130.6518 \\ 402.0 & -131.7401\end{array}$

$d(P S I t) / d z(c c a / c m)$

$\begin{array}{rrr}\text { tempo }(\boldsymbol{h}) & 10 \mathrm{~cm} & \mathbf{2 0} \mathrm{cm} \\ 0.5 & -0.970 & -0.984 \\ 1.5 & -1.032 & -1.043 \\ 2.5 & -1.038 & -1.042 \\ 3.5 & -0.956 & -0.968 \\ 4.5 & -1.042 & -1.041 \\ 5.5 & -1.114 & -1.101 \\ 12.0 & -1.077 & -1.068 \\ 24.0 & -1.129 & -1.115 \\ 42.0 & -1.183 & -1.158 \\ 66.0 & -1.040 & -1.032 \\ 90.0 & -1.007 & -1.003 \\ 114.0 & -1.099 & -1.079 \\ 138.0 & -1.182 & -1.149 \\ 162.0 & -1.292 & -1.242 \\ 186.0 & -1.333 & -1.280 \\ 210.0 & -1.397 & -1.338 \\ 234.0 & -1.438 & -1.368 \\ 258.0 & -1.381 & -1.318 \\ 282.0 & -1.348 & -1.289 \\ 306.0 & -1.322 & -1.267 \\ 330.0 & -1.297 & -1.244 \\ 354.0 & -1.277 & -1.222 \\ 378.0 & -1.285 & -1.225 \\ 402.0 & -1.294 & -1.232\end{array}$

$K$ (condutividade hidráulica, $\mathrm{cm} / \mathrm{h}$ )

$\begin{array}{rr}\text { tempo }(\mathbf{h}) & 10 \mathrm{~cm} \\ 0.5 & 0.49801 \\ 1.5 & 0.14743 \\ 2.5 & 0.08572 \\ 3.5 & 0.06535 \\ 4.5 & 0.04606 \\ 5.5 & 0.03490 \\ 12.0 & 0.01590 \\ 24.0 & 0.00732 \\ 42.0 & 0.00388 \\ 66.0 & 0.00274 \\ 90.0 & 0.00205 \\ 114.0 & 0.00146 \\ 138.0 & 0.00111 \\ 162.0 & 0.00086 \\ 186.0 & 0.00072 \\ 210.0 & 0.00061 \\ 234.0 & 0.00053 \\ 258.0 & 0.00049 \\ 282.0 & 0.00046 \\ 306.0 & 0.00043 \\ 330.0 & 0.00041 \\ 354.0 & 0.00038 \\ 378.0 & 0.00035 \\ 402.0 & 0.00033 \\ & \\ & \end{array}$

Apêndice 15. Continuação

$\begin{array}{lll}-1.34930 & 0.00264 & 1000 \\ -1.33151 & 0.00273 & 1000 \\ -1.34479 & 0.00298 & 0.999 \\ -1.35591 & 0.00311 & 0.999\end{array}$

$\begin{array}{llll}\mathbf{3 0} \mathbf{~ c m} & \mathbf{6 0} \mathbf{c m} & \mathbf{9 0} \mathbf{~ c m} & \mathbf{1 2 0} \mathbf{~ c m} \\ -0.998 & -1.040 & -1.082 & -1.124 \\ -1.053 & -1.084 & -1.114 & -1.145 \\ -1.045 & -1.056 & -1.067 & -1.078 \\ -0.980 & -1.015 & -1.051 & -1.086 \\ -1.039 & -1.036 & -1.033 & -1.030 \\ -1.088 & -1.050 & -1.012 & -0.973 \\ -1.059 & -1.032 & -1.006 & -0.979 \\ -1.100 & -1.057 & -1.014 & -0.970 \\ -1.133 & -1.058 & -0.982 & -0.907 \\ -1.024 & -1.000 & -0.976 & -0.951 \\ -1.000 & -0.990 & -0.979 & -0.969 \\ -1.060 & -1.002 & -0.944 & -0.887 \\ -1.116 & -1.017 & -0.917 & -0.818 \\ -1.191 & -1.039 & -0.886 & -0.734 \\ -1.228 & -1.072 & -0.915 & -0.759 \\ -1.278 & -1.100 & -0.922 & -0.744 \\ -1.299 & -1.091 & -0.884 & -0.676 \\ -1.255 & -1.067 & -0.878 & -0.689 \\ -1.230 & -1.052 & -0.874 & -0.696 \\ -1.212 & -1.046 & -0.881 & -0.715 \\ -1.191 & -1.033 & -0.875 & -0.717 \\ -1.167 & -1.003 & -0.839 & -0.675 \\ -1.166 & -0.987 & -0.808 & -0.629 \\ -1.170 & -0.983 & -0.797 & -0.611\end{array}$

$\begin{array}{lrlll}20 \mathrm{~cm} & 30 \mathrm{~cm} & \mathbf{6 0} \mathrm{cm} & 90 \mathrm{~cm} & 120 \mathrm{~cm} \\ 0.83724 & 1,24189 & 3,12687 & 4,62351 & 6,22393 \\ 0.25071 & 0.37377 & 0.93798 & 1,40401 & 1,90664 \\ 0.14717 & 0.22085 & 0.56027 & 0.85362 & 1,1770 \\ 0.11146 & 0.16585 & 0.40826 & 0.60728 & 0.81814 \\ 0.07974 & 0.12025 & 0.30662 & 0.47356 & 0.66131 \\ 0.06113 & 0.09317 & 0.24472 & 0.39103 & 0.56544 \\ 0.02790 & 0.04240 & 0.10901 & 0.17232 & 0.24590 \\ 0.01296 & 0.01980 & 0.05113 & 0.08211 & 0.11896 \\ 0.00695 & 0.01072 & 0.02826 & 0.04687 & 0.07031 \\ 0.00486 & 0.00740 & 0.01853 & 0.02926 & 0.04153 \\ 0.00362 & 0.00548 & 0.01349 & 0.02099 & 0.02934 \\ 0.00263 & 0.00404 & 0.01037 & 0.01695 & 0.02496 \\ 0.00202 & 0.00314 & 0.00835 & 0.01427 & 0.02211 \\ 0.00158 & 0.00249 & 0.00690 & 0.01246 & 0.02077 \\ 0.00133 & 0.00209 & 0.00578 & 0.01042 & 0.01735 \\ 0.00112 & 0.00177 & 0.00495 & 0.00910 & 0.01557 \\ 0.00098 & 0.00156 & 0.00445 & 0.00847 & 0.01528 \\ 0.00092 & 0.00145 & 0.00411 & 0.00769 & 0.01352 \\ 0.00085 & 0.00135 & 0.00379 & 0.00703 & 0.01217 \\ 0.00080 & 0.00126 & 0.00350 & 0.00640 & 0.01086 \\ 0.00075 & 0.00119 & 0.00327 & 0.00595 & 0.01001 \\ 0.00071 & 0.00112 & 0.00313 & 0.00575 & 0.00986 \\ 0.00066 & 0.00105 & 0.00296 & 0.00558 & 0.00988 \\ 0.00062 & 0.00098 & 0.00279 & 0.00530 & 0.00953\end{array}$




$\begin{array}{llll}186.0 & -0.000961 & -0.001702 & -0.002569 \\ 210.0 & -0.000846 & -0.001499 & -0.002263 \\ 234.0 & -0.000755 & -0.001339 & -0.002022 \\ 258.0 & -0.000681 & -0.001209 & -0.001826 \\ 282.0 & -0.000620 & -0.001102 & -0.001664 \\ 306.0 & -0.000569 & -0.001012 & -0.001528 \\ 330.0 & -0.000526 & -0.000935 & -0.001412 \\ 354.0 & -0.000489 & -0.000869 & -0.001312 \\ 378.0 & -0.000456 & -0.000812 & -0.001226 \\ 402.0 & -0.000427 & -0.000761 & -0.001149\end{array}$

Apêndice 15. Continuação

$\begin{array}{lll}-0.006194 & -0.009541 & -0.013173 \\ -0.005447 & -0.008391 & -0.011583 \\ -0.004858 & -0.007484 & -0.010328 \\ -0.004382 & -0.006750 & -0.009312 \\ -0.003988 & -0.006143 & -0.008474 \\ -0.003658 & -0.005635 & -0.007772 \\ -0.003377 & -0.005203 & -0.007174 \\ -0.003136 & -0.004830 & -0.006660 \\ -0.002925 & -0.004506 & -0.006212 \\ -0.002741 & -0.004222 & -0.005820\end{array}$

PSIt (cca)

$\begin{array}{rr}\text { tempo }(\boldsymbol{h}) & 10 \mathrm{~cm} \\ 0.5 & -18.1 \\ 1.5 & -36.3 \\ 2.5 & -46.9 \\ 3.5 & -51.3 \\ 4.5 & -53.8 \\ 5.5 & -57.5 \\ 12.0 & -65.6 \\ 24.0 & -75.0 \\ 42.0 & -80.0 \\ 66.0 & -86.9 \\ 90.0 & -95.6 \\ 114.0 & -101.3 \\ 138.0 & -105.0 \\ 162.0 & -108.1 \\ 186.0 & -111.3 \\ 210.0 & -113.1 \\ 234.0 & -116.9 \\ 258.0 & -122.5 \\ 282.0 & -126.9 \\ 306.0 & -130.6 \\ 330.0 & -134.4 \\ 354.0 & -140.0 \\ 378.0 & -144.4 \\ 402.0 & -145.6\end{array}$

$20 \mathrm{~cm}$
-23.7
-40.6
-50.6
-54.4
-58.1
-61.9
-71.3
-83.1
-88.8
-95.6
-105.0
-112.5
-118.1
-121.9
-125.0
-128.1
-131.9
-136.3
-140.6
-143.8
-146.9
-151.9
-156.3
-157.5

$$
\begin{array}{r}
30 \mathrm{~cm} \\
-32.5 \\
-46.3 \\
-57.5 \\
-60.6 \\
-64.4 \\
-70.0 \\
-80.6 \\
-91.9 \\
-100.0 \\
-106.9 \\
-111.9 \\
-120.6 \\
-130.0 \\
-135.0 \\
-138.8 \\
-142.5 \\
-146.3 \\
-150.6 \\
-153.8 \\
-156.3 \\
-159.4 \\
-163.8 \\
-166.9 \\
-168.1 \\
\hline
\end{array}
$$

$60 \mathrm{~cm}$
-64.4
-84.4
-97.5
-100.6
-105.0
-108.8
-117.5
-128.8
-134.4
-138.8
-146.3
-154.4
-161.9
-169.4
-175.0
-180.6
-185.0
-187.5
-190.0
-191.9
-193.8
-198.1
-202.5
-203.8

$\begin{array}{rr}\mathbf{9 0} \mathrm{cm} & \mathbf{1 2 0} \mathrm{cm} \\ -101.3 & -128.8 \\ -122.5 & -148.8 \\ -128.1 & -157.5 \\ -126.9 & -158.8 \\ -133.1 & -162.5 \\ -140.6 & -166.3 \\ -146.3 & -175.0 \\ -159.4 & -187.5 \\ -166.3 & -192.5 \\ -165.6 & -196.3 \\ -173.8 & -203.1 \\ -182.5 & -210.0 \\ -188.1 & -216.9 \\ -193.1 & -221.9 \\ -198.1 & -228.8 \\ -201.9 & -234.4 \\ -205.6 & -236.3 \\ -209.4 & -238.8 \\ -213.1 & -241.3 \\ -216.9 & -243.8 \\ -220.0 & -245.6 \\ -223.1 & -247.5 \\ -226.3 & -249.4 \\ -227.5 & -250.0\end{array}$

Ajuste à equaçäo PSIT $=a+b . z+c . z^{2}$

$\begin{array}{rr}\text { tempo }(\boldsymbol{h}) & \mathbf{a}(\mathbf{c c a}) \\ 0.5 & -5,6827 \\ 1.5 & -21,2276 \\ 2.5 & -31,9541 \\ 3.5 & -37,4332 \\ 4.5 & -39,0445 \\ 5.5 & -41.8060 \\ 12.0 & -51.7007 \\ 24.0 & -61.3551 \\ 42.0 & -66.2678 \\ 66.0 & -75.8543 \\ 90.0 & -84.4943 \\ 114.0 & -89.8023 \\ 138.0 & -94.0806 \\ 162.0 & -95.9907 \\ 186.0 & -98.6003 \\ 210.0 & -100.2723 \\ 234.0 & -103.3018 \\ 258.0 & -109.1564 \\ 282.0 & -113.7666 \\ 306.0 & -117.4074\end{array}$

$\begin{array}{rrr}b(\mathbf{c c a} / \mathbf{c m}) & c\left(\mathbf{c c a} / \mathbf{c m}^{2}\right) & r^{2} \\ -0.95557 & -0.00070 & 0.997 \\ -1.02230 & -0.00051 & 0.992 \\ -1.03454 & -0.00018 & 0.993 \\ -0.94432 & -0.00059 & 0.992 \\ -1.04277 & 0.00005 & 0.993 \\ -1.12632 & 0.00064 & 0.994 \\ -1.08574 & 0.00045 & 0.997 \\ -1.14340 & 0.00072 & 0.998 \\ -1.20849 & 0.00126 & 0.999 \\ -1.04859 & 0.00041 & 0.999 \\ -1.01019 & 0.00017 & 0.999 \\ -1.11803 & 0.00096 & 0.999 \\ -1.21544 & 0.00166 & 0.999 \\ -1.34300 & 0.00254 & 0.998 \\ -1.38474 & 0.00261 & 0.997 \\ -1.45649 & 0.00297 & 0.995 \\ -1.50691 & 0.00346 & 0.996 \\ -1.44444 & 0.00315 & 0.997 \\ -1.40764 & 0.00296 & 0.998 \\ -1.37738 & 0.00276 & 0.999\end{array}$




$\begin{array}{rrr}42.0 & -0.000459 & -0.000346 \\ 66.0 & -0.000285 & -0.000217 \\ 90.0 & -0.000206 & -0.000157 \\ 114.0 & -0.000161 & -0.000123 \\ 138.0 & -0.000131 & -0.000101 \\ 162.0 & -0.000111 & -0.000086 \\ 186.0 & -0.000096 & -0.000074 \\ 210.0 & -0.000085 & -0.000065 \\ 234.0 & -0.000075 & -0.000058 \\ 258.0 & -0.000068 & -0.000053 \\ 282.0 & -0.000062 & -0.000048 \\ 306.0 & -0.000057 & -0.000044 \\ 330.0 & -0.000053 & -0.000041 \\ 354.0 & -0.000049 & -0.000038 \\ 378.0 & -0.000046 & -0.000036 \\ 402.0 & -0.000043 & -0.000033\end{array}$

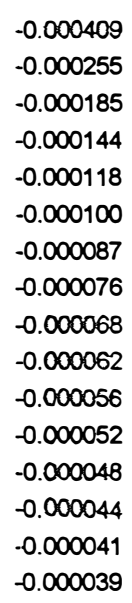

$d(T E T A) / d t \mathrm{xdz}(\mathrm{cm} / \mathrm{h})$ tempo (h)

0.5

1.5

2.5

3.5

4.5

5.5

12.0

24.0

42.0

66.0

90.0

114.0

138.0

162.0

186.0

210.0

234.0

258.0

282.0

306.0

330.0

354.0

378.0

402.0

$10 \mathrm{~cm}$
-0.482880
-0.0152219
-0.088991
-0.062487
-0.047984
-0.038862
-0.0017119
-0.008263
-0.004589
-0.002854
-0.002060
-0.001607
-0.001315
-0.001111
-0.000961
-0.000846
-0.000755
-0.000681
-0.000620
-0.000569
-0.000526
-0.000489
-0.000456
-0.000427

$q=$ Somatório $[d(T E T A) / d t \times d z](\mathrm{cm} / \mathrm{h})$

$\begin{array}{rr}\text { tempo (h) } & 10 \mathrm{~cm} \\ 0.5 & -0.482880 \\ 1.5 & -0.152219 \\ 2.5 & -0.088991 \\ 3.5 & -0.062487 \\ 4.5 & -0.047984 \\ 5.5 & -0.038862 \\ 12.0 & -0.017119 \\ 24.0 & -0.008263 \\ 42.0 & -0.004589 \\ 66.0 & -0.002854 \\ 90.0 & -0.002060 \\ 114.0 & -0.001607 \\ 138.0 & -0.001315 \\ 162.0 & -0.001111\end{array}$

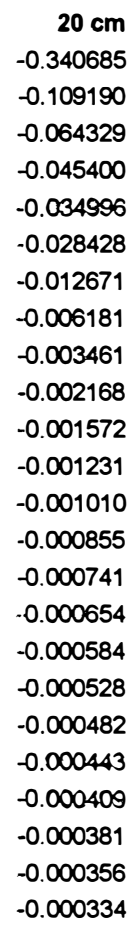

$20 \mathrm{~cm}$

$-0.823565$

$-0.261410$

$-0.153320$

$-0.107888$

$-0.082980$

$-0.067290$

$-0.029791$

$-0.014444$

$-0.008051$

.0 .005022

$-0.003633$

$-0.002838$

$-0.002325$

$-0.001966$
Apêndice 15. Continuação

$\begin{array}{lll}-0.000592 & -0.000538 & -0.000591 \\ -0.000365 & -0.000334 & -0.000365 \\ -0.000262 & -0.000240 & -0.000262 \\ -0.000204 & -0.000187 & -0.000204 \\ -0.000166 & -0.000153 & -0.000166 \\ -0.000140 & -0.000129 & -0.000140 \\ -0.000121 & -0.000112 & -0.000121 \\ -0.000106 & -0.000098 & -0.000106 \\ -0.000095 & -0.000088 & -0.000095 \\ -0.000085 & -0.000079 & -0.000085 \\ -0.000077 & -0.000072 & -0.000078 \\ -0.000071 & -0.000066 & -0.000071 \\ -0.000066 & -0.000061 & -0.000066 \\ -0.000061 & -0.000056 & -0.000061 \\ -0.000057 & -0.000053 & -0.000057 \\ -0.000053 & -0.000049 & -0.000053\end{array}$

$30 \mathrm{~cm}$
$-0,415485$
$-0,132135$
$-0,077567$
$-0,054613$
$-0,042022$
$-0,034088$
$-0,015111$
$-0,007335$
$-0,004092$
$-0,002554$
$-0,001848$
$-0,001445$
$-0,001184$
$-0,001001$
$-0,000867$
$-0,000764$
$-0,000682$
$-0,000616$
$-0,000562$
$-0,000516$
$-0,000477$
$-0,000443$
$-0,000414$
$-0,000388$

$60 \mathrm{~cm}$

$-2,012452$

$-0,622760$

$-0,360962$

$-0,252026$

$-0,192715$

$-0,155550$

0,067628

$-0,032265$

$-0,017752$

$-0,010956$

$-0,007868$

$-0,006113$

$-0,004985$

$-0,004201$

$-0,003625$

$-0,003184$

$-0,002837$

$-0,002556$

$-0,002324$

$-0,002130$

$-0,001965$

$-0,001823$

$-0,001700$

$-0,001592$
$120 \mathrm{~cm}$

$-1,993968$

$-0.618336$

$-0.358747$

$-0.250641$

$-0.191748$

$-0.154828$

$-0.067415$

$-0.032205$

$-0.017738$

$-0.010957$

$-0.007873$

$-0.006120$

$-0.004992$

$-0.004208$

$-0.003632$

.0 .003191

$-0.002844$

$-0.002563$

$-0.002331$

$-0.002137$

$-0.001971$

$-0.001829$

$-0.001706$

$-0.001597$ 
Apêndice 16. Produção de matéria seca de aveia preta.

\begin{tabular}{|c|c|c|}
\hline $\begin{array}{l}\text { Sistemas } \\
\text { de }\end{array}$ & Repetições & Matéria seca \\
\hline \multicolumn{3}{|l|}{ Preparo } \\
\hline & & $\mathrm{kg} / \mathrm{ha}$ \\
\hline & 1 & 4.220 \\
\hline \multirow[t]{3}{*}{ PD } & 2 & 4.504 \\
\hline & 3 & 4.088 \\
\hline & 1 & 4.758 \\
\hline \multirow[t]{3}{*}{$P E$} & 2 & 4.420 \\
\hline & 3 & 4.260 \\
\hline & 1 & 4.626 \\
\hline \multirow[t]{2}{*}{$P C$} & 2 & 4.386 \\
\hline & 3 & 4.344 \\
\hline
\end{tabular}


174.

Apêndice 17. Estande, produção de grãos e de palha de milho.

\begin{tabular}{|c|c|c|c|c|}
\hline $\begin{array}{c}\text { Sistemas } \\
\text { de } \\
\text { preparo }\end{array}$ & Repetiçōes & Estande & Grãos & Palha \\
\hline & & plantas/ha & $\mathrm{kg} / \mathrm{ha}$ & $\mathrm{kg} / \mathrm{ha}$ \\
\hline & 1 & 57.770 & 6.378 & 8.533 \\
\hline \multirow[t]{3}{*}{$P D$} & 2 & 56.661 & 6.144 & 7.900 \\
\hline & 3 & 64.440 & 6.222 & 7.460 \\
\hline & 1 & 45.564 & 4.200 & 5.210 \\
\hline \multirow[t]{3}{*}{$P E$} & 2 & 46.667 & 4.588 & 5.225 \\
\hline & 3 & 46.710 & 5.211 & 6.000 \\
\hline & 1 & 39.900 & 4.122 & 6.690 \\
\hline \multirow[t]{2}{*}{ PC } & 2 & 31.200 & 4.978 & 6.680 \\
\hline & 3 & 43.445 & 4.667 & 8.245 \\
\hline
\end{tabular}

